Towards Effective Use of Technology-Enabled Systems in Emergency Management and Crisis Situations

Diana Fischer-Preßler

University of Bamberg 



\title{
Towards Effective Use of Technology-Enabled Systems in Emergency Management and Crisis Situations
}

\author{
Dissertation \\ zur Erlangung des akademischen Grades \\ doctor rerum politicarum (Dr. rer. pol.) \\ der Fakultät Wirtschaftsinformatik und Angewandte Informatik \\ der Otto-Friedrich-Universität Bamberg \\ vorgelegt von \\ Diana Fischer-Preßler, M.Sc.
}

2021 
Dieses Werk ist als freie Onlineversion über das Forschungsinformationssystem (FIS; https://fis.uni-bamberg.de) der Universität Bamberg erreichbar. Das Werk steht unter der CC-Lizenz CC-BY.

Lizenzvertrag: Creative Commons Namensnennung 4.0

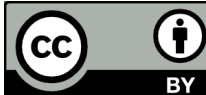
http://creativecommons.org/licenses/by/4.0.

Diese Arbeit hat der Fakultät Wirtschaftsinformatik und Angewandte Informatik der OttoFriedrich-Universität als Dissertation vorgelegen.

Erstgutachter: Prof. Dr. Kai Fischbach Zweitgutachter: Prof. Dr. Daniel Beimborn Mitglied der Promotionskommission: Prof. Dr. Barbara Drechsel

Tag der Disputation: 29.10.2021

DOI: https://doi.org/10.20378/irb-52620

URN: urn:nbn:de:bvb:473-irb-526200 


\section{Table of Contents}

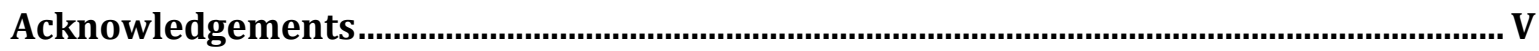

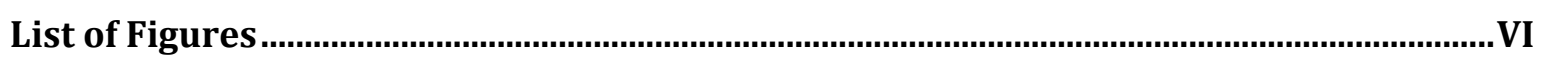

List of Tables..................................................................................................................... VII

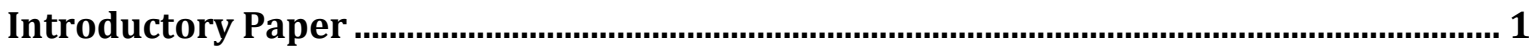

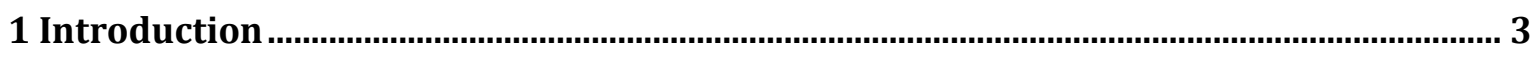

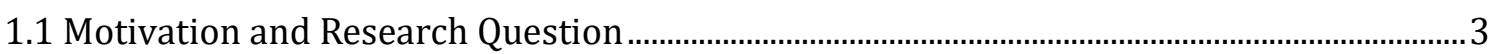

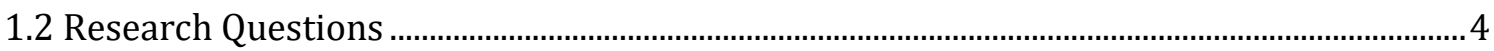

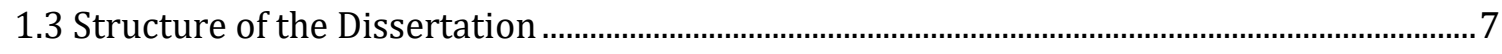

2 Research Context, Theoretical and Conceptual Foundations .............................................. 9

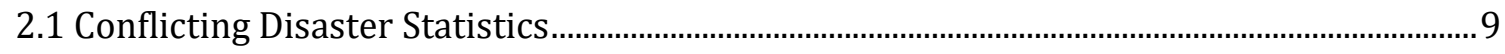

2.2 Definitions and Types of High Impact Events.........................................................................

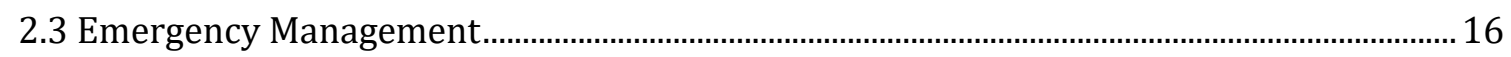

2.4 Emergency Management Information Systems ................................................................. 19

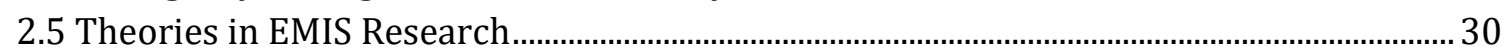

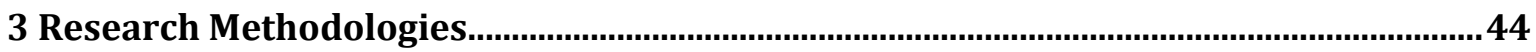

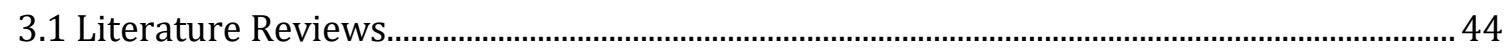

3.2 The Value of Qualitative and Quantitative Methodologies....................................................... 45

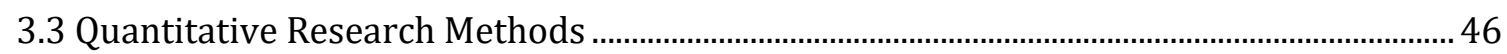

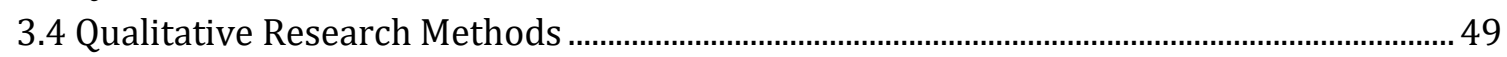

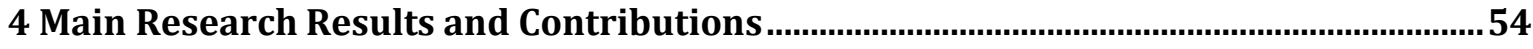

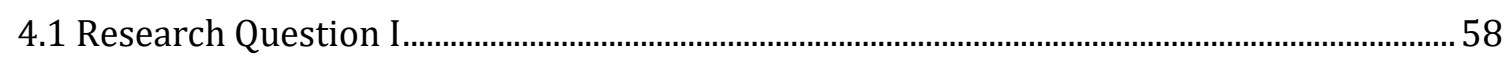

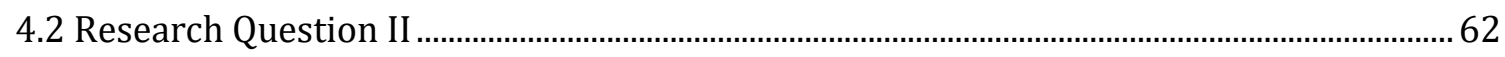

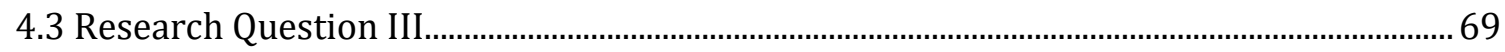

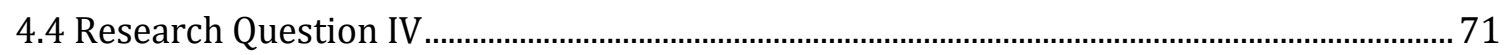

5 Limitations and Future Research Directions ................................................................ 74

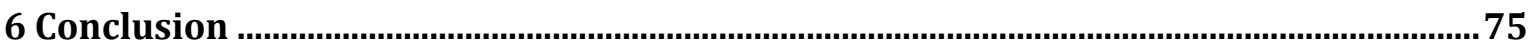

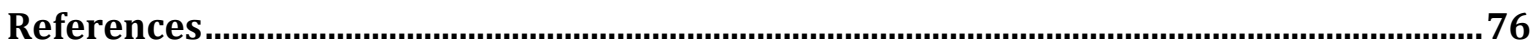

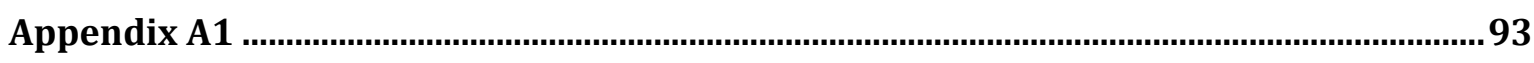

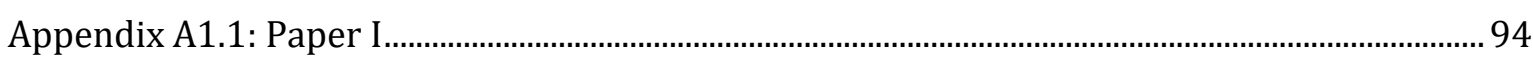

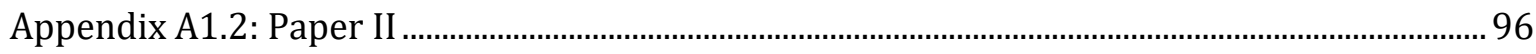

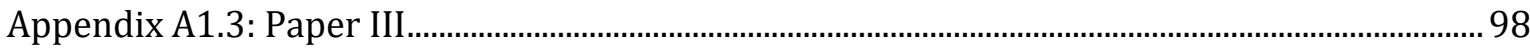

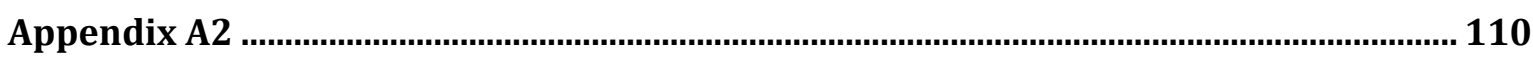

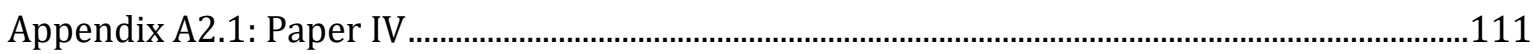

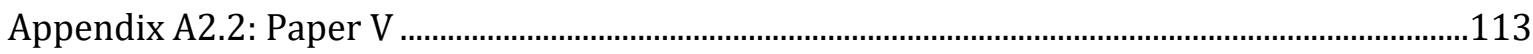

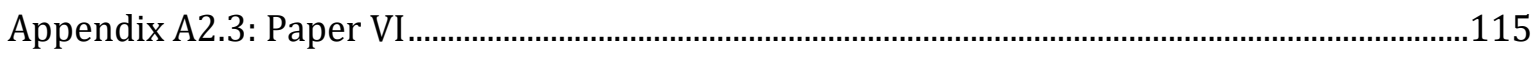

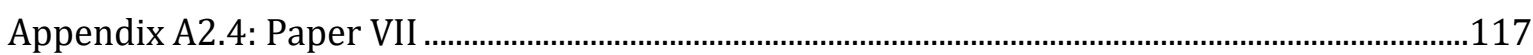

Appendix A2.5: Paper VIII...........................................................................................................119

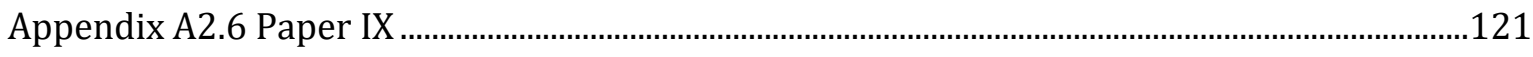

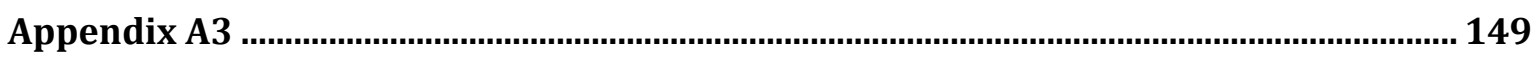




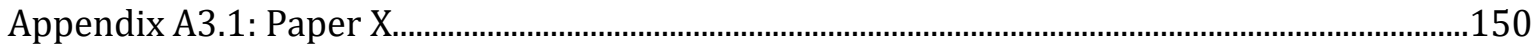

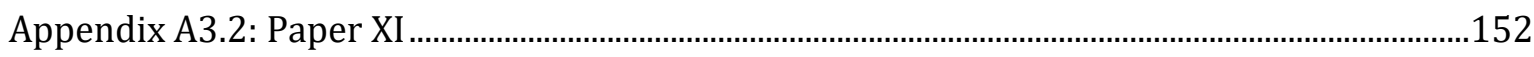

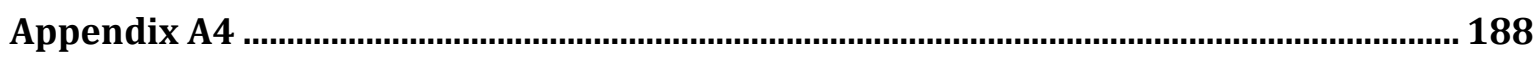

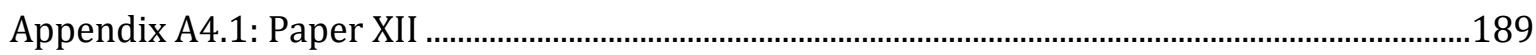

Appendix A4.2: Paper XIII.............................................................................................................191

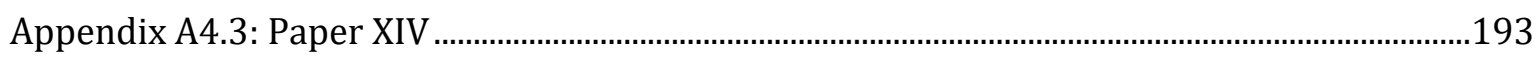

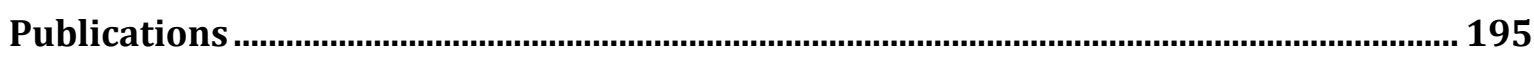

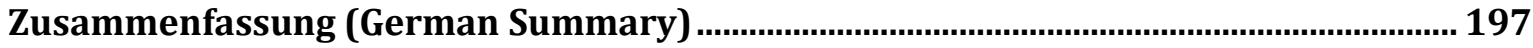




\section{Acknowledgements}

My thesis would not have been possible without the support of a number of people who have been valuable in my life. I would like to express my gratitude to all those who accompanied and helped me in the last years.

First of all, I express my deepest thanks to my supervisor, Prof. Dr. Kai Fischbach, for his continuous support and encouragement. Thank you, Kai, for caring so much about my doctoral thesis, for always taking the time to discuss the many academic topics, for providing valuable feedback, and for always encouraging me to present my findings at various international conferences. Thanks for supporting my research visits and ideas, and for your many motivating words. I am very grateful for all the good advice throughout the years and for your trust in my research ideas.

I would also like to thank the other members of my PhD committee: Prof. Dr. Daniel Beimborn, the second supervisor of my doctoral thesis, Prof. Dr. Maike Andresen and Prof. Dr. Barbara Drechsel.

A special thanks goes to my colleagues and friends Kathrin Eismann, Dr. Dario Bonaretti, and Dr. Oliver Posegga for accompanying me on the largest part of my PhD journey. Thanks to Kathrin for always sharing ideas and opinions at work, and also personally. It was my pleasure to "travel" together on our PhD journeys and, of course, to IS conferences. Thanks to Dario for inspiring discussions, encouraging words, valuable feedback, and excellent solutions to challenges in our common research projects. It has been a pleasure to develop ideas and research projects together. Thanks to Oliver for his feedback and opinions on so many academic topics, for the introduction to the information systems field, and for challenging and interesting discussions. I thank our beloved secretary, Gudrun Stilkerich, as well as my friends and colleagues Prof. Deborah Bunker, Michael Eberhardt, Christian Ehnis, Joscha Eirich, Theresa Henn, Teresa Heyder, Lisa Hepp, Dr. Susanne Imhof, Falco Klemm, Julian Marx, Nina Passlack, Dr. Johannes Putzke, Dr. Carsten Schwemmer, Florian Sobiegalla, Oliver Zuchowski, and Matthäus Zylka. A special thanks goes to Scott Cooper, from whom I learned a lot over the last years and who always shared incredibly well-thought-out explanations with me. It has been a privilege working with him. I am also grateful to my student workers, who helped me with various tasks ranging from formatting academic papers to structuring literature databases.

Thank you to my family and friends for accompanying me on this journey with great interest, some healthy distraction, and encouraging words. A special thanks to my parents, who supported me to follow my own path. Finally, I thank my husband David for his continuous support, love, and our great experiences during our travels. 


\section{List of Figures}

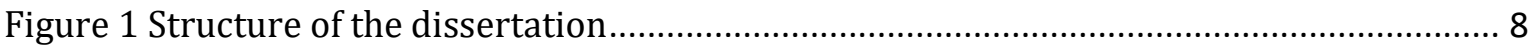

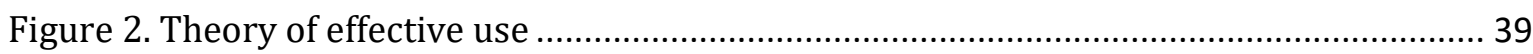

Figure 3. Activity system adapted from Engeström (1987, p. 78) ............................................. 40

Figure 4. Framework for communication during crisis management ..................................... 58

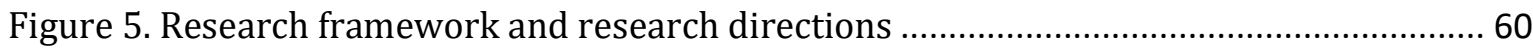

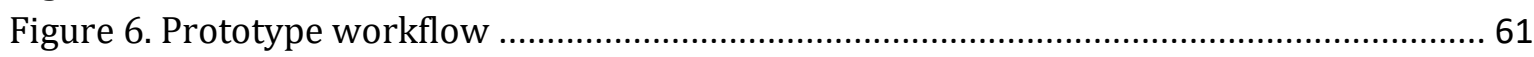

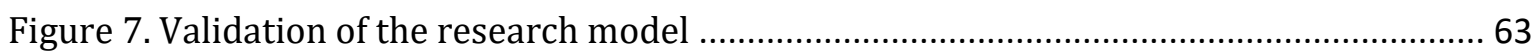

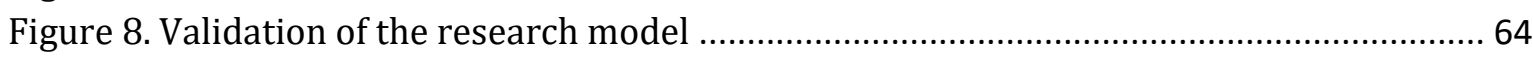

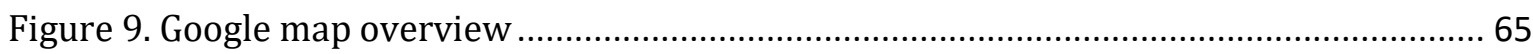

Figure 10. Theoretical model depicting levels and dimensions of use ......................................... 66

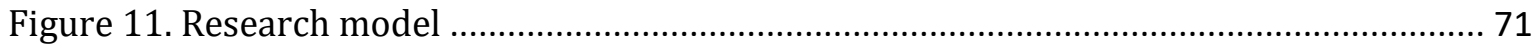

Figure 12. Model of social media-enabled sense-making...................................................... 73 


\section{List of Tables}

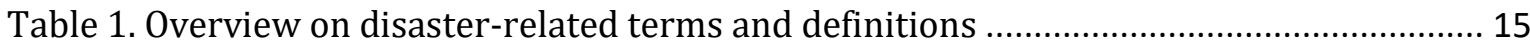

Table 2. Differences between emergency and disaster management..................................... 17

Table 3. Disaster management phases with their definitions................................................... 19

Table 4. Definition and example studies on system archetypes ............................................. 22

Table 5. Definition and example studies on EMIS deep, surface and physical structures........ 23

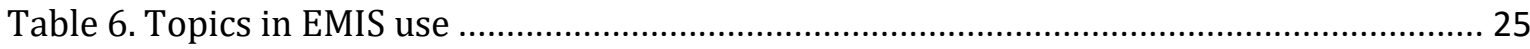

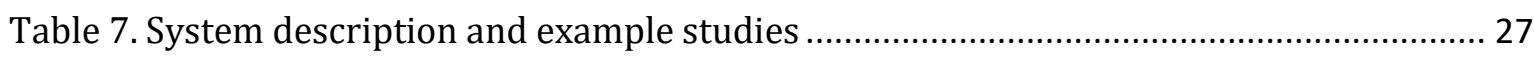

Table 8. Example studies of social media use for emergency management.............................. 29

Table 9. Phenomena associated with collective behavior on social media................................... 34

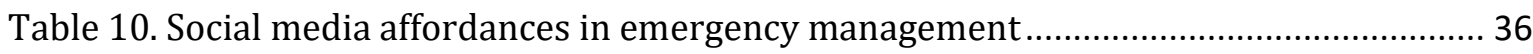

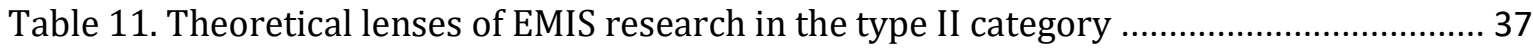

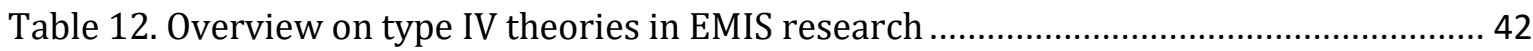

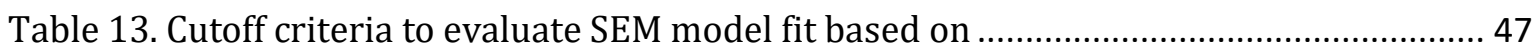

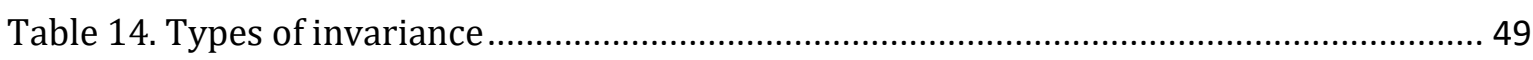

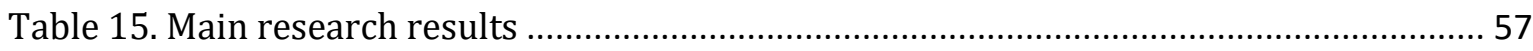

Table 16. Overview of system structures and related impediment types ................................. 68 

Introductory Paper 



\section{Introduction}

\subsection{Motivation and Research Question}

Natural and human-made disasters such as floods, epidemics, and terrorist attacks pose significant threats to societies worldwide. By definition, a disaster is a high-impact, uncertain, complex, disruptive, and unpredictable event during which a large number of organizations-such as professional emergency responders, government agencies, and businesses-as well as the communities affected collaborate to respond to the situation (Kreps 1985). To minimize causalties during disaster situations and respond effectively, those involved in disaster management depend on information. In fact, the International Federation of Red Cross and Red Crescent Societies' World Disaster Report has emphasized that "when disaster strikes, access to information is just as important as food and water" (IFRC 2013, p. 73).

Research acknowledges widely that impediments to information access and diffusion can lead to a number of failures, such as inappropriate resource allocation, late warning, delayed evacuations, and counterproductive prioritization of sequential relief operations (e.g., Day et al. 2009; Junglas and Ives 2007; Pan et al. 2012). These failures, in turn, can exacerbate a crisis escalation and even lead to higher numbers of causalties during disaster response, as several studies have verified (e.g., Bharosa et al. 2010; Day et al. 2009). This is why effective use of emergency management information systems (EMIS) is crucial in disaster management. EMIS make it possible to store, visualize, distribute, and access disaster-related information; they enable digital representations of event-specific data and support information exchange among individuals involved in disaster management activities at different locations (Turoff et al. 2004).

EMIS are a type of information system that supports disaster mitigation, preparation, response, and recovery (Turoff et al. 2004). They include tools such as proprietary response software, databases, and radio equipment (e.g., Allen et al. 2014; Chen et al. 2008a; Chen et al. 2008b); warning systems such as sirens, radio, and warning apps (e.g., Fischer-Preßler et al. 2020; Kaufhold et al. 2018; Tan et al. 2017); and open source software (e.g., Alexander 2014; Currion et al. 2007).

Many of the tasks EMIS support, such as resource allocation, warning, and collaboration, are related to specific information needs of different stakeholders. Some EMIS, such as purposebuild systems, can be accessed only by a restricted user group, whereas other systems are publicly available, such as public social media. Recently and increasingly, social media have been changing the nature of disaster-related communication (e.g., Ling et al. 2015; Reuter et al. 2018; Tim et al. 2017). Hence, EMIS respond to the information needs of different stakeholder groups that use the systems. There are information needs that arise during disaster management within and between organizations, between organizations and the public, as well as within the public. EMIS can be broadly categorized in terms of how they facilitate meeting these information needs for these different stakeholder groups.

The support EMIS offer disaster management in providing relevant information and supporting collaboration within the involved groups make their use critical. However, EMIS make a difference in disaster management only if they are leveraged and integrated effectively in the 
relevant activities (IFRC 2013, p. 10). Effective use of EMIS means they support users such as those from professional emergency response, government agencies, and affected communities and businesses in taking informed actions to respond to a disaster event-which depends highly on accurate, relevant, and timely information.

The overall objective of this cumulative dissertation is to help researchers and practitioners obtain a deeper understanding of the potential of EMIS for emergency-related information exchange and how EMIS can be leveraged effectively. The studies included in this dissertation aim to provide theoretically grounded and empirically verified insights as well as practical recommendations regarding the use of EMIS in disaster management by organizations and the public and how using EMIS can support disaster-related activities. In particular, this dissertation poses the following overarching research question:

What potential do EMIS have for emergency communication and how can this potential be leveraged?

In the following section, this overarching research question becomes four more specific research questions.

\subsection{Research Questions}

Organizations involved in disaster management such as first responders and public authorities, as well as businesses that need to restore their normal functioning and supply goods, use dedicated EMIS that support intra- and inter-organizational information needs. EMIS are indispensable for professionals responding to or mitigating a threat by supporting organizations throughout the disaster management process (Hiltz et al. 2015). For instance, as part of disaster preparation, computer simulations of different emergency scenarios can help train professionals on coordination and communication during an actual emergency. In disaster mitigation, emergency geographic information systems can support risk identification by mapping locations vulnerable to threats, therefore supporting actions to foster resiliency and reduce risks in those areas. During disaster response, systems with network capabilities can help in overcoming information gaps between responders by enabling the dissemination of information among groups of stakeholders at different locations. In the recovery phase, emergency geographic information systems can support the management of debris and other clean-up operations.

These examples show that EMIS support a variety of tasks in disaster management, all related to accessing timely, relevant, and reliable information that enables responders to gain situational awareness on which they can base decisions. When used effectively, EMIS can enhance preparedness and mitigation, improve coordination and cooperation among crisis responders, enable logistics, and limit damage and harm. The potential of EMIS to support disaster management and thus reduce causalties demonstrates the importance of research into how EMIS can contribute to disaster management.

There are, however, examples of disasters in which EMIS fail because the infrastructure does not work, the systems are perceived as difficult to use, or the responders were not sufficiently familiarized with the systems prior to the disaster (e.g., Allen et al. 2014; Bharosa et al. 2010; Day et al. 2009). A better understanding of how EMIS are used by emergency management 
organizations can, therefore, help ensure for others that these systems work most effectively to improve preparedness, response, and recovery. That understanding will be crucial not only for the future development of the technology but also to ensure that the needs of all those involved in emergency management are met. In light of potential EMIS failures in disaster management, the first of the more specific research questions of this thesis is:

RQ1: How can emergency management information systems support responder organizations in disaster management?

Successful emergency management strongly depends on the cooperation of the affected public it seeks to protect. To meet the information needs of the public, some EMIS leverage public and private infrastructure for emergency communication between organizations and the public. Specifically, technological trends such as the ubiquity of the internet, widespread use of social media, and penetration of smartphones among populations are altering disaster management (e.g., Alexander 2014; Reuter et al. 2018). Building upon this potential, responder organizations worldwide increasingly leverage the growth of lightweight IT such as smartphones for emergency communication with the public (Tan et al. 2017). Authorities began to develop ITenabled warn systems that enable the dispatching of warnings to mobile devices, such as through apps built for one- or two-way information exchange between organizations and the public. During a disaster, these systems allow for communicating emergency-related information to the public in a timely manner so people can take protective measures (e.g., Bonaretti and Fischer-Preßler 2021; Tan et al. 2017).

While these dedicated mobile warning systems create new opportunities by complementing traditional channels for issuing timely warnings, they suffer from low adoption rates (e.g., Fischer-Preßler et al. 2020; Tan et al. 2017). Effective use and widespread adoption of these technologies are, however, particularly crucial-since an alerted public can take informed actions in emergencies that may even save lives. This is why efforts to promote these EMIS are vital; they are a means to meet public expectations of receiving timely and accurate warnings in emergencies-and demonstrating that those expectations can be met is key to convincing people they should be used. It is, thus, an ongoing research endeavor to understand the factors that motivate the public to use technology-enabled emergency systems so these can inform their design. Hence the second of the more specific research questions of this thesis:

RQ2: How can EMIS for public emergency communication be leveraged effectively to support emergency management?

Another trend in disaster management flows from developments in public digital platforms, especially social media and their widespread use. These technological developments have created an increasingly networked world and have significantly changed how individuals and organizations interact during disaster situations (Ling et al. 2015). Social media such as Twitter and Facebook, converge social and digital networks, enabling public emergency-related communication in real-time such as reporting information from the scene between unspecified groups of social media users. While they may have been developed primarily for hedonic use, they by extension enable interconnectedness and real-time communication among users that increasingly alter how disaster information is managed (Reuter et al. 2018). 
In disasters, responder organizations must be prepared to communicate with a vast number of social media users (Hughes and Tapia 2015). Responder organizations must be aware of the advantages and limitations in order to govern social media and apply them effectively. There are many advantages to these platforms; for instance, they provide access to resources, such as new volunteers, donations, and reports from bystanders. However, widely acknowledged in literature is that responder organizations still struggle to adopt and govern social media within their organizational structures, for instance, because they don't have social media experts or guidelines, doubt their relevance for communication with the public, or lack knowledge about when and how to use social media (e.g., Latonero and Shklovski 2011; Palen and Anderson 2016). In summary, despite the potential of social media, many responder organizations remain reluctant to use social media. This research investigates how responder organizations can use social media for communication with the public. Hence, the third more specific research question:

\section{RQ3: How can responder organizations leverage public social media effectively?}

Since social media provide the public with a mediating platform to exchange emergency-related information in real-time (e.g., Ling et al. 2015; Tim et al. 2017), they shift vertical one-way communication from authorities to a given population to horizontal many-to-many communication. That transforms the public from solely passive recipients of emergency information to active participants in communicating, as they can access emergency-related content in real-time, such as bystander reports, as well as provide that content themselves (Kaewkitipong et al. 2016). This information can spread rapidly within digital social networks (Oh et al. 2013). This speaks to one of the main functions of social media platforms during disasters: they enable public discourse on disaster events that aid collective understanding, meaning-making, and self-organization (Mirbabaie et al. 2020).

While much research has focused on observable public responses in social media, there are fewer insights into specific social media users' needs to which this digital communication can respond. So emergency authorities can respond to such needs, it is important to understand the factors that influence public social media use during emergencies, such as the reduction of uncertainty, establishing situational awareness, and helping meet emotional needs. This is especially important during disasters in which effective information flow is critical to enable public cooperation-a basic enabler of effective disaster response. This will also assist responders in understanding how people are going to react in social media in the future when disasters occur. Hence, the fourth of the more specific research questions:

\section{RQ4: How do social media help the public respond to a disaster?}

In answering these four research questions, this thesis intends to make several theoretical and practical contributions.

From a theoretical perspective, the thesis aims to contextualize, challenge, and test theories in the emergency and disaster context. The thesis contextualizes theories such as terror management theory by studying them in the emergency context. The thesis provides evidence that intention constructs applied in routine contexts are insufficient for predicting behavior in disaster responses, thus challenging these theories. In terms of testing theories, the thesis adapts 
theories such as protection motivation theory to the emergency context and tests the adapted models.

From a practical perspective, this thesis aims to aid the effective use of dedicated EMIS and social media. Enhancing knowledge about enablers and impediments in EMIS use is of concern for practitioners since that knowledge and lessons learned will help them prepare for future events. The thesis provides frameworks as levels of abstractions that help analyze (in)effective use of EMIS. The thesis furthermore informs the design of dedicated EMIS by identifying principles that can lead to their more effective use.

\subsection{Structure of the Dissertation}

This thesis consists of the introductory paper as well as 14 research papers, none of which have been modified for this dissertation. The introductory paper motivates the research area, defines the research context, provides a literature review of EMIS types investigated in existing research, elaborates theories applied in EMIS research, and explains the research methods of the thesis. It also summarizes the main research results of the 14 research papers, highlighting their contributions to theory and practice. Finally, it explains limitations, outlines future research directions, and provides a conclusion. The 14 research articles are presented in four sections that correspond to the four research questions articulated above; Figure 1 associates each of the 14 papers with those specific questions.

The first section of the dissertation focuses on the effective use of EMIS for inter- and intraorganizational disaster management and communication. This part consists of three papers. Paper I is a systematic literature review that synthesizes past research on barriers that hinder effective disaster communication, identifying social, organizational, and technological impediments. Paper II is a systematic literature review that summarizes information systems for risk management used within the supply chain and - complemented with insights from practiceidentifies research gaps in this area. Paper III provides a prototype process that informs the analysis of emergency-related radio communication from a social network analysis perspective, using radio communication data from a large-scale emergency training.

The second section focuses on mobile-enabled warning systems and includes six papers. Papers IV and V test psychometric models for assessing a survey dataset to understand use intention and continued use intention of warning apps. Paper VI investigates the performance of SMS warnings in campus communities, based on a survey data set. Paper VII derives dimensions of effective use of mobile warn systems from the qualitative analysis of expert interviews and online review data of the respective apps. Paper VIII is a case study-building on interview data of emergency response professionals-that identifies deficiencies hindering the effective use of a warning system. Finally, paper IX presents an ethical design of Covid-19 warning apps, based on the analysis of existing app designs.

The third section provides insights on responder organization governance of social media. Paper X studies social media use of the German Red Cross from an online social capital perspective, based on interviews with that organization's social media experts. Paper XI, also based on interviews, investigates social media governance strategies and tensions within responder organizations to inform effective social media use at different organizational levels. 
Introductory paper: Motivation, research context, methodology, contributions, limitations, conclusion

Overview and foundation of emergency management information systems and of emergency communication

\section{Part I}

Focus: Reviews of and a methodological paper about use of emergency management information systems for communication and collaboration Methods: Literature reviews, conceptual paper

Papers: \#1, \#2 and \#3

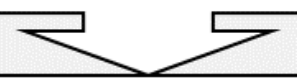

Empirical and theoretical validation of effective use of emergency management information systems

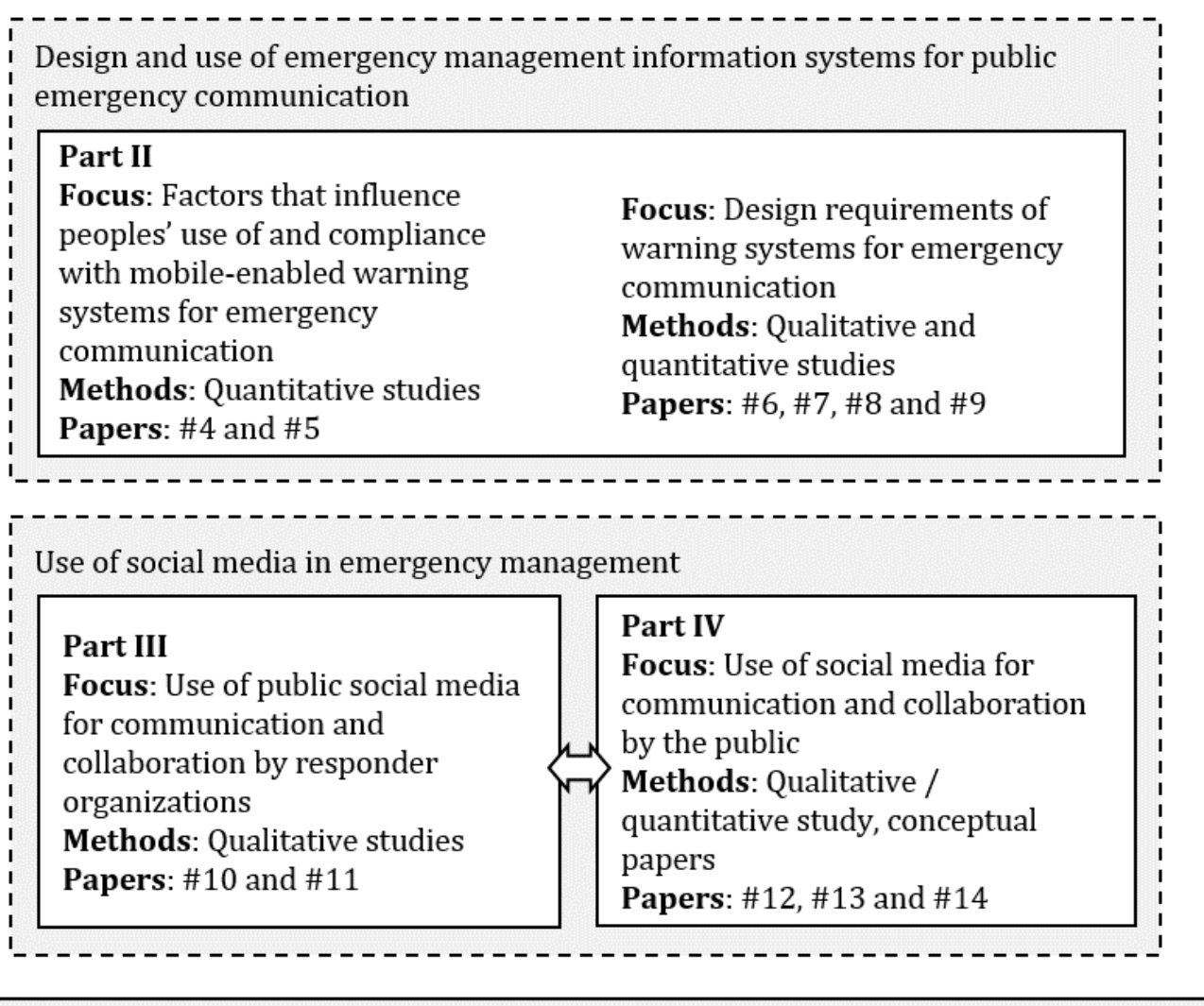

Figure 1. Structure of the dissertation

The fourth section focuses on public social media use for responding to a disaster event. It includes three papers. Paper XII considers psychological processes and explores why people use social media after a terrorist attack; it also proposes a research model with testable propositions. Paper XIII applies topic modeling to a Twitter data set about a terrorist attack that took place in Germany, and identifies coping and sense-making strategies of social media users. Paper XIV is a literature review that develops theoretical explanations and a model of online selforganization via social media. 


\section{Research Context, Theoretical and Conceptual Founda- tions}

This section begins with a discussion of conflicting disaster statistics. It then introduces definitions of foundational terms and concepts, to ensure readers have a clear understanding of the terminology used herein as well as the context of the thesis. In its final part, this section presents a literature review of EMIS types and theories used in this research stream.

\subsection{Conflicting Disaster Statistics}

Humans have always faced risks from disasters such as earthquakes, floods, epidemics, and hostile inter-group relations. In fact, disasters are "as old as when human beings started to live in groups" (Quarantelli et al. 2018, p. 61).

According to the Swiss Re (2018), there has been a continual increase in human-made and natural crisis events since 1970. The report states that on average each year during the 10-year timespan between 2008 and 2017, natural crisis events alone affected 198.8 million people, resulted in 64,186 casualties (Swiss Re 2021), and were responsible for roughly US $\$ 190$ billion in economic losses (Swiss Re 2018); 2017 set one-year records for economic losses due to natural disasters. High-impact natural disasters have been severe in terms of human casualties, economic and social losses, and damage to the environment. Examples include the 2010 earthquake in Haiti, which killed 225,500 people; the drought in India in 2015 and 2016, which affected 330 million people; and the 2011 earthquake and tsunami in Japan, which led to economic losses totaling US $\$ 201$ billion (CRED 2018). It remains questionable, though, whether the numbers of causalities, economic losses, and disasters themselves are growing. While global monetary losses (adjusted for inflation) resulting from natural disasters rose from US $\$ 66$ billion in 1980 to US\$345 billion in 2017 (Munich RE 2020b), the trends can also be explained by more efficient data collection techniques, evolving definitions of what constitutes a disaster, and socio-economic and socio-technical changes that are causing new and more severe threats.

To assist in disaster risk reduction over the short- and long terms, it is important to understand disaster event impacts, costs, patterns, and trends. Rather than addressing data needs on an ad-hoc basis, crisis managers began to push the systematic collection of disaster-related data. EMIS can support this task. For example, the web-based knowledge sharing platform PreventionWeb collects and provides disaster-related data from across the world and supports disaster-related knowledge management (UNDRR 2021). Even with such efforts, however, and with continually improving data collection methods, disaster-related data can at times appear ambiguous. These data are notoriously inaccurate-a feature of difficult data collection in chaotic environments. Hence, the statistics regarding the numbers of people affected and economic losses are often only guesses; further, exact casualty numbers often remain unknown. For instance, it is still unclear how many causalties resulted from Hurricane Katrina in 2005 (Montz et al. 2017).

In addition, research stresses the difficulty of developing a useful definition and typology of disasters, while acknowledging their importance for analyzing these events effectively. Proposals range from simple categorization approaches that differentiate between natural and humanmade events to approaches that classify disasters in terms of degrees of predictability and 
manageability, leading to what the author calls conventional, unexpected, intractable, and fundamental crises (Gundel 2005). This definitional challenge is, not only a theoretical issue but also affects practical measures. In particular, the number of disaster events reported varies because organizations that track disaster events use different criteria and definitions. For instance, the Munich RE NatCatService estimated the number of natural disasters in 2017 globally to be 723 (Munich RE 2020a), whereas the Swiss Re reported 183 natural disasters (Swiss Re 2018) and the Centre for Research on the Epidemiology of Disasters (CRED) identified 355 (CRED 2018b). Hence, disaster statistics must be seen in terms of their limitations, often resulting from the specific underlying definition (Montz et al. 2017).

While there have always been threats from disasters, some researchers argue that threats are becoming more severe (Coleman 2006; Posner 2004) and that new threats endanger societies (Quarantelli et al. 2018). In particular, new forms of disasters that combine elements of older forms while introducing new vulnerabilities have emerged. For instance, technological advancements that include chemical, nuclear, or biological threats can accidentally cause disasters. Large-scale examples include radiation fallout from the Chernobyl nuclear power facility in Ukraine in 1986 and the 2011 earthquake that hit Japan in 2011, causing a tsunami that in turn created a meltdown and the release of radioactive material from the Fukushima nuclear power plant.

There are also what Kousky and Zeckhauser (2006) refer to as human activities, private or public, that jeopardize assets and increase hazards (JARing). These actions decrease an ecosystem's ability to reduce the risks of natural disasters. Examples include urbanization, deforestation, and the drainage of wetlands that can trigger local events such as small-scale flooding while also adding to global climate change. A key aspect of such actions is that they often create short-term profit for some while creating negative externalities more broadly for others when disasters strike.

Climate change, the use of modern infrastructure and technologies, reliance on information systems, and the increasingly interconnected nature of our global society also create new risks. Volcanic ash can paralyze air traffic. Information systems fail because of sabotage (Quarantelli et al. 2018). Epidemics such as SARS and Covid-19 spread rapidly around the world. Population growth forces people to live in disaster-prone areas that were once considered uninhabitable (Eshghi and Larson 2008). Millions of people live in flood-prone areas, on hurricane or cycloneprone coasts, in regions prone to volcanic eruptions and earthquakes zones, and areas suffering from draughts (Montz et al. 2017).

A major characteristic of some of these new threats is their transboundary nature (Ansell et al. 2010). Transboundary disasters share the following six characteristics: they cross national, political, and functional boundaries, disrupting societies; they can spread very quickly; at their outset, they have no clear origin point and their effects are unclear; the number of potential victims, both direct and indirect, is quite large; traditional approaches of emergency responders to respond to them do not necessarily work; and although existing organizations are fundamentally important in the response, there is a remarkable amount of emergent behavior, and new informal networks develop (Quarantelli et al. 2018). 
The spread of Covid-19, which first appeared in China in late 2019, offers a concrete example. This infectious disease may have been transmitted from animals to humans (snakes but also other animals are thought to be the culprits). The cause and consequences of the disease, as well as how fast it could spread, were uncertain at first. International airplane travel spread Covid-19 quickly around the world. The rapid transmission, high numbers of infections and deaths, and the collapse of public health infrastructures led countries to lock down their economies, daycare, eldercare, and schools. As country after country was affected, emergent behaviors could be observed, such as the creation of platforms that connect neighbors to help each other or that connect small local shops with customers.

In summary, while inaccurate statistics and differing definitions make it impossible to infer with certainty that there are more disasters happening, it is clear that societal, technological, and economic trends are introducing new threats that are qualitatively different from those of the past events, even as we continue to have what could be considered traditional disasters (Quarantelli et al. 2018). In response to these new threats, emergency managers are increasingly required to collaborate on responses with other public officials across national boundaries. Hence, emergency managers need to share data within an increasingly large network of responders. Future EMIS need to incorporate these networks of responders and help them make informed decisions about the resources needed for disaster response.

\subsection{Definitions and Types of High Impact Events}

Disaster and crisis management is a multidisciplinary research topic that builds on several disciplines and discourses, each of which has its own particular definitions of terms. These differ widely in the context of different research purposes and audiences. As crisis informatics frequently borrows definitions from disaster sociology, many of the definitions originate in that domain.

This section defines and categorizes the terms emergency, disaster, crisis, and catastrophe. Table 1 on page 13 gives an overview of the key terms discussed in this section.

\section{Emergencies}

Emergencies are events with relatively minor consequences, such as a relatively low number of casualties and relatively limited amounts of property damage, for some segments of a community (Altay and Green 2006). House fires, automobile accidents, and minor chemical accidents at a company fall into this category. Emergencies of this sort tend to be more routine in that they happen with some frequency within communities. That ends up providing emergency responders-firefighters, paramedics, police, and other local authorities-with experience that helps them prepare for future emergencies (Lindell 2013b; Swersey 1994). Hence, emergencies tend to be relatively well understood by the responders that have been trained to deal with them on a regular basis, and they can usually be managed successfully with local resources (Lindell 2013b). Responses to some emergencies may be handled by a single local government authority using standardized protocols and specialized equipment (Quarantelli 1987). Nevertheless, each emergency event can present unusual characteristics and intricacies. For instance, every house fire requires a response adapted to the specific situation. The belief that each new fire will be like all the previous ones bears a high risk that can lead to firefighter injury or death (Brunacini 2002). 
In contrast to disasters or crises (see the next sections), emergencies are defined less unambiguously in the literature. Although emergencies may have only minor impacts on the community, they can of course be seen as a disaster by those they affect. Hence, some incidents may be characterized as disasters-in the sense that they have major consequences for those affected-because they are seen as such by those affected and by observers, such as authorities and the media. This reveals that the terms are also subject to socially constructed and local interpretations (Buchanan and Denyer 2013).

\section{Disasters}

In the early days of disaster research - the time until the end of the Second World War-definitions of the term disaster often remained implicit or partial in research (Perry 2006). Carr (1932) was the first who defined a disaster, but even that definition remained, however, rather implicit in that it proposed that a disaster is an event that generates substantial consequences.

Interest in disaster research began to grow in the early 1950s, continuing through the founding of the Disaster Research Center in 1963 (Perry 2006). In the early 1960s, sociologist Fritz (1961) published a disaster definition that inspired further debate; many definitions were developed in the years after his publication that built on the criteria he set forth (Perry 2006).

Fritz stresses the social aspect and impact of a disaster with respect to the form, mutation, or function of the social system. In particular, according to Fritz (1961, p. 655), a disaster is "an event concentrated in time and space, in which a society or one of its subdivisions undergoes physical harm and social disruption, such that all or some essential functions of the society or subdivision are impaired." The definition is far more specific than those that preceded it, classifying disasters as events with certain characteristics. Specifically, the definition discriminates between disaster events in terms of time and space and refers to the effect on the social unit (Lindell 2013a). Under this definition fall a lot of disruptive events that may be quite different in terms of how they unfold over time; for instance, a terrorist attack may result in death and destruction over a period of only a few hours, whereas the societal disruption from a flood may continue over a very long period (Staupe-Delgado 2019).

Fritz's definition has been criticized because it is in many cases difficult to mark an event clearly in time and space ( $\mathrm{t}^{\prime}$ Hard and Boin 2001). For instance, terrorist attacks can-beyond the actual event-trigger an intense post-disaster period, with long-term societal impacts such as post-traumatic stress disorder; those affected, wrought by anxiety, may make changes in their behavior as a result.

Subsequent research advanced the definition. Kreps (1985) extracted four key analytical disaster dimensions: an event, its impact on social units, and the social unit's responses. The event is a list of disaster types that differ widely in their characteristics, that is, their varying natural or human-made causes or combinations thereof (for an overview, see Shaluf 2007). Humanmade disasters are events that result from human actions and decisions, such as technological disasters, industrial accidents, terrorist attacks, and active shooter events. The 9/11 terrorist attacks in New York City and at the Pentagon are examples (Schweinberger et al. 2014), as is the 2016 terrorist attack in Berlin at the Christmas market (Fischer-Preßler et al. 2019). Natural disasters are events that result from natural causes such as epidemics, tornados, hurricanes, earthquakes, droughts, and floods (Rutherford and Boer 1982; Shaluf 2007). A third disaster 
event is a combination of human-made and natural disasters, such as the Fukushima tsunami in 2011 and the subsequent nuclear meltdown.

The disruptions that stem from such events are typically severe and sudden, unexpected, and widespread. The subsequent impacts are not restricted to physical damage but include major social effects on a community, that is, they significantly impact the routine functioning of a social unit, disrupt the unit's normal patterns of life. Hence, the effects may include loss of life, injury, hardship, and adverse health, but also include damage to or destruction of government systems, buildings, communications, essential services, and other impacts on the overall social structure (Kreps 1985). Some argue that the ultimate cause of a disaster lies in the inability of the social system to cope with it (Boin and t' Hard 2006).

The social unit dimension concerns the society affected and its subunits, within which we find individual stakeholders embedded in social, political, and economic sectors. In the social sector, these individuals belong to households, neighborhoods, and broader communities. Politically, the same individuals are stakeholders in states, provinces, and nations; and in the economic sector, these individuals are included in businesses, which, in turn, are embedded in industries and so forth (Lindell and Perry 2012). Disasters affect the social unit and create individual perceptions. In turn, a social unit's perception of a disaster affects responses to the event.

The responses are driven by new demands that flow from actual events and their impacts, and are efforts to sustain a viable social system. Given that disasters are inherently disruptive, the response and coping activities of the affected social units often exceed local communities' capacities, and external support is required (Kreps 1985).

The disruptive effect of events on the social unit and processes can also give way to new emergent patterns of social organization. Disaster researchers have long been aware of collective behavior in the form of emergent and self-organizing groups, that is, groups of volunteers from within and outside affected communities that are not otherwise involved in disaster management, but that come together to respond collaboratively to community needs (Quarantelli 1983) such as evacuation, shelter, food, clothing, medical assistance, and social care.

\section{Crisis}

In organizational and management science, in particular, the term crisis-sometimes also referred to as socio-technical disaster (e.g., Richardson 1994) - is used for an event that threatens or affects organizational goals primarily (Seeger et al. 1998; Weick 2010). Hence, the term crisis is often used when the affected referent is an organization (not a wider community), and often concerning effective organizational crisis communication (e.g., Coombs 2010; Seeger et al. 1998; Weick 2010). In such cases, disasters can spawn organizational crises, such as an organization's need to cope with the consequences of a disaster event on its operations (Coombs and Holladay 2010).

In line with this thinking, Coombs $(2007$, p. 3$)$ defines a crisis as "the perception of an unpredictable event that threatens important expectancies of stakeholders related to health, safety, environmental, and economic issues, and can seriously impact an organization's performance 
and generate negative outcomes." Stakeholders are groups of people related to the organization facing the crisis. That it is a "crisis" depends on their perceptions, which may arise from negative media stories about the organization, the failure to meet customer expectations, organizational accidents, or the effects of an external disaster event (Coombs 2007).

Responder organizations themselves can also experience organizational crises that affect their goals. For instance, there have been incidents reported in the press as far back as the 1990s about financial and sexual misdeeds by responder organizations employees that have negatively affected these organizations' reputations and created public indignation (Gibelman and Gelman 2001).

In the social sciences, some researchers argue that a crisis is not as clear cut as a disaster and that the former is used as a catch-all for a wider array of events than the former, including to characterize everything from IT crashes, economic disruptions (such as recessions), prison riots, and wars (Boin and t' Hard 2006). Others posit that a disaster is "a crisis with a bad ending" and they are few manifest in number (Quarantelli et al. 2006, p. 23). Similar to this perspective, a crisis may be seen as a situation in which there is a higher than normal probability of an extreme event occurring-for instance, a hurricane approaching a coastal community may be characterized as a crisis as the probability of casualties and damage increases when the hurricane comes closer to shore. The urgency of the danger requires increased attention and, at some point, action to minimize the impacts should the hurricane make landfall (Lindell 2013b). However, these discriminations (interested readers are referred to Quarantelli et al. 2018 for further distinctions) are not commonly applied in the current interdisciplinary disaster and crisis literature.

In fact, while there is a long and ongoing discussion, as well as a lack of common ground, regarding how to differentiate between the terms crisis and disaster, research is "far from having standardized terms and similar connotations and denotations" (Quarantelli et al. 2006, p. 24). Hence, despite all these differentiations between disaster and crisis and the absence of a general agreement that these terms can be seen as broadly describing the same phenomena, the two terms are nevertheless used interchangeably in research (e.g., Ansell et al. 2010; Menoni and Pugliano 2013; Quarantelli et al. 2006).

An alternative approach to drawing a clear differentiation between the two terms is to focus on event types and categorize events according to certain characteristics, identifying traits that events have in common. The presumably oldest and most commonly used typology, which was introduced earlier in this manuscript, distinguishes between the technological/ human causes of events (such as terrorist attacks) and those caused by nature (such as floods or fires) (Rosenthal and Kouzmin 1993), or more specific typologies (e.g., Shaluf 2007). The broad distinction between human-made and natural disasters, arguably, has some merit since it is very broad. For instance, natural disasters can include both local flooding and worldwide events such as global warming - in the latter case the population is both victim and offender (Gundel 2005).

Gundel (2005) discusses the problems of developing a useful typology and argues that the classes should be mutually exclusive, exhaustive, relevant to practice and pragmatic, and contain a reasonable number of classifications. However, he concludes that it is difficult to categorize all types of potential crises to a manageable number of mutually exclusive classes and questions 
the utility of proposed typologies. In addition, as mentioned in the emergency section, defining and categorizing an event also depends on local interpretations and socially constructed meanings. Hence, sustainable disaster or crisis definitions and categories are difficult to establish and no common ground is reached so far.

\begin{tabular}{|l|l|}
\hline Term & Key characteristics \\
\hline Emergency & $\begin{array}{l}\text { Events that cause minor consequences for a part of a community, such as a few } \\
\text { casualties and/or a limited amount of property damage. } \\
\text { Relatively well-understood phenomena that can be managed by local emergency } \\
\text { responders. }\end{array}$ \\
\hline Disaster & $\begin{array}{l}\text { Natural, human-made, or events that combine both and have major physical and } \\
\text { social impacts, such as loss of life or disruption of social processes of a social unit, } \\
\text { and that require a response to respond to them. }\end{array}$ \\
\hline Crisis & $\begin{array}{l}\text { Events for which local responder organizations require help from the wider com- } \\
\text { munity to manage. }\end{array}$ \\
& $\begin{array}{l}\text { Crisis and disaster are often used interchangeably; there is no common agreement } \\
\text { on their definitions in the social sciences literature. }\end{array}$ \\
& $\begin{array}{l}\text { A crisis differs from a disaster in that it tends to be about the affected referent, } \\
\text { which in the organizational crisis literature is often an organization. As such, crises } \\
\text { can be defined as events related to health, safety, environmental, or economic is- } \\
\text { sues that threaten or affect organizational goals and lead to negative outcomes. }\end{array}$ \\
\hline Catastrophe & $\begin{array}{l}\text { An extreme disaster event with a much more severe and widespread level of dev- } \\
\text { astation than a disaster. }\end{array}$ \\
\hline
\end{tabular}

Table 1. Overview on disaster-related terms and definitions

\section{Catastrophes}

Historically, it is difficult to distinguish a disaster or crisis from a catastrophe and the distinction mainly hinges on the interpretation of event characteristics held by the people involved. A catastrophe is specified as an extreme disaster event with much more severe and widespread devastation. Specifically, it is a large-scale disaster whose impacts and damages overwhelm responder organizations, which find themselves unable to cope with and respond to the situation effectively. Local responder organizations lack the facilities and resources to cope with such an event, the scope of which is so far-reaching that even nearby communities that would typically be counted on for assistance are not available or sufficient. Hence, federal or international organizations must take the reins and manage the situation (Hiltz et al.2015). One aspect of catastrophes is that most community functions disappear in the absence of leadership, infrastructure (e.g., hospitals) is destroyed, much of the housing becomes uninhabitable, schools shut down, and damage might be so great that survivors can find only limited assistance, if any. Hurricane Katrina, which is a vivid example of these phenomena, is referred to as a catastrophe (Rodríguez et al. 2006).

\section{Summary}

In summary, emergencies, disasters and crises, and catastrophes may be seen as variations of event types in terms of scale, scope, and duration along a continuum (Fischer 2003). The interpretation of an event's boundaries with respect to scale, scope, and duration are, however, vague and depend on social interpretations. Furthermore, studies in this context define the terms quite differently depending upon the phenomena under investigation, the socially constructed meanings of the events, and/or the underlying academic discipline. 
In this dissertation's papers, these terms are used and defined depending on the events being studied and the given paper's relevant literature stream. In the section that immediately follows, the two terms, disaster and crisis, are used synonymously.

\subsection{Emergency Management}

Despite its name, research in emergency management-at times also referred to as crisis or disaster management (e.g., Boin et al. 2005)—often focuses on disasters rather than emergencies because responders are fully skilled to address most needs in routine emergencies (McEntire 2006). Nevertheless, emergency responders need to manage all the hazards elaborated in the preceding section-that is the overarching function of emergency management. In addition, many of the basic tasks of emergency management, such as warning the population or taking care of those who have been affected, are tasks in disasters as well. Of course, disaster management scales differently depending on the type, scope, and scale of the disaster.

Emergency or disaster management is, hence, broadly defined as follows:

The set of activities aimed at taking countermeasures and coordinating emergency responders, resources, and information to mitigate, prevent, respond to, and/or recover from complex, unexpected, and dynamic situations that threaten lives and the environment.

If emergency management is effective, it can minimize potential risks and-in response to the threat-organizations and individuals can take protective measures.

Certainly, there are differences between responding to routine emergencies and disasters. Depending on the particular situation, different sets of emergency responders will be involved and different strategies and procedures are applied. For instance, local police, fire, and emergency medical services are on-site in minor emergencies, whereas in disaster events resources and responders from outside the community are needed to augment these local resources (Altay and Green 2006). Table 2 on page 15 is an overview of differences in the management of disasters and emergencies based on Quarantelli et al. (2006) and Turoff (2002).

As explained above, disaster management is more complex than routine emergency management and is typically divided into phases numbering between three and eight, which often overlap and are not entirely determinable. The most common model has four phases: mitigation, preparedness, response, and recovery activities each described below (Hiltz et al. 2015; McLoughlin 1985). Other models with a larger number of phases incorporate these four.

Mitigation phase:

The mitigation phase comprises activities before disasters strike that seek to identify risks and thus reduce the impacts of emergencies such as casualties and property damage. Communities can undertake a host of different mitigation activities; many involve land use and building construction practices (Lindell 2013a). Geographical information systems may be used to identify floodplains or wind patterns that could result in fires. Once risks have been identified, steps can be taken to decrease them and make communities more resilient in the face of potential disasters. For instance, vulnerabilities can be reduced with new zoning regulations that keep buildings from disaster-prone areas or that stipulate construction requirements that make buildings less vulnerable to hazards. 


\begin{tabular}{|c|c|c|}
\hline $\begin{array}{l}\text { Management Charac- } \\
\text { teristics }\end{array}$ & Emergency & Disaster \\
\hline $\begin{array}{l}\text { Organizations in- } \\
\text { volved }\end{array}$ & $\begin{array}{l}\text { Local emergency management or- } \\
\text { ganizations. }\end{array}$ & $\begin{array}{l}\text { An unspecific number of local and na- } \\
\text { tional emergency management organi- } \\
\text { zations, authorities, affected communi- } \\
\text { ties, businesses. }\end{array}$ \\
\hline $\begin{array}{l}\text { Command and con- } \\
\text { trol }\end{array}$ & $\begin{array}{l}\text { Established command-and-con- } \\
\text { trol structures to address local } \\
\text { emergencies. }\end{array}$ & $\begin{array}{l}\text { A common incident command system is } \\
\text { established to manage the specific situ- } \\
\text { ation and coordinate all responder or- } \\
\text { ganizations involved effectively; once } \\
\text { the situation has been resolved, the } \\
\text { command system is dismantled. }\end{array}$ \\
\hline $\begin{array}{l}\text { Communications and } \\
\text { responsibilities }\end{array}$ & $\begin{array}{l}\text { Responders tend to know each } \\
\text { other well from shared experi- } \\
\text { ences responding to local emer- } \\
\text { gencies, so established points of } \\
\text { contact are employed. }\end{array}$ & $\begin{array}{l}\text { Contact points and responsibilities may } \\
\text { be unclear due to the large number of } \\
\text { responder organizations involved. }\end{array}$ \\
\hline Processes & $\begin{array}{l}\text { Routine and well-trained re- } \\
\text { sponse processes; local re- } \\
\text { sponder organizations know their } \\
\text { tasks and responsibilities well. }\end{array}$ & $\begin{array}{l}\text { Specific actions cannot be predeter- } \\
\text { mined; processes may need to be } \\
\text { adapted to the situation. }\end{array}$ \\
\hline Resources & $\begin{array}{l}\text { Responder organizations can ad- } \\
\text { dress the situation with local re- } \\
\text { sources. }\end{array}$ & $\begin{array}{l}\text { Responder organizations need addi- } \\
\text { tional public and private resources to } \\
\text { address the situation. }\end{array}$ \\
\hline Information supply & $\begin{array}{l}\text { Standardized processes and } \\
\text { structures. }\end{array}$ & $\begin{array}{l}\text { Complex information diffusion; impedi- } \\
\text { ments to providing accurate and } \\
\text { needed information to the right re- } \\
\text { sponder organizations at the right time } \\
\text { because of missing standards. }\end{array}$ \\
\hline
\end{tabular}

Table 2. Differences between emergency and disaster management

Preparedness phase:

The preparedness phase comprises activities that, like those in the mitigation phase, take place prior to disasters. They involve building amassing human and material resources and establishing operational capabilities for responding to a disaster at the time of impact. These activities make it possible for responder organizations and the public to respond effectively when a disaster strikes. Examples include training EM personnel, which may involve disaster scenarios and computer simulations, and preparing and practicing how to use EMIS for coordination and communication during an actual disaster. Other preparedness activities include creating websites and social media webpages that inform the public about how to prepare themselves for different disaster situations and how to act when they occur. Preparedness also includes disaster operations and resource management planning, development of warning systems, maintaining disaster operating centers, and practicing disaster communications, establishing mutual aid agreements.

Response phase:

The response phase includes all activities from the moment a disaster event is detected until the situation is stabilized. These activities aim to save lives, minimize property damage, and improve recovery in the next phase. There are four basic response functions for professional emergency responders: disaster assessment, disaster operations, population protection, and 
incident management. Disaster assessment involves diagnosing the situation to guide the response actions. Disaster operations are actions responder organizations take to limit the magnitude and duration of an event. Population protection involves actions that safeguard people from a disaster's impact. Incident management refers to actions that prioritize and mobilize human and physical resources to respond to the event. These functions are similar but not identical to the functions of the incident command structure-established in case of disaster for a common control and command structure of all responder organizations-of command, operations, planning, logistics, and finance and administration (Lindell 2013b).

Concrete examples of actions in the response phase include placing disaster personnel and supplies, searching for and rescuing victims, evacuations, and housing those affected in safe areas. Others include activating disaster plans and systems, issuing disaster instructions to the public, providing disaster medical assistance, and staffing disaster operations centers. In this phase, EMIS are crucial for coordination and communication efforts and to ensure that resources such as rescue workers, materials, and supplies (e.g., water, food, medical) are distributed to where they are needed.

Disaster response activities typically involve diverse groups of people, some formally constituted and others emergent and based on volunteers.

Recovery phase:

Recovery actions, which are typically distinguished as short- or long-term, begin after a disaster situation has been stabilized and last until a community returns back to normal life. Shortterm recovery activities aim to restore vital life-support systems to minimum operating standards, whereas long-term activities aim for a return to normal life through cleanup, relief management, reconstruction, and rehabilitation. In some cases, the recovery phase is never really completed, because the memory of a past event tends to keep people who were affected focused on its possible reoccurrence, and thus on continual preparation.

Typical relief activities include clearing debris, restoring access to the affected location, rebuilding infrastructure, and reestablishing economic activities (Lindell 2013b). EMIS can support all sorts of recovery activities, including being used to collecting donations for recovery efforts.

Table 3 is an overview of four phases of disaster management. The phases are not mutually exclusive; mitigation and preparedness, for instance, generally take place concurrently during the pre-impact period. There are also overlaps in the post-impact period: some neighborhoods in a disaster-stricken community may still be in the response phase while others have already entered the recovery phase. Finally, a new mitigation phase is often implemented during a recovery phase, based on what has been newly learned from the most recent event (Lindell 2013a). Hence, these phases should be seen as an ideal way to structure the main activities of disaster management and not as an immutable sequential process.

\begin{tabular}{|l|l|l|l|}
\hline EM phase & \multicolumn{2}{l}{ Timeframe } & \multicolumn{2}{l|}{ Definition } & Examples \\
\hline Mitigation & $\begin{array}{l}\text { Pre-impact pe- } \\
\text { riod }\end{array}$ & $\begin{array}{l}\text { Pre-impact activities that iden- } \\
\text { tify and reduce long-term risks } \\
\text { of casualties and property dam- } \\
\text { age resulting from emergencies. }\end{array}$ & $\begin{array}{l}\text { Regulations regarding flam- } \\
\text { mable items, building codes, } \\
\text { land-use policies. }\end{array}$ \\
\hline
\end{tabular}




\begin{tabular}{|l|l|l|l|}
\hline Preparedness & & $\begin{array}{l}\text { Pre-impact activities to provide } \\
\text { responder organizations with } \\
\text { operational capabilities to re- } \\
\text { spond to emergencies effectively. }\end{array}$ & $\begin{array}{l}\text { Training and routinization of } \\
\text { responses, standardized pro- } \\
\text { cesses, assignment of respon- } \\
\text { sibilities, identification, and } \\
\text { supply of resources, early } \\
\text { warning, hazard/vulnerability } \\
\text { analysis. }\end{array}$ \\
\hline Response & $\begin{array}{l}\text { During the } \\
\text { event }\end{array}$ & $\begin{array}{l}\text { Activities taken immediately be- } \\
\text { fore, during, or directly after an } \\
\text { unfolding disaster to save lives, } \\
\text { minimize property damage, and } \\
\text { improve recovery. }\end{array}$ & $\begin{array}{l}\text { Warnings, evacuations, build- } \\
\text { ing shelters, management of } \\
\text { resources such as facilities, } \\
\text { personnel, equipment, materi- } \\
\text { als, and information. }\end{array}$ \\
\hline Recovery & $\begin{array}{l}\text { Post-impact } \\
\text { period }\end{array}$ & $\begin{array}{l}\text { Short-term activities that aim to } \\
\text { restore vital life-support systems } \\
\text { to minimum operating stand- } \\
\text { ards. } \\
\text { Long-term activities that aim to } \\
\text { return to normal life by restoring } \\
\text { the environment, relief, recon- } \\
\text { struction, and rehabilitation. }\end{array}$ & $\begin{array}{l}\text { Restoring destroyed infra- } \\
\text { structure, rebuilding houses, } \\
\text { clearing debris, contamination } \\
\text { control, disaster unemploy- } \\
\text { ment assistance, temporary } \\
\text { housing, and facility restora- } \\
\text { tion. }\end{array}$ \\
\hline
\end{tabular}

Table 3. Disaster management phases with their definitions

\subsection{Emergency Management Information Systems}

This section, based on a literature review conducted for this framework paper, introduces the EMIS types and frameworks discussed in IS research. It is divided into three subsections: the first discusses EMIS that focus on intra- and inter-organizational emergency management; the second introduces EMIS developed and used to communicate with the public for emergency management purposes; and the third subsection is an overview of how public social media are leveraged for disaster communication within the public and from organizations to the public.

\section{Research on Professional EMIS for Intra- and Inter-Organizational Disaster Communication and Collaboration}

To coordinate and communicate effectively, emergency management relies on technical solutions, which span an array of EMIS (e.g., Dorasamy et al. 2013; Turoff et al. 2004). Originally, research referred to EMIS as information systems for responder organizations designed to enable communication and coordination between and within organizations during emergencies (Turoff et al. 2004). This definition concentrates on proprietary tools for responder organizations that support their professional response activities. The EMIS market is filled with different technical solutions varying in focus, functionality, and interoperability (Neville et al. 2018).

The EMIS literature focuses on three system archetypes in discussing professional response software (see Table 4): geographic information systems (GIS), decision support systems (DSS), and knowledge management systems (KMS). These archetypes are not specific only to EM, but are widely investigated in other IS literature streams. In contrast to systems used in routine contexts, however, EMIS design needs to consider the complex situational factors in which these systems operate, that is, uncertain and dynamic disaster situations, diverse stakeholder groups and needs, and diverse information requirements (Dorasamy et al. 2013). 
In the course of the literature review, it became apparent that a large variety of systems are referred to within this broad categories and that these systems often share similar features. For instance, GIS include decision support functionalities and thus are a specialized type of DSS (e.g., Ai et al. 2016). KMS for emergency management can include tools that incorporate mapbased features and provide decision support features by incorporating best practices (Dorasamy et al. 2013). Decision support processes and knowledge management processes complement each other in that knowledge storage and distribution enable the development and maintenance of decision models that enhance decision support and vice versa (Bolloju et al. 2002). These wide conceptualizations impose limits on the comparability of the systems. In addition, GIS in particular are widely studied outside the IS field (see example topics in Table 4).

One way to discuss the three EMIS types is from the main perspective they adopt in terms of the processed data and the system's main function. For GIS systems, the data basis is some form of spatial data, such as geolocation data, that enable threat assessment, monitoring, identification, and reduction of vulnerability of land and its inhabitants (e.g., Keenan and Jankowski 2019). Decision support systems, in contrast, process a variety of data such as social media, satellite imagery, spatial, or big data; often, the data are gathered or at least updated during an ongoing emergency event. The main function of a DSS is the real-time processing of data to support decision making in emergency response (e.g., Ai et al. 2016). In KMS-related EMIS research, the data are seen as some form of emergency management knowledge from past emergencies (re-usable, tacit, or explicit) such as best practices and lessons learned that can inform current and future emergency management activities (e.g., Jennex 2007). Best practices and lessons learned in turn enable responder organizations to prepare for new events and aid decision making for emergency management activities.

Hence, all these studies understand EMIS as a tool to organize different kinds of emergency data-such as spatial data, knowledge/experience related data, or real-time data-of a spatially restricted disaster event. All of these data types are crucial for effective emergency management, as they inform different emergency management activities and stakeholders. Nevertheless, it is well known that during disaster settings access to and distribution of high-quality data is often limited (Day et al. 2009). Hence, a crucial and ongoing research endeavor is to understand how to design EMIS so that they can supply and deliver timely, relevant, trusted, and accurate data during an evolving, uncertain, and complex situation to a network of involved stakeholders, the number of which was unspecific prior to the event.

In addition, research shows a huge interest in GIS for disaster management and the development of different methods that support decision making that depends upon spatial knowledge (for a review see, for example, Hoque et al. 2017; Keenan and Jankowski 2019). Almost any emergency has a spatial component and hence emergency responders need maps and spatial information for their decision making, for instance, on how best to reach people on-site and meet demands at an affected area. In fact, many tasks such as the supply of goods and resources, shelter planning, identification of risk areas, and search and rescue activities depend on some geo-location knowledge. The timely availability of spatial data is critical to these tasks, requiring that existing data be updated through real-time data collection and/or crowdsourcing during an evolving event and that data be shared among all organizations involved. 
Moreover, research is interested in the use of artificial intelligence (AI) algorithms for decision support. While research acknowledges that AI will not replace the knowledge of professionals in the near future and that its use presents challenges, it can support the analysis of big data and perform predictive analysis to support decision makers during all phases of disaster management. Applications range from machine listening approaches that automatically identify keywords with high priority to support the classification of emergency calls to the use of supervised models and deep learning to extract data from a variety of sources such as social medial, mobile phones, remote sensing, and aerial images. Despite its potential, however, AI for disaster management is still in its infancy and faces many hurtles related to accessibility, completeness, security, privacy, and ethical issues (for a review, see Sun et al. 2020). In addition, only a small proportion of highly innovative responder organizations currently apply AI in their operations, exposing a gap between where research stands and what is applied in practice.

\section{EMIS archetypes $\quad$ Example studies and topics within the domain}

Geographical Information Systems (GIS): Information systems that store, retrieve, manipulate, analyze, and visualize geoous types of spatial data sets for emergency management (Thomas et al. 2009) graphical content in vari-

- Development of a GIS-based system architecture that combines GIS capabilities with web-based voice translation to coordinate emergency response notifications effectively (Thomas et al. 2009).

- Planning and aiding decision making for emergency logistics such as emergency facility location for fire stations (Aktaş et al. 2013), planning of resource allocation during urban flood emergencies (Chang et al. 2007), and planning for refugee camp locations (Çetinkaya et al. 2016).

- Vulnerability assessment of specific locations through GIS-based mapping to strengthen the resiliency of locations vulnerable (Chuang et al. 2020) to natural hazards (Canevari-Luzardo et al. 2017) such as cyclones (Espada 2019), flooding (e.g., Zachos et al. 2016; Rodríguez et al. 2018), and earthquakes (Vona et al. 2017), as well as toxic hazards (Anjana et al. 2018).

- Evacuation planning for disasters with short lead times ( $\mathrm{Na}$ and Banerjee 2019), hurricanes (Fahad et al. 2019), and planning of evacuations of aging populations (Ozguven et al. 2016).

- Methods to provide earthquake emergency maps for different audiences (Xu et al. 2020) or assess the impact of volcanic ash dispersal on airport infrastructure and support decision making during a response (Scaini et al. 2014).

- Design principles for GIS that support situational awareness (Luokkala and Virrantaus 2014).

Decision support systems (DSS): Information systems that support complex decision making and problem solving in emergency management (Keenan and Jankowski 2019; Turoff et al. 1993)
- EMIS features to support public authorities with disease surveillance, detection, reporting, and response (Liang and Xue 2004).

- Design and implementation of DSS that incorporate big data sources (Fertier et al. 2020).

- Design and development of prototype GIS-centric, social mediabased dynamic DSS to enable self-organized information networks to support decision making and collective actions in emergency situations (Ai et al. 2016).

- DSS that enable prevention and examination of the spread of wild fires using satellite imagery, simulation of fire behavior, fire risk assessment, and GIS (Bonazountas et al. 2007).

- A model of web-aided DSS to assess public facilities as evacuation centers for the victims of weather-related disasters (Hadiguna et al. 2014). 


\begin{tabular}{|l|l|}
\hline & $\begin{array}{l}\text { Method aiding decision makers to assign rescue units to incidents } \\
\text { during the response phase of a disaster (Schryen et al. 2015) and } \\
\text { to assess the effectiveness of smartphone-based emergency re- } \\
\text { sponse networks (Khalemsky and Schwartz 2017). }\end{array}$ \\
\hline $\begin{array}{l}\text { Knowledge management } \\
\text { systems (KMS): Infor- } \\
\text { mation systems that assist } \\
\text { in the management of } \\
\text { knowledge, that is, they } \\
\text { aim to organize, capture, } \\
\text { retain, share, and apply } \\
\text { knowledge effectively (Do- } \\
\text { rasamy et al. 2013) }\end{array}$ & $\begin{array}{l}\text { Development and implementation of a prototype KMS based on } \\
\text { information visibility, information sharing, and dissemination that } \\
\text { guides effective design requirements for KMS to support EM (Do- } \\
\text { rasamy et al. 2017). }\end{array}$ \\
\hline
\end{tabular}

Table 4. Definition and example studies on system archetypes

Another perspective addresses different EMIS components of the system under investigation. These components can be classified broadly as part of the system's deep, surface, and physical structure (Burton-Jones and Grange 2013). Studies often focus on one of the different levels (see Table 5). One type of study examines the deep structure, that is, the underlying data structure of a system to represent the domain. This literature is interested in developing databases for sharing information among involved stakeholders (e.g., Chen et al. 2008b; Li et al. 2014). While responder organizations aim at completing their own tasks during emergency responses, these activities are often interconnected and need to be coordinated between all involved. Research on data standards and database design offers insights into strategies to build databases that connect different responder organizations during emergency management and enable interoperability of information (e.g., Chen et al. 2008b; Li et al. 2014). Research also addresses the difficulties of capturing the chaotic environment an emergency event triggers within the EMIS design. Based on the notion that IS are representations of real-world systems, ontologies can be used to help define and build EMIS and the underlying data structure of a system that contains the necessary representations of real-world entities (Chou et al. 2014).

Moreover, emergency systems need to support rapid decision making, and the clarity of information display in the surface structure - that is, the user interface such as a dashboard to access the deep structure-is crucial for their success. Rich data sources and increased complexity during emergencies increase the challenge of presenting information in the system in a way that reflects the needs of decision makers (add Keenan and Jankowski 2019). The surface structure needs to provide a rich representation of the data but also be easy to comprehend and allow for interaction that is intuitive to support complex decision making in complex disaster situations. A type of study responds to that issue by investigating the graphical user interface (McNab et al. 2011; Shen et al. 2012). These studies provide insights into the effective design of EMIS surface structures, for instance, by providing color cues or personalized design; they also discuss how the user interface supports decision making and the boundary conditions of an effective design.

Regarding the physical structure, EMIS research focuses on the variety of hardware used in responding to a crisis event. For instance, Aros and Gibbons (2018) modeled different combinations of communication tools and their effectiveness in meeting the communication requirements. The literature review uncovered that studies on the infrastructure, interface design, and capacities, as well as database design for EM, are still rare. In addition, while studies of system 
components offer insights into one of the system's structures, they are limited in providing an integrated view of EMIS for response activities. The functionality of the overall infrastructure of EMIS during disaster events depends on how well these components are integrated to address collaborative processes and tasks, making the overall assessment of the effectiveness at the single system level difficult.

\begin{tabular}{|c|c|}
\hline Structural levels & Example studies and topics within the domain \\
\hline $\begin{array}{l}\text { Deep structure: A data- } \\
\text { base-a structured set } \\
\text { of data captured in an } \\
\text { information system } \\
\text { that is accessible in var- } \\
\text { ious ways }\end{array}$ & $\begin{array}{l}\text { - A strategy to form a community-based virtual database, which con- } \\
\text { nects local resource databases of suppliers that provide information } \\
\text { and human resources for emergency management (Li et al. 2014). } \\
\text { An XML-based data model that prescribes a comprehensive set of data } \\
\text { standards (semantics and internal structures) for emergency manage- } \\
\text { ment to better address the challenges of information interoperability } \\
\text { (Chen et al. 2008b). } \\
\text { An ontology to provide a framework for understanding the complete- } \\
\text { ness of disaster websites (Chou et al. 2014). }\end{array}$ \\
\hline $\begin{array}{l}\text { Physical structure: The } \\
\text { physical infrastructure } \\
\text { of information systems, } \\
\text { such as telephone, } \\
\text { email, and centralized } \\
\text { EMIS used in combina- } \\
\text { tion to support EM } \\
\text { communication }\end{array}$ & $\begin{array}{l}\text { - Simulations for planning a mix of emergency management communi- } \\
\text { cation technologies for effective emergency response (Aros and Gib- } \\
\text { bons 2018). } \\
\text { - Linking conceptually traditional crisis infrastructure and external } \\
\text { sources of information with social media technologies (Harnesk } \\
\text { 2013). } \\
\text { Resource-based view on assets necessary in crisis response (Leidner } \\
\text { et al. 2009). } \\
\text { The challenges of adoption, information sharing, communication } \\
\text { flows, and coordination among agencies that do not share a unity of } \\
\text { command (Aedo et al. 2010). }\end{array}$ \\
\hline $\begin{array}{l}\text { Surface structure: The } \\
\text { visual surface that ena- } \\
\text { bles interacting with } \\
\text { the deep structure of a } \\
\text { system using items } \\
\text { such as windows, icons, } \\
\text { and menus }\end{array}$ & $\begin{array}{l}\text { Color cues that improve task performance. The use of these cues be- } \\
\text { comes even more crucial as time pressure and task complexity in- } \\
\text { creases (McNab et al. 2011). } \\
\text { - Design of a display that supports decision making (Shen et al. 2012). } \\
\text { - Evaluation of interfaces that provide information effectively and ena- } \\
\text { ble decision making of firefighters (Prasanna et al. 2013). }\end{array}$ \\
\hline
\end{tabular}

Table 5. Definition and example studies on EMIS deep, surface, and physical structures

In addition, empirical studies of EMIS adoption and use remain rather unspecific with respect to the types of tools investigated, and include a variety of systems under the umbrella term EMIS (e.g., Lee et al. 2011, Prasanna et al. 2013). As such, EMIS are widely defined as systems used by responder organizations to assist in disaster response (Jennex 2007). However, the umbrella term EMIS is limited, as these studies do not account for system-specific features such as certain design features that may influence their use or effectiveness, nor do they explicate the structural level of analysis. The connectivity to these studies is almost impossible: What factors did respondents include and exclude when evaluating the system? What system-specific components lead to effective use? How can results be generalized when EMIS are so different?

Furthermore, a number of conceptual papers have made an impact in this field, offering frameworks and design requirements for developing EMIS. For instance, EMIS research engaged with requirements for improved design (Turoff et al. 2004), bringing human factors into focus (Carver and Turoff 2007). Seppänen and Virrantaus (2015) introduced general data quality 
principles for EMIS to support situational awareness. Sakurai and Kokuryo (2014) suggest developing a frugal disaster IS; in doing so, focusing on four information drivers: universality, ubiquity, uniqueness, and unison. They stress the importance of building a system that adapts to new tasks and needs, which is different than a system operating in a stable context. Developing these frameworks is based on evaluations of existing EMIS and in-use cases involving these systems, leading to rather general frameworks. Suggestions for how practitioners can apply these frameworks are often missing.

Other research in this area has studied the EMIS in-use and stresses the practical perspective in EMIS research. What research seems to agree with is that the majority of users stick to IT with which they are familiar because there is hardly time to understand new EMIS in highly dynamic crisis situations. Turoff et al. (2004), in line with Allen et al. (2014), found that EMIS use can fail when only used in emergencies; that hinders responders organizations from achieving an adequate level of familiarity with a system. Others find impediments to the adoption and use of collaborative EMIS built for responding to disasters (Aedo et al. 2010). It is striking that these studies often focus on the organizational level, neglecting system use by individuals. Emergency management is, however, a highly interdependent endeavor, depending on individual roles and actions. Erroneous actions by individuals who work as part of a greater team can lead to response activities failing. In addition, further insights lie in answering questions about how to fix issues that have been identified through appropriate re-engineering of a concrete system. See Table 6 for an overview.

Another concern is that research often does not consider the characteristics of the specific user group for which the system is built, and does not explain how the system fits into the organizational structure. A variety of established groups in EM-government authorities, fire fighters, police, paramedics, and NGOs, to name only a few-rely on these systems, and these groups have different tasks during an evolving disaster event, different organizational structures of command and control, and thus different system requirements. Many studies, however, only imply who actually uses EMIS, who gets value from their use, and how the systems are used. It remains questionable how these responder organizations integrate EMIS in their monolithic command-and-control structures.

\begin{tabular}{|c|c|}
\hline $\begin{array}{l}\text { Topics on } \\
\text { EMIS }\end{array}$ & Example studies and topics within the domain \\
\hline $\begin{array}{l}\text { Adoption and } \\
\text { use }\end{array}$ & $\begin{array}{l}\text { - Tests user satisfaction, perceived benefit of use influence EMIS use intention } \\
\text { (Lee et al. 2011). } \\
\text { - System quality, information quality, and service quality as factors influencing } \\
\text { user satisfaction and use intention, which are factors in EMIS success (Petter } \\
\text { and Fruhling 2011). } \\
\text { - Factors (e.g., trust, emergency type, social influence) that affect compliance in- } \\
\text { tention with Campus warnings (Han et al. 2015). } \\
\text { - Factors (e.g., interagency communication, dispatch system capacity, knowledge } \\
\text { repository) that affect asset allocation capability, which in turn affects emer- } \\
\text { gency response performance (Chen et al. 2010). }\end{array}$ \\
\hline $\begin{array}{l}\text { Design re- } \\
\text { quirements } \\
\text { and frame- } \\
\text { works }\end{array}$ & $\begin{array}{l}\text { - Study on training and drills, use of contingency plans and analysis tools for de- } \\
\text { cision making, data standardization to support integration with various EMIS, } \\
\text { use of redundant communication methods, the creation of common terminol- } \\
\text { ogy and templates (Jennex 2004). }\end{array}$ \\
\hline
\end{tabular}




\begin{tabular}{|c|c|}
\hline & $\begin{array}{l}\text { - Eight fundamental EMIS design requirements, including a hierarchical data } \\
\text { structure, data quality standards such as timeliness and status of the data, ver- } \\
\text { tical and open communication among all involved, enable easy content search, } \\
\text { tracking and updating of data in line with dynamic situation, linking related } \\
\text { data, the account of top-down decision making, and supporting mental and so- } \\
\text { cial needs of the response team (Turoff et al. 2004). } \\
\text { - Identification of main EMIS functions for large-scale events: connectivity } \\
\text { among those involved, foster situation awareness, and security of IT infra- } \\
\text { structure (Ng and Kankanhalli 2012). } \\
\text { - Conceptual components of humanitarian information systems, including vul- } \\
\text { nerability and poverty assessment, early warning, emergency needs assess- } \\
\text { ment, impact evaluation, risk monitoring, and lessons learned (Maxwell and } \\
\text { Watkins 2003). } \\
\text { Key requirements of a frugal IS for disaster situations, that is, an IS developed } \\
\text { and used with minimal resources to meet a user's goal, and support EM during } \\
\text { major disasters. The EMIS requirements are proposed for all stages of a disas- } \\
\text { ter (before, during, and after), including process and technology related prin- } \\
\text { ciples (Sakurai and Kokuryo 2014). } \\
\text { A framework for defining the critical information and relevant information } \\
\text { quality elements required to build shared situational awareness in disaster re- } \\
\text { sponse (Seppänen and Virrantaus 2015). }\end{array}$ \\
\hline $\begin{array}{l}\text { Practical use } \\
\text { of EMIS }\end{array}$ & $\begin{array}{l}\text { - Identifying technological and organizational issues that constrain responder or- } \\
\text { ganizations' interoperability and information sharing (Allen et al. 2014). } \\
\text { Challenges of EMIS adoption, information sharing, communication flows, and } \\
\text { coordination among agencies that do not share a unity of command (Aedo et al. } \\
\text { 2010). } \\
\text { - Design and in-use evaluation of an integrated information platform for large- } \\
\text { scale events (Yang et al. 2012). } \\
\text { Design and evaluation of the effectiveness of a wireless Internet EMIS for med- } \\
\text { ical response in disasters (Lenert et al. 2011). } \\
\text { - Studies the information chain as an industrial process modeled by the IDEF0 } \\
\text { language. Identifies each function of the process, the inputs, outputs, and nec- } \\
\text { essary controls and resources (Bevilacqua et al. 2012). } \\
\text { Use of radio broadcasting to disseminate disaster-related information (Romo- } \\
\text { Murphy et al. 2011). }\end{array}$ \\
\hline
\end{tabular}

Table 6. Topics in EMIS use

Finally, in response to section 2.1, research on how EMIS can support transboundary disasters is rare but is needed in order for responder organizations to respond to these new threats. Disaster response still largely involves traditional practices, procedures, and concepts that may not be optimal for the modern, interconnected world. Information and knowledge about disasters are scattered among various agencies, jurisdictions, sectors, and media platforms. EMIS research has not kept pace with the changing environment. To respond to disasters that are transboundary in nature, research needs to focus on how to build such systems and how they can be used effectively to respond to disasters.

\section{Research on Dedicated EMIS for Emergency Communication between Organiza- tions and the Affected Public}

Ongoing technological developments have led to continual changes in EMIS use in disaster management. Since around 2007, disaster response has also continued to change with the widespread use of social media and then other digital platforms, the ubiquity of the internet, and the proliferation of smartphones among the population. These developments offer new 
ways to harness digital data streams to inform EM initiatives. Hence, EMIS research has begun more recently to consider a wide array of technologies, including IT-enabled mobile systems, public digital platforms, and social media, which are introduced below.

Traditionally, different channels have been used to transmit emergency-related information to the public, including face-to-face contact, radio, television, newspapers, and sirens (Botterell and Addams-Moring 2007; Mayhorn et al. 2006). While mass media such as television and radio have the potential to be precise in terms of content and, at least in theory, can reach the intended population quickly, these media need to be used actively so people actually receive the information. Sirens can only warn people about the existence of a threat, but cannot communicate any details about an acute emergency - and they are useless if not heard.

Hence, responder organizations worldwide have increasingly begun to leverage public and private IT infrastructure such as the internet and smartphones to communicate with the public as part of emergency management. Emergency apps, for example, enable simple one-way communication between responder organizations and the public for distributing warnings and emergency-related information from authorities (Tan et al. 2017). So-called warning apps are prominent among these; they run on mobile devices such as smartphones and tablets and serve as platforms for distributing crisis-related information. Warnings and recommendations for action are the core features of these mobile applications (Meissen et al. 2014). Running in the background, warning apps provide information via push notifications, which are typically short descriptions of a crisis at hand or on the horizon (e.g., flood, terrorist attack, the spread of hazardous substances, etc.) complemented with recommendations for action, such as to shelter in place.

In 2020, Covid-19 tracing apps-smartphone applications that enable the tracing of contacts among users-became another example of mobile-enabled warning systems. Contact tracing apps enable tracing epidemic infection chains and stopping the spread of an epidemic by warning users who have been in contact with infected users but may not yet be symptomatic. Tracing apps trace physical contacts between users, often using Bluetooth-a radio technology that enables digital devices to communicate over short distances. The app alerts a user about a possible infection if the user has been close (e.g., one or two meters) to another user diagnosed with Covid-19 for an epidemiologically relevant time interval (e.g., 15 or more minutes). For alerting a user, the infected user needs to update her status in the app within a relevant timeframe from that encounter (e.g., an estimated incubation period of 14 days). Those users can then be advised to self-isolate and get tested, thus potentially interrupting infection chains (Trang et al. 2020).

In addition, the rapid penetration of sensors and wearables (i.e. the Internet of Things) leads to a wide variety of data sources that can be used for EM. Mobile devices such as smartphones and tablets, for instance, have multiple sensors such as cameras, GPS, and microphones that when used in an emergency can become sensing devices (Kamel Boulos et al. 2011). From an emergency management perspective, these human sensors create opportunities because they can gather emergency-related information from a scene to support situational awareness for emergency responders (Tan et al. 2017). Hence, there have been efforts to create emergency apps for two-way emergency information exchange between the public and emergency management organizations that leverage human sensing. 
Volunteer developers around the world, driven by a desire to help, have created a variety of platforms - especially in and for poorer countries - to aid in disaster response and self-organization. These systems are based on Free and Open Source Software (FOSS) principles, meaning they are open and transparent, that is, the source code is available for anyone to adapt freely. After the initial cost of setting up such systems, they are generally maintainable at a low cost. In addition, the systems are web-based and thus do not require the installation of additional software. These factors enable the reuse and adaptation of the systems to different disaster contexts, making them more responsive to specific situations and usable under conditions in which resources are scarce (Currion et al. 2007).

Typically, these kinds of open-source crowdsourcing platforms leverage the digital infrastructure for producing and accessing disaster-related and spatial information, connecting those in areas with those that can help. For instance, disaster mapping combined with crowdsourcing enables locals to report conditions at a disaster area and receive help from others. Hence, by supporting interaction between networks of people, the platforms facilitate the formation of social capital (Alexander 2014). Ushahidi, designed to report on 2008 post-election violence in Kenya using spatial data, is a notable example of such a platform (Ushahidi 2021). It allows data collection from emails, forms, tweets, and other unstructured methods and analysis of these data in forms such as tag clouds, trends, and other filters (Gao et al. 2011). Some of these open source platforms are continuously developed and even provide IT solutions for the entire disaster management cycle, supporting different tasks such as logistics, collaboration, warning of the population, risk assessment, and mapping (Sahana 2021). Table 7 is an overview of emergency applications and open source software for emergency management.

\begin{tabular}{|l|l|}
\hline System description & Example studies and topics within the domain \\
\hline $\begin{array}{l}\text { Emergency applica- } \\
\text { tions: information sys- } \\
\text { tems that enable one- } \\
\text { or two-way emergency } \\
\text { communication be- } \\
\text { tween responder or- } \\
\text { ganizations and the } \\
\text { public. }\end{array}$ & $\begin{array}{l}\text { Design requirements of effective use of apps built for emergency warn- } \\
\text { ing (e.g., Fischer-Preßler et al. 2020; Kaufhold et al. 2020). }\end{array}$ \\
& $\begin{array}{l}\text { Compliance with and use intention of SMS warnings during campus } \\
\text { emergencies (e.g., Bonaretti and Fischer-Preßler 2021; Han et al. } \\
\text { 2015), and use of warning apps (Fischer 2018; Fischer-Preßler et al. } \\
\text { 2021). }\end{array}$ \\
& $\begin{array}{l}\text { Comparison of mobile-enabled warn systems vis-á-vis traditional } \\
\text { warning systems such as sirens, radio, and TV (e.g., Jagtman 2010; } \\
\text { Klafft 2013). }\end{array}$ \\
\hline $\begin{array}{l}\text { Free and Open Source } \\
\text { Software EMIS: Infor- } \\
\text { mation systems that } \\
\text { can be adapted to dif- } \\
\text { ferent disaster situa- } \\
\text { tions as the source code } \\
\text { is public and adaptable. }\end{array}$ & $\begin{array}{l}\text { porting on emergencies from the scene (e.g., Romano et al. 2016; Tan } \\
\text { et al. 2017). }\end{array}$ \\
\hline
\end{tabular}

Table 7. System description and example studies

\section{Social Media in Emergency Communication}

Along with the increasing popularity and use of various kinds of social media platforms such as Twitter and Instagram among the population, these platforms receive plenty of attention in 
emergency management research. In particular, some social media users tend to leverage the platforms for disaster response activities due to their capability to provide real-time information and that they can be used on any device with internet access, creating the potential to share information with a huge audience. Seminal studies that acknowledge the role of the public in social media disaster communication were first published in 2007 (Palen and Liu 2007, Liu et al. 2008). Since then, a growing body of research attests to the widespread adoption of social media and the role they are playing in facilitating information sharing during disasters (e.g., Alexander 2014; Eismann et al. 2016; Reuter et al. 2018).

Summarizing the breadth of disaster-related social media literature, users repeatedly leverage these platforms to search for and disseminate event-related information, share eyewitness accounts, offer support and remedies for those affected, seek actionable information, request and offer assistance, and seek and offer emotional support to others. For communities, the use of social media creates enhanced abilities to participate in disaster response activities, mobilize resources, and coordinate with other disaster management (e.g., Ling et al. 2015; Neubaum et al. 2014, Tim et al. 2017). Studies also explain the role of social media to monitor responder organizations, making them more accountable. For responder organizations, social media enable direct, up-to-date crisis communication with an unspecified audience and, thus, extend their reach to users who may have been inaccessible absent social media (Alexander 2014).

To be part of the social media conversation, some emergency responders began to integrate social media into their formal work practices. From a responder organization's perspective, social media platforms-despite having been developed primarily for leisure-can be considered a form of socio-technical EMIS that support situational awareness, decision making, and emergency communication (Hughes and Tapia 2015). These platforms shift the perspective from proprietary technologies used only by responder organizations, such as KMS or DSS (see above), to public platforms that support situational awareness through data gathered and disseminated collectively. Social media also shift emergency communication from responder organization-centric to something that increasingly needs to engage with and integrate the public. Some researchers even describe social media as a "boon" for EM, as they overcome the "common pitfall of being misquoted by the official media" by enabling direct communication to the social media community (Alexander 2014, p. 722). Although the capacity of social media to support situational awareness and facilitate information-sharing practices has generally been described with a great deal of optimism, these platforms are also well known for creating new challenges and tasks.

For responder organizations, the effective integration of public social media is repeatedly pointed out to be a challenge (e.g., Bergstrand and Stenmark 2016; Kavanaugh et al. 2012; Latonero and Shklovski 2011). Some responder organizations struggle to govern social media use efficiently within their organizational structure simply because they lack resources such as employees who are interested in using social media (Latonero and Shklovski 2011). Specifically, some responder organizations rely on a single interested and motivated employee or volunteer who becomes the social media expert within the organizations, often the organization is missing general guidelines and best practices (Latonero and Shklovski 2011). Similarly, social media roles-meaning dedicated social media experts-are in some responder organizations just not institutionalized. This may stem from doubt on the relevancy of social media for EM (Palen 
and Anderson 2016). In addition, a top-down hierarchical organizational structure and standard procedures stand in contrast to a channel that supports vertical many-to-many communication. Social media are, however, "inherently about participation" (Palen and Anderson 2016, p. 225). This also affects the incorporation of digital volunteers because, despite an increasing demand for resources during disasters, responder organizations struggle to integrate digital volunteers in their hierarchical command and control structures and work processes effectively.

Despite the potential of social media to support situational awareness by leveraging emergency-related data streams, the data may suffer in terms of reliability, relevancy, and timeliness (Bergstrand and Stenmark 2016). Researchers have repeatedly pointed, for instance, to the difficulties associated with identifying meaning clearly in short Twitter messages as well as the potential for information overload (e.g., Kaufhold et al. 2020; Kavanaugh et al. 2012). In fact, these issues create new tasks for responder organizations, which must detect misinformation and rumors on social media platforms during ongoing events and help stop their spread by publishing up-to-date and reliable information (Andrews et al. 2016). Depending on the specifics of an emergency, such information can be difficult to provide. During highly dynamic and uncertain situations such as a terrorist attack, verification of information can take time. In addition, in such situations, releasing information may even cause greater uncertainty among the population and hence, for tactical reasons, may not be advisable. Despite the challenges, responder organizations' openness to information sharing with the public and media is crucial, because-in most cases-a better-informed public will be able to respond more effectively.

\begin{tabular}{|c|c|}
\hline System description & Example studies and topics within the domain \\
\hline $\begin{array}{l}\text { Social media are web- } \\
\text { based platforms that } \\
\text { allow users to create } \\
\text { unique user profiles } \\
\text { and digital content, } \\
\text { protect access to that } \\
\text { content, and establish, } \\
\text { view, and traverse re- } \\
\text { lational connections } \\
\text { to other platform us- } \\
\text { ers (Kane et al. 2014). }\end{array}$ & $\begin{array}{l}\text { - Investigation of social media affordances for crisis management activi- } \\
\text { ties (e.g., Maresh-Fuehrer and Smith 2016). } \\
\text { Adoption of and challenges perceived by responder organizations when } \\
\text { using social media within their organizations for public communication } \\
\text { (e.g., Bergstrand and Stenmark 2016; Panagiotopoulos et al. 2016; Stieg- } \\
\text { litz et al. 2018a). } \\
\text { Counteracting rumors in social media during crises (e.g., Andrews et al. } \\
\text { 2016; Arif et al. 2017; Oh et al. 2013). } \\
\text { Technological aspects and methods that enable leveraging of social me- } \\
\text { dia data for emergency management (e.g., Kaufhold et al. 2020; Stieglitz } \\
\text { et al. 2018c). } \\
\text { Collective behavior in social media, such as self-organization, spreading } \\
\text { of misinformation, sense-making, and coping with disaster events (e.g., } \\
\text { Fischer-Preßler et al. 2019; Ling et al. 2015; Mirbabaie et al. 2020). } \\
\text { Tensions and synergies of platforms, community, and command-and- } \\
\text { control logics that shape the information landscape in emergency man- } \\
\text { agement (Karanasios et al. 2019). }\end{array}$ \\
\hline
\end{tabular}

Table 8. Example studies of social media use for emergency management

Studies of how to govern and use social media within responder organizations, however, are rare. Many social media studies adopt a case study design, investigating social media communication and collective phenomena (e.g., Oh et al. 2013; Oh et al. 2015), design and features of social media (e.g., Maresh-Fuehrer and Smith 2016), data gathering applications, and their use during an exercise scenario (e.g., Kaufhold et al. 2020) or challenges during a certain crisis event (e.g., Stieglitz et al. 2018c). These studies remain rather descriptive; for example, they explain the spread of certain topics during an ongoing crisis event (e.g., Stieglitz et al. 2018b), 
the potentials of certain social media features (e.g., Stieglitz et al. 2018c), and aggregated analysis of social media data (e.g., Oh et al. 2013). In addition, many studies use Twitter data due to its easily accessible API. Those studies aggregate disaster-related social media data and analyze it without a good understanding of (or only a bounded understanding of) the data sources, which stands in contrast to an informed emergency management decision making process. For EM professionals, these studies, therefore, have limited managerial implications: they provide no meaningful solutions for practice in terms of responding to and handling behavioral phenomena such as self-organization in professional disaster response activities. Hence, research calls for the development of enduring social media solutions that focus on design-in-use, which is meaningful for emergency management practice (Palen and Anderson 2016). Table 8 is an overview of topics.

\section{Summary of Research on Emergency Management Information Systems}

In summary, this section shows that EMIS can be considered as a broad set of different tools and applications that can be categorized into three different archetypes based on the users involved and the main communication flow: EMIS for inter- and intra-organizational emergency communication; dedicated EMIS for emergency-related communication between organizations and the public; and public social media that enable emergency-related communication within an unspecified user group.

The papers in this thesis contribute to all three of these different archetypes: In terms of EMIS used for inter- and intra-organizational emergency communication, paper I contributes a literature review on communication barriers that need to be considered when using EMIS in disaster management; paper II is a literature review on EMIS types that exist to support organizational supply chains for mitigating emergencies, in preparation for and in response to emergencies; and paper III describes a method to investigate digital trace data of EMIS that are used for organizational communication during emergencies. In terms of EMIS that are used and designed for emergency communication with the public, papers IV and V investigate factors that affect public use of such EMIS; paper VI identifies design deficiencies that can hamper effective use of such EMIS by the public; paper VII provides design dimensions for effective use; paper VIII contributes by uncovering deficiencies that lead to failures, from the organizational perspective, of such EMIS; and paper IX provides insights into guidelines for warning apps that will conform with information privacy. Finally, in terms of the role of social media in disaster management, papers X and XI study the use and governance of social media by responder organizations for raising social capital, and papers XII, XIII, and XIV analyze disaster-related social media use by the public.

\subsection{Theories in EMIS Research}

This section synthesizes the theoretical landscape of EMIS research. The scope of this summary is based on theories prevalent in EMIS and IS research; it is not a comprehensive review of all theories applied in EMIS research. ${ }^{1}$

\footnotetext{
${ }^{1}$ These theories were selected because of their prevalence in and relevance to IS-related EMIS research. This review focused on IS journals and completed research papers from the two major IS conferences, ECIS and ICIS, and did not include domain conferences such as the Conference on Information Systems for Crisis Response And Management (ISCRAM).
} 
EMIS research considers a variety of theoretical lenses, frameworks, and concepts borrowed from other disciplines, such as cognitive science (e.g., situational awareness), sociology (e.g., collective behavior), and communication science (e.g., media richness). Each of these theoretical or conceptual lenses could comprise its own review. The focus here is limited specifically to EMIS studies that apply the theories.

The theoretical lenses, framework, and concepts can be classified using the three prevalent types in EMIS research from among five in Gregor (2006): theories for analyzing (type I), theories for explaining (type II), and theories for explaining and prediction (type IV) (Gregor 2006). Type I theories are analytic and describe and categorize certain dimensions or characteristics of individuals, groups, situations, and events. These theories are not merely descriptive; they also summarize "salient phenomena and relationships among phenomena," which are, however, "not explicitly causal" (Gregor 2006, p. 623). In EMIS research, theories for analyzing are typically found in literature reviews that apply a conceptual framework to synthesize prior research.

Type II theories for explanation elaborate on the how and why of certain phenomena. These theories aim to foster understanding by explaining the world from their points of view, thus enabling altered or new insights (Gregor 2006). Such theories can be found in EMIS research on social media as well as on research about dedicated EMIS.

Finally, EMIS research is interested in type IV theories of explanation and prediction, that is, theories that "correspond to commonly held views of theory in both the natural and social sciences" (Gregor 2006, p. 626). These theories provide causal explanations, testable propositions, and predictions and, hence, mainly comprise probabilistic theories. Such theories are found mainly in EMIS research that evaluates psychometric research models for predicting use intention.

Note that some of the theories may correspond to several types. For instance, the theory of effective use had not been tested empirically when introduced by its authors (Burton-Jones and Grange 2013) but was subsequently extended and tested empirically with psychometric models (Trieu et al. forthcoming). In the subsequent review of this paper, the theories were classified in terms of how they are predominantly applied in EMIS research. Furthermore, some of the theoretical lenses in EMIS research may be seen as concepts, phenomena, or frameworks, rather than as theories. ${ }^{2}$ However, as introduced above, this review follows Gregor's (2006) broad categorization and also classifies concepts and frameworks into one of the respective theory types.

The subsequent sections provide examples of studies applying these theory types on different EMIS.

\section{Type I: Conceptual Frameworks in EMIS Research}

In the EMIS context, theories for analyzing are presented primarily in literature reviews that apply analytical frameworks. Disaster-related social media use is of particular interest in this line of research and constitutes a large amount of social media studies in this area. For instance,

\footnotetext{
${ }^{2}$ The interested reader is referred to Zur Shapira (2011); Burton-Jones et al. (2015); Weber (2003).
} 
Eismann et al. (2016) discuss the results of a scoping literature review of disaster-related online collective behavior according to a process model that includes several concepts: the event, its impact, the social unit, the response, and collective behavior. Categorizing the literature on challenges in topic discovery, data collection, and data preparation, Stieglitz et al. (2018c) use a four-stage process: discovery, tracking, preparation, and analysis. Reuter et al. (2018), in contrast, elaborate their review results in four relational communication types in social media: authorities-to-citizens, citizens-to-citizens, authorities-to-authorities, and citizens-to-authorities.

Beyond social media, research is also interested in summarizing the EMIS landscape into frameworks. Tan et al. (2017) for instance use a framework based on one-to-one, one-to-many, and many-to-many communication to classify what they call built-for-disaster-purpose apps. Similarly, Fischer et al. (2016) identify communication flows within and between organizations and the public to classify research on technological, social, and organizational barriers in crisis management.

\section{Type II: Theories for Explaining}

Theories for explaining are widely used in EMIS research to study all kinds of different EMIS types. The following section begins by summarizing the theories and phenomena for explaining that are applied in studies of social media, which draw significant interest in the research community. The section that follows introduces theories used for explaining in research on dedicated EMIS.

\section{Type II Theories in EMIS Research on Social Media}

The convergence of digital and social networks in various types of social media platforms enables the collection of data and subsequent investigation of behavior that were previously not as easy to observe. A large strand of disaster-related social media studies, thus, has focused on studying different forms of digital-enabled collective behavior. According to Coleman (1990), collective behavior involves a number of people that perform similar, inter-dependent actions at the same time. These actions are unstable and transient in nature. This broad definition of collective behavior comprises a class of different phenomena studied in social media, such as collective sense-making (e.g., Fischer-Preßler et al. 2019; Stieglitz et al. 2018b), self-organization (e.g., Ling et al. 2015; Tim et al. 2017), and crowdsourcing (e.g., Alexander 2014; Gao et al. 2011). ${ }^{3}$

While social media make public emergency management activities visible, the finding of a selforganizing crowd is not a new phenomenon. Disaster-affected communities have always been the first responders in emergencies, materializing in different emergent and organized groups of volunteers (Quarantelli 1983). Often, these emergent organizations continue efforts after professionals arrive at the disaster scene. Social media provide these volunteers with the mediating platform, once lacking, with which to coordinate response activities and accelerate community empowerment (Ling et al. 2015). They also allow people remote to the event to

\footnotetext{
${ }^{3}$ This section on forms of collective behavior on social media does not aim to be a complete literature review of all social media studies related to collective behavior during disasters. That literature corpus has grown enormously. Rather, it is an overview of key concepts in recent research.
} 
join the activities (Starbird 2011). As a mediating digital platform among people, social media can, thus, foster the emergence of new groups during disaster events.

Research points to the potential of disaster-related crowdsourcing in social media, that is, the practice of obtaining information of and allowing a large number of people to participate in disaster-related tasks such as validating information, providing information from on site, and managing that information (Gao et al. 2011). For example, Ushahidi is a prominent crowdsourcing platform that supports gathering resources for response and recovery activities. Leveraging social media crowdsourcing underlies the notion of collective wisdom, as the aggregated activities of information sharing exhibit intelligent behavior that exceeds individual abilities (Gao et al. 2011). Social media users comprising such a crowd are often referred to as digital volunteers, that is, mainly non-professional individuals who engage in disaster response, performing their activities primarily online (Starbird 2011). Their manifestation depends upon the disaster event, disaster phase, affected region, and society (Simon et al. 2015).

Social media has furthermore been found to facilitate sense-making processes in disaster settings. During low-probability, high-impact, uncertain, and ambiguous situations, people are very likely to seek clarification regarding what is happening and fill the cognitive gaps these situations cause (Weick 1988). Sense-making is "a process, prompted by violated expectations, that involves attending to and bracketing cues in the environment, creating intersubjective meaning through cycles of interpretation and action, and thereby enacting a more ordered environment from which further cues can be drawn" (Maitlis and Christianson 2014, p. 67). Using dedicated social media platform features such as keyword searches and automated information streams, users can follow topics of interest and access information shared by otherwise unrelated others. This is a crucial mechanism to enable and sustain collective sense-making practices during disasters among a larger number of users (Oh et al. 2015).

The high uncertainty, emotional discomfort, and information gaps people experience during disasters have also been found to be propitious grounds for the spreading of rumors in social media. Hence, a line of research is interested in understanding both the diffusion and control of rumors during disasters (e.g., Oh et al. 2013; Ross et al. 2018). Rumoring can also be seen as a collective sense-making process in which people communicate and attempt to make sense of imperfect and incomplete information. Oh et al. explored online rumoring as a process of collective sense-making, aiming to identify the causes of rumor propagation. The main factors were unclear information sources, personal involvement, and anxiety. In addition, although rumors or inaccurate information can spread during an emergency, social media users have been found to strive for corrections, making social media to some degree self-regulating-a commonly held perception building upon theories of collective intelligence that the online crowd identifies, challenges, and corrects misinformation (Arif et al. 2017). Nevertheless, according to the echo effect, this process can take time. That effect is based on evidence that outdated information often is shared even after updated information has already been posted by the original source (Jong and Dückers 2016).

The tendency on social media to coalesce public opinions during disasters reveals aspects of a collective emotional or mental state towards a disaster event (Alexander 2014). During humanmade crisis events in particular, social media are frequently used to make sense and cope (e.g., 
Heverin and Zach 2012; Neubaum et al. 2014). For instance, Neubaum et al. (2014) investigated social media use related to the Love Parade stampede in Duisburg, Germany in 2010. Taking the perspective of uses and gratification, they argue people use social media to fulfill their current needs, which depend upon the environmental conditions. In the case of the Love Parade stampede, social media users who had been present or who lost friends or family shared emotions, feelings, and thoughts about the event.

Table 9 is an overview of these social media phenomena.

\begin{tabular}{|l|l|l|}
\hline Phenomena & Definition & \multicolumn{2}{l|}{ Example references } \\
\hline Crowdsourcing & $\begin{array}{l}\text { Focuses on the practice of allowing a large } \\
\text { number of digital volunteers to participate in } \\
\text { disaster-related tasks enabled by a digital plat- } \\
\text { form. }\end{array}$ & $\begin{array}{l}\text { Gao et al. 2011; Simon et al. } \\
\text { 2015; Starbird 2011 }\end{array}$ \\
\hline $\begin{array}{l}\text { Collective sense- } \\
\text { making }\end{array}$ & $\begin{array}{l}\text { Focuses on how social media users collectively } \\
\text { construct meaning of a disaster situation. }\end{array}$ & $\begin{array}{l}\text { Fischer-Preßler et al. 2019; } \\
\text { Heverin and Zach 2012; Oh } \\
\text { et al. 2015 }\end{array}$ \\
\hline $\begin{array}{l}\text { Rumour propaga- } \\
\text { tion }\end{array}$ & $\begin{array}{l}\text { Focuses on the diffusion of unverified infor- } \\
\text { mation in social media during disasters. }\end{array}$ & $\begin{array}{l}\text { Andrews et al. 2016; Arif et } \\
\text { al. 2017; Oh et al. 2013 }\end{array}$ \\
\hline $\begin{array}{l}\text { Self-organization } \\
\text { tablished in disaster situations to assist in dis- } \\
\text { aster-related tasks, empowered by social media } \\
\text { platforms. }\end{array}$ & $\begin{array}{l}\text { Fischer 2018; Kaewkitipong } \\
\text { et al. 2016; Ling et al. 2015; } \\
\text { Tim et al. 2017 }\end{array}$ \\
\hline $\begin{array}{l}\text { Digital volunta- } \\
\text { rism }\end{array}$ & $\begin{array}{l}\text { Focuses on mainly non-professional individuals } \\
\text { who respond to disasters and perform their ac- } \\
\text { tivities primarily online. }\end{array}$ & $\begin{array}{l}\text { Hughes and Tapia 2015; } \\
\text { Starbird and Palen 2011 }\end{array}$ \\
\hline $\begin{array}{l}\text { Digital coping and } \\
\text { commemoration }\end{array}$ & $\begin{array}{l}\text { Focuses on how social media users collectively } \\
\text { share emotions, feelings, and thoughts about a } \\
\text { disaster event for emotional relief. }\end{array}$ & $\begin{array}{l}\text { Eriksson 2016; Fischer- } \\
\text { Preßler et al. 2019; Neu- } \\
\text { baum et al. 2014; Walter } \\
\text { 2015 }\end{array}$ \\
\hline
\end{tabular}

Table 9. Phenomena associated with collective behavior on social media

The enabling mechanism for disaster related social media communication can be referred to as affordances these platforms provide (Karahanna et al. 2018). Specifically, social media affordances are action potentials of social media features. Social media platforms differ in their options for providing content, attracting user groups, and topics, and so affordances show different action potentials depending on the respective platforms. Still, four overarching social media features stand out: user profile, visible digital relations, easy content contribution, and content access mechanisms. These features enable users to retrieve information and updates on an ongoing emergency event in real-time, regardless of the user's location, and thus attain situational awareness (Kane et al. 2014).

The social media affordances in Table 10 are action potentials. When leveraged, they can support professional emergency management. Responder organizations, however, struggle to leverage these social media potentials. The section on social media elaborated that it would be naïve to conclude that all responder organizations currently incorporate them effectively in their practices. Nevertheless, when governed effectively throughout the organization, social media can provide responder organizations with a means to acquire resources, legitimacy, and other potentials in table 10. Hence, responder organizations can benefit from occupying a particular structural position and from being able to access different network resources through 
their relational ties. This conceptualization points to the relevance of social capital in this context (Kim and Hastak 2018).

Nahapiet and Ghoshal (1998, p. 243) define social capital as the "sum of actual and potential resources embedded within, available through, and derived from the network of relationships possessed by individuals." They highlight three social capital dimensions: structural, relational, and cognitive. EMIS research has found that social capital is crucial for disaster management since a central position in the network structure can influence information diffusion during disasters, leveraging relationships can enable access to resources such as food and water, and content exchange can support emotional comfort (e.g., Ling et al. 2015).

\begin{tabular}{|c|c|c|}
\hline Platform features & $\begin{array}{l}\text { Example affordance for emergency manage- } \\
\text { ment }\end{array}$ & Example reference \\
\hline $\begin{array}{l}\text { Digital profile: The digital } \\
\text { representation of a user } \\
\text { (e.g., an organization or in- } \\
\text { dividual) on a given social } \\
\text { media platform, which is } \\
\text { created and maintained by } \\
\text { the user, but also popu- } \\
\text { lated by the content of } \\
\text { other network members }\end{array}$ & $\begin{array}{l}\text { Accessing contact points to and retriev- } \\
\text { ing information about emergency re- } \\
\text { sponders and involved people. } \\
\text { Attaining situational awareness through } \\
\text { updates on emergency events, real-time } \\
\text { status updates of tasks, response activi- } \\
\text { ties, and resources. } \\
\text { Enabling many-to-many emergency com- } \\
\text { munication to a large number of users. }\end{array}$ & $\begin{array}{l}\text { Abedin and Babar } \\
\text { 2018; Hong et al. } \\
2018\end{array}$ \\
\hline $\begin{array}{l}\text { Digital user relations: Con- } \\
\text { nections between users of } \\
\text { a social media platform } \\
\text { that can be viewed, trav- } \\
\text { ersed, and edited and that } \\
\text { enable interaction be- } \\
\text { tween users }\end{array}$ & $\begin{array}{l}\text { - Sharing of emergency-related content } \\
\text { across and within digital networks. } \\
\text { Connecting and collaborating in digital } \\
\text { spaces, such as groups that allow the for- } \\
\text { mation of communities of practice inter- } \\
\text { ested in disaster response. } \\
\text { Enabling two-way and many-to-many } \\
\text { communication between users during } \\
\text { emergency management. }\end{array}$ & $\begin{array}{l}\text { Ahmed and Sinnap- } \\
\text { pan 2013; Brengarth } \\
\text { and Mujkic 2016; Lu } \\
\text { and Yang 2011; } \\
\text { Neubaum et al. } 2014\end{array}$ \\
\hline $\begin{array}{l}\text { Network transparency: } \\
\text { Visibility of network con- } \\
\text { nections by the network } \\
\text { owner as well as other so- } \\
\text { cial media users }\end{array}$ & $\begin{array}{l}\text { Drawing the attention of a potentially } \\
\text { large audience to the disaster event, in- } \\
\text { dependent of location and time and thus } \\
\text { enabling broad calls for resources. } \\
\text { Enabling finding of new and relevant } \\
\text { profiles through navigation across and } \\
\text { within networks. }\end{array}$ & $\begin{array}{l}\text { Brengarth and Mujkic } \\
\text { 2016; Ling et al. 2015; } \\
\text { Tim et al. } 2017\end{array}$ \\
\hline $\begin{array}{l}\text { Content provision: The } \\
\text { way of contributing con- } \\
\text { tent and the form of digital } \\
\text { content a social media } \\
\text { platform supports }\end{array}$ & $\begin{array}{l}\text { Uploading from a device with internet } \\
\text { access of user-generated content such as } \\
\text { bystander reports independent of geo- } \\
\text { graphic and temporal constraints. } \\
\text { Reuse of disaster-related content by so- } \\
\text { cial media users other than the origina- } \\
\text { tor, through share mechanisms. } \\
\text { Support to uploading and reuse of a vari- } \\
\text { ety of data formats such as photos, vid- } \\
\text { eos, and text, allowing rich representa- } \\
\text { tion of the event. }\end{array}$ & $\begin{array}{l}\text { Abedin and Babar } \\
\text { 2018; Bergstrand and } \\
\text { Stenmark 2016; Lin et } \\
\text { al. } 2016\end{array}$ \\
\hline $\begin{array}{l}\text { Content access and search } \\
\text { mechanism: Platform fea- } \\
\text { tures that enable explora- } \\
\text { tion of digital content }\end{array}$ & $\begin{array}{l}\text { Providing search mechanisms such as } \\
\text { hashtags that enable easy access to and } \\
\text { locating of emergency-related content. }\end{array}$ & $\begin{array}{l}\text { Kaufhold et al. 2020; } \\
\text { Oh et al. 2013; Stieg- } \\
\text { litz et al. 2018c }\end{array}$ \\
\hline
\end{tabular}




\begin{tabular}{|l|l|l|}
\hline & $\begin{array}{l}\text { Enabling automated user notifications on } \\
\text { relevant emergency-related content up- } \\
\text { dates. }\end{array}$ \\
$\qquad \begin{array}{l}\text { Gathering of emergency-related digital } \\
\text { trace data for analysis to learn about an } \\
\text { emergency event in real-time as well as } \\
\text { afterward (for preparation). }\end{array}$ & \\
\hline
\end{tabular}

Table 10. Social media affordances in emergency management

A further theoretical lens in EMIS-related social media studies is from a social network analysis perspective. EMIS research is particularly interested in diffusion processes of information during disaster events applying different network measures (e.g., Kim and Hastak 2018). In this regard, research has explored how the constitution of a network in terms of the overall structure, such as density but also at the node level in terms of a node's centrality, influences the distribution of information in terms of timeliness and amount of information during ongoing emergencies, for instance.

Yoo et al. (2016), for example, investigated the influence of degree centrality (i.e., the number of network relations a node possesses) of an information cascade originator on the spreading of information during Hurricane Sandy. They concluded that well-connected users positively affected the speed of the information distribution. Researchers of rumor propagation are also interested in diffusion processes during disaster events (e.g., Lee et al. 2015; Oh et al. 2013). For instance, Lee et al. (2015) found that the number of followers positively affected the distribution of rumors in the Boston Marathon bombing case. Studies of this kind can inform responder organizations about how to detect rumors and stop them from spreading in social media. Responder organizations may strive to develop new social media relations in the platforms to improve their network positions, which in turn helps distribute verified digital information rapidly in the network during a disaster (Yoo et al. 2016).

Since information is so critical during disasters, information diffusion is a topic that goes beyond social media. Pan et al. (2012) identified four network prototypes for information diffusion: information star, information pyramid, information forest, and information black-out. The networks are different in terms of information intensity and network density. Depending on the disaster event, the authors argue, responder organizations may choose and follow the structure of one of the network prototypes they deem appropriate for distributing the information efficiently. Furthermore, Eismann et al. (2018) investigate how social network analysis can be applied to understand radio communication from emergency events. Finally, not in the context of social media but in the context of diffusion processes, Fedorowicz and Gogan (2010) investigated the reinvention of a bio-terror surveillance system.

\section{Type II Theories in EMIS Research on Dedicated Systems for Emergency Management}

EMIS studies on dedicated EMIS such as DSS or warning apps also focus on applying theories of explaining. Table 11 lists theoretical lenses applied on dedicated EMIS for emergency management. The last row in the table includes example theories that have been applied only very rarely (sometimes only once) in EMIS/IS research and hence are not further explained in the subsequent section. 


\begin{tabular}{|c|c|c|c|}
\hline Theoretical lens & Explanation & $\begin{array}{l}\text { Studied EMIS } \\
\text { type }\end{array}$ & Example studies \\
\hline $\begin{array}{l}\text { Situational } \\
\text { awareness }\end{array}$ & $\begin{array}{l}\text { Focuses on an individual's percep- } \\
\text { tion of environmental clues and } \\
\text { events, the understanding of their } \\
\text { meaning, and-based on that-the } \\
\text { projection of a future status. }\end{array}$ & $\begin{array}{l}\text { Conceptual, } \\
\text { warning apps }\end{array}$ & $\begin{array}{l}\text { Bonaretti and Piccoli } \\
\text { 2018; Fischer-Preßler } \\
\text { et al. 2020; Luokkala } \\
\text { and Virrantaus 2014; } \\
\text { Ng and Kankanhalli } \\
2012\end{array}$ \\
\hline Effective use & $\begin{array}{l}\text { Focuses on explaining how people } \\
\text { can use information systems effec- } \\
\text { tively to guide their decision mak- } \\
\text { ing and actions. }\end{array}$ & $\begin{array}{l}\text { Conceptual, } \\
\text { warning apps, } \\
\text { dashboards }\end{array}$ & $\begin{array}{l}\text { Bonaretti and Fischer- } \\
\text { Preßler 2021; Fischer- } \\
\text { Preßler et al. 2021; } \\
\text { Recker } 2021\end{array}$ \\
\hline Activity theory & $\begin{array}{l}\text { A descriptive meta-theory or } \\
\text { framework that considers an en- } \\
\text { tire work/activity system, includ- } \\
\text { ing teams and organizations, and } \\
\text { accounts for environment, per- } \\
\text { sonal history, culture, role of the } \\
\text { artifact, motivations, and the com- } \\
\text { plexity of the real-life activity. }\end{array}$ & $\begin{array}{l}\text { Database, model- } \\
\text { ing of systems, } \\
\text { tools for inter- } \\
\text { agency collabo- } \\
\text { ration }\end{array}$ & $\begin{array}{l}\text { Allen et al. 2014; Chen } \\
\text { et al. 2008a; Chen et al. } \\
\text { 2013; Valecha et al. } \\
2019\end{array}$ \\
\hline $\begin{array}{l}\text { Institutional } \\
\text { logics and insti- } \\
\text { tutional theory }\end{array}$ & $\begin{array}{l}\text { Focuses on how social and institu- } \\
\text { tional contexts provide organizing } \\
\text { principles that guide actors with } \\
\text { the "means and ends" (Vila-Pozo } \\
\text { and Sundeep 2018, p. 3) of individ- } \\
\text { ual behavior. }\end{array}$ & $\begin{array}{l}\text { Digital platforms, } \\
\text { EMIS for intra- } \\
\text { and inter-organi- } \\
\text { zational commu- } \\
\text { nication and col- } \\
\text { laboration }\end{array}$ & $\begin{array}{l}\text { Bharosa et al. 2010; Ka- } \\
\text { ranasios et al. 2019; } \\
\text { Vila-Pozo and Sundeep } \\
2018\end{array}$ \\
\hline Media richness & $\begin{array}{l}\text { Focuses on the differences be- } \\
\text { tween communication means with } \\
\text { respect to their ability to convey } \\
\text { information richness, which is the } \\
\text { ability to change understanding } \\
\text { within a certain time interval in an } \\
\text { exchange. }\end{array}$ & $\begin{array}{l}\text { Communication } \\
\text { tools }\end{array}$ & $\begin{array}{l}\text { Ada et al. 2016; Aros } \\
\text { and Gibbons } 2018\end{array}$ \\
\hline $\begin{array}{l}\text { Resource-based } \\
\text { view }\end{array}$ & $\begin{array}{l}\text { Focuses on an organization's re- } \\
\text { sources and how it can deploy } \\
\text { those resources to create value } \\
\text { and success. }\end{array}$ & $\begin{array}{l}\text { EMIS infrastruc- } \\
\text { ture }\end{array}$ & $\begin{array}{l}\text { Chen et al. 2010; Leid- } \\
\text { ner et al. } 2009\end{array}$ \\
\hline Others & $\begin{array}{l}\text { Actor network theory (Thapa et al. } \\
\text { 2017); information supply chains } \\
\text { (Day et al. 2009); game theory } \\
\text { (Wakolbinger et al. 2013); ontol- } \\
\text { ogy to evaluate the completeness } \\
\text { of disaster websites (Chou et al. } \\
\text { 2014). }\end{array}$ & $\begin{array}{l}\text { Digital tools; } \\
\text { tools for infor- } \\
\text { mation sharing; } \\
\text { disaster websites }\end{array}$ & $\begin{array}{l}\text { Chou et al. 2014; Day et } \\
\text { al. 2009; Thapa et al. } \\
\text { 2017; Wakolbinger et } \\
\text { al. } 2013\end{array}$ \\
\hline
\end{tabular}

Table 11. Theoretical lenses of EMIS research in the type II category

\section{Situational Awareness}

The concept of situational awareness (SA) - originally developed in the domain of the military pilot-has become a crucial concept in disaster research because of its importance to informed decision making. Endsley (1995) defines SA as "the perception of the elements in the environ- 
ment within a volume of time and space, the comprehension of their meaning, and the projection of their status in the near future" (Endsley 1995b, p. 36). SA unfolds over three hierarchical levels: 1) perceiving the elements in the environment; 2) understanding the current situation; and 3) projecting the future status of the situation (Endsley 1995a; Endsley 1995b; Endsley et al. 2003).

The first level of SA is to perceive the relevant information in a situation. Much of the information comes directly from perceiving the environment. The first SA level is crucial as it serves as the foundation upon which the second and third levels will be constructed, and most of the reasons that prevent achieving SA are associated with the first level (Endsley et al. 2003). The second level is to understand the meaning of the information in relation to the goals and objectives of a person. Therefore, a person needs to judge and prioritize information in relation to the goals. Once the person understands the elements and their meaning in relation to current goals, the third SA level comprises the ability to predict what those elements will do in the future-at least in the short term. Achieving the third level demands expertise, since a person can only do so by understanding the situation, the operations, and dynamics of the system in which they are working. In EMIS research, generally, there is a strong emphasis on the first level, as information systems and their surface structures help users observe more information useful for managing their operations (Bonaretti and Piccoli 2018).

A closer examination of EMIS research reveals that it applies the SA concept very differently in terms of the level of analysis. Many EMIS researchers introduce the notion of SA as an outcome or favorable mental state without developing the concept further. This may stem from the fact that SA focuses on mental processes, which are supported only by using EMIS effectively during a disaster event. Nevertheless, a few EMIS studies base their research on Endsley's conceptual model, seeking to advance it or using it to inform system design along the three levels. Seppänen and Virrantaus (2015), for instance, investigate static or a priori, situational, and operational information, stressing that situational information is particularly crucial for the comprehension level of situational awareness but often suffers from bad quality. Luokkala and Virrantaus (2014) combine the three levels of SA with another cognitive model-the two mind theory-putting the individual into focus. Establishing SA along the three levels is seen as a function of an individual's experience and the social context (Luokkala and Virrantaus 2014).

\section{Effective Use of EMIS}

EMIS researchers contextualized the theory of effective use (EUT) in the emergency context (Bonaretti and Piccoli 2018). EUT explains how individuals can use information systems effectively to guide their decision making and actions (Burton-Jones and Grange 2013). The theory is rooted in representation theory (RT), which posits that information systems support decision making by providing individuals with digital representations of real-world entities (e.g., emergency events) (Burton-Jones and Grange 2013). Digital representations are seen as more efficient representations for decision making and actions than non-digital ones. For instance, a warning transmitted via a warning app offers a richer representation of an ongoing emergency event than the sound of a siren. Digital representations that faithfully mirror the real world, thereby enabling representational fidelity, support effective decision making, which, in turn, increases performance (i.e., compliance). 
To achieve effective use EUT requires that individuals activate three levels of use (see Figure 2. Theory of effective use): transparent interaction, representational fidelity, informed action (Burton-Jones and Grange 2013). Individuals can actualize transparent interaction by "accessing the system's representations unimpeded by its surface” (Burton-Jones and Grange 2013, p. 643). That means individuals must interact effectively with the system's interface to access the system's deep structure. The physical structure enables the interaction between the interface and the deep structure. Through the interface, users retrieve digital representations of the realworld domain. Ideally, digital representations will faithfully mirror the real world, enabling representational fidelity. Fidelity enables attaining informed action. Contextualized to emergency management, subsequent research suggested assessing effectiveness against situational awareness rather than informed action (Bonaretti and Piccoli 2018).

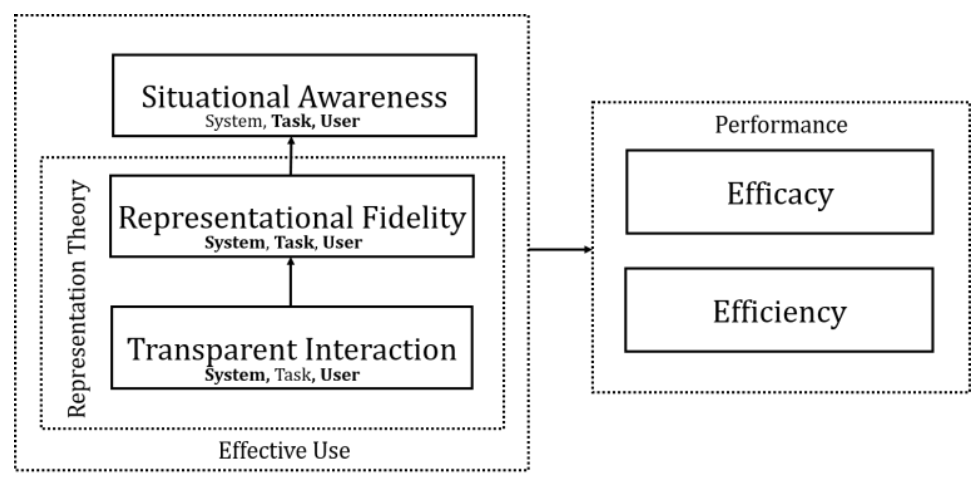

Figure 2. Theory of effective use adapted from Burton-Jones and Grange (2013)

To date, EMIS researchers have mainly applied the theory as an analytical framework to understand EMIS in use. In particular, Fischer-Preßler (2020) investigated the effective use of a warning app at the three levels of EUT, aiming to understand how it enables a faithful representation of an emergency event. Others have based their research on the notion of a faithful representation of a disaster event. For instance, Recker (2021) applied the idea on the Robert Koch Institute Covid-19 dashboard from a design science perspective, answering the question of how state tracking helps faithfully represent the current status of Covid-19 in Germany.

\section{Activity Theory and EMIS Research}

Activity theory provides a meta-theoretical framework frequently used as a methodological and conceptual tool in EMIS research (e.g., Allen et al. 2014; Chen et al. 2008a). Fundamentally, the theory suggests studying human activity, which is directed towards an object, as socially situated phenomena. In so doing, the essential lens of analysis is an "activity," that is, in IS research typically a computer-supported interaction between individuals and collective structures. Hence, activity theory accounts for the collective setting in disaster management as it provides a framework to study the use of a system as part of group activity and system design from a human perspective (Bertelsen and Bødker 2003).

Rather than explaining certain phenomena, activity theory provides a conceptual framework with a set of basic principles. An activity is a structure typically conceptualized with various sub-activities that collate or extend the core activities (Bertelsen and Bødker 2003). The activity transforms either an ideal or a material object. The active element in this process is a subject, which is either an individual or a collective. The transformation process is further enabled 
and supported by various physical or logical instruments. Each instrument provides the subjects with the experience historically collected by their communities (Fuentes et al. 2003). During the interaction, subjects internalize and/or externalize their cognitive schemes and their understanding of the relationship between themselves and the external objects, instruments, surroundings, and other factors. Several approaches of activity exist in IS, such as the activity checklist for HCI design (Kaptelinin et al. 1999), the activity theoretical evaluation method (Quek and Shah 2004), and third-generation activity theory (Engeström 1987).

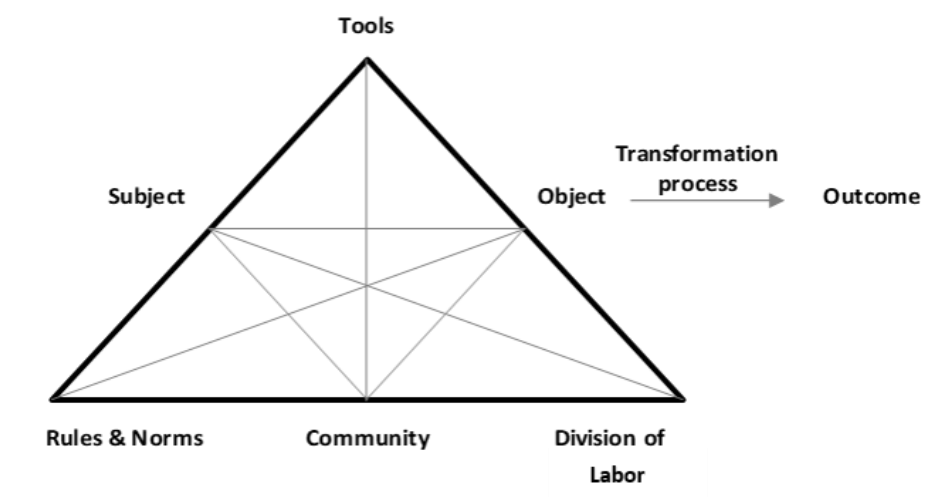

Figure 3. Activity system adapted from Engeström (1987, p. 78)

EMIS researchers tend to build on Engeström's (1987) model depicted in Figure 3, which extends the core elements of an activity system by adding rules and norms, the division of labor, and the community as interrelated elements that influence an activity. For instance, Allen et al. (2014) base their study on this model and conceptualize emergency response as the commonly shared object around the activity systems of different responder organizations. They conclude that the philosophy of designing EMIS specifically for emergency response activities is flawed because systems will be of limited use when they are only for emergencies only. Instead, researchers should focus on designing EMIS that also work in routine settings and can expand to solve more anomalous emergencies. In addition, a focus on technology alone limits understanding emergency response, since response activities depend upon several organizations and their collaboration; response activities often need to overcome issues intrinsically linked to norms and values of these responder organizations. Others-also building on third-generation theory-apply the framework to identify data elements that guide the building of a database for a shared emergency response system (e.g., Chen et al. 2008a; Chen et al. 2013). Hence, activity theory has provided researchers with a framework for understanding broader response activities as well as individual system design.

\section{Institutional Theory, Actor Network Theory, and EMIS Research}

Institutional theory and socio-technical systems consider a broader social context. While multiple notions of institutional logics exist, they all agree on a core meta-theory, which stresses that individual and organizational behavior is embedded in a social and institutional context that regulates that behavior but also provides an opportunity for change (Thornton and Ocasio 2008). Institutional logics are the organizing principles based on rules and guidelines that in- 
dividuals in a certain context create and consolidate and that make their behavior and perspectives more or less predictable. In short, institutional logic is "the particular way a social world works" (Thornton and Ocasio 2008, p. 101).

EMIS researchers have drawn on the concept of institutional logics. Karanasios et al. (2019), for instance, studied the interplay between three logics that occur when leveraging a digital platform in emergency management: first, the command and control typical for professional emergency response management; second, the community logic as a principle of close community relationships and empowering the public to support resilience; and third, the platform logic as a mediator between groups, enabling hyper-personalization, crowdsourcing, empowerment, peer-to-peer, distributed ownership, and democratization of information. The authors furthermore identified tensions between these logics that shift to the liberalization of, but eventual persistence of, the command-and-control logic. Bharosa et al. (2010), in contrast, identified several challenges, from an institutional perspective, related to the organization, community, and individual in emergency response. They point out that inter-organizational sharing is impeded by focusing on institutional routines and that responders-focusing on their own operations-are simply not aware of the information needs of different organizations. Finally, Vila-Pozo and Sundeep (2018) investigated the design of a humanitarian health management information system from an institutional perspective. They find that major design flaws stem from wrong assumptions regarding the institutional logics. In particular, the system was designed under assumptions of stability of the environment, independent from an internet connection, and the existence of homogeneous environments, which does not, however, align with the needs during highly dynamic disaster situations.

\section{Communication Theories in EMIS Research}

EMIS research has also investigated how the richness of a certain tool influences communication. Media richness theory assesses and ranks the richness of different communication media, such as phone calls, video conferencing, and email (Daft and Lengel 1984). For instance, a phone call does not afford visual social cues such as gestures between the people involved, which makes it less rich than video conferencing, which affords visual cues in addition to the sound of a voice. The theory postulates that richer, personal communication media are generally more effective than leaner, less rich media for communicating equivocal issues. The theory is of interest in EMIS research for understanding which technologies are more efficient in professional disaster response communication (Aros and Gibbons 2018) and how the richness of technology influences its adoption for warning purposes (Ada et al. 2016). Note that Ada et al. (2016) used a quantitative approach and, hence, media richness also classifies for type IV theories in EMIS research.

\section{Resource-Based View}

EMIS researchers are also interested in understanding disaster response from a competitive advantage perspective manifested in the lens of the resource-based view (RBV). RBV is a managerial framework that is applied to define the strategic resources a firm can exploit to achieve sustainable competitive advantage in a given market (Barney 1991). In disasters, various responder organizations need to coordinate existing assets and capabilities in new combinations to respond as quickly as possible and avoid any escalation. Hence, Leidner et al. (2009) argue 
it is important to understand what resources are valuable in crisis response and how to manage them effectively. In comparing disaster response to the competitive market context, they find that in contrast to the competitive context, in the disaster context IT infrastructure together with IT skills are highly valuable and essential for responding. Similarly, Chen et al. (2010) draw on a psychometric research model for their analysis, using the RBV lens, and find that response performance is positively influenced by the IT asset allocation among the network of disaster responders.

\section{Type IV: Theories on Explaining and Predicting in EMIS Research}

EMIS research has also considered predictive theories, as Table 12 shows. A focus on an intention construct, such as the intention to use a certain EMIS, dominates this research.

\begin{tabular}{|c|c|c|}
\hline Theory & Description & Example studies \\
\hline IS success model & $\begin{array}{l}\text { Focuses on factors such as information, system, and } \\
\text { service quality to predict use intention and satisfac- } \\
\text { tion, which in turn predict net benefits. }\end{array}$ & $\begin{array}{l}\text { Lee et al. 2011; Petter } \\
\text { and Fruhling } 2011\end{array}$ \\
\hline $\begin{array}{l}\text { Technology ac- } \\
\text { ceptance model }\end{array}$ & $\begin{array}{l}\text { Focuses on perceived ease of use, perceived useful- } \\
\text { ness, and attitude towards use to predict use inten- } \\
\text { tion. }\end{array}$ & $\begin{array}{l}\text { Aedo et al. 2010; Han et } \\
\text { al. 2011; Lee et al. 2011; } \\
\text { Lee et al. } 2013\end{array}$ \\
\hline $\begin{array}{l}\text { Unified theory of } \\
\text { technology ac- } \\
\text { ceptance }\end{array}$ & $\begin{array}{l}\text { Focuses on performance expectancy, effort expec- } \\
\text { tancy, social influence, and facilitating conditions to } \\
\text { predict behavioral intention. }\end{array}$ & $\begin{array}{l}\text { Fischer et al. 2019; Pra- } \\
\text { sanna et al. 2013; Wei- } \\
\text { dinger et al. } 2021\end{array}$ \\
\hline $\begin{array}{l}\text { Protection moti- } \\
\text { vation theory }\end{array}$ & $\begin{array}{l}\text { Focuses on perceived vulnerability, perceived se- } \\
\text { verity, response cost, response efficacy, maladap- } \\
\text { tive rewards, and self-efficacy to predict use inten- } \\
\text { tion. }\end{array}$ & $\begin{array}{l}\text { Fischer-Preßler et al. } \\
\text { 2021; Han et al. } 2011\end{array}$ \\
\hline Others & $\begin{array}{l}\text { Compliance theory: focuses on subjective norm, } \\
\text { perceived safety, and financial threat, and infor- } \\
\text { mation quality trust to predict compliance intention } \\
\text { (Han et al. 2015). } \\
\text { Cue-summation theory: focuses on positive or nega- } \\
\text { tive effects on the performance of information con- } \\
\text { veyed in cues within the EMIS (McNab et al. 2011). }\end{array}$ & $\begin{array}{l}\text { Han et al. 2015; McNab et } \\
\text { al. } 2011\end{array}$ \\
\hline
\end{tabular}

Table 12. Overview on type IV theories in EMIS research

EMIS research into theories for prediction draws from related research in technology acceptance, as well as theories that consider use and continued use intention such as the DeLone and McLean IS success model (Petter and Fruhling 2011, Lee et al. 2011), technology acceptance model (Aedo et al. 2010), unified theory of acceptance and use of technology (Prasanna et al. 2013), compliance theory (Han et al. 2015), and protection motivation (Fischer-Preßler et al. 2021).

To understand acceptance of professional response software, Aedo and Prasana investigated EMIS, drawing on the dominant IS research stream in this area. In particular, Davis' (1989) technology acceptance model (TAM) is among the seminal IS papers that address technology acceptance. It has been subjected to several meta-analyses (e.g., King and He 2006; Schepers and Wetzels 2007). TAM explains a person's intention to accept a technology using two constructs: perceived usefulness and perceived ease of use of technology. In the initial version of TAM, Davis (1989) posited that the relationship between perceived ease of use/perceived usefulness and intended use is mediated by an individual's attitude toward new technology. In 
terms of EMIS research, Aedo et al. (2010), for instance, stress that not only perceived usefulness but also trust is a major factor for using a collaborative EMIS during an ongoing event.

TAM went through several evolutions, such as in Venkatesh and Davis (2000) and in Venkatesh et al. (2003). In the latter, Venkatesh et al. (2003) integrated several theories of technology acceptance (such as TAM, the theory of reasoned action, the motivational model, the theory of planned behavior, innovation diffusion theory, and social cognitive theory) into a unified model called UTAUT. Prasanna et al. (2013) investigated UTAUT and TAM in their research; they found that performance expectancy, effort expectancy, social influence, and information quality affect symbolic adoption - a combination of mental acceptance and psychological attachment towards an EMIS. Petter (2011) investigated use intention and the success of a professional emergency management DSS, drawing on the IS success model from DeLone and McLean, which focuses on the effects of information and system quality as predictors for use intention. They found that system quality, information quality, service quality, and satisfaction positively affect use intention. Combining the IS success model and TAM, Lee et al. (2011), in contrast, showed that expected group value positively influences intention to use. The EMIS investigated in these studies are quite different in terms of functions and user groups and, hence, studies in this area are difficult to compare because success factors have to be reflected in terms of the respective context.

A further EMIS research strand in this area explores use and compliance intention of mobileenabled warning technologies. While these systems vary in terms of functions, they all share a main feature: transmitting a digital representation of an emergency event to an affected population. Drawing on compliance theory, Han et al. (2015), for instance, investigate students' intention to comply with campus alerts based on subjective norms, perceived safety threats, perceived financial threats, and information quality trust. Research in the mobile-enabled warning context has studied the determinants of use of (e.g., Ada et al. 2016; Han et al. 2015; Lee et al. 2013) and compliance with campus emergency warning systems (Han et al. 2015). The dependent variable in this context can be seen as a form of protective motivation-it manifests in the form of compliance intention (e.g., Han et al. 2015) or use intention of a particular warning system (Bonaretti and Fischer-Preßler 2021). This gives way to drawing on the perspective of protection theory (PMT) to understand protective behavior.

Based on expectancy-value theory, PMT provides a detailed account of the social and cognitive processes underlying protective behaviors (Rogers 1975). The theory is organized according to two major processes: threat and coping appraisal. Individuals' perception of how threatened they feel by a certain risk governs the threat appraisal process, in which the threat is evaluated. Only people who conclude that a threat affects them will consider a preventive behavior. Hence, the threat and the fear it generates must be weighted more heavily than rewards received by persisting in maladaptive behavior; otherwise, there is no motivation to protect oneself. In the coping appraisal process, individuals evaluate the efficacy of protection responses, their perceived self-efficacy in light of the threat, and the response costs. For protection motivation to occur, the person's response efficacy and self-efficacy must outweigh the response cost (Maddux and Rogers 1983; Rogers 1975, 1983).

\section{Summary of EMIS Research on Type I, II, and IV Theories}

The preceding section classified theories being used in EMIS research into three main categories: theories for analyzing (type I), theories for explaining (type II), and theories for explaining and prediction (type IV). This thesis includes papers that apply theories from each of these 
categories. There are two papers based on theories for analyzing (papers I and II). In particular, two literature reviews are based on conceptual frameworks to synthesize the past research landscape. In addition, several of the papers draw on theories for explaining-specifically, papers VI and VII on EUT and paper VIII on representation theory-to understand effective mobile warning system use. Papers X and XI use social capital theories to explain social media use by emergency responder organizations. Paper XII applies uses and gratification and terror management theory to explain factors that lead to public social media use and sense-making in the aftermath of terrorist attacks. Paper XIII builds on sense-making and terror management theory to explore reasons for digital coping in the aftermath of terrorist attacks. Paper XIV draws on self-organization to explain the relationships among factors that lead to social mediaenabled self-organization. Finally, the thesis includes papers on theories for explaining and predicting. Specifically, paper IV verifies a research model based on a model that builds on UTAUT, and paper V is based on PMT to explain warning app use and continued use.

\section{Research Methodologies}

Scientific knowledge is highly dependent on the techniques and tools used for collecting, analyzing, and interpreting data. This section introduces the literature-based, quantitative, and qualitative research methods used in this thesis.

\subsection{Literature Reviews}

The metaphor "like dwarfs standing on the shoulder of giants" 4 is often used to express that science builds on knowledge accrued from prior research. That fact stresses the importance for cumulative knowledge building of uncovering the relevant research status of a specific topic of interest, which requires a rigorous literature review. A review is also necessary if researchers are to question existing and advancing knowledge and hence establish knowledge anew.

A literature review "synthesizes past knowledge on a topic or domain of interest, identifies important biases and knowledge gaps in the literature and proposes corresponding future research directions" (Rowe 2014, 243). Generally, literature reviews are of one of two types: those that provide the context and background for the research question, that is, the theoretical background of the broader article in which they appear; and those aimed at summarizing the literature in a field and thus constitute a research article on their own (Paré et al. 2015). The latter typically follow a certain method for identifying the literature corpus and use the identified literature as the data to be analyzed (Schwarz et al. 2007), such as in a systematic literature review (e.g., Kitchenham and Charters 2007; Okoli and Schabram 2010; Paré et al. 2015).

A systematic literature review aims to make the selection of the literature corpus as transparent as possible to establish credibility and enable reproducibility by others who follow the same review approach (Kitchenham and Charters 2007). In doing so, it follows certain guidelines and describes the literature search and assessment process in detail, including the search terms and databases used and the criteria for inclusion and exclusion of the literature. It thus enables other researchers to assess the scope of the review and the findings with confidence (Vom Brocke et al. 2009).

\footnotetext{
${ }^{4}$ The shoulders-of-giants metaphor was used by Bernard of Chartres, Isaac Newton, Robert Merton, and others. While its exact meaning is unclear, it is commonly used today to refer to cumulative knowledge building and scientific progress (Merton 1993).
} 
This thesis includes two systematic literature reviews: Paper I focuses on communication barriers in crisis management, using a conceptual framework as the analytical tool with which to map the literature, identify knowledge gaps, and outline future research directions. Paper II synthesizes the literature on the intersection of IT and organizational risk management, providing a thorough description and evaluation of that work based on the four risk management phases: risk reduction, risk identification, risk analysis, and risk monitoring. It also spells our directions for future research.

In contrast to review articles, which have the purpose of consolidating literature for which a comprehensive analysis of prior literature is essential, papers in which a framework is developed aim to integrate and conceptualize (Schwarz et al. 2007). Framework papers typically set forth new conceptual frameworks or develop theories (Rowe 2014). For this purpose, researchers need to examine critically that part of the literature that unifies the particular research stream and the theoretical ideas being considered (Schwarz et al. 2007).

This thesis includes two framework papers based on a rigorous (but not systematic) literature review. They both offer theoretical explanations and propose new conceptual frameworks to aid in understanding the relationships between the proposed theoretical concepts. In particular, paper XII proposes a framework of drivers of social media use during terrorist attacks, based on a literature review, that combines terror management theory and uses and gratifications theory. Paper XIV suggests a theoretical framework to explain drivers of social media use for the purpose of self-organization by the public, based on a review of the crisis management literature.

\subsection{The Value of Qualitative and Quantitative Methodologies}

Research methods make assumptions about the world and what constitutes warrantable knowledge, both an (implicit) ontological one concerning what exists in the human world about which to acquire knowledge about, and another epistemological one regarding how knowledge is created (Mingers 2001). From epistemological (e.g., constructivism vs. objectivism) and ontological assumptions (e.g., one reality exists, not multiple realities) stem philosophical perspectives - a system of generalized views of the world that guide any research (e.g., positivism vs. interpretivism) (Moon and Blackman 2014).

While the general purpose of quantitative and qualitative research methods is the same-gaining a better understanding of the world better with the intent of making valid scientific inferences-their methodologies and epistemic and ontic presuppositions can-but not necessarily have to (Myers 1997) — differ (Goertz and Mahoney 2012). In brief, while quantitative methods are often associated with theory testing, positivism, and objectivism, qualitative research is associated primarily with theory generation, interpretivism, and constructivism (Bryman 2016). As these presuppositions are more or less strongly associated with either qualitative or quantitative research, methods can be viewed as competing ways for studying reality (for a deeper discussion, see for instance, Lee 1991; Mingers 2001; Myers 1997). ${ }^{5}$

\footnotetext{
${ }^{5}$ There is an exhaustive debate on what constitutes qualitative and quantitative research and whether a distinction between the two is useful at all, a detailed discussion of which is beyond the scope of this thesis. However, there is little evidence for a decline in the use of the quantitative/qualitative distinction and, for this thesis, it is a useful distinction for classifying the different approaches applied (Bryman 2016).
} 
Contrasting that view, some researchers emphasize the value of combining different research methods, as the combination provides a richer understanding of the research topic, enables the researcher to deploy the method with the best fit to a particular research question and "to deal effectively with the full richness of the real world" (Mingers 2001, p. 243). In this view, quantitative and qualitative research methods are simply different ways of conducting investigations conceived of as appropriate for answering different research questions, and these methods can be combined or integrated (Goertz and Mahoney 2012).

This thesis follows this view of methodological pluralism and justifies the research methods applied in the context of each of the fourteen papers (see the subsequent sections in which the methods applied in the papers are discussed, and the paper for a full description). In particular, the methods employed to answer the research questions in this thesis include literature reviews (as introduced above), qualitative studies based on the analysis of expert interviews, participant observations, documents, and online review data, as well as quantitative studies based on the analysis of survey data and Twitter data. Whereas the use of quantitative methods provides empirical evidence of the validity of proposed research models, the use of qualitative methods enables the exploration of new phenomena.

\subsection{Quantitative Research Methods}

The word quantitative derives its meaning from Latin: "quantitas refers to a primary focus on differences in amount" (Erickson 2011, p. 43). That is, however, insufficient to explain the notion of what many researcher understand to comprise quantitative methods in the social sciences (Bryman 1988). Generally, quantitative research methods in the social sciences (and also in the IS discipline) aim to follow the logic and procedures from the natural sciences. The fact that the study objects of the social sciences (i.e., people) think, communicate, have feelings, attribute meaning to their environments, and generally appear as individuals to be very different from each other-characteristics normally not held by the study objects of the natural science-is not an impediment to a natural science approach (Bryman 2016). This is considered an objective reality that can be measured, and further that relationships between entities can be captured in reasonably representative and accurate data. Although many of the constructs are social constructions, the enduring presence of these constructs in the real world allows them to be evaluated (Straub and Gefen 2004).

A further characteristic of quantitative research is the view that scientific knowledge is produced by accumulating facts that add to a theoretical foundation in a particular domain. In particular, theory represents the accumulated findings of empirical research. In brief, theories involve theoretical concepts connected via relationships from which hypotheses are derived. By operationalizing these concepts, hypotheses can be tested statistically. If rejected, a theory must be revised (for a deeper discussion see, for instance, Bryman 1988). Hence, from this point of view, quantitative methods are useful for testing theory and for answering questions of causality between theoretically derived concepts.

\section{Survey Research}

Quantitative research is associated with a number of different approaches for data collection and analysis. Survey research is one of the main methods of data collection. The survey's capacity for producing large amounts of quantifiable data for testing theories and/or hypotheses from participants representative of a wider population has been viewed by many researchers as "a means of capturing many of the ingredients of a science" (Bryman 1988, p. 11). 
Survey research is a quantitative method that focuses on testing theory, that is, a clearly defined research model consisting of independent and dependent variables that are connected via relationships. Surveys aim to produce quantitative descriptions of some aspect of a population and capture standardized data from the study participants. Hence, the main data-gathering technique is to ask representatives of a wider population a set of structured and defined questions through a questionnaire. The responses comprise the data to be analyzed. Since the data collected are only from a sample of the study population, that sample should be large enough to allow adequate statistical analysis and ideally allow for generalizing the findings to the full population (Pinsonneault and Kraemer 1993).

In this thesis, papers IV, V, and VI apply a survey research method. Papers IV and V build on the same data set and test a research model that proposes the use of warning apps such as NINA and Katwarn as a form of protection motivation. We used a covariance-based structural equation model (SEM) to test the model. Paper VI, in contrast, tests why warning SMS may be a limited method to enable effective use of a warning system.

\section{Structural Equation Modelling}

Structural equation modeling (SEM) aims to test the relationship between multiple variables empirically and investigate how well a preconceived theory fits the reality represented by the observed data (Hair et al. 2017). The basic idea of a covariance-based SEM is to use variances and covariances of observable variables to draw conclusions about dependency relationships of these hypothetical latent constructs. In particular, covariance analysis aims to estimate parameters so that the generated model-theoretic correlation matrix reproduces the empirical correlation matrix as exactly as possible. The parameter estimates can then be used to examine the specific relationship structures between the hypothesized (latent) constructs and the measured variables. As the validation is conducted by how well the theoretical model can be estimated, it is often used in confirmatory research aimed at verifying theories (Weiber and Mühlhaus 2014). A battery of fit indices (see Table 13) is typically used to evaluate whether a proposed model fits the data well.

\begin{tabular}{|l|l|}
\hline Global fit indices & Cutoff criteria \\
\hline Goodness of Fit Index (GFI) & $>=0.9$ \\
\hline Normed Fit Index (NFI) & $>=0.9$ \\
\hline Comparative Fit Index (CFI) & $>=0.9$ \\
\hline Tucker-Lewis Index (TLI) & $>=0.9$ \\
\hline Root Mean Squared Error of Approximation (RMSEA) & $<=0.05-0.08$ \\
\hline $\mathrm{X}^{2} / \mathrm{df}$ & $<=2.5$ \\
\hline
\end{tabular}

Table 13. Cutoff criteria to evaluate SEM model fit based on (Weiber and Mühlhaus 2014) and (Hu and Bentler 1999)

\section{Biases and Validity Tests}

As inference drawn from research methods that cannot prove validity and reliability is meaningless, it is important to account for that issue. Many different types of validation exist, and new types are developed routinely (see, for instance, Weber forthcoming). The papers of this dissertation use several established validity and reliability measurements when conducting SEM. 


\section{Content Validity}

Straub and Gefen (2004, p. 424) define content validity as "[t]he degree to which items in an instrument reflect the content universe to which the instrument will be generalized." In other words, to evaluate content validity researchers need to define the construct they aim to measure and understand what falls into the domain of the construct's definition. This is commonly done through literature reviews and expert judges and panels (Straub and Gefen 2004). To ensure content validity, papers IV and V used mainly established items from prior research articles; the items were discussed and reviewed within the group of authors.

\section{Discriminant Validity}

Discriminant validity reflects the extent to which items of a construct differ from items of other constructs. It is tested by statistically controlling whether a battery of items measuring a construct has different scores than items from other constructs. Hence, discriminant validity is checked based on the correlations "that exist among the indicators themselves and the indicators used to measure other constructs" (Weber forthcoming p. 35). The Fornell-Larcker criterion is used quite commonly: it compares the square root of the average variance extracted (AVE) with all construct correlations. The square root of the AVE should exceed the values of the corresponding construct correlations (Fornell and Larcker 1987).

\section{Construct Validity}

Construct validity is about the internal consistency of the latent variable. It is assessed through convergent, discriminant (see above), and nomological validity (Weiber and Mühlhaus 2014). Concerning convergent validity, the factor loadings of all indicators for the latent constructs should be greater than the 0.7 benchmark and highly significant and the AVE should be at least 0.5 (Fornell and Larcker 1987). For nomological validity, the confirmatory factor analysis needs to show a good model fit (see Table 13) (Bagozzi 1979; Weiber and Mühlhaus 2014). In addition, we assessed the traditional Cronbach's Alpha value, which should be at least 0.7. Construct (including discriminant validity) validity is established in papers IV and V.

\section{Common Method Bias}

Common method bias (CMB) is defined as the variance that is "attributable to the measurement method rather than to the constructs the measures are assumed to represent" (Podsakoff et al. 2003, p. 879). It is a potential problem when using subjective or self-reported measures because the method may cause a systematic effect on the observed correlation between the measures used. As it can threaten the validity of conclusions about tested relationships between measures, it is important to control for CMB. In accordance with the procedure by (Podsakoff et al. 2003), we controlled for CMB in paper V using a single unmeasured latent method factor, and compared whether the differences in goodness of fit between the CFA models with and without the single method factor was significant.

\section{Multi-Group Analysis}

Multi-group analysis uses observable characteristics of a sample, such as gender, to divide data into groups and estimates based on separate models of the defined groups (Weiber and Mühlhaus 2014). The path coefficients of the different groups almost always differ, but the question a multi-group analysis aims to answer is whether those differences are statistically significant (Hair et al. 2018). 
When applying a multi-group analysis, which involves comparing the same latent variable across different groups or across time, testing for measurement invariance is important. Measurement invariance tests whether the items of a latent variable have similar meanings across groups. Testing measurement invariance is necessary because individuals in different groups may understand items differently because the groups differ in terms of culture, age, gender, and in other ways. Hence, for comparing results between different groups, it is crucial to check that the meaning of the measurement is equal between the groups (Putnick and Bornstein 2016).

\begin{tabular}{|c|c|c|}
\hline $\begin{array}{l}\text { Type of in- } \\
\text { variance }\end{array}$ & Description & Implication \\
\hline Configural & $\begin{array}{l}\text { Interpretation: The same CFA model is speci- } \\
\text { fied for each group, but parameters are freely } \\
\text { estimated in each group. The models sepa- } \\
\text { rately show good fit. } \\
\text { Operationalization: The measurement model } \\
\text { of both groups fit well compared to the un- } \\
\text { constrained simultaneous measurement } \\
\text { model. }\end{array}$ & $\begin{array}{l}\text { The factor structure operates simi- } \\
\text { larly between groups. Still, factors } \\
\text { may have unequal pattern coeffi- } \\
\text { cients, intercepts, or error variances } \\
\text { for some indicators. }\end{array}$ \\
\hline $\begin{array}{l}\text { Metric (or } \\
\text { "weak") }\end{array}$ & $\begin{array}{l}\text { Interpretation: Equality constraints are im- } \\
\text { posed on unstandardized factor loadings. } \\
\text { Operationalization: The constrained (factor } \\
\text { loadings) simultaneous measurement model } \\
\text { fits well compared to the unconstrained sim- } \\
\text { ultaneous measurement model. }\end{array}$ & $\begin{array}{l}\text { The constructs manifest in the same } \\
\text { way within each group. Factor scores } \\
\text { are calculated using the same } \\
\text { weighting schemes in both groups } \\
\text { because the slopes of regressing the } \\
\text { indicators on their respective factors } \\
\text { are equal. Comparison of relation- } \\
\text { ships between constructs is allowed. }\end{array}$ \\
\hline Scalar & $\begin{array}{l}\text { Interpretation: Mean differences in the latent } \\
\text { construct capture all mean differences in the } \\
\text { shared variance of the items. } \\
\text { Operationalization: Constraining the item in- } \\
\text { tercepts to be equal in the two groups. If the } \\
\text { overall model fit is not significantly worse in } \\
\text { the scalar invariance model compared to the } \\
\text { metric invariance model, it indicates that } \\
\text { constraining the item intercepts across } \\
\text { groups does not significantly affect the model } \\
\text { fit, and scalar invariance is supported. }\end{array}$ & $\begin{array}{l}\text { The constants (measurement inter- } \\
\text { cepts) of the indicators of the meas- } \\
\text { urement models match between the } \\
\text { groups. Comparison of the means of } \\
\text { the latent construct is accepted. }\end{array}$ \\
\hline
\end{tabular}

Table 14. Types of invariance

Paper VI uses a multi-group analysis between factors that influence protection motivation via the use of a warning app in a group of non-users and users. As Table 14 indicates, there are different stages of measurement invariances. We followed the procedure by Chen (2007) and Byrne (2004) to test for measurement invariance. If configural and metric invariance is confirmed then partial measurement invariance holds, and comparison of the relationships across the groups is allowed.

\subsection{Qualitative Research Methods}

Qualitative research methods were originally developed in the social sciences for the study of social and cultural phenomena. There is a variety of these methods that share some characteristic and purposes (Kaplan and Maxwell 2005; Myers 1997). Specifically, the methods aim at understanding particular real-world situations by investigating peoples' perspectives and behaviors in situations with different contexts. Qualitative research thus attempts to make sense 
of or interpret phenomena in terms of the meanings people bring to them, and focuses on the subjective meanings of behaviors (Aspers and Corte 2019). This focus is also reflected in the Latin origin of the term qualitas - which "refers to a primary focus on the qualities, the features, of entities" (Erickson 2011, p. 43).

To achieve its objective of understanding people as well as the social and cultural contexts in which they act (Kaplan and Maxwell 2005), qualitative research is often conducted in natural settings. Its methods are primarily inductive, and data come from words rather than numbers. Hence, qualitative research often follows an interpretative, naturalistic approach to its subject matter (Kaplan and Maxwell 2005), as is the case in this thesis.

It is words that comprise the data in qualitative research; these data include, among others types, written observational descriptions of activities and conversations, transcripts of openended interviews, and real-world documents. The data are analyzed in a way that retains their textual nature, because qualitative research typically aims at understanding phenomena from the perspectives of the study participants (Kaplan and Maxwell 2005). This results in rich descriptions and narratives of specific phenomena and situations as the basis for the analysis (Goodwin and Horowitz 2002).

Kaplan and Maxwell (2005) spell out five reasons for conducting qualitative research in the IS domain: to understand how users perceive and evaluate a system; to understand the influence of the social and cultural context on system use; to understand how causal processes work; to evaluate system design in progress by providing in-depth, timely feedback; and to improve use of findings and implications by connecting them to the real-world perception of practitioners and other end users. Questions posed in qualitative studies are framed as what, how, and why questions rather than as true/false with respect to a particular hypothesis. In this thesis, papers VII, VIII, IX, X, XI, and XIII follow some form of qualitative inquiry (discussed in more detail in the subsequent sections), aiming to answer "what," "how," and "why" questions by investigating words rather than numbers.

\section{Expert Interviews, Online Review Data, Observations, and Documents}

Three of the papers in this thesis employ qualitative data-collection methods such as expert interviews and observation complemented with an analysis of several related digital and analogue documents. The expert interview is a method applied in studies: experts in the domain of interest-people who possess special knowledge and skills and play an expert role in the social setting of the research topic (Gläser and Laudel 2009) - are interviewed as sources of information that can lead to understanding situations, perceptions, and processes from their point of view. Their expert knowledge is typically result of special learning and training. Physicians, paramedics, and architects are examples of experts.

Beyond the role of experts as interviewees, there is also what Gläser and Laudel call interviewees as experts (Gläser and Laudel 2009). For instance, a person treated by a paramedic possesses special knowledge about that process from a patient perspective. The two expert roles are not disjunctive: in social settings, one, the other, or both may be relevant to the research.

Papers VII, VIII, X, and XI in this thesis use expert interviews for data collection. Interviewees gave their full informed consent to being interviewed for research. We conducted interviews with professionals who play an expert role in emergency communication. For paper VII we interviewed German emergency responders from different responder organizations about their use of warning apps from an end-user perspective; they were not responsible for sending 
warning messages. Thus, they comprise a group of interviewees as experts as defined above, and aided in identifying the end-user perception of effective warnings. The interviews supplemented other data, including an in-depth analysis of the warning app. Paper VII also draws on the analysis of online user review data to understand the factors that hinder or contribute to effective warning app use. While in interviews answers can be probed or additional details elicited, the reviews are particularly useful because users raise issues they experience when using the app that matter to them.

For paper VIII, we asked experts directly involved in the dissemination of warning messages and are thus experts in the field. The paper investigates the process of effective warning dissemination and aims to understand the processes and impediments in the entire process of warning transmission. We based our interview guide on effective use theory and a preliminary analysis of relevant websites and official documents. Furthermore, the first author took part in a large-scale emergency exercise to observe the entire warning process in practice. This participant observation was an opportunity to observe warning process errors and flaws-such as the source and occurrence of conflicting recommendations for actions in a warning-in the "real world."

In papers $\mathrm{X}$ and $\mathrm{XI}$, we used semi-structured interviews based on social capital theory with social media experts from different responder organizations to understand how social media is used on different organizational levels and how these experts perceive that their use can help their organizations build social capital. We also investigated the social media profiles of the experts to gain a better understanding of social media use and to provide more conclusive evidence beyond the interview results.

Finally, paper IX aims at informing a privacy-compatible design for Covid-19 contact tracing apps. The paper's data are based on the online documentation of tracing apps from five different countries. In particular, we studied official documentation about the apps' privacy policies, data usage, functions, and requirements for using the apps. This approach enabled a comparison of the five apps, evaluation of their privacy terms, and compare the apps' terms of use with the theoretical framework of the study.

\section{Qualitative Content Analysis}

The papers in this thesis draw on qualitative content analysis to analyze data. The goal is the systematic investigation and coding of the different kind of communicative material, such as transcripts, online review data, or textualized observations, to identify themes and patterns (Mayring 2004). While there are different methodological approaches, these papers focused on thematic content analysis-one of the most common approaches (Franzosi 2003). During the coding process, words and phrases that share the same meaning are captured in contentrelated and dominant categories to enable replicable and valid inferences from textual data (Cavanagh 1997). The category system may then result in a model, conceptual system, or categories (Elo and Kyngäs 2008). Papers in this thesis developed categories and their descriptions (i.e., subcategories) that emerged from the data. Content analysis may be used in an inductive or deductive approach. The papers in this thesis follow a deductive approach, that is, the analysis is operationalized on a theory and moves from there to more specific conclusions (Elo and Kyngäs 2008). This approach is justified, as the papers aim to test, develop, and adapt the theories in new contexts. 


\section{Limitations of Qualitative Methods}

While qualitative methods are useful for (and not limited to) the reasons explained above, they have been subjected to some criticisms. One reoccurring criticism refers to validity threats, which concern the subjective manner in which data are collected and analyzed, which may differ from one researcher to another. For instance, researchers with the same research question may collect different data, or the same data may be interpreted differently (Kaplan and Maxwell 2005). Thus, it is important that researchers acknowledge their role in the research process and explicitly explain their beliefs and/or knowledge. In this thesis, these beliefs and knowledge were framed by the theoretical lens used to interpret the data in each paper.

Researchers use one or more different methods to account for validity and reliability in qualitative content analysis. Reproducibility is a form of inter-coder reliability that refers to the extent to which coders classify data in the same way: Would different coders using the same coding scheme find the same coding categories (Cavanagh 1997)? A kappa-coefficient of 0.70 is commonly seen as sufficient (Mayring 2004). We controlled for inter-coder reliability in papers II, VII, and XIII. Where the researchers did not reach agreement, we discussed the differences, reflected upon the coding rules, clarified ambiguity in the text, and came to a shared conclusion.

Validity ${ }^{6}$ in general refers to the extent to which an instrument measures "what it claims to measure" (Cavanagh 1997, p. 12). In qualitative content analyses as undertaken in this thesis, the validity concerns the categories and subcategories and the interpretation gleaned from the data (Weber 1995). To say that a subcategory is valid means that there is a relationship between the theoretical concept and the categories emerging from the data. One method for confirming validity is triangulation - using data from different sources (interviews, reviews, social media data, observations) and searching for convergence when developing the categories. Multiple sources increase the robustness of the results by enabling the cross-validation of the findings (Kaplan and Maxwell 2005). In this thesis, papers VII, VIII; X, and XI draw on multiple sources.

Nevertheless, the results of a qualitative analysis are interpretive and can never be considered purely objective. Hence, it is crucial that different researchers-when possible-analyze the data and compare their results. Discrepancies in interpretations do not necessarily invalidate results (Kaplan and Maxwell 2005); rather, they require adapting and refining the coding scheme and analyzing the data several times until agreement between researchers is reached. Most of the studies in this thesis that use qualitative content analysis were conducted by two researchers and adopt a particular theoretical lens as the tool for analysis. Using a particular lens helped prevent the researchers from overlooking important issues and guided the interpretation and focus of the research.

\section{Topic Modeling}

Finally, one paper of this thesis applied topic modeling. A topic is a set of words representing interpretable themes within documents. A topic model is a statistical model that aims to discover themes that occur in large numbers of documents. It is based on an algorithm that analyzes the word of a text to discover the different themes within that text, how those themes are

\footnotetext{
${ }^{6}$ It is acknowledged that there are many types of validity that have been used in a variety of ways in research (Weber 1995). Many of the validity types used in quantitative research, however, are not necessarily useful in qualitative research. Nevertheless, a qualitative inquiry needs to demonstrate that its results are credible.
} 
connected, and how they change over time. The algorithms do not require prior annotations or document labeling, as the topics appear from the analysis of the original documents. Topic modeling thus enables the organization and summary of large amounts of digital data that would be impossible for humans to annotate (Blei 2012). The automatic analysis of a large volume of textual data is the quantitative part of topic modeling. The researchers interpret these textual data, which is the qualitative part of the approach.

Paper XIII aims to identify the topics of Twitter users related to the Berlin terrorist attack in 2016. It is thus based on topic modeling that used a tweet data set over the time period from the start of the attack to six days after, collected based on hashtags employed by Twitter users to refer to the terrorist attack. The documents in our data set are the tweets. Documents are a mixture of topics, and a tweet contains proportions of several topics. Generally speaking, a tweet might be ascribed mainly to one topic (e.g., with a proportion of 60\%) and to other topics with a smaller proportion (e.g., a proportion of $30 \%$ to a second topic and $10 \%$ among remaining topics). As tweets at the time of the terrorist attack were limited to 140 characters, their content often refers to one specific topic.

After fitting all models, the semantic coherence and exclusivity of the statistical measures were calculated to determine the best model. Semantic coherence is higher if more probable words in a topic frequently co-occur (Mimno et al. 2011), whereas exclusivity achieves higher values if more words are exclusive to corresponding topics. In terms of desirable statistical properties, the models with 10 and 20 topics outperform the larger models with 30 and 40 topics, as they both achieve better values for semantic coherence and exclusivity. Beyond statistical diagnostics, validation by humans is the most important way to evaluate topic models. Using an application for qualitative validation of structural topic models, two of the paper's authors independently investigated the models with 10 and 20 topics by analyzing the most likely words and tweets with the highest proportions for a given topic to determine whether the structure made sense. In doing so, the 50 most-likely terms of a topic, as well as the 50 documents with the highest proportions for a topic, were analyzed. Corresponding labels were assigned in accordance with the highest proportions of words and highly representative documents for each topic. The final model contains 20 topics and was the best and most intuitive model for our research task; the topics were neither too broad nor too narrow. Similar to the papers in which content analysis was conducted, we checked for inter-coder reliability to control for the reproducibility of the findings from our theoretical perspective. Disregarding some minor wording differences, intercoder reliability reached a value of 0.9 for this model.

More traditional data-collection methods enable researchers to obtain informed consent for data collection directly from study participants, but this is not so simple when it comes to digital trace data. The sheer quantity of data such as tweets may not allow a reasonable way to obtain informed consent from every user. Hence, researchers often do not ask permission of every single user to process their data. Also, while some platforms have policies that clearly state that researchers may access public tweets and use them tweets for their research, as in the case of Twitter, the majority of Twitter users is not aware of this as they do not understand or even read the platform's terms and conditions (Fiesler and Proferes 2018). This has led to a debate over informed consent and appropriate research ethics when using digital trace data.

In their study of social media ethics, which is based on a survey of Twitter users, Fiesler and Proferes (2018) present different implications regarding research ethics. We followed these implications in paper XIII. In particular, they found that Twitter users are more comfortable when researchers employ larger data sets; we used a data set of 51,256 tweets from 22,439 
Twitter users. We did not analyze the data in tandem with any particular user's profile, nor did we quote tweets verbatim, to ensure Twitter users' anonymity. Similarly, paper VII, which uses online app review data, ensures anonymity because the reviews are not traceable to a particular app user.

\section{Main Research Results and Contributions}

This section describes the contributions of each paper included in this thesis. Altogether, the cumulative dissertation includes 14 research papers that contribute to the research questions raised in the introduction of this framework paper. Table 15 is an overview of the papers, their publication status, and their contribution to the research questions (in the "RQ" column). The subsequent section explains the contribution of each paper in detail. For a detailed explanation of each paper's contribution, see the full description in the papers. 


\begin{tabular}{|c|c|c|c|c|c|}
\hline \# & Contribution & $\mathrm{RQ}$ & Authors & Title & Status \\
\hline I & $\begin{array}{l}\text { - Comprehensive overview of technological, social, } \\
\text { and organizational causes of impediments that } \\
\text { hinder effective emergency response } \\
\text { - Outline of future research directions based on } \\
\text { identified gaps in the existing research literature }\end{array}$ & 1 & $\begin{array}{l}\text { Fischer, D., } \\
\text { Posegga, O., and } \\
\text { Fischbach, K. }\end{array}$ & $\begin{array}{l}\text { Communication Bar- } \\
\text { riers in Crisis Man- } \\
\text { agement: A Litera- } \\
\text { ture Review }\end{array}$ & $\begin{array}{l}\text { Published in } 2016 \text { as a conference } \\
\text { paper in the Proceedings of the } \\
\text { European Conference on Infor- } \\
\text { mation Systems }\end{array}$ \\
\hline II & $\begin{array}{l}\text { - Overview of EMIS types for risk management, i.e., } \\
\text { EMIS that enable intra- and inter-organizational } \\
\text { business continuity along the supply chain } \\
\text { - Identification of gaps in research on EMIS types } \\
\text { for risk management }\end{array}$ & 1 & $\begin{array}{l}\text { Fischer-Preßler, } \\
\text { D., Eismann, K., } \\
\text { Pietrowski, R., } \\
\text { Fischbach, K., } \\
\text { and Schoder, D. }\end{array}$ & $\begin{array}{l}\text { Information Technol- } \\
\text { ogy and Risk Man- } \\
\text { agement in Supply } \\
\text { Chains }\end{array}$ & $\begin{array}{l}\text { Published in } 2020 \text { as a journal ar- } \\
\text { ticle in the International Journal } \\
\text { of Physical Distribution \& Logis- } \\
\text { tics Management }\end{array}$ \\
\hline III & $\begin{array}{l}\text { Evaluation of a large-scale emergency exercise } \\
\text { scenario based on radio communication } \\
\text { - Outline of a network analysis-based method to as- } \\
\text { sess and analyze radio communication during an } \\
\text { emergency event }\end{array}$ & 1 & $\begin{array}{l}\text { Eismann, K., Fi- } \\
\text { scher, D., Po- } \\
\text { segga, O., and } \\
\text { Fischbach, K. }\end{array}$ & $\begin{array}{l}\text { Using Social Network } \\
\text { Analysis to Make } \\
\text { Sense of Radio Com- } \\
\text { munication in Emer- } \\
\text { gency Response }\end{array}$ & $\begin{array}{l}\text { Published in } 2018 \text { as a conference } \\
\text { paper in the Proceedings of the } \\
\text { Second International Workshop } \\
\text { on Modeling, Analysis, and Man- } \\
\text { agement of Social Networks and } \\
\text { Their Applications }\end{array}$ \\
\hline IV & $\begin{array}{l}\text { Identification of factors that lead to use intention } \\
\text { of warning apps, based on a psychometric model: } \\
\text { risk perception, trust, subjective norm foster use, } \\
\text { whereas privacy concerns negatively influence } \\
\text { use intention } \\
\text { - } \begin{array}{l}\text { Development and conceptualization of a research } \\
\text { model based on a scoping literature review }\end{array}\end{array}$ & 2 & $\begin{array}{l}\text { Fischer, D., Hat- } \\
\text { tori-Putzke, J., } \\
\text { and Fischbach, K. }\end{array}$ & $\begin{array}{l}\text { Crisis Warning Apps: } \\
\text { Investigating the } \\
\text { Factors Influencing } \\
\text { Usage and Compli- } \\
\text { ance with Recom- } \\
\text { mendations for Ac- } \\
\text { tion }\end{array}$ & $\begin{array}{l}\text { Published in } 2019 \text { as a conference } \\
\text { paper in the Proceedings of the } \\
\text { Hawaii International Conference } \\
\text { on System Science }\end{array}$ \\
\hline V & $\begin{array}{l}\text { Identification of factors that influence non-users } \\
\text { use intention and users' continued use intention } \\
\text { of warning apps, based on a psychometric model } \\
\text { - Contextualization and evaluation of protection } \\
\text { motivation theory to the emergency context }\end{array}$ & 2 & $\begin{array}{l}\text { Fischer-Preßler, } \\
\text { D., Bonaretti, D., } \\
\text { and Fischbach, K. }\end{array}$ & $\begin{array}{l}\text { A Protection-Motiva- } \\
\text { tion Perspective to } \\
\text { Explain Intention to } \\
\text { Use and Continue to } \\
\text { Use Mobile Warning } \\
\text { Systems }\end{array}$ & $\begin{array}{l}\text { Published in } 2021 \text { as a journal ar- } \\
\text { ticle in Business \& Information } \\
\text { Systems Engineering (BISE) }\end{array}$ \\
\hline
\end{tabular}




\begin{tabular}{|c|c|c|c|c|c|}
\hline VI & $\begin{array}{l}\text { Provides evidence that compliance intention is a } \\
\text { limiting factor for understanding effective use of } \\
\text { SMS warnings; calls for caution in applying theo- } \\
\text { ries of reasoned action as a performance indicator } \\
\text { for warning systems } \\
\text { - Finds that the absence of spatial awareness on the } \\
\text { part of warning receivers can hinder actual com- } \\
\text { pliance }\end{array}$ & 2 & $\begin{array}{l}\text { Bonaretti, D. and } \\
\text { Fischer-Preßler, } \\
\text { D. }\end{array}$ & $\begin{array}{l}\text { The Problem with } \\
\text { SMS Campus Warn- } \\
\text { ing: An Evaluation } \\
\text { Based on Recipients' } \\
\text { Spatial Awareness }\end{array}$ & $\begin{array}{l}\text { Published in } 2021 \text { as a journal ar- } \\
\text { ticle in the International Journal } \\
\text { of Disaster Risk Reduction }\end{array}$ \\
\hline VII & $\begin{array}{l}\text { Identification of several information quality di- } \\
\text { mensions for digital warnings to enable effective } \\
\text { use of a warning app, based on the perspective of } \\
\text { the theory of effective use } \\
\text { - Contextualization of the theory of effective use to } \\
\text { the emergency context }\end{array}$ & 2 & $\begin{array}{l}\text { Fischer-Preßler, } \\
\text { D., Bonaretti, D., } \\
\text { and Fischbach, K }\end{array}$ & $\begin{array}{l}\text { Effective Use of Mo- } \\
\text { bile-Enabled Emer- } \\
\text { gency Warning Sys- } \\
\text { tems }\end{array}$ & $\begin{array}{l}\text { Published in } 2020 \text { as a conference } \\
\text { paper in the Proceedings of the } \\
\text { European Conference on Infor- } \\
\text { mation Systems, Marakesh, Ma- } \\
\text { rocco }\end{array}$ \\
\hline VIII & $\begin{array}{l}\text { - Showcasing of an approach to investigate an } \\
\text { emergency warning system, from the perspective } \\
\text { of a layered analysis } \\
\text { - Identification of deficiencies that hinder effective } \\
\text { use of public warning systems, from the authority } \\
\text { perspective on different system structures } \\
\text { - Derivation of an additional system structure re- } \\
\text { ferred to as "environmental structure," in which } \\
\text { deficiencies can occur }\end{array}$ & 2 & $\begin{array}{l}\text { Fischer-Preßler, } \\
\text { D., Bonaretti, D., } \\
\text { and Fischbach, }\end{array}$ & $\begin{array}{l}\text { Understanding Fail- } \\
\text { ures of Emergency } \\
\text { Warning Systems: A } \\
\text { Representation Per- } \\
\text { spective }\end{array}$ & $\begin{array}{l}\text { Published in } 2021 \text { as a conference } \\
\text { paper in the Proceedings of the } \\
\text { International Conference on Infor- } \\
\text { mation Systems, Austin, Texas }\end{array}$ \\
\hline IX & $\begin{array}{l}\text { Investigation of contact tracing apps provided in } \\
\text { five Western democracies, from a normative per- } \\
\text { spective } \\
\text { - Discussion of design of contact tracing apps from } \\
\text { the perspective of information privacy concerns }\end{array}$ & 2 & $\begin{array}{l}\text { Eismann, K., Fi- } \\
\text { scher-Preßler, } \\
\text { D., and Fisch- } \\
\text { bach, K. }\end{array}$ & $\begin{array}{l}\text { Applied Ethics and } \\
\text { Digital Information } \\
\text { Privacy: Informing } \\
\text { the Design of Covid- } \\
19 \text { Contact Tracing } \\
\text { Apps }\end{array}$ & $\begin{array}{l}\text { Under second review in the Aus- } \\
\text { tralasian Journal of Information } \\
\text { Systems }\end{array}$ \\
\hline
\end{tabular}




\begin{tabular}{|c|c|c|c|c|c|}
\hline $\mathrm{X}$ & $\begin{array}{l}\text { - Analysis of social media profiles of different units } \\
\text { of a responder organization } \\
\text { - Refinement of online social capital raising strate- } \\
\text { gies of internal and external social media use by re- } \\
\text { sponder organizations }\end{array}$ & 3 & $\begin{array}{l}\text { Fischer-Preßler, } \\
\text { D., Marx, J., Eh- } \\
\text { nis, C. and Fisch- } \\
\text { bach, K. }\end{array}$ & $\begin{array}{l}\text { Leveraging Online } \\
\text { Social Capital: How } \\
\text { the German Red } \\
\text { Cross Uses Social } \\
\text { Networking Sites }\end{array}$ & $\begin{array}{l}\text { Published in } 2019 \text { as conference } \\
\text { paper in the Proceedings of the } \\
\text { Australasian Conference on Infor- } \\
\text { mation Systems }\end{array}$ \\
\hline XI & $\begin{array}{l}\text { Derivation of managerial implications for strate- } \\
\text { gies to build online social capital via social media } \\
\text { by humanitarian NGOs } \\
\text { - Identification of tensions of social media use be- } \\
\text { tween different organizational units that can im- } \\
\text { pede building social capital by an NGO }\end{array}$ & 3 & $\begin{array}{l}\text { Fischer-Preßler, } \\
\text { D., Marx, J., Bun- } \\
\text { ker, D., Stieglitz, } \\
\text { S., and Fisch- } \\
\text { bach, K. }\end{array}$ & $\begin{array}{l}\text { Humanitarian Aid } \\
\text { NGOs and Virtual } \\
\text { Communities: An Al- } \\
\text { truistic Guide to Or- } \\
\text { ganizational Online } \\
\text { Social Capital }\end{array}$ & $\begin{array}{l}\text { Submitted in June } 2021 \text { to Infor- } \\
\text { mation \& Management }\end{array}$ \\
\hline XII & $\begin{array}{l}\text { Development of a research model that explains } \\
\text { peoples' social media use after terrorist attacks } \\
\text { - Factors such as worldview defense and self-es- } \\
\text { teem foster social media use for sense-making }\end{array}$ & 4 & $\begin{array}{l}\text { Fischer, D., Eis- } \\
\text { mann, K., and } \\
\text { Fischbach, K. }\end{array}$ & $\begin{array}{l}\text { Usage Behavior of } \\
\text { Social Network Sites } \\
\text { in the Aftermath of } \\
\text { Terrorist Attacks }\end{array}$ & $\begin{array}{l}\text { Published in } 2016 \text { as research-in- } \\
\text { progress paper in the Proceedings } \\
\text { of the International Conference on } \\
\text { Information Systems }\end{array}$ \\
\hline XIII & $\begin{array}{l}\text { - Identification of sense-making and terror manage- } \\
\text { ment dimensions in digital social networks after } \\
\text { terrorist attacks } \\
\text { - Dimensions are search for meaning and sense; na- } \\
\text { tionalistic sentiment; counter-bigotry activism; al- } \\
\text { truistic or pro-social behaviors; gratitude for help- } \\
\text { ers; information seeking and sharing }\end{array}$ & 4 & $\begin{array}{l}\text { Fischer-Preßler, } \\
\text { D., Schwemmer, } \\
\text { C., and Fisch- } \\
\text { bach, K. }\end{array}$ & $\begin{array}{l}\text { Collective sense- } \\
\text { making in times of } \\
\text { crisis: Connecting } \\
\text { terror management } \\
\text { theory with Twitter } \\
\text { user reactions to the } \\
\text { Berlin terrorist at- } \\
\text { tack }\end{array}$ & $\begin{array}{l}\text { Published in } 2019 \text { as a journal pa- } \\
\text { per in Computers in Human Be- } \\
\text { havior }\end{array}$ \\
\hline XIV & $\begin{array}{l}\text { Development of a research model for social media } \\
\text { enabled self-organization, based on a scoping lit- } \\
\text { erature review } \\
\text { - Identification of factors that positively affect social } \\
\text { media use of the public for self-organization }\end{array}$ & 4 & Fischer, D. & $\begin{array}{l}\text { Social Networking } \\
\text { Sites in the After- } \\
\text { math of a Crisis - The } \\
\text { Enabling Role for } \\
\text { Self-organization }\end{array}$ & $\begin{array}{l}\text { Published in } 2018 \text { as a conference } \\
\text { paper in the Proceedings of the } \\
\text { Hawai'i International Conference } \\
\text { on System Science (Best Paper } \\
\text { Nomination) }\end{array}$ \\
\hline
\end{tabular}

Table 15. Main research results 


\subsection{Research Question I}

The articles summarized in this section contribute to the first research question: How can emergency management information systems support responder organizations in disaster management? Paper I summarizes the basic EMIS types and their potential for risk management. Paper II studies communication barriers in crisis management, with an emphasis on the role of technology in this context; overcoming these barriers enables effective disaster management. Paper III provides a method for examining digital trace data from emergency management to prepare for future events.

\section{Paper I: Communication Barriers in Crisis Management: A Literature Review}

Paper I is a systematic literature review on communication barriers in crisis management.

Motivation and Goal. Effective communication is crucial for responding to crisis events. However, due to the unpredictable, highly dynamic, and complex situation during a disaster, the organizations involved face many problems. The numerous stakeholders involved in crisis response and the different EMIS used make it challenging to get the right information to the right person at the right time. Despite advances in EMIS and crisis management, research emphasizes shortcomings in crisis communication (e.g., Bharosa et al. 2010; Day et al. 2009). This paper provides a systematic literature review of communication barriers in crisis management.

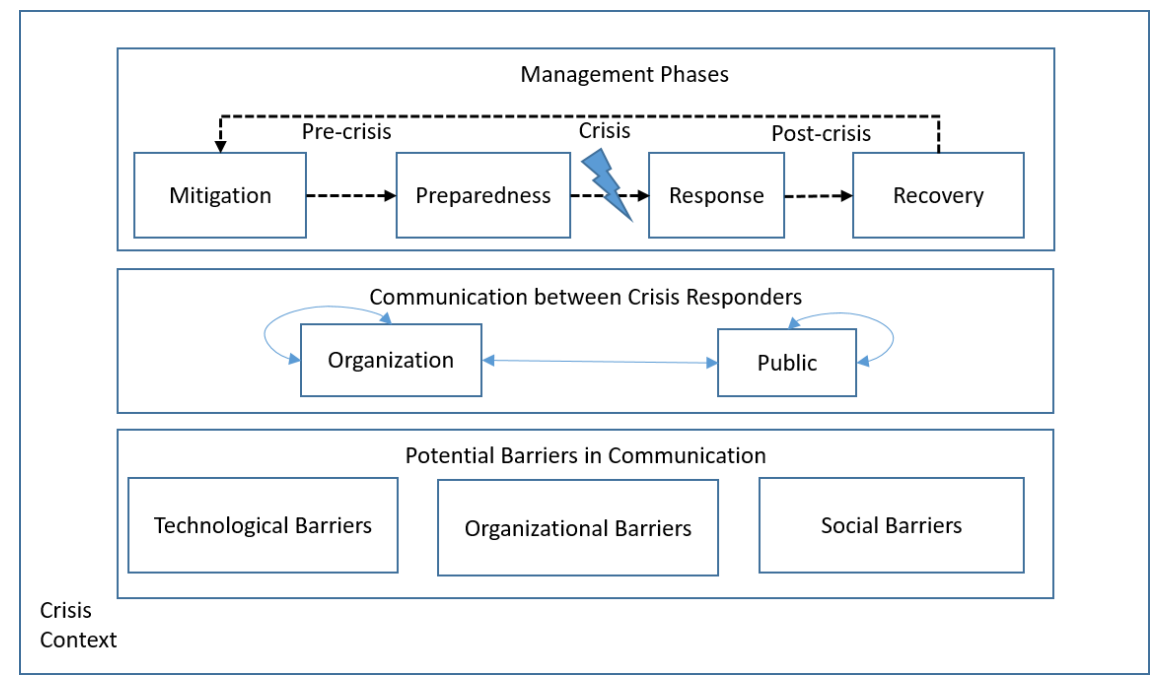

Figure 4. Framework for communication during crisis management from Fischer et al. (2016, p. 4)

Findings. The paper identifies potential barriers in technological, organizational, and social communication (see Figure 4) that can arise between and within organizations and between and within the public. Technological communication barriers are obstacles related to all kinds of EMIS and the technical infrastructure, including infrastructure failures, the absence of EMIS having been accepted by users, use of different EMIS, and social media misuse. Organizational communication barriers, which occur between and within involved organizations, result from organizational differences such as culture and structures that hinder sharing information between organizations, the absence of networks that link organizations, as well as location and resource issues. Finally, social communication barriers relate to the personal characteristics different stakeholders bring to a situation that can hinder effective communication. Social com- 
munication barriers occur due to the diversity of different stakeholders, for instance, with respect to language, skills, and beliefs. They can also occur because individuals may not communicate effectively, do not understand each other, or because of data quality issues.

The paper also identifies communication tasks during the four management phases. During the mitigation phase, communication takes place between and within the organization to reduce disaster risk and make possible risks known to the population. During the preparedness phase, organizations communicate for training and to provide early warning to the population, among other reasons. In the response phase, communication is highly dynamic and can be hampered by the communication barriers described earlier. In the recovery phase, the speed of communication slows down, and responders can learn from the management of the event.

\section{Paper II: Information Technology and Risk Management in Supply Chains}

Paper II is a systematic literature review on supply chain risk management (SCRM) and information technology (IT) that derives a proposal for research directions.

Motivation and Goal. Disasters are disruptive events with far-reaching effects on modern, highly complex modern supply chains. It is a complex task to detect and assess the possible sources of risk and their effects on supply chain operations. Companies need to understand risks in their own operations, risks to all other supply chain partners, and the risks caused by the relations between these organizations (Knemeyer et al., 2009). Companies, hence, often invest in IT to help manage risks (Sambhara et al., 2016). The increasing vulnerability of supply chains to risks that arise not only from regular operations but also from disruptive events point to the importance of research into how IT can help in managing those risks. This paper provides a systematic literature review on the interplay between SCRM and IT, a framework for analyzing IT in SCRM, and a structured proposal for future research directions.

Findings. The literature review's main contribution is the identification of three primary research gaps regarding IT in SCRM. First, many studies have investigated the potential of IT for supply chain risk reduction, but only a few address IT support for risk identification, analysis, and monitoring. Second, there is a lack of research on specific sources of disruption and how IT can help in managing those risks, especially with respect to the management of businessrelated supply chains. Third, the focus of research has been on the potential of IT to enable information supply and sharing, while neglecting risks to physical products and materials in a supply chain.

Furthermore, the paper proposes a two-dimensional framework that builds on the results of the literature review and insights from practitioners working in a three-year international research project (see Figure 5). The framework classifies IT potential for SCRM according to the source and impact of disruption risk on physical supply chain flows. It furthermore proposes and discusses nine areas for further research aimed at mitigating existing research gaps identified at the intersection of SCRM and IT.

In figure 5, the gray cells include topics that have already been studied but for which some research gaps remain. The white cells are topics that need more attention in future research. The figure indicates that harmful, modified, or damaged products are a major problem in SCRM practice. Only a few studies exist on potential applications of IT to deal with intentional humanmade and different types of natural risk sources that harm physical goods. To prevent intentional human activities that lead to such harm, IT could help with security initiatives aimed at protecting possible points of attack along the supply chain. 


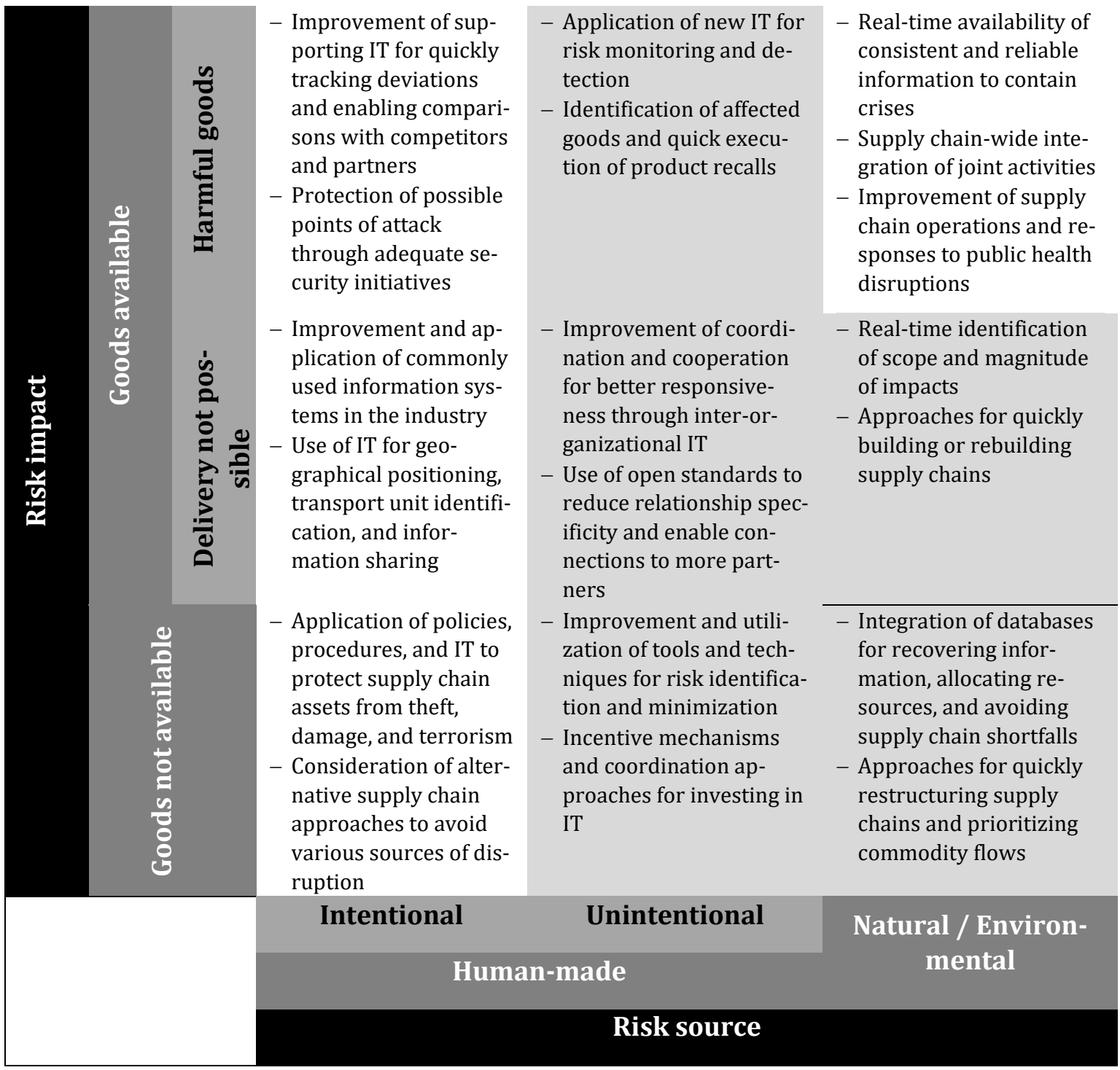

Figure 5. Research framework and research directions from Fischer-Preßler et al. (2020 p. 246)

\section{Paper III: Using Social Network Analysis to Make Sense of Radio Communication in Emergency Response}

Paper III provides a method for modeling social networks based on digital trace data obtained from radio systems in the emergency response field.

Motivation and Goal. Radio communication is a crucial communication medium in emergency response, as it provides a basic and fail-safe tool when other infrastructure has been destroyed. Naturally, radio data afford opportunities to apply tools and methods from the repertoire of social network analysis (SNA) that can be applied to understand radio communication in the context of emergency response. Since radio communication is a baseline communication tool in emergency response, it provides unique insights into the communication structures of response activities (Butts et al. 2007). In addition, radio interoperability issues are still major communication problems emergency responders experience (Fischer et al. 2016; Manoj and Baker 2007). Hence, the goal of this paper is to develop a prototype workflow to analyze digital trace data from radio communication during emergency response. 
Findings. The paper outlines SNA challenges and opportunities that are based on radio networks, following the work of Howison et al. (2011). The analysis is of radio communication data from a large-scale emergency response field exercise adapted from a past disaster-a flash flood in a German city, occurring from a river. In this scenario, emergency responders aimed to evacuate a fake festival venue set up for the exercise. The organizations established an incident structure of command and control based on a clear chain of command. The data gathered consists of the authors' personal observations during the exercise and a dataset with a full record of all radio communication throughout the exercise, including identifiers of individual roles along with complete audio recordings of the conversations.

The paper identifies challenges and opportunities related to extracting communication events from the radio system: modeling actors and communication ties from event data; modeling radio communication networks from actors and communication ties; selecting appropriate network measures; and inferring theoretical constructs from network measures. In so doing, the paper outlines a prototype workflow, depicted in Figure 6, that can be utilized to understand radio communication from an SNA perspective. Hence, this study provides a useful starting point for future research that applies SNA tools and methods to radio networks in the context of emergency response and beyond.
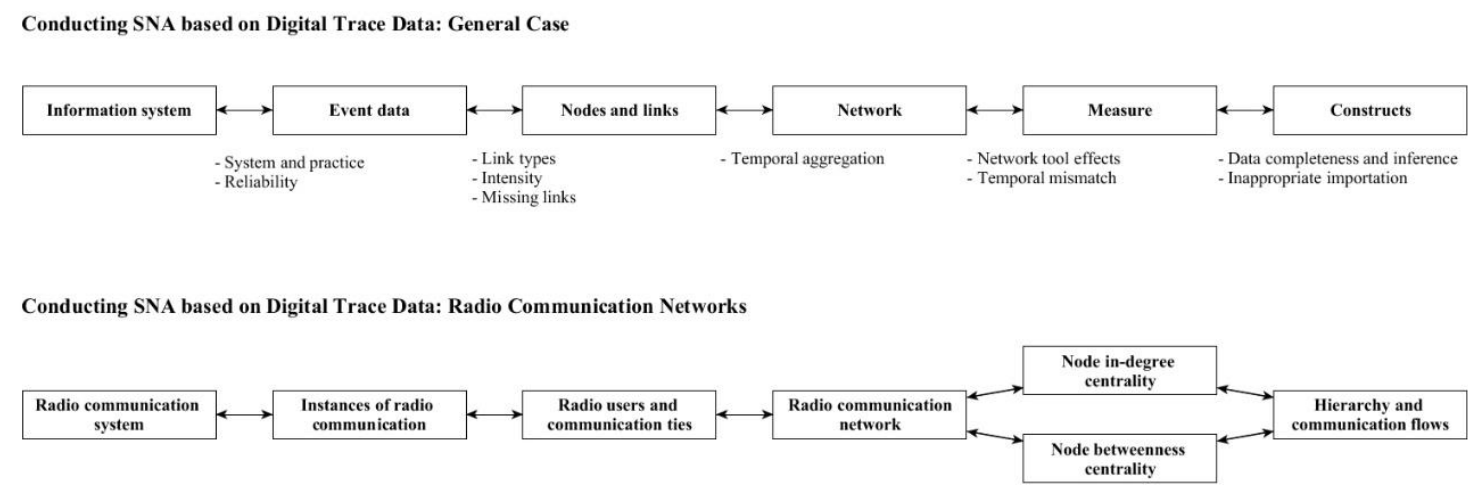

Figure 6. Prototype workflow from Eismann et al. (2018, Chapter 2, "SNA for Digital Trace Data") 


\subsection{Research Question II}

The papers in this section contribute to the second research question: How can EMIS for public emergency communication be leveraged effectively to support emergency management? Paper IV investigates a psychometric model that depict factors that impede or foster people using a warning app. In a similar vein, paper $V$ studies factors of non-users' use intention and users' continued use intention of warning apps. Paper VI explains why SMS warnings are limited in their ability to transmit spatial awareness and why intention-like constructs are limited to predicting compliance intention. Paper VII examines factors relevant to the effective transmission of warning messages, and Paper VIII studies deficiencies that hinder effective use of warning systems from an authority perspective and that must be overcome to enable effective use of a warning system. Finally, paper IX studies principles for designing of Covid-19 tracing apps in ways that protect privacy.

\section{Paper IV: Crisis Warning Apps: Investigating the Factors Influencing Usage and Compliance with Recommendations for Action}

Paper IV studies, based on a psychometric model, the factors affecting warning app use and compliance intention with recommendations for action transmitted via the apps.

Motivation and Goal. To increase the resiliency of a society in case of a disaster, it is important that people receive warnings in a timely manner so they can respond to threats. Hence, authorities worldwide began using mobile warning systems to distribute warning messages in a timely manner to smartphones. However, these systems suffer from low adoption rates (Reuter et al. 2017). Prior research in the field of technology for emergency notifications and crisis warnings has focused on identifying the antecedents of students' intention to use warning systems or comply with warning messages (Han et al. 2015; Lee et al. 2013), but has left intention to use warning systems among the public to future research. Hence, this paper aims to contribute to research on warning app use and compliance by the public by evaluating a research model that combines factors that influence warning app use intention and compliance intention with recommendations for action.

Findings. The research model was evaluated by means of a structural equation model based on 456 study participants. Figure 7 is an overview of the results of the estimates of the structural equation model. The perceived probability of being directly affected by a crisis shows a positive effect on the intention to use mobile warning apps and the intention to comply with recommendations for action. This finding is in accordance with Han et al. (2015). Previous IS security research, in contrast, did not find support for a positive effect of perceived severity of the risk on behavioral compliance intentions with IS security policies (Ifinedo 2012), perhaps because IS security research concerns data and information security and not personal threats.

Perceived trust affects both the intention to use the app as well as the intention to comply with recommendations for action. This suggests that people who perceive that warnings will be relevant, accurate, and timely are more likely to use a warning app and comply with the information received. The latter result is also consistent with prior findings that identified trust as an important factor in compliance intention with warnings in campus emergencies (Han et al. 2015). Furthermore, subjective norms influence people's intention to use a warning app. Hence, if a person cares more about the expectations of other people, that person is more likely to use a warning app and comply with recommendations for action. This finding corresponds with prior results in the context of campus emergencies that investigated the use intention of mobile warning systems (Ada et al. 2016). In addition, concerns about data security have a 
strong negative effect on the use of a warning app and a weak negative effect on compliance intention. This finding adds to research in IT-enabled emergency risk communication by pointing to the importance of data security as a factor in people's decisions to use a mobile warning system. Furthermore, warning app use intention influences people's motivation to comply with recommendations for action. Hence, people who intend to use a warning app are also likely to follow the behavior the app recommends. Altogether, the predictors explain 63.1 percent of the variance of usage intention and 60.7 percent of the variance of compliance intention, suggesting that the model serves as a useful theoretical foundation in the warning app usage context.

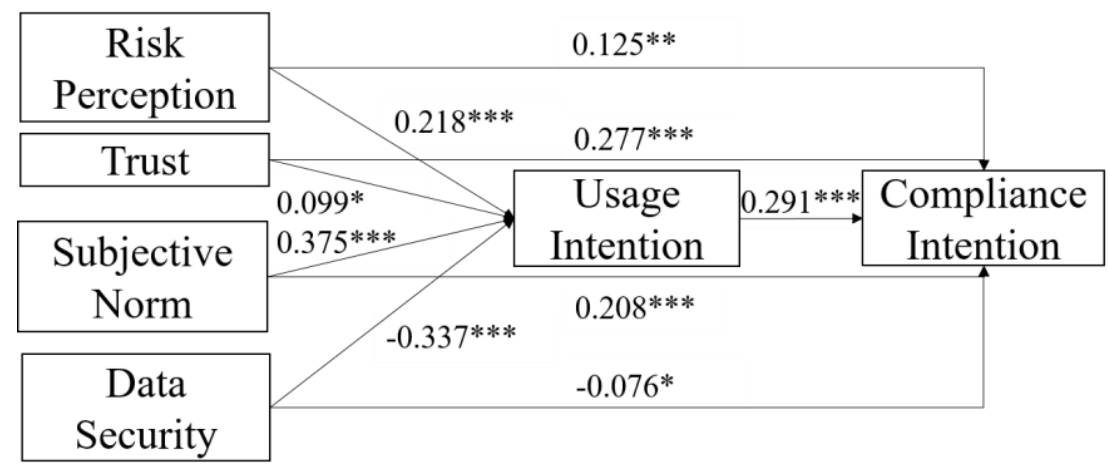

$$
* * * \mathrm{p}<0.001 ; * * \mathrm{p}<0.01 ;{ }^{*} \mathrm{p}<0.1
$$

Figure 7. Validation of the research model from Fischer et al. (2019, p. 6)

The findings also have practical relevance: Authorities and providers of warning apps that seek to promote the use of mobile warning app can explain the likelihood of emergencies or threat situations, since people tend to prepare only for threats they perceive as imminent, as well as outline why warning apps are effective for receiving alerts. Explaining the risk of such threats and how warning apps could help in quickly and reliably alerting affected people positively influences the use of warning apps.

The study, furthermore, found that trust is a crucial factor in the context of warning app use intention. To increase trust in their applications, authorities should ensure the timeliness and correctness of alerts and explain why location-based settings are important for effective alerts. Authorities should also thoroughly outline the details of the providers' data security policies to decrease user concerns about data security that could hinder warning app use. Finally, subjective norms were found to be an important determinant of respondents' intention to use a warning app as well as to comply with behavioral recommendations. Hence, to foster use intention of warning apps, authorities could incorporate features such as "recommend this app to a friend" into their warning apps. 


\section{Paper V: A Protection-Motivation Perspective to Explain Intention to Use and Continue to Use Mobile Warning Systems}

Paper V investigates the factors that influence people to use or continue to use a warning app from a protection motivation perspective.

Motivation and Goal. The widespread use of smartphones and the ubiquity of the internet have made mobile-enabled emergency communication a crucial asset for warning affected people in cases of emergency (Tan et al. 2017). Examples of mobile-enabled waring systems include warning apps such as the FEMA app, NOAA Weather Alerts, and KATWARN (Reuter et al. 2017). Their effectiveness depends on reaching a critical number of users and maintaining these numbers of users over time (Trang et al. 2020). Hence, it is important to understand the factors that lead people to use and continue to use a warning app.

Findings. The study validated a psychometric model (see Figure 8), based on 226 users and 230 non-users, to explain what motivates a person to install a warning app for the first time and keep using it over time (please see the paper for a detailed description of the study setup). In particular, the study applied multi-group covariance-based structural equation modeling to model the answers to a survey that measured the drivers of intention to begin using or continue using a warning app. The model shows that, for both non-users and users, trust, social influence, and response efficacy positively affect intention to use and continue use warning apps, and that maladaptive rewards have negative effects. However, while perceived vulnerability influences use intention, response cost and self-efficacy affect continued use intention. Hence, this study enhances the theoretical understanding of technology-enabled protection behaviors and provides practitioners with a list of factors to consider when pushing the adoption of emergency warning applications.

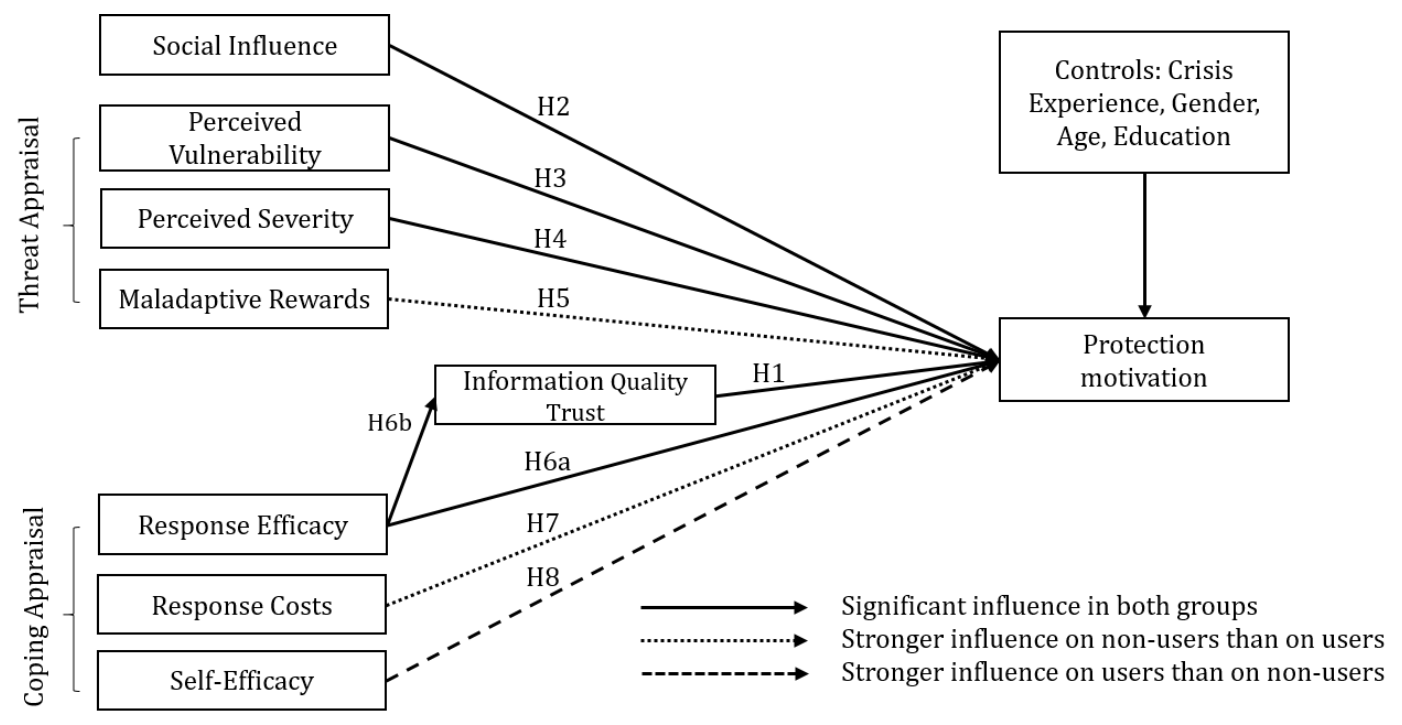

Figure 8. Validation of the research model from Fischer-Preßler et al. (2021)

\section{Paper VI: The Problem with SMS Campus Warning: An Evaluation Based on Re- cipients' Spatial Awareness}

Paper VI investigates whether campus warning SMS convey sufficient information to enable effective counteraction by the receiver. 
Motivation and Goal. Due to the importance of SMS warnings during campus emergencies to alert affected people in a timely manner, research on its effectiveness is crucial. Studies thus far have focused on understanding intention to counteract in fictional emergency scenarios applied in a lab experiment (Kim et al. 2019) or in a survey (Han et al. 2015). However, these studies ignored whether the content of SMS warnings can, in fact, enable recipients to counteract a threat. The warning SMS is effective only if the system enables actual compliance. Hence, this paper investigates the effectiveness of SMS warnings.

Findings. The paper analyzed SMS warnings disseminated at a large U.S. public university. In particular, the study conducted a survey in which students $(n=393)$ read an SMS about a campus emergency and were then asked to trace the event on an interactive Google map (see Figure 9). The results show that students have difficulties determining the exact location of an emergency when the only referent in the SMS is a street or building name. This limited knowledge, in turn, hampers compliance with the recommendations for actions (e.g., avoid the area), even when the intention to comply is high.

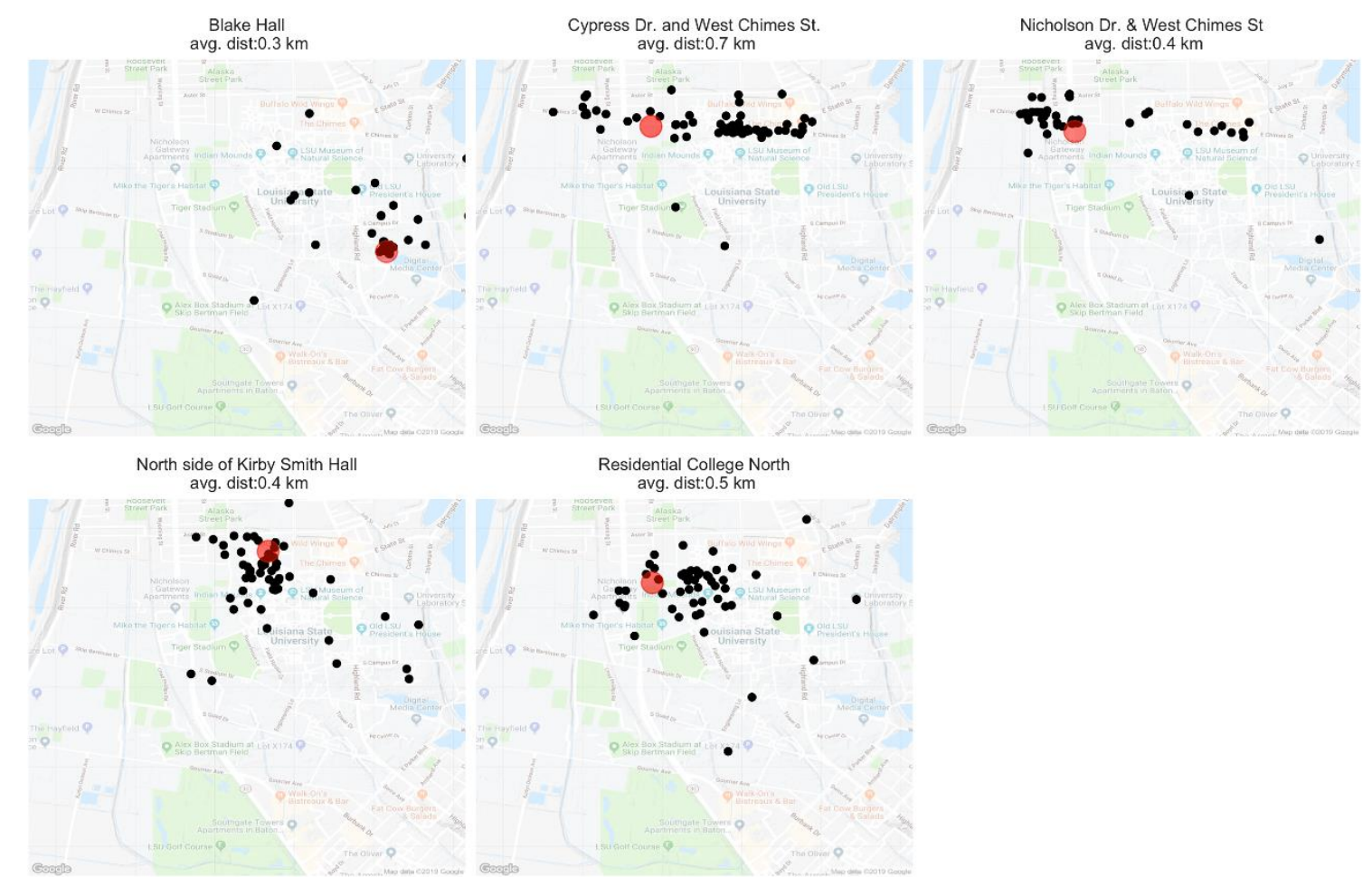

Figure 9. Google map overview from Bonaretti and Fischer-Preßler (2021, p. 6)

In summary, SMS alerts fail to provide their receivers with adequate spatial awareness, which, in turn, hinders the receivers' ability to take counteractions in an active emergency. The paper highlights that despite its rudimentary interface, SMS remains a popular channel for mass alerts. Nevertheless, the limitations of campus SMS warning systems in terms of enabling users to attain situational (spatial) awareness constitute a major design flaw. This result questions the relevance of using compliance intention to measure EWS performance, since intention alone does not necessarily lead to actual compliance-simply because receivers of the SMS may be unaware of their own or the emergency's location. Hence, reasoned action perspectives and intention to comply are insufficient for measuring EWS performance. In fact, they can even be problematic for supporting practitioners with actionable EWS design knowledge. Hence, while reasoned action is largely applied, its use in emergency research calls for extra caution. Research should instead explain EWS performance when students actually avoid an endangered area, not simply whether students show high intention to avoid the area. Since such as measure 
is difficult to establish, assessing effective EWS use could focus on the system's semantics. Specifically, those who receive an SMS alert should be able to understand the semantics of a digital representation that allows the projection of spatially defined counteraction.

\section{Paper VII: Effective Use of Mobile-Enabled Emergency Warning Systems}

Paper VII investigates the effective use of mobile warning systems from the perspective of the theory of effective use (EUT).

Motivation and Goal. Fundamentally, warning apps should provide timely warning messages. Beyond that, users seek information that helps them respond to an emergency, including recommendations for action, "all-clear" messages, information about contact points, and so on (Reuter et al. 2017). These user expectations call for a deeper theoretical understanding of warning apps to guide their design and evaluation. Hence this paper investigates the dimensions of effective warning app use.

Findings. Based on online reviews of warning apps and interview data, the paper identified lower-level dimensions of effective use (see Figure 10). These use dimensions enable understanding effective use in the context of mobile warnings systems. In emergencies, each level of use has time constraints and, hence, timeliness is a critical environmental stressor of effective use both before and during an emergency. This stressor is mirrored in a time-related dimension for each level of use: activation, currency, and promptness. Hence, timeliness is a dimension of each level and not a distinct construct that moderates or mediates the levels of use.

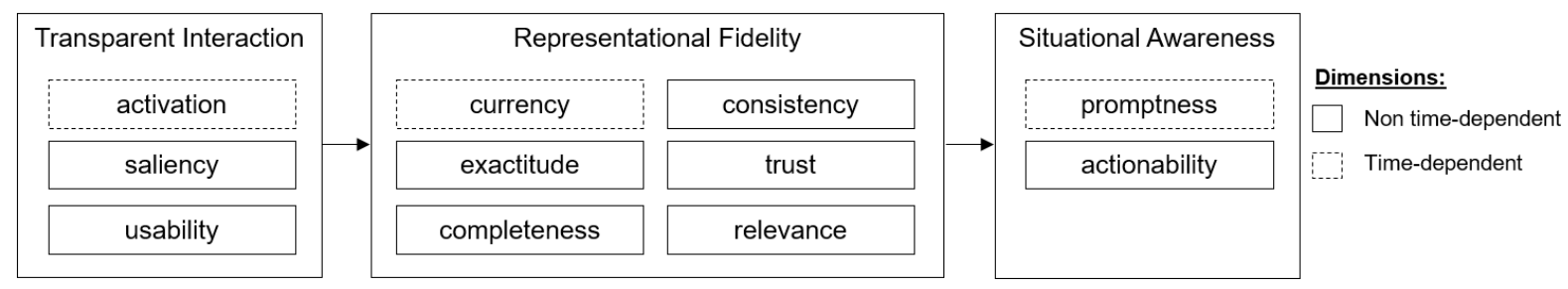

Figure 10. Theoretical model depicting levels and dimensions of use from Fischer-Preßler et al. (2020, p. 12)

The paper's contextualization of EUT can serve as a kernel theory (Walls et al. 1992, p. 42) for future EWS design research. While theory-driven discussion of how to design EWS is crucial for evaluating existing systems, the study found only one theory-driven discussion of EWS design (Kotthaus et al. 2016). The EUT perspective entails that EWS should be concerned primarily with faithful representations of a threat. While authorities, however, may not necessarily embrace fidelity as a design principle, our study stresses the importance of faithful representations in different emergencies.

Finally, with respect to effective use of EWS, the study surfaces a symbolic and substantive function of effective use (Fisher et al. 2002). This distinction refines the conceptualization of effective EWS use. When using EWS, there may be a tradeoff between satisfying the two functions. For instance, frequent warnings show that authorities are vigilant (i.e., symbolic function), but some of these warnings may not be about an immediate threat. If the intended EWS use concentrates on fulfilling a substantive function, it is needless to "prove" to the users ongoing vigilance when there is no real emergency. Hence, authorities need to understand the symbolic/substantive expectations of the end users to foster adoption and continued use of warning apps. This research contributes effective use dimensions that researchers can apply to study both functions of effective use. 


\section{Paper VIII: Understanding Failures of Emergency Warning Systems: A Repre- sentation Perspective}

Paper VIII investigates failures of public warning systems (EWS) from a representation perspective.

Motivation and Goal. Using digital platforms for emergency communication is a strategic and critical asset for public authorities (Tan et al. 2017). In particular, EWS enable multi-channel dispatching of emergency alerts to the population through different channels such as radio, TV, sirens, SMS, and warning apps. Public authorities and emergency management organizations, however, struggle to use them effectively (Fischer-Preßler et al. 2020). Hence, this paper aims to understand the failures of public EWS. It is important to note that EWS use involves multiple interdependent actors at different levels and their efforts to use the system effectively to warn an affected population. Hence, understanding the nature of an EWS involves all of its parts and their interactions (Strong and Volkoff 2010). The paper draws on RT (Wand and Weber 1995) to identify relevant levels of abstraction-that is, the latent, deep, surface, and physical structures-to investigate impediments to effective EWS use.

Findings. The study was conducted to understand failures of public EWS. Table 16 summarizes the seven types of impediments that affect different EWS structures. Impediments in the latent structure are network dependencies and role misfits associated with the EWS. Physical structure impediments, in contrast, are those that arise when the technical infrastructure fails or causes delays. Surfaces structure impediments arise because of an ineffective user interface (Strong and Volkoff 2010). Impediments related to the deep structure arise when the data do not faithfully represent the event in the EWS. Finally, the study identified the environmental structure to capture the EWS artifact fully and to capture event-related stressors and undesired reactions. Since these occur outside the EWS but fundamentally shape how the EWS is used, the environmental structure is important for the effective use of the EWS. In addition to the impediments, this paper contributes to recent efforts to understand effective use from an RT perspective (Burton-Jones and Grange 2013) and responds to the call to apply RT to new contexts (Burton-Jones and Volkoff 2017).

The study is also of practical relevance: Articulating the EWS-specific impediments and breaking down the problems that lead to EWS failures provide practitioners with a framework for diagnosing (in)effective use. In particular, practitioners can analyze EWS impediments and translate that analysis into actionable responses for EWS improvement.

\begin{tabular}{|l|l|l|}
$\begin{array}{l}\text { System } \\
\text { structures }\end{array}$ & Impediments \\
$\begin{array}{l}\text { Environ- } \\
\text { mental }\end{array}$ & $\begin{array}{l}\text { Event-related } \\
\text { stressors }\end{array}$ & $\begin{array}{l}\text { Arise when the emergency event's environment and characteristics } \\
\text { (e.g., unknown nature, scope, location, time) reduce effective EWS } \\
\text { use }\end{array}$ \\
\cline { 2 - 3 } & $\begin{array}{l}\text { Undesirable } \\
\text { reactions }\end{array}$ & $\begin{array}{l}\text { Arise when EWS prompt undesirable reactions from recipients. These } \\
\text { include both non-compliance and dangerous reactions (e.g., people } \\
\text { approaching the emergency area, panic) }\end{array}$ \\
\hline Latent & Network issues & $\begin{array}{l}\text { Arise when the network of individual and organizational dependen- } \\
\text { cies hinders effective use. These may result from ineffective collabo- } \\
\text { ration among responsible actors, which manifests in higher idle } \\
\text { times, inconsistencies, bottlenecks, and data quality issues }\end{array}$ \\
\cline { 2 - 3 } & Role misfits & $\begin{array}{l}\text { Arise when the roles defined by the EWS are mismatched with real- } \\
\text { world roles and competencies (e.g., skills, control, knowledge) }\end{array}$ \\
\hline
\end{tabular}




\begin{tabular}{|l|l|l|}
\hline Physical & $\begin{array}{l}\text { Infrastructure } \\
\text { failure }\end{array}$ & $\begin{array}{l}\text { Arise when the technical infrastructure of the EWS hampers the dis- } \\
\text { patch of warning messages or diminishes their effectiveness; exam- } \\
\text { ples include the physical structure failing, causing delays and deterio- } \\
\text { rating data quality }\end{array}$ \\
\hline Surface & $\begin{array}{l}\text { Ineffective } \\
\text { user interface }\end{array}$ & $\begin{array}{l}\text { Arise when the interface used to record representations in the deep } \\
\text { structure misguides users. Ineffective interface design entails usabil- } \\
\text { ity issues, including designs that do not promote accuracy, con- } \\
\text { sistency, completeness, and timeliness in warning messages }\end{array}$ \\
\hline Deep & $\begin{array}{l}\text { Data impedi- } \\
\text { ments }\end{array}$ & $\begin{array}{l}\text { Arise when data structures, meta-data, and stored representations of } \\
\text { the warning objects do not faithfully represent real-world domains } \\
\text { (e.g., events, activities, roles) because the digital representations are } \\
\text { incomplete, inconsistent, untimely, or not current }\end{array}$ \\
\hline
\end{tabular}

Table 16. Overview of system structures and related impediment types

\section{Paper IX: Applied Ethics and Digital Information Privacy: Informing the Design of Covid-19 Contact Tracing Apps}

Paper IX investigates principles for the design of Covid-19 tracing apps and discusses initial conditions necessary or sufficient for the design of contact tracing apps that protect user information privacy.

Motivation and Goal. To counteract the further spread of Covid-19 and prevent the loss of human lives and sustained economic damage, authorities began to provide mobile contact tracing apps to trace infections and provide health advice to users. Contact tracing apps are, however, only effective if a sufficient number of people use them. Concerns about data protection in these apps could lower people's intention to use them (Fischer et al. 2019). Therefore, it is crucial that apps be designed in accordance with socially accepted privacy standards and employ appropriate measures to protect user information privacy. This paper looks in particular at the tension between large-scale collection and recombination of personal information and user information privacy.

Findings. The paper identifies an understanding of information privacy from current Covid19 contact tracing apps used in five liberal democracies. It analyzes the design and other principles applied to apps to protect user information privacy. The paper explains how these principles can balance the fundamental tradeoff between restricted access and use of personal information and the need to gather and process that information for pandemic containment. Based on that, the paper articulates necessary and sufficient conditions for the design of such apps to account for user information privacy. These insights support technical design decisions in empirically observed and theoretically valid principles, integrate latent information privacy conceptualizations evident from existing artifacts and theory, and provide tentative guidelines for evaluating applied information privacy conceptualizations.

Different countries will continue to pursue different approaches to the development of tracing apps. To raise awareness of alternative design approaches and justifications, the paper outlines current design choices. The study is also relevant for other digital ICT used in different social and economic settings that also enable large-scale data collection and public surveillance. Fitness apps, for instance, enable the gathering of personal fitness and health data. Dating apps are another example; they collect data to match users based on their locations and many other more individual criteria. Restaurants and hotels manage reservations digitally; often, those data remain poorly protected in cloud services, and there is little awareness of information privacy issues. Hence, knowledge of existing conceptualizations of information privacy and how to protect users' information privacy is crucial. 


\subsection{Research Question III}

The two articles summarized in this section contribute to the third research question: How can responder organizations leverage public digital platforms effectively? Paper X explores how responder organizations use social media to leverage online social capital. Paper XI investigates how responder organizations govern social media use at different organizational levels to raise online social capital.

\section{Paper X: Leveraging Online Social Capital: How the German Red Cross Uses So- cial Networking Sites}

Paper X focuses on how the German Red Cross (GRC) uses affordances of social network sites (SNS) to build social capital.

Motivation and Goal. Emergency responder organizations such as the GRC use SNS to inform the public about what is needed to support their activities, create awareness of their goals, and make their achievements known. These online activities are investments in a metaphorical stock of social resources often referred to as online social capital (Ellison et al. 2007). Social capital increases the capabilities of organizations to access resources from more distant social structures (Burt 1995). The primary objective of this paper is to investigate how SNS use creates value for a responder organization's operational activities.

Findings. The study identifies social capital raising options in platform structures, online relationships, and cognitive (content-related) elements. Predefined platform structures, for instance, define the digital space and where and with whom online social capital circulates and may be stored, such as in closed groups or profiles. Platform affordances do not, however, automatically entail organizational use in predefined structures. For instance, some public social media profiles instead serve an internal "bulletin board" or "newsletter" dedicated to an organization's members rather than as a stakeholder community incubator and, hence, function more as enterprise social platforms. Defining the overarching goal of an organization's social media use specifies the aim of building and maintaining specific online relationships. First, profiles are used as an organizational intranet to keep volunteers as well as staff up to date to overcome structural holes via SNS (Burt 1995) that could not be filled by interpersonal offline communication. Second, SNS are used to inform the public about their activities to form an organizational image and promote events. Finally, the shared cognitive elements of social capital created entry points for building organizational online social capital. In particular, providing narratives from the organization's perspective on SNS enables fostering a common understanding, culture, and collective visions within the community. Regarding community engagement, the study highlights that responder organizations use certain SNS affordances such as hashtags, links, or likes quite differently, and that there is potential for improvement in using these affordances more effectively.

\section{Paper XI: Social Media Governance and Social Capital Raising: Strategies for Hu- manitarian Non-Governmental Organizations}

Paper XI investigates governance of social media use by response organizations on different organizational levels.

Motivation and Goal. Depending on resources such as volunteers, knowledge, and monetary support, responder organizations draw on their networks of individuals, organizations, and governments to achieve their objectives. As web-based public social media have become pervasive, responder organizations have increasingly embraced their potential value for managing humanitarian aid activities (Zheng and Yu 2016). However, strategic social media use re- 
quires resources such as funds that can be dedicated to creating digital content, favorable organizational structures, and trained employees. In addition, responder organizations often act at different levels (e.g., regional, national) and thus involve different networks of collaborators with differing aims. Regional organizational units act within certain geographical boundaries that create regional identities. National units act at a level that often reaches a broader network of civil society. While researchers agree that social media offer humanitarian non-governmental organizations (HNGOs) a low-cost way to strengthen their networks and build social capital (Lovejoy and Saxton 2012), scholarship has yet to provide guiding principles regarding how social media strategies for HNGOs at multiple levels translate to the creation and maintenance of social capital. This study analyzes social media governance at different organizational levels through the eyes of response organizations social media experts.

Findings. This study investigates HNGO social media governance and strategies to foster building organizational online social capital. Through interviews with experts at the regional, intermediate, and national levels of five HNGOs, the study provides insights into how social media are used at different organizational levels to build and maintain a network of collaborators, and thus, foster relationships with volunteers, cooperation within and among organizations, and collective action. The study identifies eight focus areas of organizational online social capital. In the structural dimension, network retention, network growth, and resource pooling facilitate organizational online social capital. In the relational dimension, we identify the establishment of trust, community management, and brokerage. The cognitive dimension of online social capital can be addressed by emotional empathy and building a common identity. For each focus area, the study identifies emerging tensions between organizational levels and derives strategies social media experts and organizations can implement to leverage these key drivers to cultivate online social capital. In addition, while regional units focus on regional community management by maintaining smaller communities and more homogenous networks, the focus shifts to maintaining larger and/or more heterogeneous communities at the intermediate and national levels. Beyond officially managed social media groups, the study identifies unofficial, topic-related, and self-governed groups created by interested members. From that analysis, the study derives implications for managing social media within HNGOs based on this shift of focus. 


\subsection{Research Question IV}

The articles summarized here contribute to answering the fourth research question: How do digital platforms help the public respond to a disaster? Paper XII develops a research model to understand why people use social media in the aftermath of terrorist attacks; paper XIII studies the use of social media for collective sense-making after the Berlin terrorist attack in 2016; and paper XIV develops a research model that explains factors that lead people to self-organize on social media after a disaster.

\section{Paper XII: Usage Behavior of Social Network Sites in the Aftermath of Terrorist Attacks}

Paper XII is a conceptual paper about factors that drive peoples' social media use after a disaster event, based on terror management theory (TMT) and uses and gratifications theory (U\&G).

Motivation and Goal. Due to the widespread use of SNS, disaster-related information no longer comes exclusively from a central, official responder agency, but also from people who use SNS (Heverin and Zach 2012; Ling et al. 2015). In crisis events, people use SNS to access news on the consequences of disasters, share opinions and moral support, connect with other users quickly, and receive information about the wellbeing of family and friends (Kaewkitipong et al. 2016). Only a few studies to date have addressed the issue of SNS use by the general public in the wake of a terrorist attack. The purpose of this research-in-progress paper is to examine how increased perceptions of mortality salience due to terrorist attacks influence SNS usage intentions with respect to information seeking and social communication.

Findings. TMT suggests that humans collectively negotiate their worldviews through their social environment. According to TMT, terrorist attacks remind people of their vulnerability and mortality, and thus threaten their cultural worldviews, which typically protect them from this awareness (Dunkel 2002; Pyszczynski et al. 2003). Hence, when people are confronted with reminders of mortality, they employ psychological defenses aimed at reducing anxiety by embracing their worldviews and enhancing their self-esteem (Hayes et al. 2010). U\&G proposes that psychological needs and goal-directed behavior induce people to use certain media for need satisfaction (Katz et al. 1973/1974). Combining the insights of both theories in the context of terrorism, the paper argues that people need to reestablish a stable conception of reality and meaning in the aftermath of a terrorist attack. Hence, people may use SNS to overcome the threat of terrorist attacks and reestablish their worldviews. The Figure 11 model depicts the process.

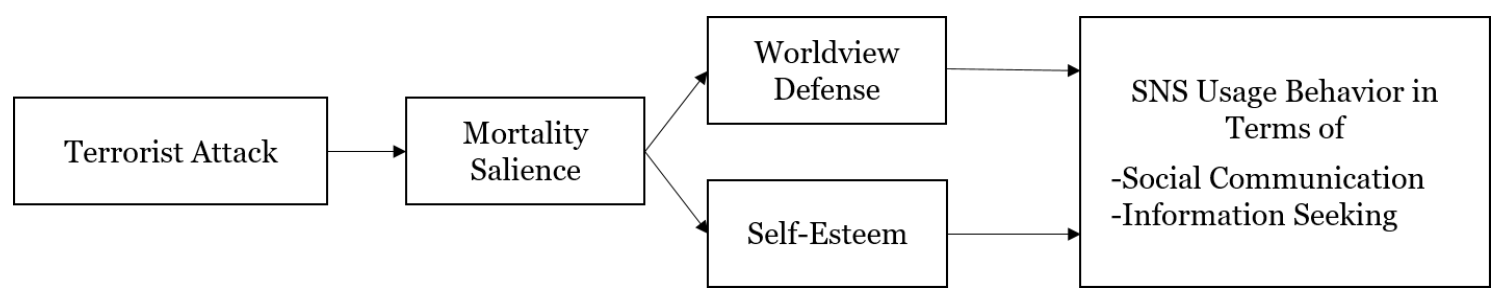

Figure 11. Research model from Fischer et al. (2016, p. 5)

The paper contributes to the understanding of people's use behavior of SNS in the aftermath of terrorist attacks. It brings together two complementary theories, TMT and U\&G, to hypothesize why individuals use SNS for social communication and information seeking in the wake of terrorist attacks. The paper's focus is on the individual psychological motivations that precede 
actual SNS usage. Hence, using TMT together with U\&G, the paper provides a meaningful explanation of the emergence of psychological needs in the aftermath of terrorist attacks and the implications of these needs for SNS use.

\section{Paper XIII: Collective Sense-making in Times of Crisis: Connecting Terror Man- agement Theory with Twitter User Reactions to the Berlin Terrorist Attack}

The purpose of paper XIII is to identify common terror management reactions and their timely patterns on social networking sites (SNS) at the collective level in the aftermath of the 2016 Berlin Christmas market terrorist attack.

Motivation and Goal. SNS are particularly helpful in facilitating sense-making during disasters due to their affordances, such as real-time communication, search mechanisms, and ubiquitous access to users with internet connections. In the case of terrorist attacks, terror management theory complements the sense-making perspective by explaining why people who perceive an existential threat take certain social actions and uphold a particular set of values and beliefs to reestablish their sense. Terrorist attacks are "natural" death reminders and can be seen further as attacks against one's cultural worldview (e.g., basic Western beliefs and values such as democracy (Pyszcynski et al. 2003). People who have been threatened existentially by reminders of mortality try to buffer their death anxiety by maintaining their self-esteem, holding up their cultural worldviews, and defending their own "in" groups (Greenberg et al. 1986). Although many studies have investigated terror management at the individual level, fewer data are available about the reaction to terrorism at the collective level. This paper, therefore, investigates collective SNS user reactions in the aftermath of a terrorist attack.

Findings. By complementing sense-making with TMT, the paper explains why it is so important for people to seek and share information and verify feelings, behavior, and opinions. The results indicate that people used Twitter to make sense of the events and as part of typical reactions in TMT, that is, to validate their worldviews and maintain their self-esteem. In particular, the study identifies togetherness, the search for meaning and sense, xenophobia, decreased tolerance and calls for tolerance, calls for political change, stands against right-wing propaganda, sympathy and prayers, community condolences, gratitude for helpers, avoidance of rumor-spreading, criticism of reporting, and operational updates as topics particularly relevant for Twitter users. From a TMT perspective, these reactions indicate that some Twitter users seemed to reestablish their worldviews and self-esteem collectively by connecting with others and sharing opinions, sympathy, and information. In addition, these reactions serve as anxiety-buffering, worldview-defense, and self-esteem-bolstering functions of terror management strategies.

The results suggest further that SNS help complement the specific communication needs people have in the days after a terrorist attack, and that this is also affected by timely patterns. Information sharing through Twitter, as well as pro-social behavior such as the search for meaning and sense, sympathy and prayers, togetherness, and calls for tolerance, dominated the first two days after the terrorist attack; these are typical sense-making and TMT reactions. However, after those first two days, when the perpetrator's motive had become clear and the initial shock had subsided, we find fewer emotion-related and more opinion-related tweets in the topic proportions. In line with evidence from TMT research, tweets indicate a tendency to support those who share one's political orientation or religion while rejecting people with different views. 


\section{Paper XIV: Social Networking Sites in the Aftermath of a Crisis - The Enabling Role for Self-organization}

Paper XIV investigates the motives that influence people's different SNS use behavior for the goal of self-organization, as well as the underlying mechanisms of this behavior.

Motivation and Goal. With the growing ubiquity, accessibility, and efficiency of information exchange, social media are playing an increasingly critical role in response actions following disaster events. SNS empower people at the scene of a disaster-equipped with digital devices-to provide breaking news about the events in a timely manner and organize themselves via these platforms. To provide an analytical framework (see Figure 12) for this behavior and understand it in greater detail, this paper complements the uses and gratification (U\&G) perspective with the literature on crisis communication and crisis informatics.

Findings. This paper explores the role of specific needs that may arise during crisis circumstances and their influence on people's use of SNS for information seeking, information sharing, and commenting with the goal of self-organization during crisis events. By considering crisis situations as the context, the paper explains why SNS use under highly dynamic conditions is driven by factors other than those found in more routine situations. Hence, it adds to the current theoretical explanation of SNS use behavior and provides a deeper theoretical understanding of the needs that drive SNS use. This paper also provides theoretical insights by conceptualizing the mechanisms underlying people's SNS usage for self-organization in the aftermath of a crisis. The framework furthermore provides a starting point for conceptualizing selforganization via SNS during crisis situations. Figure 12 depicts the framework developed.

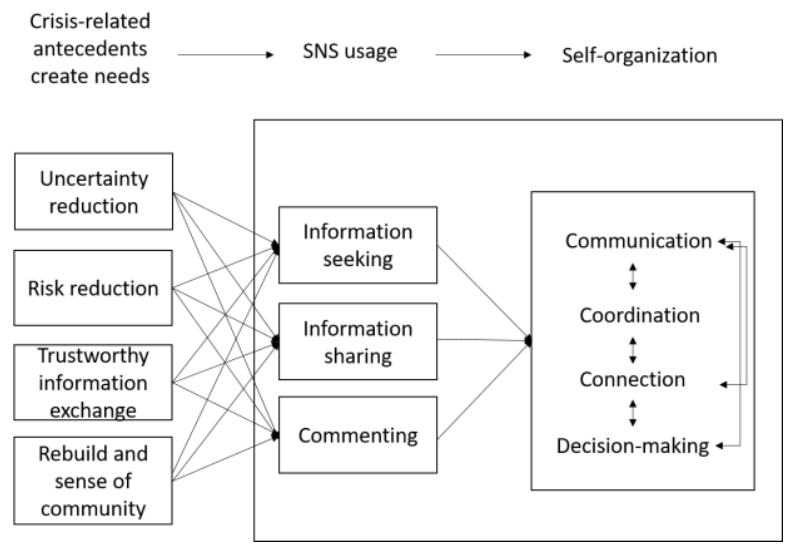

Figure 12. Model of social media-enabled sense-making from Fischer (2018, p. 4)

The model also has practical implications for public authorities and responder organizations that must deal with inquiries and provide information through SNS during crises. As public authorities and responder organizations begin to realize the potential of internet-facilitated citizen coproduction of information during crises, it is increasingly important that scholars and practitioners have an analytical framework for examining such behaviors to evaluate their impact properly and identify emerging best practices. Thus, understanding the factors that influence SNS use for self-organization can help crisis responders connect with people more effectively. 


\section{Limitations and Future Research Directions}

As pointed out in the literature review, EMIS cover a variety of different tools used in emergency management. This thesis studies: EMIS used to coordinate and communicate within organizations; mobile-enabled warning systems used for emergency communication from organizations to the public; and social media that leverage public involvement in disaster response activities.

Regarding EMIS used for intra- and inter-organizational disaster management, the thesis provides a broad overview of EMIS for emergency management, identifying research gaps rather than delving into design principles of a particular technology (Papers I and II). In providing an overview, the papers encourage future research to examine current research gaps in terms of proprietary EMIS in use in greater detail to push forward the research agenda on how to use these systems effectively.

With respect to mobile-enabled warning systems (papers IV-IX), the thesis provides empirical research on public use intention of mobile-warning systems and how responder organizations can use these systems more effectively. Most of the empirical papers are based on German samples and case studies and thus the results cannot necessarily be considered representative of other countries that may have different cultural perceptions, be using different EMIS, or have different organizational structures. While there is no specific reason to doubt the applicability to other regions or countries of the general trends and notions that emerge from the studies, they need to be tested in future research.

Regarding social media use, the thesis provides insights into forms of collective behavior. Papers XII and XIII specifically study sense-making after a terrorist attack from a terror management perspective; paper XIV studies the role of social media for self-organization in the aftermath of a disaster. While these papers consider public use of social media, they do not investigate how responder organizations with top-down organizational structures handle community-based self-organization via social media during disaster response. Rather, papers X and XI examine responder organizations' social media governance and use within the organization for public communication, without informing strategies for inclusion of grassroots public participation in professional response activities. Practical and theoretical strategies to accomplish that are still missing. Future research could investigate and develop dynamic strategies adaptable to disaster situations to inform practitioners and effectively involve digital volunteers.

Furthermore, the methods applied in this thesis are limited. First, the literature reviews (papers I and II) focus on a subset of relevant studies but are restricted to highly relevant ones without capturing all possible outlets. For instance, we acknowledge that there are conferences that focus on emergency management, such as the Conference on Information Systems for Crisis Response and Management (ISCRAM), that were not included in the literature searches; instead, the reviews focused on journals and conferences that are relevant and highly ranked in a quality list. The scope of the literature in the reviews is, hence, representative of the papers' particular focus, but not comprehensive. Future research could aim for comprehensive reviews in this research area.

Second, papers in this thesis apply both quantitative and qualitative analysis. As discussed earlier, both methodological approaches have their merits in terms of answering particular research questions, as well as limitations. These limitations are addressed in the papers by incorporating validity and reliability measures proposed by the literature in the respective research streams; detailed in the methodological section of this thesis.

Studying EMIS during disaster response is a highly context-dependent and complex endeavor due to the dynamic, uncertain, and sudden nature of many disasters. Data collection during such events is almost impossible, as most of the events are unpredictable, and undertaking data collection during them is ethically questionable (at best) given that lives are at stake. That, 
however, makes it even more important to understand EMIS use for disaster management and use multiple methodological approaches to achieve as comprehensive an understanding as possible. Hence, the papers apply several methods to answer different research questions.

\section{Conclusion}

Relevant information, available in a timely manner, is crucial in a disaster. It helps emergency responders minimize damage and save lives. EMIS are basic enablers of that information and its accessibility. Despite advances in EMIS being used, and in EMIS research, efficient communication during a disaster response is difficult to achieve because it must be communicated upand downstream, within organizations and between organizations, and to the public-all as a highly dynamic situation is unfolding.

This thesis uncovers the use of a variety of EMIS applied in inter- and intra-organizational emergency management, for public emergency communication and disaster-related social media use. It aims to foster an understanding of how EMIS enable intra- and inter-organizational emergency management as well as the impediments to leveraging these collaboration and communication tools effectively. Furthermore, the thesis sheds light on the effective use of mobile warning systems to communicate emergencies to the affected public. Finally, the thesis provides insights into public use of social media in response to disasters, social media that are increasingly leveraged, and that are changing disaster management. 


\section{References}

Abedin, B., and Babar, A. 2018. "Institutional vs. Non-institutional use of Social Media during Emergency Response: A Case of Twitter in 2014 Australian Bush Fire," Information Systems Frontiers (20:4), pp. 729-740 (doi: 10.1007/s10796-017-9789-4).

Ada, S., Sharman, R., Han, W., and Brennan, J. A. 2016. "Factors impacting the intention to use emergency notification services in Campus emergencies: An empirical investigation," IEEE Transactions on Professional Communication (59:2), pp. 89-109.

Aedo, I., Díaz, P., Carroll, J. M., Convertino, G., and Rosson, M. B. 2010. "End-User Oriented Strategies to Facilitate Multi-Organizational Adoption of Emergency Management Information Systems," Information Processing \& Management (46:1), pp. 11-21 (doi: 10.1016/j.ipm.2009.07.002).

Ahmed, A., and Sinnappan, S. 2013. "The Role of Social Media during Queensland Floods: An Empirical Investigation on the Existence of Multiple Communities of Practice (MCoPs)," Pacific Asia Journal of the Association for Information Systems (5:2), pp. 1-22.

Ai, F., Comfort, L. K., Dong, Y., and Znati, T. 2016. "A Dynamic Decision Support System Based on Geographical Information and Mobile Social Networks: A Model for Tsunami Risk Mitigation in Padang, Indonesia," Safety Science (90:3), pp. 62-74 (doi: 10.1016/j.ssci.2015.09.022).

Aktaş, E., Özaydın, Ö., Bozkaya, B., Ülengin, F., and Önsel, Ş. 2013. "Optimizing Fire Station Locations for the Istanbul Metropolitan Municipality," Interfaces (43:3), pp. 240-255 (doi: 10.1287/inte.1120.0671).

Alexander, D. E. 2014. "Social Media in Disaster Risk Reduction and Crisis Management," Science and Engineering Ethics (20:3), pp. 717-733 (doi: 10.1007/s11948-013-9502-z).

Allen, D. K., Karanasios, S., and Norman, A. 2014. "Information sharing and interoperability: the case of major incident management," European Journal of Information Systems (23:4), pp. 418-432 (doi: 10.1057/ejis.2013.8).

Altay, N., and Green, W. G. 2006. “OR/MS research in disaster operations management," European Journal of Operational Research (175:1), pp. 475-493 (doi: 10.1016/j.ejor.2005.05.016).

Andrews, C., Fichet, E., Ding, Y., Spiro, E. S., and Starbird, K. 2016. "Keeping Up with the TweetDashians," in Proceedings of the $19^{\text {th }}$ ACM Conference on Computer-Supported Cooperative Work \& Social Computing, D. Gergle, M. R. Morris, P. Bjørn and J. Konstan (eds.), San Francisco California USA. 2016, New York, NY, USA: ACM, pp. 452-465.

Anjana, N. S., Amarnath, A., and Harindranathan Nair, M. V. 2018. "Toxic hazards of ammonia release and population vulnerability assessment using geographical information system," Journal of Environmental Management (210), pp. 201-209 (doi: 10.1016/j.jenvman.2018.01.021).

Ansell, C., Boin, A., and Keller, A. 2010. "Managing transboundary crises: Identifying the building blocks of an effective response system," Journal of Contingencies and Crisis Management (18:4), pp. 195-207 (doi: 10.1111/j.1468-5973.2010.00620.x).

Arif, A., Robinson, J. J., Stanek, S. A., Fichet, E. S., Townsend, P., Worku, Z., and Starbird, K. 2017. "A Closer Look at the Self-Correcting Crowd," in Proceedings of the 2017 ACM Conference on Computer Supported Cooperative Work and Social Computing, C. P. Lee, S. Poltrock, L. Barkhuus, M. Borges and W. Kellogg (eds.), Portland Oregon USA. 250220170103 2017, New York, NY, USA: ACM, pp. 155-168.

Aros, S. K., and Gibbons, D. E. 2018. "Exploring Communication Media Options in an Inter-Organizational Disaster Response Coordination Network Using Agent-Based Simulation," 
European Journal of Operational Research (269:2), pp. 451-465 (doi: 10.1016/j.ejor.2018.02.013).

Aspers, P., and Corte, U. 2019. "What is Qualitative in Qualitative Research," Qualitative Sociology (42:2), pp. 139-160 (doi: 10.1007/s11133-019-9413-7).

Bagozzi, R. P. 1979. "The role of measurement in theory construction and hypothesis testing," in Conceptional and Theoretical Developments in Marketing, 0. C. Ferrel, S. W. Brown and C. W. Lamb (eds.), Chicago: American Marketing Association, pp. 15-33.

Barney, J. B. 1991. “Firm resources and sustained competitive advantage," Journal of Management (17), pp. 99-120.

Bergstrand, F., and Stenmark, D. 2016. "Leveraging Bystander Reports in Emergency Response Work: Framing Emergency Managers Social Media Use," in 49th Hawaii International Conference on System Sciences.

Bertelsen, O. W., and Bødker, S. 2003. "Activity Theory," in HCI Models, Theories, and Frameworks, Toward an Interdisciplinary Science, J. M. Caroll (ed.), pp. 291-324.

Bevilacqua, M., Ciarapica, F. E., and Paciarotti, C. 2012. "Business Process Reengineering of Emergency Management Procedures: A Case Study," Safety Science (50:5), pp. 1368-1376 (doi: 10.1016/j.ssci.2012.01.002).

Bharosa, N., Lee, J., and Janssen, M. 2010. "Challenges and obstacles in sharing and coordinating information during multi-agency disaster response: Propositions from field exercises," Information Systems Frontiers (12:1), pp. 49-65 (doi: 10.1007/s10796-009-9174-z).

Blei, D. M. 2012. "Probabilistic topic models," Communications of the ACM (55:4), pp. 77-84 (doi: 10.1145/2133806.2133826).

Boin, A., Hart, P. 't, Stern, E., and Sundelius, B. 2005. The Politics of Crisis Management, Cambridge: Cambridge University Press.

Boin, A., and t' Hard, P. 2006. "The crisis approach," in Handbook of Disaster Research, H. Rodríguez, E. L. Quarantelli and R. R. Dynes (eds.), Newark, Delaware: Springer, pp. 4254.

Bolloju, N., Khalifa, M., and Turban, E. 2002. "Integrating Knowledge Management into Enterprise Environments for the Next Generation Decision Support," Decision Support Systems (33:2), pp. 163-176 (doi: 10.1016/S0167-9236(01)00142-7).

Bonaretti, D., and Fischer-Preßler, D. 2021. "The problem with SMS campus warning systems: An evaluation based on recipients' spatial awareness," International Journal of Disaster Risk Reduction (54:4), p. 102031 (doi: 10.1016/j.ijdrr.2020.102031).

Bonaretti, D., and Piccoli, G. 2018. "Effective use of information systems in emergency management: A representation theory perspective," International Conference on Information Systems, pp. 1-17.

Bonazountas, M., Kallidromitou, D., Kassomenos, P., and Passas, N. 2007. "A Decision Support System for Managing Forest Fire Casualties," Journal of Environmental Management (84:4), pp. 412-418 (doi: 10.1016/j.jenvman.2006.06.016).

Botterell, A., and Addams-Moring, R. 2007. "Public warning in the networked age: Open standards to the rescue?" Communications of the ACM (50:3), pp. 59-60.

Brengarth, L. B., and Mujkic, E. 2016. "WEB 2.0: How Social Media Applications Leverage Nonprofit Responses during a Wildfire Crisis," Computers in Human Behavior (54:3), pp. 589596 (doi: 10.1016/j.chb.2015.07.010).

Brunacini, A. V. 2002. Fire Command: The Essentials of IMS, Quincy, MA: National Fire Protection Association.

Bryman, A. 1988. Quantity and Quality in Social Research, London and New York: Routlege.

Bryman, A. 2016. Social Research Methods, Oxford, United Kingdom: Oxford University Press. 
Buchanan, D. A., and Denyer, D. 2013. "Researching Tomorrow's Crisis: Methodological Innovations and Wider Implications," International Journal of Management Reviews (15:2), pp. 205-224 (doi: 10.1111/ijmr.12002).

Burt, R. S. 1995. Structural Holes: The Social Structure of Competition, Cambridge: Harvard University Press.

Burton-Jones, A., and Grange, C. 2013. "From use to effective use: A representation theory perspective," Information Systems Research (24:3), pp. 632-658 (doi: 10.1287/isre.1120.0444).

Burton-Jones, A., McLean, E. R., and Monod, E. 2015. "Theoretical perspectives in IS research: from variance and process to conceptual latitude and conceptual fit," European Journal of Information Systems (24:6), pp. 664-679 (doi: 10.1057/ejis.2014.31).

Burton-Jones, A., and Volkoff, 0. 2017. "How can we develop contextualized theories of effective use? A demonstration in the context of community-care electronic health records," Information Systems Research (28:3), pp. 468-489.

Butts, C. T., Petrescu-Prahova, M., and Cross, R. B. 2007. "Responder Communication Networks in the World Trade Center Disaster: Implications for Modeling of Communication Within Emergency Settings," The Journal of Mathematical Sociology (31:2), pp. 121-147 (doi: 10.1080/00222500601188056).

Byrne, B. M. 2004. "Testing for multigroup invariance using AMOS graphics: A road less traveled," Structural Equation Modeling: A Multidisciplinary Journal (11:2), pp. 272-300 (doi: 10.1207/s15328007sem1102_8).

Canevari-Luzardo, L., Bastide, J., Choutet, I., and Liverman, D. 2017. "Using partial participatory GIS in vulnerability and disaster risk reduction in Grenada," Climate and Development (9:2), pp. 95-109 (doi: 10.1080/17565529.2015.1067593).

Carr, L. J. 1932. "Disaster and the sequence-pattern concept of social change," American Journal of Sociology (38), pp. 207-218.

Carver, L., and Turoff, M. 2007. "Human-Computer Interaction: The Human and Computers as a Team in Emergency Management Information Systems," Communications of the ACM (50:3), pp. 33-38.

Cavanagh, S. 1997. "Content analysis: concepts, methods and applications," Nurse researcher (4:3), pp. 5-16 (doi: 10.7748/nr.4.3.5.s2).

Çetinkaya, C., Özceylan, E., Erbaș, M., and Kabak, M. 2016. “GIS-based fuzzy MCDA approach for siting refugee camp: A case study for southeastern Turkey," International Journal of Disaster Risk Reduction (18), pp. 218-231 (doi: 10.1016/j.ijdrr.2016.07.004).

Chang, M.-S., Tseng, Y.-L., and Chen, J.-W. 2007. "A scenario planning approach for the flood emergency logistics preparation problem under uncertainty," Transportation Research Part E: Logistics and Transportation Review (43:6), pp. 737-754 (doi: 10.1016/j.tre.2006.10.013).

Chen, F. F. 2007. "Sensitivity of goodness of fit indexes to lack of measurement invariance," Structural Equation Modeling: A Multidisciplinary Journal (14:3), pp. 464-504 (doi: 10.1080/10705510701301834).

Chen, R., Rao, H. R., Sharman, R., Upadhyaya, S. J., and Chakravarti, N. 2008a. "Emergency response information system interoperability: Development of chemical incident response data model," Journal of the Association for Information Systems (9:3/4), pp. 200-230.

Chen, R., Rao, H. R., Sharman, R., Upadhyaya, S. J., and Kim, J. 2010. "An Empirical Examination of IT-Enabled Emergency Response: The Cases of Hurricane Katrina and Hurricane Rita," Communications of the Association for Information Systems (26) (doi: 10.17705/1CAIS.02608). 
Chen, R., Sharman, R., Chakravarti, N., Rao, H. R., and Upadhyaya, S. 2008b. "Emergency Response Information System Interoperability: Development of Chemical Incident Response Data Model," Journal of the Association for Information Systems (9:3), pp. 200-230 (doi: 10.17705/1jais.00153).

Chen, R., Sharman, R., Rao, H. R., and Upadhyaya, S. J. 2013. "Data Model Development for Fire Related Extreme Events: An Activity Theory Approach," MIS Quarterly (37:1), pp. 125147.

Chou, C., Zahedi, F. M., and Zhao, H. 2014. "Ontology-based evaluation of natural disaster management websites: A Multistakeholder perspective," MIS Quarterly (38:4), pp. 997-1016.

Coleman, J. S. 1990. Foundations of Social Theory, Cambridge, MA: Harvard University Press.

Coleman, L. 2006. "Frequency of Man-Made Disasters in the 20 $0^{\text {th }}$ Century," Journal of Contingencies and Crisis Management (14:1), pp. 3-11 (doi: 10.1111/j.14685973.2006.00476.x).

Coombs, W. T. 2007. Ongoing crisis communication: Planning, managing, and responding, Thousand Oaks, CA: Sage.

Coombs, W. T. 2010. "Parameters for Crisis Communication," in The Handbook of Crisis Communication, W. T. Coombs and S. J. Holladay (eds.), Oxford, UK: Wiley-Blackwell, pp. 1753.

Coombs, W. T., and Holladay, S. J. (eds.) 2010. The Handbook of Crisis Communication, Oxford, UK: Wiley-Blackwell.

CRED 2018. Natural disasters 2018: An opportunity to prepare. https://www.cred.be/sites/default/files/CREDNaturalDisaster2018.pdf. Accessed 29 July 2019.

Currion, P., Silva, C. d., and van de Walle, B. 2007. "Open source software for disaster management," Communications of the ACM (50:3), pp. 61-65 (doi: 10.1145/1226736.1226768).

Daft, R. L., and Lengel, R. H. 1984. "Information richness: A new approach to managerial behavior and organizational design," Research in Organizational Behavior (6), pp. 191-233.

Davis, F. D. 1989. "Perceived usefulness, perceived ease of use, and user acceptance of information technology," MIS Quarterly (13:3), pp. 319-340.

Day, J. M., Junglas, I., and Silva, L. 2009. "Information Flow Impediments in Disaster Relief Supply Chains*," Journal of the Association for Information Systems (10:8), pp. 637-660.

Devadoss, P. R., Pan, S. L., and Singh, S. 2005. "Managing Knowledge Integration in a National Health-Care Crisis: Lessons Learned from Combating SARS in Singapore," IEEE transactions on information technology in biomedicine : a publication of the IEEE Engineering in Medicine and Biology Society (9:2), pp. 266-275 (doi: 10.1109/TITB.2005.847160).

Dorasamy, M., Raman, M., and Kaliannan, M. 2013. "Knowledge management systems in support of disasters management: A two decade review," Technological forecasting and social change (80:9), pp. 1834-1853 (doi: 10.1016/j.techfore.2012.12.008).

Dorasamy, M., Raman, M., and Kaliannan, M. 2017. "Integrated community emergency management and awareness system: A knowledge management system for disaster support," Technological forecasting and social change (121:4), pp. 139-167 (doi: 10.1016/j.techfore.2017.03.017).

Eismann, K., Fischer, D., Posegga, O., and Fischbach, K. 2018. "Using social network analysis to make sense of radio communication in emergency response," in Second International Workshop on Modeling, Analysis, and Management of Social Networks and Their Applications, Erlangen, Germany.

Eismann, K., Posegga, O., and Fischbach, K. 2016. "Collective behaviour, social media, and disasters: A systematic literature review," in Proceedings of the European Conference on Information Systems. 
Ellison, N. B., Steinfield, C., and Lampe, C. 2007. "The Benefits of Facebook "Friends:" Social Capital and College Students' Use of Online Social Network Sites," Journal of ComputerMediated Communication (12:4), pp. 1143-1168 (doi: 10.1111/j.10836101.2007.00367.x).

Elo, S., and Kyngäs, H. 2008. "The qualitative content analysis process," Journal of Advanced Nursing (62:1), pp. 107-115 (doi: 10.1111/j.1365-2648.2007.04569.x).

Endsley, M. R. 1995a. "Measurement of situation awareness in dynamic systems," Human Factors (37:1), pp. 65-84.

Endsley, M. R. 1995b. "Toward a theory of situation awareness in dynamic systems," Human Factors: The Journal of the Human Factors and Ergonomics Society (37:1), pp. 32-64 (doi: 10.1518/001872095779049543).

Endsley, M. R., Bolte, B., and Jones, D. 2003. Designing for Situation Awareness: An Appraoch to User-Centered Design, Boca Raton: Taylor \& Francis Group.

Engeström, Y. 1987. Learning by Expanding: An Activity-Theoretical Approach to Developmental Research, Helsinki: Orienta-Konsultit.

Erickson, F. 2011. "A history of qualitative inquiry in social and educational research," in The Sage handbook of qualitative research, N. K. Denzin and Y. S. Lincoln (eds.), Thousand Oaks, CA, London, UK, New Delhi, India: Sage Publications, pp. 43-59.

Eriksson, M. 2016. "Managing collective trauma on social media: the role of Twitter after the 2011 Norway attacks," Media, Culture \& Society (38:3), pp. 365-380 (doi: 10.1177/0163443715608259).

Eshghi, K., and Larson, R. C. 2008. "Disasters: Lessons from the past 105 years," Disaster Prevention and Management (17:1), pp. 62-82.

Espada, R. 2019. "Integrating information and communications technology (ICT) assets in assessing tropical cyclone risk in the Philippines," International Journal of Disaster Risk Reduction (39), p. 101141 (doi: 10.1016/j.ijdrr.2019.101141).

Fahad, M. G. R., Nazari, R., Bhavsar, P., Jalayer, M., and Karimi, M. 2019. "A decision-support framework for emergency evacuation planning during extreme storm events," Transportation Research Part D: Transport and Environment (77), pp. 589-605 (doi: 10.1016/j.trd.2019.09.024).

Fedorowicz, J., and Gogan, J. L. 2010. "Reinvention of interorganizational systems: A case analysis of the diffusion of a bio-terror surveillance system," Information Systems Frontiers (12:1), pp. 81-95 (doi: 10.1007/s10796-009-9167-y).

Fertier, A., Barthe-Delanoë, A.-M., Montarnal, A., Truptil, S., and Bénaben, F. 2020. "A new emergency decision support system: the automatic interpretation and contextualisation of events to model a crisis situation in real-time," Decision Support Systems (133:1), p. 113260 (doi: 10.1016/j.dss.2020.113260).

Fiesler, C., and Proferes, N. 2018. "“Participant" perceptions of Twitter research ethics," Social Media + Society (4:1), 205630511876336 (doi: 10.1177/2056305118763366).

Fischer, D. 2018. "Social networking sites in the aftermath of a crisis - The enabling role for selforganization," in Proceedings of the 51 ${ }^{\text {st }}$ Hawaii International Conference on System Sciences, pp. 83-92.

Fischer, D., Hattori-Putzke, J., and Fischbach, K. 2019. "Crisis warning apps: Investigating the factors influencing usage and compliance with recommendations for action"," in Hawai'i International Conference on System Science, Hawaii, USA.

Fischer, D., Posegga, O., and Fischbach, K. 2016. "Communication barriers in crisis management: A literature review," in Proceedings of the European Conference on Information Systems. 
Fischer, H. W. 2003. "The sociology of disaster: Definitions, research questions, \& measurements continuation of the discussion in a post-September 11 environment," International Journal of Mass Emergencies and Disasters (21:1), pp. 91-107.

Fischer-Preßler, D., Bonaretti, D., and Fischbach, K. 2021. "A Protection-Motivation Perspective to Explain Intention to Use and Continue to Use Mobile Warning Systems," Business \& Information Systems Engineering, 59(2).

Fischer-Preßler, D., Bonaretti, D., and Fischbach, K. 2020. "Effective use of mobile-enabled emergency warning systems," in Proceedings of the 28th European Conference on Information Systems.

Fischer-Preßler, D., Schwemmer, C., and Fischbach, K. 2019. "Collective sense-making in times of crisis: Connecting terror management theory with Twitter user reactions to the Berlin terrorist attack," Computers in Human Behavior (100), pp. 138-151 (doi: 10.1016/j.chb.2019.05.012).

Fisher, B., Hartman, J. L., Cullen, F. T., and Turner, M. G. 2002. "Making campuses safer for students: The clery act as a symbolic legal reform," Stetson Law Review (XXXII), pp. 61-89.

Fornell, C., and Larcker, D. F. 1987. "Evaluating structural equation models with unobservable and measurement error," Journal of Marketing Research (18:1), pp. 39-50.

Franzosi, R. 2003. "Content analysis," in The SAGE Encyclopedia of Social Science Research Methods, M. S. Lewis-Beck, A. E. Bryman and T. Futing (eds.), Thousand Oaks, CA, London, UK, New Delhi, India: Sage Publications, pp. 186-189.

Fritz, C. E. 1961. "Disaster," in Contemporary Social Problems, R. K. Merton and R. A. Nisbet (eds.), New York: Harcourt, Brace and World, pp. 651-694.

Fuentes, R., Gomez-Sanz, J. J., and Pavon, J. 2003. "Social Analysis of Multi-Agent Systems with Activity Theory," in 10 th Conference of the Spanish Association for Artificial Intelligence.

Gao, H., Barbier, G., and Goolsby, R. 2011. "Harnessing the Crowdsourcing Power of Social Media for Disaster Relief," in IEEE Intelligent Systems.

Gibelman, M., and Gelman, S. R. 2001. "Very public scandals: Nongovernmental organizations in trouble," Voluntas: International Journal of Voluntary and Nonprofit Organizations (12:1), pp. 49-66.

Gläser, J., and Laudel, G. 2009. "On interviewing "good" and "bad" experts," in Interviewing Experts, A. Bogner, B. Littig and W. Menz (eds.), Hampshire, England: Palcrave Macmillan, pp. 117-137.

Goertz, G., and Mahoney, J. 2012. A tale of two cultures: Qalitative and quantitative research in the social science, Princeton: Princeton University Press.

Goodwin, J., and Horowitz, R. 2002. "Introduction: The methodological strengths and dilemmas of qualitative sociology," Qualitative Sociology (25:1), pp. 33-47 (doi: 10.1023/A:1014300123105).

Greenberg, J., Pyszcynski, T., and Salomon, S. 1986. "The causes and consequences of the need for self-esteem: A terror management theory," in Public Self and Private Self, R. F. Baumeister (ed.), New York, Berlin, Heidelberg, London, Paris, Tokyo: Springer Verlag, pp. 189-212.

Gregor, S. 2006. “The Nature of Theory in Information Systems," MIS Quarterly (30:3), pp. 611642.

Gundel, S. 2005. "Towards a New Typology of Crises," Journal of Contingencies and Crisis Management (13:3), pp. 106-115.

Hadiguna, R. A., Kamil, I., Delati, A., and Reed, R. 2014. "Implementing a web-based decision support system for disaster logistics: A case study of an evacuation location assessment for Indonesia," International Journal of Disaster Risk Reduction (9), pp. $38-47$ (doi: 10.1016/j.ijdrr.2014.02.004). 
Hair, J. F., Babin, B. J., and Krey, N. 2017. “Covariance-based structural equation modeling in the Journal of Advertising: Review and recommendations," Journal of Advertising (46:1), pp. 163-177 (doi: 10.1080/00913367.2017.1281777).

Hair, J. F., Sarstedt, M., Ringle, C. M., and Gudergan, S. P. 2018. Advanced Issues in Partial Least Squares Structural Equation Modeling, Los Angeles, London, New Delhi, Singapore, Washington D.C., Melbourne: Sage.

Han, W., Ada, S., Sharman, R., Brennan, J. A., and Rao, H. R. 2011. "Critical factors affecting compliance to campus alerts," in ICIS.

Han, W., Ada, S., Sharman, R., and Rao, H. R. 2015. "Campus emergency notification systems: An examination of factors affecting compliance with alerts," MIS Quarterly (39:4), pp. 909929.

Harnesk, D. 2013. "Collective IT Artifacts: Toward Inclusive Crisis Infrastructure," Journal of Information Technology Theory and Application (14:4), pp. 27-48.

Heverin, T., and Zach, L. 2012. "Use of Microblogging for Collective Sense-making During Violent Crises: A Study of Three Campus Shootings," Journal of the American Society for Information Science and Technology (63:1), pp. 34-47 (doi: 10.1002/asi.21685).

Hiltz, S. R., van de Valle, B., and Turoff, M. 2015. "The domain of emergency management information," in Information Systems for Emergency Management, B. van de Valle, M. Turoff and S. R. Hiltz (eds.), New York: Routlege, pp. 3-22.

Hong, L., Fu, C., Wu, J., and Frias-Martinez, V. 2018. "Information Needs and Communication Gaps between Citizens and Local Governments Online during Natural Disasters," Information Systems Frontiers (20:5), pp. 1027-1039 (doi: 10.1007/s10796-018-9832-0).

Hoque, M. A.-A., Phinn, S., Roelfsema, C., and Childs, I. 2017. "Tropical Cyclone Disaster Management Using Remote Sensing and Spatial Analysis: A Review," International Journal of Disaster Risk Reduction (22:8), pp. 345-354 (doi: 10.1016/j.ijdrr.2017.02.008).

Howison, J., Wiggins, A., and Crowston, K. 2011. "Validity Issues in the Use of Social Network Analysis with Digital Trace Data," Journal of the Association for Information Systems (12:12), pp. 767-797 (doi: 10.17705/1jais.00282).

Hu, L.-t., and Bentler, P. M. 1999. "Cutoff criteria for fit indexes in covariance structure analysis: Conventional criteria versus new alternatives," Structural Equation Modeling: A Multidisciplinary Journal (6:1), pp. 1-55.

Hughes, A. L., and Tapia, A. H. 2015. "Social Media in Crisis: When Professional Responders Meet Digital Volunteers," Journal of Homeland Security and Emergency Management (12:3), p. 467 (doi: 10.1515/jhsem-2014-0080).

Ifinedo, P. 2012. "Understanding information systems security policy compliance: An integration of the theory of planned behavior and the protection motivation theory," Computers \& Security (31:1), pp. 83-95 (doi: 10.1016/j.cose.2011.10.007).

IFRC 2013. World disaster report: Focus on technology and the future of humanitarian action. https://www.ifrc.org/PageFiles/134658/WDR\%202013\%20complete.pdf.

Jagtman, H. M. 2010. “Cell broadcast trials in The Netherlands: Using mobile phone technology for citizens' alarming," Reliability Engineering \& System Safety (95:1), pp. 18-28 (doi: 10.1016/j.ress.2009.07.005).

Jennex, M. E. 2004. "Emergency Response System: The Utility Y2K Experience," Journal of Information Technology Theory and Application (6:3), pp. 85-102.

Jennex, M. E. 2007. "Modeling Emergency Response Systems," in Proceedings of the $40^{\text {th }}$ Hawaii International Conference on System Sciences.

Jong, W., and Dückers, M. L.A. 2016. "Self-Correcting Mechanisms and Echo-Effects in Social Media: An Analysis of the "Gunman in the Newsroom" Crisis," Computers in Human Behavior (59:3), pp. 334-341 (doi: 10.1016/j.chb.2016.02.032). 
Junglas, I. A., and Ives, B. 2007. "Recovering IT in a Disaster: Lessons from Hurricane Katrina," MIS Quarterly Executive (6:1), pp. 39-51.

Kaewkitipong, L., Chen, C. C., and Ractham, P. 2016. "A Community-Based Approach to Sharing Knowledge Before, During, and After Crisis Events: A Case Study from Thailand," Computers in Human Behavior (54:2), pp. 653-666 (doi: 10.1016/j.chb.2015.07.063).

Kamel Boulos, M. N., Resch, B., Crowley, D. N., Breslin, J. G., Sohn, G., Burtner, R., Pike, W. A., Jezierski, E., and Chuang, K.-Y. S. 2011. "Crowdsourcing, Citizen Sensing and Sensor Web Technologies for Public and Environmental Health Surveillance and Crisis management: trends, OGC standards and application examples," International Journal of Health Geographics (10), p. 67 (doi: 10.1186/1476-072X-10-67).

Kane, G. C., Alavi, M., Labianca, G., and Borgatti, S. P. 2014. "What's different about social media networks? A framework and research agenda," MIS Quarterly (38:1), pp. 275-304.

Kaplan, B., and Maxwell, J. A. 2005. "Qualitative research methods for evaluating computer information systems," in Evaluating the Organizational Impact of Healthcare Information Systems, J. G. Anderson and C. E. Aydin (eds.), New York: Springer-Verlag, pp. 30-55.

Kaptelinin, V., Nardi, B. A., and Macaulay, C. 1999. "The Activity Checklist: A Tool for Representing the "Space" of Context," Interactions (6:6), pp. 27-39.

Karahanna, E., Xin Xu, S., Xu, Y., and Zhang, N. 2018. "The Needs-Affordances-Features Perspective for the Use of Social Media," MIS Quarterly (42:3), pp. 737-756 (doi: 10.25300/MISQ/2018/11492).

Karanasios, S., Cooper, V., Hayes, P., and Adrot, A. 2019. “"An Iron Hand in a Velvet Glove”: The Embodiment of the Platform Logic in the Emergency Sector," in Fortieth International Conference on Information Systems.

Kaufhold, M., Rupp, N., Reuter, C., and Amelunxen, C. 2018. "Design and evaluation of a mobile crisis app for bidirectional communication between emergency services and citizens," in Twenty-Sixth European Conference on Information Systems.

Kaufhold, M.-A., Rupp, N., Reuter, C., and Habdank, M. 2020. "Mitigating Information Overload in Social Media during Conflicts and Crises: Design and Evaluation of a Cross-Platform Alerting System," Behaviour \& Information Technology (39:3), pp. 319-342 (doi: 10.1080/0144929X.2019.1620334).

Kavanaugh, A. L., Fox, E. A., Sheetz, S. D., Yang, S., Li, L. T., Shoemaker, D. J., Natsev, A., and Xie, L. 2012. "Social Media Use by Government: From the Routine to the Critical," Government Information Quarterly (29:4), pp. 480-491 (doi: 10.1016/j.giq.2012.06.002).

Keenan, P. B., and Jankowski, P. 2019. "Spatial Decision Support Systems: Three Decades on," Decision Support Systems (116:3), pp. 64-76 (doi: 10.1016/j.dss.2018.10.010).

Khalemsky, M., and Schwartz, D. G. 2017. "Emergency Response Community Effectiveness: A simulation modeler for comparing Emergency Medical Services with smartphone-based Samaritan response," Decision Support Systems (102:3), pp. 57-68 (doi: 10.1016/j.dss.2017.07.003).

Kim, G., Martel, A., Eisenman, D., Prelip, M., Arevian, A., Johnson, K. L., and Glik, D. 2019. “Wireless Emergency Alert messages: Influences on protective action behaviour," Journal of Contingencies and Crisis Management (27:4), pp. 374-386 (doi: 10.1111/14685973.12278).

Kim, J., and Hastak, M. 2018. "Social Network Analysis: Characteristics of Online Social Networks after a Disaster," International Journal of Information Management (38:1), pp. 8696 (doi: 10.1016/j.ijinfomgt.2017.08.003).

King, W. R., and He, J. 2006. "A meta-analysis of the technology acceptance model," Information \& Management (43:6), pp. 740-755. 
Kitchenham, B., and Charters, S. 2007. "Guidelines for performing systematic literature reviews in software engineering: Technical report EBSE-2007-01," School of Computer Science and Mathematics, Keele University, Software Engineering Group (ed.).

Klafft, M. 2013. "Diffusion of emergency warnings via multi-channel communication systems an empirical analysis," in 2013 IEEE Eleventh International Symposium on Autonomous Decentralized Systems (ISADS), Mexico City, Mexico, IEEE, pp. 1-5.

Kotthaus, C., Ludwig, T., and Pipek, V. 2016. "Persuasive system design analysis of mobile warning apps for citizens," in Adjunct Proceedings of the 11 th International Conference on Persuasive, Salzburg, Austria.

Kousky, C., and Zeckhauser, R. 2006. "JARring actions that fuel the floods," in On Risk and Disaster: Lessons from Hurricane Katrina, R. J. Daniels, D. F. Kettl and H. Kunreuther (eds.), pp. 59-73.

Kreps, G. A. 1985. "Disasters and the social order," Sociological Theory (3:1), pp. 49-64.

Latonero, M., and Shklovski, I. 2011. "Emergency Management, Twitter, and Social Media Evangelism," International Journal of Information Systems for Crisis Response and Management (3:4), pp. 1-16 (doi: 10.4018/jiscrm.2011100101).

Lee, A. S. 1991. "Integrating positivist and interpretive approaches to organizational research," Organizational Science (2:4), pp. 342-365.

Lee, D., Chung, J. Y., and Kim, H. 2013. "Text me when it becomes dangerous: Exploring the determinants of college students' adoption of mobile-based text alerts short message service," Computers in Human Behavior (29:3), pp. 563-569.

Lee, J., Agrawal, M., and Rao, H. R. 2015. "Message Diffusion through Social Network Service: The Case of Rumor and Non-Rumor Related Tweets during Boston bombing 2013," Information Systems Frontiers (17:5), pp. 997-1005 (doi: 10.1007/s10796-015-9568-z).

Lee, J., Bharosa, N., Yang, J., Janssen, M., and Rao, H. R. 2011. "Group value and intention to use - A study of multi-agency disaster management information systems for public safety," Decision Support Systems (50:2), pp. 404-414 (doi: 10.1016/j.dss.2010.10.002).

Leidner, D. E., Pan, G., and Pan, S. L. 2009. "The Role of IT in Crisis Response: Lessons from the SARS and Asian Tsunami Disasters," The Journal of Strategic Information Systems (18:2), pp. 80-99 (doi: 10.1016/j.jsis.2009.05.001).

Lenert, L. A., Kirsh, D., Griswold, W. G., Buono, C., Lyon, J., Rao, R., and Chan, T. C. 2011. “Design and Evaluation of a Wireless Electronic Health Records System for Field Care in Mass Casualty Settings," Journal of the American Medical Informatics Association : JAMIA (18:6), pp. 842-852 (doi: 10.1136/amiajnl-2011-000229).

Li, J., Li, Q., Liu, C., Ullah Khan, S., and Ghani, N. 2014. "Community-Based Collaborative Information System for Emergency Management," Computers \& Operations Research (42:2), pp. 116-124 (doi: 10.1016/j.cor.2012.03.018).

Liang, H., and Xue, Y. 2004. "Investigating public health emergency response information system initiatives in China," International journal of medical informatics (73:9-10), pp. 675685 (doi: 10.1016/j.ijmedinf.2004.05.010).

Lin, X., Spence, P. R., Sellnow, T. L., and Lachlan, K. A. 2016. "Crisis Communication, Learning and Responding: Best Practices in Social Media," Computers in Human Behavior (65:4), pp. 601-605 (doi: 10.1016/j.chb.2016.05.080).

Lindell, M. K. 2013a. "Disaster studies," Current Sociology (61:5-6), pp. 797-825 (doi: 10.1177/0011392113484456).

Lindell, M. K. 2013b. "Emergency management," in Encyclopedia of Natural Hazards, P. T. Bobrowsky (ed.), Dordrecht: Springer, pp. 263-271. 
Lindell, M. K., and Perry, R. W. 2012. "The protective action decision model: theoretical modifications and additional evidence," Risk Analysis: An Official Publication of the Society for Risk Analysis (32:4), pp. 616-632 (doi: 10.1111/j.1539-6924.2011.01647.x).

Ling, C. L. M., Pan, S. L., Ractham, P., and Kaewkitipong, L. 2015. "ICT-enabled community empowerment in crisis response: Social media in Thailand flooding 2011," Journal of the Association for Information Systems (16:3), pp. 174-212.

Lovejoy, K., and Saxton, G. D. 2012. "Information, Community, and Action: How Nonprofit Organizations Use Social Media*," Journal of Computer-Mediated Communication (17:3), pp. 337-353 (doi: 10.1111/j.1083-6101.2012.01576.x).

Lu, Y., and Yang, D. 2011. "Information Exchange in Virtual Communities under Extreme Disaster Conditions," Decision Support Systems (50:2), pp. 529-538 (doi: 10.1016/j.dss.2010.11.011).

Luokkala, P., and Virrantaus, K. 2014. "Developing information systems to support situational awareness and interaction in time-pressuring crisis situations," Safety Science (63), pp. 191-203 (doi: 10.1016/j.ssci.2013.11.014).

Maddux, J. E., and Rogers, R. W. 1983. "Protection motivation and self-efficacy: A revised theory of appeals and attitude change," Journal of Experimental Social Psychology (19), pp. 469479.

Maitlis, S., and Christianson, M. 2014. "Sensemaking in Organizations: Taking Stock and Moving Forward," Academy of Management Annals (8:1), pp. 57-125 (doi: 10.5465/19416520.2014.873177).

Manoj, B. S., and Baker, A. H. 2007. "Communication challenges in emergency response," Communications of the ACM (50:3), pp. 51-53 (doi: 10.1145/1226736.1226765).

Maresh-Fuehrer, M. M., and Smith, R. 2016. "Social Media Mapping Innovations for Crisis Prevention, Response, and Evaluation," Computers in Human Behavior (54:6), pp. 620-629 (doi: 10.1016/j.chb.2015.08.041).

Maxwell, D., and Watkins, B. 2003. "Humanitarian Information Systems and Emergencies in the Greater Horn of Africa: Logical Components and Logical Linkages," Disasters (27:1), pp. 72-90 (doi: 10.1111/1467-7717.00220).

Mayhorn, C. B., Yim, M., and Orrock, J. A. 2006. "Warnings and hazard communication for natural and technological disasters," in Handbook of Warnings, M. S. Wogalter (ed.), Mahwah, New Jersey, London: Lawrence Erlbaum Associates, Publishers, pp. 763-769.

Mayring, P. 2004. "Qualitative content analysis," in A Companion to Qualitative Research, U. Flick, E. von Kardoff and I. Steinke (eds.), London, UK, Thousand Oaks, CA, New Delhi, India: Sage Publications, pp. 266-270.

McEntire, D. A. 2006. "Local emergency management organizations," in Handbook of Disaster Research, H. Rodríguez, E. L. Quarantelli and R. R. Dynes (eds.), Newark, Delaware: Springer, pp. 168-182.

McLoughlin, D. 1985. "A framework for integrated emergency management," Public Administration Review, (45), pp. 165-172.

McNab, M. L., Hess, T. J., and Valacich, J. S. 2011. "Designing Emergency Response Dispatch Systems for Better Dispatcher Performance," AIS Transactions on Human-Computer Interaction (3:1), pp. 26-55.

Meissen, U., Hardt, M., and Voisard, A. 2014. "Towards a general system design for communitycentered crisis and emergency warning systems," in Proceedings of the $11^{\text {th }}$ International Conference on Information Systems for Crisis Response, pp. 155-159.

Menoni, S., and Pugliano, A. 2013. "Civil protection and crisis management," in Encyclopedia of Natural Hazards, P. T. Bobrowsky (ed.), Dodrecht, Heidelberg, New York, London: Springer, pp. 69-78. 
Merton, R. K. 1993. On the shoulders of giants. A shandean postscript. The post-italianate edition. With a foreword by Umberot Eco, An afterword by Denis Denoghue, and a preface and postface by the author, Chicago and London: University of Chicago Press.

Mimno, D., Wallach, H. M., Talley, E., Leenders, M., and McCallum, A. 2011. "Optimizing semantic coherence in topic models," in Proceedings of the Conference on Empirtcal Methods in Natural Language Processing, pp. 262-272.

Mingers, J. 2001. "Combining IS research methods: Towards a pluralist methodology," Information Systems Research (12:3), pp. 240-259 (doi: 10.1287/isre.12.3.240.9709).

Mirbabaie, M., Bunker, D., Stieglitz, S., Marx, J., and Ehnis, C. 2020. "Social media in times of crisis: Learning from Hurricane Harvey for the coronavirus disease 2019 pandemic response," Journal of Information Technology (35:3), pp. 195-213 (doi: 10.1177/0268396220929258).

Montz, B. E., Tobin, G. A., and Hagelman, R. R. 2017. Natural Hazards Explanations and Integration, New York, London: The Guilford Press.

Moon, K., and Blackman, D. 2014. "A guide to understanding social science research for natural scientists," Conservation biology : the journal of the Society for Conservation Biology (28:5), pp. 1167-1177 (doi: 10.1111/cobi.12326).

Munich RE 2020a. NatCatSERVICE. https://natcatservice.munichre.com/events/1?filter=ey[5ZWFyRnJvbSI6MjAxNywieWVhclRvIjoyMDE3fQ\%3D\%3D\&type=1. Accessed May $21^{\text {st, }} 2020$.

Munich RE 2020b. Overall and insured losses in US\$ for relevant natural loss events worldwide $1980 \quad-\quad 2017 . \quad$ https://natcatservice.munichre.com/overall/1?filter=ey[5ZWFyRnJvbSI6MTk4MCwieWVhclRvIjoyMDE3fQ\%3D\%3D\&type=1. Accessed 21st May, 2020.

Myers, M. D. 1997. "Qualitative research in information systems," MIS Quarterly (21:2), pp. 241242.

Na, H. S., and Banerjee, A. 2019. "Agent-based discrete-event simulation model for no-notice natural disaster evacuation planning," Computers \& Industrial Engineering (129:3), pp. 44-55 (doi: 10.1016/j.cie.2019.01.022).

Nahapiet, J., and Ghoshal, S. 1998. "Social Capital, Intellectual Capital, and the Organizational Advantage," Academy of Management Review (23:2), pp. 242-266 (doi: 10.5465/amr.1998.533225).

Neubaum, G., Rösner, L., Rosenthal-von der Pütten, A. M., and Krämer, N. C. 2014. "Psychosocial Functions of Social Media Usage in a Disaster Situation: A Multi-Methodological Approach," Computers in Human Behavior (34), pp. 28-38 (doi: 10.1016/j.chb.2014.01.021).

Neville, K., O’Riordan, S., Pope, A., and Ó’Lionáird, M. 2018. "Evaluating an Emergency Management Decision Support System with Practitioner-Driven Scenarios: Action Design Research," in Thirty Ninth International Conference on Information Systems, San Francisco.

Ng, B., and Kankanhalli, A. 2012. "Pacific Asia Journal of the Association for Information Systems Vol. 4 No. 3, pp.15-44 / September 201215 Information Systems for Large-Scale Event Management: A Case Study," Pacific Asia Journal of the Association for Information Systems (4:3), pp. 15-44.

Oh, O., Agrawal, M., and Rao, H. R. 2013. "Community intelligence and social media service: A rumor theoretic analysis of tweets during social crisis," MIS Quarterly (37:2), pp. 407426.

Oh, O., Eom, C., and Rao, H. R. 2015. "Research Note - Role of Social Media in Social Change: An Analysis of Collective Sense Making During the 2011 Egypt Revolution," Information Systems Research (26:1), pp. 210-223 (doi: 10.1287/isre.2015.0565). 
Okoli, C., and Schabram, K. 2010. "A guide to conducting a systematic literature review of information systems research," Sprouts: Working Papers on Information (10:26), pp. 1-49.

Ozguven, E. E., Horner, M. W., Kocatepe, A., Marcelin, J. M., Abdelrazig, Y., Sando, T., and Moses, R. 2016. "Metadata-based Needs Assessment for Emergency Transportation Operations with a Focus on an Aging Population: A Case Study in Florida," Transport Reviews (36:3), pp. 383-412 (doi: 10.1080/01441647.2015.1082516).

Palen, L., and Anderson, K. M. 2016. "Crisis Informatics-New Data for Extraordinary Times. Focus on Behaviors, not on Fetishizing Social Media Rools," Science (353:6296).

Pan, S., Pan, G., and Leidner, D. 2012. "Crisis Response Information Networks," Journal of Association of Information Systems (13:1), pp. 31-56.

Panagiotopoulos, P., Barnett, J., Bigdeli, A. Z., and Sams, S. 2016. "Social Media in Emergency Management: Twitter as a Tool for Communicating Risks to the Public," Technological forecasting and social change (111), pp. 86-96 (doi: 10.1016/j.techfore.2016.06.010).

Paré, G., Trudel, M.-C., Jaana, M., and Kitsiou, S. 2015. "Synthesizing information systems knowledge: A typology of literature reviews," Information \& Management (52:2), pp. 183-199 (doi: 10.1016/j.im.2014.08.008).

Perry, R. W. 2006. "What is a disaster?" in Handbook of Disaster Research, H. Rodríguez, E. L. Quarantelli and R. R. Dynes (eds.), Newark, Delaware: Springer, pp. 1-15.

Petter, S., and Fruhling, A. 2011. "Evaluating the success of an emergency response medical information system," International journal of medical informatics (80:7), pp. 480-489 (doi: 10.1016/j.ijmedinf.2011.03.010).

Pinsonneault, A., and Kraemer, K. 1993. "Survey research methodology in management information systems: An assessment," Journal of Management Information Systems (10:2), pp. 75-105 (doi: 10.1080/07421222.1993.11518001).

Podsakoff, P. M., MacKenzie, S. B., Lee, J.-Y., and Podsakoff, N. P. 2003. “Common method biases in behavioral research: A critical review of the literature and recommended remedies," The Journal of Applied Psychology (88:5), pp. 879-903 (doi: 10.1037/00219010.88.5.879).

Posner, R. A. 2004. Catastrophe: Risk and Response, New York: Oxford University Press.

Prasanna, R., Yang, L., and King, M. 2013. "Guidance for Developing Human-Computer Interfaces for Supporting Fire Emergency Response," Risk Management (15:3), pp. 155-179 (doi: 10.1057/rm.2013.3).

Putnick, D. L., and Bornstein, M. H. 2016. "Measurement invariance conventions and reporting: The state of the art and future directions for psychological research," Developmental review : $D R$ (41), pp. 71-90 (doi: 10.1016/j.dr.2016.06.004).

Pyszcynski, T., Greenberg, J., and Salomon, S. 2003. In the Wake of 9/11: The Psychology of Terror, Washington, DC: American Psychological Association.

Quarantelli, E. L. 1983. "Emergent behavior at the emergency time periods of disasters," Final Project Report \#31.

Quarantelli, E. L. 1987. "What should we study? Questions and suggestions for reserachers about the concept of disasters," International Journal of Mass Emergencies and Disasters (5), pp. 7-32.

Quarantelli, E. L., Boin, A., and Lagadec, P. 2018. "Studying Future Disasters and Crises: A Heuristic Approach," in Handbook of Disaster Research, H. Rodríguez, W. Donner and J. E. Trainor (eds.), Cham: Springer International Publishing, pp. 61-83.

Quarantelli, E. L., Lagadec, P., and Boin, A. 2006. "A heuristic approach to future disasters and crises: New, old, and in-between types," in Handbook of Disaster Research, H. Rodríguez, E. L. Quarantelli and R. R. Dynes (eds.), Newark, Delaware: Springer, pp. 16-41. 
Quek, A., and Shah, H. 2004. "The Activity Theoretical Iterative Evaluation Method," in 1st International Workshop on Activity Theory Based Practical Methods for IT Design.

Recker, J. 2021. "Improving the State-Tracking Ability of Corona Dashboards," European Journal of Information Systems.

Reuter, C., Hughes, A. L., and Kaufhold, M.-A. 2018. "Social Media in Crisis Management: An Evaluation and Analysis of Crisis Informatics Research," International Journal of HumanComputer Interaction (34:4), pp. 280-294 (doi: 10.1080/10447318.2018.1427832).

Reuter, C., Kaufhold, M., Leopold, I., and Knipp, H. 2017. "KATWARN, NINA, or FEMA? Multimethod study on distribution, use, and public views on crisis apps," in Proceedings of the $25^{\text {th }}$ European Conference on Information Systems.

Richardson, B. 1994. "Socio-technical Disasters: Profile and Prevalence," Disaster Prevention and Management: An International Journal (3:4), pp. 41-69 (doi: 10.1108/09653569410076766).

Rodríguez, H., Donner, W., and Trainor, J. E. (eds.) 2018. Handbook of Disaster Research, Cham: Springer International Publishing.

Rodríguez, H., Trainor, J., and Quarantelli, E. L. 2006. "Rising to the challenges of a catastrophe: The emergent and prosocial behavior following Hurricane Katrina," The ANNALS of the American Academy of Political and Social Science (604:1), pp. 82-101 (doi: 10.1177/0002716205284677).

Rogers, R. W. 1975. "A protection motivation theory of fear appeals and attitude change," Journal of Psychology (91:1), pp. 93-114.

Rogers, R. W. 1983. "Cognitive and physiological processes in fear appeals and attitude change: A revised theory of protection motivation," in Social Psychophysiology - A Sourcebook, J. T. Cacioppo (ed.), New York: Guilford, pp. 153-176.

Romano, M., Onorati, T., Aedo, I., and Diaz, P. 2016. "Designing mobile applications for emergency response: Citizens acting as human sensors," Sensors (Basel, Switzerland) (16:3) (doi: 10.3390/s16030406).

Romo-Murphy, E., James, R., and Adams, M. 2011. "Facilitating disaster preparedness through local radio broadcasting," Disasters (35:4), pp. 801-815 (doi: 10.1111/j.14677717.2011.01234.x).

Rosenthal, U., and Kouzmin, A. 1993. "Globalizing an Agenda for Contingencies and Crisis Management: An Editorial Statement," Journal of Contingencies and Crisis Management (1:1), pp. 1-12 (doi: 10.1111/j.1468-5973.1993.tb00001.x).

Ross, B., Jung, A., Heisel, J., and Stieglitz, S. 2018. "Fake news on social media: The (in)effectiveness of warning messages," in Thirty Ninth International Conference on Information Systems.

Rowe, F. 2014. "What literature review is not: diversity, boundaries and recommendations," European Journal of Information Systems (23:3), pp. 241-255 (doi: 10.1057/ejis.2014.7).

Rutherford, W. H., and Boer, J. de 1982. "The definition and classification of disasters," The British Journal of Accident Surgery (15:1), pp. 10-12.

Sahana 2021. Features. https://sahanafoundation.org/eden/features/\#core.

Sakurai, M., and Kokuryo, J. 2014. "Design of a resilient information system for disaster response," in International Conference on Information Systems.

Scaini, C., Folch, A., Bolić, T., and Castelli, L. 2014. "A GIS-based tool to support air traffic management during explosive volcanic eruptions," Transportation Research Part C: Emerging Technologies (49:2463-2529), pp. 19-31 (doi: 10.1016/j.trc.2014.09.020).

Schepers, J., and Wetzels, M. 2007. "A meta-analysis of the technology acceptance model: Investigating subjective norm and moderation effects," Information \& Management (44:1), pp. 90-103. 
Schryen, G., Rauchecker, G., and Comes, T. 2015. "Resource Planning in Disaster Response," Business \& Information Systems Engineering (57:4), pp. 243-259 (doi: 10.1007/s12599015-0381-5).

Schwarz, A., Mehta, M., Johnson, N., and Chin, W. W. 2007. "Understanding frameworks and reviews: A commentary to assist us in moving our field forward by analyzing our past," ACM SIGMIS Database: the DATABASE for Advances in Information Systems (38:3), pp. 2950 (doi: 10.1145/1278253.1278259).

Schweinberger, M., Petrescu-Prahova, M., and Vu, D. Q. 2014. "Disaster response on September 11, 2001 through the lens of statistical network analysis," Social networks (37), pp. 4255 (doi: 10.1016/j.socnet.2013.12.001).

Seeger, M. W., Sellnow, T. L., and Ulmer, R. R. 1998. "Communication, organization and crisis," in Communication Yearbook 21, Thousand Oaks, CA: Sage, pp. 231-275.

Seppänen, H., and Virrantaus, K. 2015. "Shared Situational Awareness and Information Quality in Disaster Management," Safety Science (77:1), pp. 112-122 (doi: 10.1016/j.ssci.2015.03.018).

Shaluf, I. M. 2007. "An overview on disasters," Disaster Prevention and Management (16:5), pp. 687-703.

Shen, M., Carswell, M., Santhanam, R., and Bailey, K. 2012. "Emergency Management Information Systems: Could Decision Makers be Supported in Choosing Display Formats?" Decision Support Systems (52:2), pp. 318-330 (doi: 10.1016/j.dss.2011.08.008).

Simon, T., Goldberg, A., and Adini, B. 2015. "Socializing in Emergencies-A Review of the Use of Social Media in Emergency Situations," International Journal of Information Management (35:5), pp. 609-619 (doi: 10.1016/j.ijinfomgt.2015.07.001).

Starbird, K. 2011. "Digital Volunteerism During Disaster: Crowdsourcing Information Processing," in Conference on Human Factors in Computing Systems, Vancouver: ACM, pp. 712.

Starbird, K., and Palen, L. 2011. “''Voluntweeters': Self-Organizing by Digital Volunteers in Times of Crisis," in Proceedings of the 29 $9^{\text {th }}$ ACM Conference on Human Factors in Computing Systems, pp. 1071-1080.

Staupe-Delgado, R. 2019. "Progress, traditions and future directions in research on disasters involving slow-onset hazards," Disaster Prevention and Management: An International Journal (28:5), pp. 623-635 (doi: 10.1108/DPM-11-2018-0358).

Stieglitz, S., Mirbabaie, M., Fromm, J., and Melzer, S. 2018a. "The Adoption of Social Media Analytics for Crisis Management - Challenges and Opportunities"," in ECIS.

Stieglitz, S., Mirbabaie, M., and Milde, M. 2018b. "Social Positions and Collective Sense-Making in Crisis Communication," International Journal of Human-Computer Interaction (34:4), pp. 328-355 (doi: 10.1080/10447318.2018.1427830).

Stieglitz, S., Mirbabaie, M., Ross, B., and Neuberger, C. 2018c. "Social Media Analytics - Challenges in Topic Discovery, Data Collection, and Data Preparation," International Journal of Information Management (39:1), pp. 156-168 (doi: 10.1016/j.ijinfomgt.2017.12.002).

Straub, D., and Gefen, D. 2004. "Validation guidelines for IS positivist research," Communications of the Association for Information Systems (13) (doi: 10.17705/1CAIS.01324).

Strong, D. M., and Volkoff, O. 2010. "Understanding organization-enterprise system fit: A path to theorizing the information technology artifact," MIS Quarterly (34:4), pp. 731-756.

Sun, W., Bocchini, P., and Davison, B. D. 2020. "Applications of Artificial Intelligence for Disaster Management,” Natural Hazards (103:3), pp. 2631-2689 (doi: 10.1007/s11069-02004124-3). 
Swersey, A. J. 1994. "Chapter 6 The deployment of police, fire, and emergency medical units," in Operations Research and The Public Sector, S. M. Pollock, A. Rothkopf and A. Barnett (eds.), Elsevier, pp. 151-200.

Swiss Re 2017. Natural catastrophes and man-made disasters in 2016: a year of widespread damages. https://reliefweb.int/sites/reliefweb.int/files/resources/sigma1 2018 en.pdf. Accessed 29 July 2019.

Swiss Re 2018. sigma: Natural catastrophes and man-made disasters in 2017: A year of recordbreaking losses. $\quad \underline{\text { https://reliefweb.int/sites/reliefweb.int/files/re- }}$ sources/sigma1 2018 en.pdf. Accessed 21 $1^{\text {st }}$ May, 2020.

Swiss Re 2021. sigma 2/2020: Natural catastrophes in times of economic accumulation and climate change: Facts and Figures. https://www.swissre.com/institute/research/sigmaresearch/sigma-2020-02.html. Accessed 17 June 2021.

t' Hard, P., and Boin, A. 2001. "Between crisis and normalcy: the long shadow of post-crisis," in Managing Crises: Threats, Dilemmas, Opportunities, U. Rosenthal, A. Boin and L. K. Comfort (eds.), Springfield,: Charles C. Thomas Publisher, pp. 28-48.

Tan, M. L., Prasanna, R., Stock, K., Hudson-Doyle, E., Leonard, G., and Johnston, D. 2017. "Mobile applications in crisis informatics literature: A systematic review," International Journal of Disaster Risk Reduction (24:6), pp. 297-311 (doi: 10.1016/j.ijdrr.2017.06.009).

Thapa, D., Budhathoki, N., and Munkvold, B. E. 2017. "Analyzing Crisis Response through ActorNetwork Theory: The Case of Kathmandu Living Labs," Communications of the Association for Information Systems (41), pp. 414-428 (doi: 10.17705/1CAIS.04119).

Thomas, M., Andoh-Baidoo, F. K., Redmond, R., and Yoon, V. 2009. "Moving Beyond Traditional Emergency Response Notification with VoiceXML," Journal of Information Technology Theory and Application (10:1), aricle 3.

Thornton, P. H., and Ocasio, W. 2008. "Institutional Logics," in The SAGE Handbook of Organizational Institutionalism, pp. 99-129.

Tim, Y., Pan, S. L., Ractham, P., and Kaewkitipong, L. 2017. "Digitally enabled disaster response: the emergence of social media as boundary objects in a flooding disaster," Information Systems Journal (27:2), pp. 197-232 (doi: 10.1111/isj.12114).

Trang, S., Trenz, M., Weiger, W. H., Tarafdar, M., and Cheung, C. M.K. 2020. "One app to trace them all? Examining app specifications for mass acceptance of contact-tracing apps," European Journal of Information Systems (29:4), pp. 415-428 (doi: 10.1080/0960085X.2020.1784046).

Trieu, V., Burton-Jones, A., Green, P., and Cockroft, S. forthcoming. "Applying and extending the theory of effective use in a business intelligence context," MIS Quarterly.

Turoff, M. 2002. "Past and future emergency response information systems," Communications of the ACM (45:4), pp. 29-32 (doi: 10.1145/505248.505265).

Turoff, M., Chumer, M., Van de Valle, B., and Yao, X. 2004. "The design of a dynamic emergency response management information system (DERMIS)," The Journal of Information Technology Theory and Application (5:4), pp. 1-35.

Turoff, M., Hiltz, S. R., Bahgat, A. N. F., and Rana, A. R. 1993. "Distributed Group Support Systems," MIS Quarterly (17:4), pp. 399-417.

UNDRR 2021. Prevention Web The Knowledge Platform for Disaster Risk Reduction. https://www.preventionweb.net/english/.

Ushahidi 2021. About Ushahidi. https://www.ushahidi.com/about.

Valecha, R., Rao, H. R., Upadhyaya, S. J., and Sharman, R. 2019. "An Activity Theory Approach to Modeling Dispatch-Mediated Emergency Response," Journal of the Association for Information Systems (20), pp. 33-57 (doi: 10.17705/1jais.00528). 
Venkatesh, V., and Davis, F. D. 2000. "A theoretical extension of the technology acceptance model: Four longitudinal field studies," Management Science (46:2), pp. 186-204.

Venkatesh, V., Morris, M. G., Davis, G. B., and Davis, F. D. 2003. "User acceptance of information technology: Toward a unified view," MIS Quarterly (27:3), pp. 425-478.

Vila-Pozo, M. M., and Sundeep, S. 2018. "Humanitarian health information systems: Different challenges and responses," in ECIS.

Vom Brocke, J., Simons, A., Niehaves, B., and Riemer, K. 2009. "Reconstructing the giant: On the importance of rigour in documenting the literature search process," in ECIS.

Vona, M., Cascini, G., Mastroberti, M., Murgante, B., and Nolè, G. 2017. "Characterization of URM buildings and evaluation of damages in a historical center for the seismic risk mitigation and emergency management," International Journal of Disaster Risk Reduction (24), pp. 251-263 (doi: 10.1016/j.ijdrr.2017.05.008).

Wakolbinger, T., Fabian, F., and Kettinger W. J. 2013. "IT-enabled Interorganizational Information Sharing Under Co-opetition in Disasters: A Game-Theoretic Framework," Communications of the Association for Information Systems (33:5), pp. 67-80.

Walls, J. G., Widmeyer, G. R., and El Sawy, O. A. 1992. "Building an information system design theory for vigilant EIS," Information Systems Research (3:1), pp. 36-59.

Walter, T. 2015. "New Mourners, Old Mourners: Online Memorial Culture as a Chapter in the History of Mourning," New Review of Hypermedia and Multimedia (21:1-2), pp. 10-24 (doi: 10.1080/13614568.2014.983555).

Wand, Y., and Weber, R. 1995. "On the deep structure of information systems," Information Systems Journal (5:3), pp. 203-223 (doi: 10.1111/j.1365-2575.1995.tb00108.x).

Weber, R. forthcoming. "Constructs and indicators: An ontological analysis," MIS Quarterly.

Weber, R. 2003. "Editor's comments. Theoretically speaking," MIS Quarterly (27:3), pp. iii-xii.

Weber, R. P. 1995. "Basic content analysis," in Research Practice. International Handbook of Quantitative Application in the Social Science, M. S. Lewis-Beck (ed.), London: Sage.

Weiber, R., and Mühlhaus, D. 2014. Strukturgleichungsmodellierung Eine anwendungsorientierte Einführung in die Kausalanalyse mit Hilfe von AMOS, SmartPLS und SPSS, Berlin, Heidelberg: Springer Gabler.

Weick, K. E. 1988. "Enacted sensemaking in crisis situations," Journal of Management Studies (25:4), pp. 305-317.

Weick, K. E. 2010. "Reflections on enacted sensemaking in the Bhopal disaster," Journal of Management Studies (47:3), pp. 537-550 (doi: 10.1111/j.1467-6486.2010.00900.x).

Weidinger, J., Schlauderer, S., and Overhage, S. 2021. "Information Technology to the Rescue? Explaining the Acceptance of Emergency Response Information Systems by Firefighters," IEEE Transactions on Engineering Management, pp. 1-15 (doi: 10.1109/TEM.2020.3044720).

$\mathrm{Xu}$ J., Zhou, H., Nie, G., and An, J. 2020. "Plotting earthquake emergency maps based on audience theory," International Journal of Disaster Risk Reduction (47:2), p. 101554 (doi: 10.1016/j.ijdrr.2020.101554).

Yang, L., Su, G., and Yuan, H. 2012. "Design principles of integrated information platform for emergency responses: The case of 2008 Beijing Olympic Games," Information Systems Research (23:3-part-1), pp. 761-786 (doi: 10.1287/isre.1110.0387).

Yoo, E., Rand, W., Eftekhar, M., and Rabinovich, E. 2016. "Evaluating Iformation Diffusion Speed and its Determinants in Social Media Networks during Humanitarian Crises," Journal of Operations Management (45:1), pp. 123-133 (doi: 10.1016/j.jom.2016.05.007). 
Zachos, L. G., Swann, C. T., Altinakar, M. S., McGrath, M. Z., and Thomas, D. 2016. "Flood vulnerability indices and emergency management planning in the Yazoo Basin, Mississippi," International Journal of Disaster Risk Reduction (18), pp. 89-99 (doi: 10.1016/j.ijdrr.2016.03.012).

Zheng, Y., and Yu, A. 2016. "Affordances of social media in collective action: the case of Free Lunch for Children in China," Information Systems Journal (26:3), pp. 289-313 (doi: 10.1111/isj.12096).

Zur Shapira 2011. “'I've Got a Theory Paper-Do You?": Conceptual, Empirical, and Theoretical Contributions to Knowledge in the Organizational Sciences," Organization Science (22:5), pp. 1312-1321 (doi: 10.1287/orsc.1100.0636). 
Appendix A1

Emergency Management Information Systems in Organizations 


\section{Appendix A1.1: Paper I}

Communication Barriers in Crisis Management: A Literature Review

\section{Fact Description}

Bibliographic data $\quad$ Fischer, D., Posegga, O., and Fischbach, K. (2016). "Communication Barriers in Crisis Management: A Literature Review," in Proceedings of the European Conference on Information Systems, Istanbul, Turkey.

https://aisel.aisnet.org/ecis2016_rp/168/ 


\section{Appendix A1.2: Paper II}

Information Technology and Risk Management in Supply Chains

\section{Fact Description}

Bibliographic data

Fischer-Preßler, D., Eismann, K., Pietrowski, R., Fischbach, K., and

Schoder, D. (2020). "Information Technology and Risk Manage-

ment in Supply Chains," in International Journal of Physical Distri-

bution \& Logistics Management, 50(2), pp. 233-254.

DOI: 10.1108/IJPDLM-04-2019-0119

https://www.emerald.com/insight/content/doi/10.1108/IJPDLM-

04-2019-0119/full/html 


\section{Appendix A1.3: Paper III}

\section{Using Social Network Analysis to Make Sense of Radio Communica- tion in Emergency Response}

\section{Fact Description}

Bibliographic data $\quad$ Eismann, K., Fischer, D., Posegga, O., and Fischbach, K. (2018). “Using Social Network Analysis to Make Sense of Radio Communication in Emergency Response," in Proceedings of the International Workshop on Modeling, Analysis, and Management of Social Networks and their Applications.

Status of publication Published as completed research paper.

Copyright notice Reprinted in accordance with the conference's copyright terms: „Kopien und Ausdruck dürfen nur zum...sonstigen eigenen Gebrauch angefertigt werden." 


\title{
Using Social Network Analysis to Make Sense of Radio Communica- tion in Emergency Response
}

\begin{abstract}
In the wake of an increasing interest in the communication networks of emergency responders, radio communication systems have been recognized as an important source of digital trace data. In this paper, we explore how radio data can be used as part of social network analysis (SNA). In particular, we investigate how social networks can be modeled and analyzed based on digital trace data obtained from radio systems in the emergency response field. We outline SNA challenges and opportunities based on radio networks, following the work of [9]. Utilizing radio data from a recent emergency response field exercise, we illustrate an example of a workflow that can be applied for modeling social networks from emergency responders' radio communication and discuss the implications of our findings for the analysis and interpretation of radio network structures. Hence, this paper is a useful starting point for future research that applies tools and methods from the SNA repertoire to radio networks in the context of emergency response and beyond.
\end{abstract}

Keywords: Social Network Analysis, Radio Communication, Digital Trace Data, Emergency

\section{Introduction}

Radio communication - that is, telecommunication by means of radio waves [11] - has largely disappeared from the public consciousness but remains a common communication medium in many fields of operation, such as in ground, air, and water transportation, in businesses with factories and other industrial sites, and in care facilities.

Naturally, radio data afford opportunities to apply tools and methods from the repertoire of social network analysis (SNA) to communication networks [1]. While such research was once rare, new interest in the communication networks of emergency responders has emerged in recent years $[8,12,13,14,19]$. Radio is crucial for emergency responders, especially when other communication infrastructures are compromised or destroyed by disasters or extreme events [10], and has thus remained the baseline communication tool of emergency services in many places $[8,14]$. Radio interoperability disruptions are still among the most severe communication problems emergency responders face $[7,13,15]$. Research also suggests that studying radio communication provides unique insights into the social structure of emergency response operations $[2,17]$.

Utilizing radio as a basis for SNA is not without challenges, though. In this paper, we focus on the modeling and analysis of social networks based on radio communication as a special case of digital trace data. We outline key issues in utilizing digital trace data for SNA based on [9] (section 2). We then discuss the SNA challenges and opportunities for radio networks based on our experiences in a research project involving three major German relief organizations, and share our insights from a recent emergency response field exercise (section 3). Finally, we outline the contributions of our work (section 4).

\section{SNA for Digital Trace Data}

Digital trace data are "records of activity (trace data) undertaken through an online information system (thus, digital)" [9]. Unlike traditional network data, which are produced for research (e.g. from interviews, observations, or archival records 1 In technical terms, radio communication is any transmission, emission, or reception of signs, signals, writings, images, 
sounds, or intelligence of any nature using radio waves (i.e., electromagnetic waves of frequencies arbitrarily lower than $3,000 \mathrm{GHz}$, transmitted in space without artificial guide such as wire) [11]. [16, 20]), digital trace data are found. Furthermore, whereas traditional network data typically describe specific relationships, digital trace data are event-based, and they are longitudinal records of events instead of cross-sectional network snapshots.

Digital trace data thus enable scholars to understand the structure and outcomes of social networks on an unprecedented scale. This type of data does, however, require scholars to make crucial assumptions regarding the nodes, ties, and structures they model from it [9]. According to [9], five steps are necessary to construct and analyze social networks from digital trace data such as radio communication. In the first step, digital trace data have to be understood and interpreted in alignment with the context and characteristics of the information systems they emerge from. In this context, issues relating to the reliability of the information systems from which communication events are to be extracted in the first place, as well as practical usage behaviors deviating from the intended information systems usage, need to be considered. In the second step, the network elements (i.e., the nodes and links of the network) have to be modeled from the identified communication events. In particular, digital trace data typically allow for different ways to handle the multiplexity, intensity, and directionality of ties. Furthermore, missing ties may be an issue when the records provided by the information system are incomplete or limited to a partial representation of the relationships and interactions within the context of a study.

In the third step, the identified network elements have to be aggregated into a network, which may entail difficulties in the temporal aggregation of nodes and links. In the fourth step, appropriate network measures that align with both the intended theoretical construct to be analyzed and the social network at hand have to be selected. This can be challenging especially if there is mismatch between the temporal dynamics of constructs and network representation, or if software tools applied to support computation of measures yield invalid results. Finally, in the fifth step, the theoretical constructs inferred from the network measures have to be interpreted and generalized in a valid way, which is an important for SNA-based research in general, but particularly challenging when working with digital trace data.

In the case of communication networks modeled from radio communication, it is necessary to initially extract communication events (i.e., instances of radio communication between two or more users of the radio communication system) from the electronic records of radio communication. Based on this, unique actors that constitute the nodes of the communication network have to be identified from the radio names of users (i.e., the aliases radio users rely on to address their peers).

Furthermore, the trade-offs of considering directed and weighted communication links between these users as opposed to simple undirected and unweighted links, as well as the potential consequences of omitting unobserved communication events have to be discussed. In the next step, several options are available for the temporal aggregation of these network elements, in particular, aggregation of communication links over the entire period of observation, over limited periods using sliding windows, or over fixed periods focusing on specific events. Once a communication network has been generated from the identified nodes and edges, it is important to select appropriate network measures. In particular, we discuss the applicability of standard measures that are often applied to the analysis of digital trace data. Finally, we turn to the implications of the identified network structures for the interpretation of the communication network. 
Figure 1 provides an overview on the chain of reasoning described by [9], which covers the major assumptions that have to be made in the process of modeling networks from digital trace data in general. In addition, the figure includes an adaption of this concept for radio communication networks in particular, which we use as an example to discuss the challenges and opportunities involved in modeling and analyzing such networks.

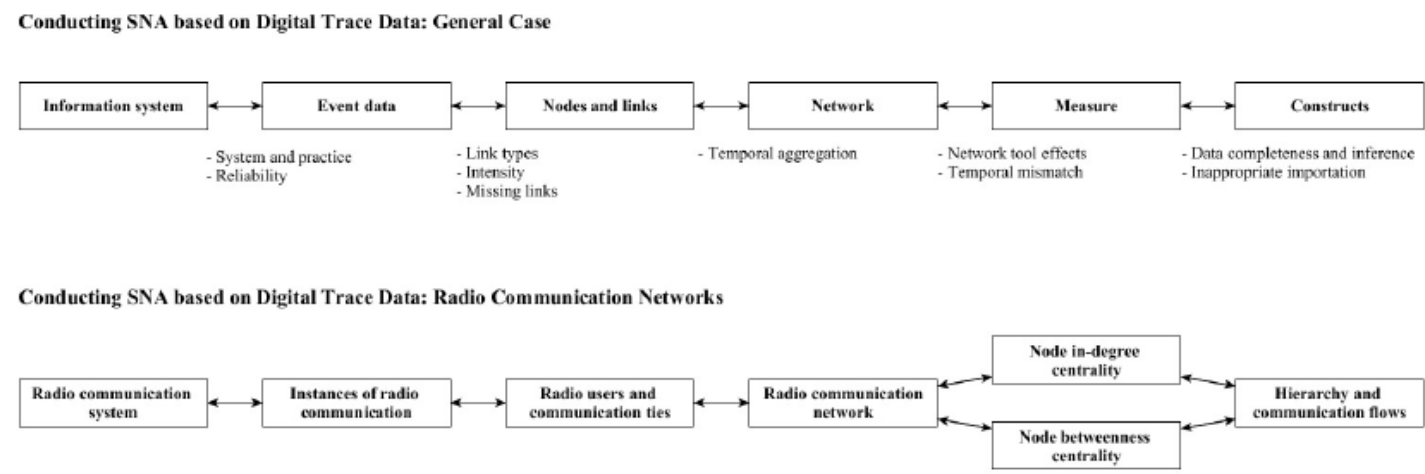

Figure 1. Conducting SNA based on Radio Communication Data (adapted from [9])

In the following section, we discuss in detail how digital trace data of emergency responders' radio communication can be utilized for SNA based on findings from a research project with relief organizations in Germany and insights from the analysis of empirical radio data obtained from a recent emergency response field exercise.

\section{Challenges and Opportunities of SNA for Radio Networks in the Emergency Response Field}

\subsection{Case Description}

We utilize data from a recent emergency response field exercise to illustrate SNA challenges with respect to radio networks. The exercise scenario was based on a past crisis event - a flash flooding of a river during a large festival in a medium sized city in Germany. In the emergency response exercise, emergency responders from three German relief organizations simulated this incident with a particular focus on the evacuation of the festival venue. They were accompanied by representatives of the police, fire brigades, coastguard, local governmental authorities, and an observing research team, to which the authors belonged. In addition, the exercise involved groups of disaster volunteers spontaneously joining the relief efforts.

For the time of the exercise, the three relief organizations established a shared incident command system based on hierarchical relationships under a single director of operations. This structure of command and control based on a clear chain of command and control that is common in established relief organizations in Germany and that is manifested in their basic organizational routines and working rules, such as the "Dienstvorschrift 100" that has a counterpart also in the military service regulations.

The staffing of the exercise included a command center that was located several kilometers away from the exercise site and which hosted the operation controllers and the director of operations, who were responsible for planning and coordinating the response efforts in the field, as well as representatives of the other aforementioned organizations resuming advisory functions. Additionally, two operations control groups located in mobile command vehicles nearby the command center (in the following referred to as "mobile command units") were 
responsible for ensuring the radio communication flow and thus served as information hubs between the operation controllers and the responders in the field. The immediate area of operations was divided into three sub-areas, each of which was staffed with a local operation commander and approximately nine additional responders. Owing to the requirements of the exercise scenario, each response team worked on similar tasks related to the evacuation of persons and equipment simultaneously.

Observers from other organizations and researchers were admitted to all locations at any time during the approximately three hours of operation. Our data consist of personal observations of the operation controllers, mobile command units, and response operations in the field. Furthermore, we were given access to a dataset that contains all records of radio communication taking place during the exercise, including unique identifiers of the communicating individuals and the complete audio records of their conversations. 2 Hence, we could listen to the radio communication and observe when and between which radio users the communication took place in the aftermath of the event.

Below, we describe an exemplary workflow of conducting SNA research based on digital trace data as were obtained from this exercise.

\subsection{Practical SNA Challenges and Opportunities for Radio Networks in the Emergency Response Field}

Extracting communication events from the radio system. Initially, we identified from the radio system concrete instances of communication among users. These communication events are the basis for the extraction of network nodes and links and thus the first step of conducting SNA based on radio data.

In the emergency response field, radio systems that enable at least half-duplex communication - that is, non-simultaneous two-way communication, such as giving orders and receiving status updates - are common [3]. Responders taking part in the field exercise relied on a digital radio system that included an electronic interface by which the system can be connected to computers, making available electronic records of the communication, which includes detailed metadata, such as the technical identifiers of sending and receiving radio devices. While those identifiers are unique and exclusively assigned to specific individuals taking part ${ }^{7}$ in the emergency response field exercise, we had to employ qualitative coding techniques to match those technical identifiers with the corresponding radio names (used on the organizational level by the participants to address each other). Accordingly, we transcribed all radio communication records and manually coded the radio names of the senders and receivers of each radio message (i.e., the technical identifier and the radio names), the instant of time at which the message was sent, and the content of the message. This provides us with the necessary data to model the nodes of the network (defined by radio names and the corresponding technical identifiers) and the edges (defined by the recorded radio messages).

Further, based on the transcript of all radio messages, we identified events that occurred during the emergency response field exercise and which caused an increased amount of observa-

\footnotetext{
${ }^{7}$ Note, however, that recording emergency responders' radio communication can be problematic because German relief organizations require permission to do so. For the field exercise, the local authorities granted us permission to record emergency responders' radio communication.
} 
ble radio communication. A typical example of a communication event extracted from the digital record of radio communication is given in table 1 and refers to the launch of unmanned aerial vehicles (drones) to surveil the field.

\begin{tabular}{llll} 
Time & Sender & Receiver & Content of communication \\
\hline 10:01 AM & Responder 1 & Responder 2 & We will launch the drones in five minutes. \\
10:05 AM & Responder 1 & Responder 2 & We are launching the drones. \\
10:14 AM & Responder 1 & Responder 2 & The drones are back on the ground. \\
10:15 AM & Responder 2 & Responder 1 & Let us know when you are flying again. \\
\hline
\end{tabular}

Table 1. Radio communication example

We experienced several issues during coding that we suspect are common problems when dealing with radio systems. The first has to do with radio charts and radio discipline. Members of relief organizations we talked to often praised radio for enabling reliable and standardized patterns of communication among responders.

In particular, this is based on the common practice to prepare radio charts that define the radio name, operational role, and designated radio contacts of all users of a radio system prior to the actual emergency operations. This results in a well structured and hierarchical organizational chart of communication paths among the responders. Relief professionals we interviewed also expressed their intent to ensure compliance with radio discipline, meaning the avoidance of unnecessary calls and calls outside of the predefined routine. Nevertheless, we witnessed cases in which radio charts were incorrect or incomplete, or in which inadequate flows of communication could not be prevented.

During the field exercise, for instance, not all radio names and operational roles were predefined, which led to some confusion because some responders initially did not respond to their assigned radio names. Such unexpected patterns of radio usage can heavily complicate the practical identification of communication events from radio. This issue is, at least in part, related to the inter-organizational nature of emergency relief efforts. In this particular case, one of the relief organizations took the leading role in organizing the exercise. Due to organizational communication barriers, especially lack of trust and information sharing between the involved organizations, some members of other involved relief organizations did not receive all of the information that had been distributed beforehand. Such barriers, which manifest themselves as gaps in the inter-organizational flow of information, are a common phenomenon in this context $[7,13,15]$.

Other problems arose from the quality of the available audio records. While common standards of radio communication (e.g., specifying the radio name of both senders and receivers at the beginning of a message) facilitate identifying users, we were not always able to do so because some recorded passages were inaudible. We were able, however, to identify senders and receivers and the timestamps of communication by relying on additional information from the electronic interface of the digital radio system.

Moreover, we noted that records of radio communication are almost necessarily incomplete. Relief organizations usually intend that all emergency-related communication take place via radio. During the field exercise, however, we could observe that communication, especially for 
longer messages, also took place via unrecorded channels, such as instant messaging, telephone, and face-to-face. Naturally, such communication is not covered by the radio system, which means that records might include non-random and possibly indiscernible discontinuities in the communication flow.

Modeling actors and communication ties from event data. The second challenge we faced was determining network nodes and ties from the event data. While radio users - as indicated by their radio names - could readily be regarded as nodes of the communication network, it was less clear when to assume a communication tie between them.

We discussed the modeling of different types of communication ties and decided to define a tie as the occurrence of a communication event between any pair of sender and (potentially multiple) receivers, under the condition that it referred to the ongoing emergency response operations. In our view, not incorporating additional information on the content of communication is acceptable in the restricted case of a simulated event with a narrow focus on the general structure of emergency responders' operational communications.

Next, we considered the strength and direction of ties. With regard to tie strength, we believe that dichotomization is mostly uncritical in the given context because radio communication essentially reproduced the predefined structures of the radio chart, with repeated communication stressing the role of the known information hubs in the network. As to the directionality of ties, including the directionality of the information flow enables insights into the role of specific users in the communication process. This is information is relevant to our analysis for two reasons.

First, including the direction of ties allows us to distinguish between simple (one directional) commands and information exchanges (reciprocal ties). Second, the normative structure imposed by the participating organizations and emergency relief work in general suggests that the network shows strong hierarchical patterns resembling the information flows suggested by the radio charts. Those hierarchies define directed information flows, which can only be analyzed in directed radio communication networks. Therefore, we distinguish between the senders and receivers of messages and model edges as directed ties flowing from the former to the latter. Note, however, that we regarded receivers' affirmative responses to incoming calls - common in radio communications to signal that receivers are listening or have understood - to be part of the initial call directed towards them, which is part of the standard radio communication protocol that applies in this context.

Figure 2 illustrates different ways of modeling communication ties based on the radio communication recorded during the field exercise. Figure $2 \mathrm{a}$ is the directed, unweighted network on which our subsequent explanations are based. The directed edges indicate the flow of information from the sender (i.e., the radio user initiating the radio call) to the receiver (i.e., the radio user responding to the call).

In contrast, figure $2 \mathrm{~b}$ is the directed, weighted network in which the strength of a communication tie corresponds to the number of concrete instances of communication between two users. The tie strength indicates the sum of communication events between two users. Figure $2 \mathrm{c}$ is the undirected, weighted network and figure $2 \mathrm{~d}$ is the undirected, unweighted network. With regard to the direction of ties, we can see that there are actors who serve primarily as senders 
or receivers of communication, which implies that they might fulfill specific roles in the communication networks (e.g., as coordinators [17]).

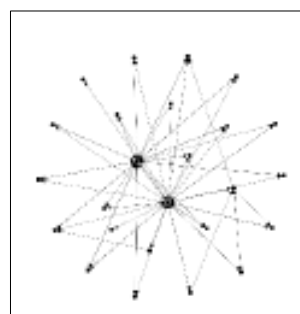

(a)

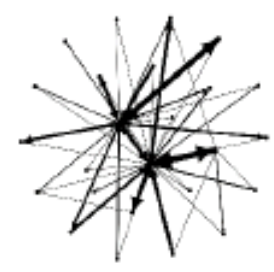

(b)

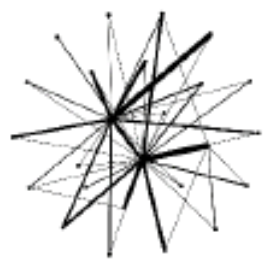

(c)

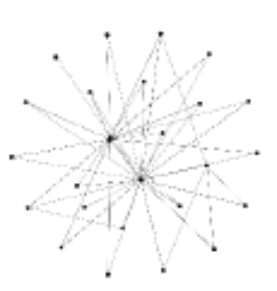

(d)

Figure 2. Temporal aggregation of communication ties in a radio network

Finally, missing ties were a minor problem for our analyses. As already pointed out, radio systems are systematically biased against unrecorded communication events. Such gaps in the records could be of considerable interest, however, because they indicate users' bypassing the designated structures of communication. Missing ties might furthermore derive from the partly untargeted nature of radio communication because emergency responders are used to listening in to bystanders' radio to keep up on the latest information. Therefore, it is not possible to define an exclusive set of receivers, even if the identity of active users is known.

Drawing from our experience, we recommend that radio data should be complemented by other sources, such as observations, interviews, and additional audio records wherever possible. During the field exercise, for instance, we collected additional data through observations and interviews. These additional data allowed us to validate our modeling decisions and verify the results we obtained through SNA. Ideally, network-based research in this context should follow a mixed methods design, which systematically integrates (quantitative) SNA and qualitative methods [6].

Modeling radio communication networks from actors and communication ties. In the next step, we aggregated the network elements extracted from the event data into a communication network. We were concerned in particular with the temporal aggregation of network ties. Our records of radio communication events included exact timestamps, which enabled us to investigate the dynamics of the radio communication network.

We decided to divide the dataset into activity-based timeframes - that is, we generated multiple snapshots of the network, each corresponding to a timeframe covering a specific event during the field exercise. This approach is common in the analysis of digital trace data that are collected in the wake of extreme events.

For instance, previous research has aggregated social media messages that were initiated by the progress of crisis events or specific instances of communication (e.g., warning messages issued by the government) $[4,5]$. The timeframes were identified through a qualitative assessment of all available datasets: radio data, field observations, and interviews.

Figure 3 shows four network snapshots generated based on our approach. Network 3a represents the structure of radio communication between a local responder and a member of a mobile command unit while launching an unmanned aerial vehicle. It includes various status updates of the responder and covers a 15 -minute period. Network $3 \mathrm{~b}$ depicts the communication 
network of several local responders and an operation controller on the issue of coordinating a group of volunteers.

\begin{tabular}{|c|c|c|c|c|}
\hline Figure & Time & Sender & Receiver & Content of communication \\
\hline $3 a$ & $10: 34 \mathrm{AM}$ & Responder 1 & Responder 2 & $\begin{array}{l}\text { We have arrived at the operation } \\
\text { area; We will report as soon as we } \\
\text { are ready for the operation. }\end{array}$ \\
\hline \multirow[t]{5}{*}{$3 b$} & $11: 35 \mathrm{AM}$ & Responder 3 & Responder 4 & $\begin{array}{l}\text { The coordinator of spontaneous } \\
\text { crisis volunteers informed me that } \\
\text { there are no volunteers available } \\
\text { for operation area } 2 \text {. Is that right? }\end{array}$ \\
\hline & $11: 35$ AM & Responder 3 & Responder 4 & That is correct. \\
\hline & $11: 36 \mathrm{AM}$ & Responder 5 & Responder 4 & $\begin{array}{l}\text { We start with the pitching of the } \\
\text { tents in area } 2 \text {. }\end{array}$ \\
\hline & 11:37 AM & Responder 3 & Responder 4 & $\begin{array}{l}\text { Request for security: Are there no } \\
\text { volunteers for operation area } 2 ?\end{array}$ \\
\hline & 11:37 AM & Responder 4 & Responder 3 & $\begin{array}{l}\text { We have four spontaneous crisis } \\
\text { volunteers, which are assigned ex- } \\
\text { clusively to area } 1 \text { and } 3 \text {. More are } \\
\text { not available. }\end{array}$ \\
\hline $3 c$ & $12: 14 \mathrm{AM}$ & Responder 1 & All responders & $\begin{array}{l}\text { Mission accomplished; Lock up the } \\
\text { vehicles and walk to the meeting } \\
\text { place. }\end{array}$ \\
\hline
\end{tabular}

Table 2. Communication events

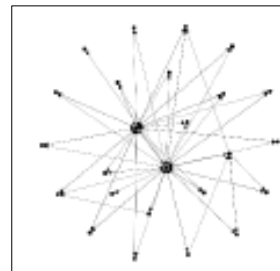

(a)

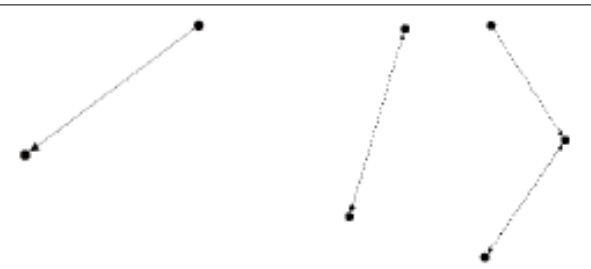

(b) (c)

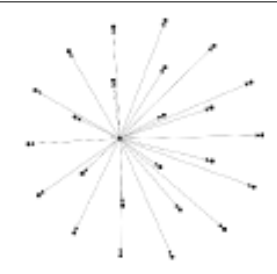

(d)

Figure 3. Four (unweighted, directed) radio communication networks covering four different events

In this case, the network illustrates the exchange of information and orders between users over an 8-minute period. Network $3 \mathrm{c}$ illustrates the final announcement of the upcoming end of operations by a member of a mobile command unit to all radio users in the last minutes of the field exercise. The specific events of radio communication on which these snapshots are based are described in table 2 .

As these examples show, the network structure - and thus the outcomes of SNA based on these structures - depends strongly on the extent of temporal aggregation. Furthermore, the 
figure indicates that variations in the network structure can be captured well by an eventbased approach.

It is noteworthy that radio data allow for precisely identifying the underlying patterns of peerto-peer communication. Figure $3 \mathrm{~b}$, for instance, is an example of unicast communication, in which one sender targets one receiver. In contrast, figure $3 \mathrm{c}$ illustrates a case of concast communication, in which multiple senders address one receiver. Finally, figure $3 \mathrm{~d}$ is an example for multicast communication in which one sender communicates to multiple receivers. While radio communication generally provides various opportunities for these types of communication between the radio users, the common practice of radio system usage prevents broadcast communication by suppressing interactions between users outside the predefined hierarchy.

Table 3 provides an overview of different communication patterns [21] enabled by radio communication in emergency response, to which we also added insights into the role of radio users in the communication process and example instances of this kind of communication.

Selecting appropriate network measures. Having generated a communication network from the radio data, we now focus on appropriate network measures. One instance that was of key interest to us was the hierarchical structure of the communication flows and the role of the mobile command units as central information hubs in the radio network. Although most activities involved only a few users (as figures $3 \mathrm{~b}$ and $3 \mathrm{c}$ illustrate), almost all activities involved members of one or both of the mobile command units. This indicates that these users are essential for controlling the information flow in the network. The relative importance of the units seemed to vary, however, as they took turns answering and passing along calls. We suppose that computing user centralities for each activity-based window could help clarify the role of key users. For instance, the in-degree centrality could assist receivers in identifying users' respective workloads, as indicated by the number of incoming radio messages, and the betweenness centrality could indicate the importance of these users for information diffusion.

\begin{tabular}{lll}
$\begin{array}{l}\text { Communication } \\
\text { pattern }\end{array}$ & Roles of involved radio users & $\begin{array}{l}\text { Functionality of communication } \\
\text { (examples) }\end{array}$ \\
\hline Unicast (1:1) & $\begin{array}{l}\text { Both local responders and infor- } \\
\text { mation hubs as senders and receiv- } \\
\text { ers of communication }\end{array}$ & $\begin{array}{l}\text { Giving and receiving commands, } \\
\text { sending and receiving status up- } \\
\text { dates }\end{array}$ \\
Concast (m:1) & $\begin{array}{l}\text { Both local responders and infor- } \\
\text { mation hubs as senders and receiv- } \\
\text { ers of communication, but infor- } \\
\text { mation hubs as coordinators of } \\
\text { communication }\end{array}$ & $\begin{array}{l}\text { Coordination of response activi- } \\
\text { ties and interactive reporting on } \\
\text { the situation }\end{array}$ \\
& $\begin{array}{l}\text { Operation controllers or members } \\
\text { of the mobile command units as } \\
\text { sulticast (1:m) } \\
\text { manders as well as mobile com- }\end{array}$ & Announcements \\
& $\begin{array}{l}\text { ground as receivers on the } \\
\end{array}$ & \\
\hline
\end{tabular}

Table 3. Communication patterns, roles, and examples of the field exercise 
Inferring theoretical constructs from network measures. Finally, we discuss the insights of our example analysis of a radio network. At first glance, the overall network structure, as illustrated by figure 3a, resembles the information star network as identified by [18]. In particular, the network is highly centralized and characterized by two central information hubs - the mobile command units - that receive and distribute the larger share of information both horizontally and vertically within and between the organizational units. Apart from these hubs, only three other users have more than two communication ties to others. It follows that users mostly stuck to the predefined hierarchical communication structures as stipulated in the radio chart. This insight is not surprising since it mirrors the predefined hierarchical structure imposed by the radio chart that also reflects the hierarchical nature of relief organizations in general.

Considering specific action-based windows instead suggests a more dynamic view of both network structures and the role of the central users within them. Contrasting the degree and betweenness centralities within these windows suggests that the two information hubs alternated in their respective workloads and relevance for ensuring overall communication flow. While this finding is trivial for the small communication network obtained from the field exercise, such knowledge can be crucial during actual emergency response operations, for instance, to ensure an efficient flow of information among responders, design robust communication structures, and prevent information overload of central actors.

Since the field exercise was restricted to a timeframe of only three hours, the extent of observed network dynamics is, of course, limited. Furthermore, the field exercise was the result of a long planning process and involved only low degrees of stress and uncertainty for responders, which is atypical in emergency response operations. Nevertheless, operational tasks were chosen by experienced emergency managers and judged to be realistic by experts from all three relief organizations involved. Therefore, our results allow for initial insights into patterns of communication that might also be observed in a similar way under similar circumstances in a non-simulated emergency response. More importantly, however, we have described an example workflow of how radio data can be utilized for SNA, pointing to the challenges and opportunities of radio systems and indicating initial opportunities for future analyses.

\section{Conclusion}

Our paper's purpose was to discuss how SNA can be used to understand radio communication networks in the context of emergency response. In particular, we outline the importance of modeling and analyzing radio networks appropriately based on [9], experiences from a research project in the emergency management field, and a radio network obtained in an emergency response field exercise. We document and prototype a workflow that can be utilized for generating and analyzing emergency responders' radio communications from an SNA perspective. Given the growing interest in emergency response communication in general $[13,14,19]$, and emergency responders' radio communication in particular $[2,17]$, our work is as a starting point for further SNA research based on such data.

\section{References}

1. Butts, C.T.: Revisiting the Foundations of Network Analysis. Science 325(5939), 414-416 (2009)

2. Butts, C.T., Miruna, P., Cross, R.B.: Responder Communication Networks in the World Trade Center Disaster: Implications for Modeling of Communication within Emergency Settings. Journal of Mathematical Sociology 31(2), 121-147 (2007) 
3. Camp, P.J., Hudson, J.M., Keldorph, R.B., Lewis, S., Mynatt, E.D.: Supporting Communication and Collaboration Practices in Safety-Critical Situations. CHI '00 Extended Abstracts on Human Factors in Computing Systems pp. 249-250 (2000)

4. Chatfield, A.T., Reddick, C.G.: All Hands on Deck to Tweet \#Sandy: Networked Governance of Citizen Coproduction in Turbulent Times. Government Information Quarterly (2017)

5. Chatfield, A.T., Scholl, H.J.J., Brajawidagda, U.: Tsunami Early Warnings via Twitter in Government: Net-Savvy Citizens' Co-Production of Time-Critical Public Information Services. Government Information Quarterly 30(4), 377-386 (2013)

6. Domínguez, S., Hollstein, B.: Mixed Methods Social Networks Research: Design and

Applications. Cambridge University Press (2014)

7. Fischer, D., Posegga, O., Fischbach, K.: Communication Barriers in Crisis Management: A Literature Review. ECIS Proceedings (2016)

8. Houghton, R.J., Baber, C., Richard, M., Stanton, N.A., Salmon, P., Stewart, R., Walker, G.: Command and Control in Emergency Services Operations: A Social Network Analysis. Ergonomics 49(12-13), 1204-1225 (2006)

9. Howison, J., Wiggins, A., Crowston, K.: Validity Issues in the Use of Social Network Analysis with Digital Trace Data. Journal of the Association for Information Systems 12(12), 767797 (2011)

10. International Telecommunication Union (ITU): Emergency and Disaster Relief: ITUR Special Supplement (2006)

11. International Telecommunication Union (ITU): Radio Regulations: Articles (2006)

12. Kapucu, N.: Interorganizational Coordination in Dynamic Context: Networks in Emergency Response Management. Connections 26(2), 33-48 (2005)

13. Kapucu, N.: Interagency Communication Networks during Emergencies: Boundary Spanners in Multiagency Coordination. American Review of Public Administration 36(2), 207-225 (2006)

14. Kapucu, N., Arslan, T., Collins, M.: Examining Intergovernmental and interorganizational Response to Catastrophic Disasters: Toward a Network-Centered Approach. Administration \& Society 42(2), 222-247 (2010)

15. Manoj, B., Baker, A.: Communication Challenges in Emergency Response. Communications of the ACM 50(3), 51-53 (2007)

16. Marsden, P.V.: Network Data and Measurement. Annual Review of Sociology 16, 435- 463 (1990)

17. Miruna, P., Butts, C.T.: Emergent Coordination in the World Trade Center Disaster. imbsdev.ss.uci.edu/files/docs/technical/2005/mbs05_03.pdf, accessed 2018-01-07 (2005)

18. Pan, S.L., Pan, G., Leidner, D.E.: Crisis Response Information Networks. Journal of the Association for Information Systems 13(1), 31-56 (2012)

19. Uhr, C., Johansson, H., Fredholm, L.: Analysing Emergency Response Systems. Journal of Contingencies and Crisis Management 16(2), 80-90 (2008)

20. Wassermann, S., Faust, K.: Social Network Analysis: Methods and Applications (1994)

21. Wittmann, R., Zitterbart, M.: Multicast Communication: Protocols, Programming, \& Applications. Morgan Kaufmann (2000) 
Appendix A2

Emergency Management Information Systems for Public Emergency Communication 


\section{Appendix A2.1: Paper IV}

Crisis Warning Apps: Investigating the Factors Influencing Usage and Compliance with Recommendations for Action

\section{Fact Description}

Bibliographic data $\quad$ Fischer, D., Hattori-Putzke, J., and Fischbach, K. (2019). "Crisis Warning Apps: Investigating the Factors Influencing Usage and Compliance with Recommendations for Act," in Proceedings of the Hawaiian Conference on Information Systems, Maui, Hawaii.

https://aisel.aisnet.org/hicss-52/cl/crisis_and_emergency_management/3/ 


\section{Appendix A2.2: Paper V}

A Protection-Motivation Perspective to Explain Intention to Use and Continue to Use Mobile Warning Systems

\section{Fact Description}

Bibliographic data $\quad$ Fischer-Preßler, D., Bonaretti, D., and Fischbach, K., (forthcoming) "A Protection-Motivation Perspective to Explain Intention to Use and Continue to Use Mobile Warning Systems," Business \& Information Systems Engineering (BISE).

DOI: $10.1007 / \mathrm{s} 12599-021-00704-0$

https://link.springer.com/article/10.1007/s12599-021-00704-0 


\section{Appendix A2.3: Paper VI}

The Problem with Campus Warning: An Evaluation Based on Recipients Spatial Awareness

\section{Fact Description}

Bibliographic data
Bonaretti, D. and Fischer-Preßler, D. (2021) "The Problem with Campus Warning: An Evaluation Based on Recipients Spatial Awareness," in International Journal of Disaster Risk Reduction.

DOI: $10.1016 / j . i j d r r .2020 .102031$

https://www.sciencedirect.com/science/article/abs/pii/S2212420920315338 


\section{Appendix A2.4: Paper VII}

\section{Effective Use of Mobile-Enabled Emergency Warning Systems}

\section{Fact Description}

Bibliographic data $\quad$ Fischer-Preßler, D., Bonaretti, D., and Fischbach, K. (2020). "Effective Use of Mobile-Enabled Emergency Warning Systems," in 28th European Conference on Information Systems, Marrakesh, Marocco.

https://aisel.aisnet.org/ecis2020_rp/130/ 


\section{Appendix A2.5: Paper VIII}

Understanding Failures of Emergency Warning Systems: A Representation Perspective

\section{Fact Description}

Bibliographic data $\quad$ Fischer-Preßler, D., Bonaretti, D., and Fischbach, K., (2021) “Understanding Failures of Emergency Warning Systems: A Representation Perspective," in Proceedings of the International Conference on Information Systems, Austin, Texas. (Best Paper Nomination).

https://aisel.aisnet.org/icis2021/is_resilience/is_resilience/1/ 


\section{Appendix A2.6 Paper IX}

\section{Applied Ethics and Digital Information Privacy: Informing the Design of Covid-19 Contact Tracing Apps}

\section{Fact Description}

Bibliographic data $\quad$ Eismann, K., Fischer-Preßler, D., and Fischbach, K., "Applied Ethics and Digital Information Privacy: Informing the Design of Covid-19 Contact Tracing Apps."

Status of publication Unpublished working paper under second review in the Australasian Journal of Information Systems

Copyright notice The copyright resides with the authors. 


\title{
Applied Ethics and Digital Information Privacy: Informing the De- sign of Covid-19 Contact Tracing Apps
}

\begin{abstract}
To counteract the spread of Covid-19, many countries have introduced mobile applications for contact tracing, which raises considerable questions about how these apps protect users' information privacy. Through an exploratory analysis of Covid-19 contact tracing apps being used in Australia, France, Germany, Japan, and New Zealand, we identify normative and technical principles for the design of privacy-sensitive contact tracing apps. Based on a Restricted Access/Limited Control (RALC) account of information privacy, we discuss how the apps protect users' information privacy through limiting access to and allowing users to actively manage their personal information. Our findings illustrate what understanding of information privacy is evident from the various designs of Covid-19 contact tracing apps, and how competing design principles can contribute to users' information privacy. From a practical perspective, our findings can inform the design of contact tracing apps and the development of privacy approaches that can be applied in particular contexts. Our work thus bridges the gap between ethical design guidelines and technical analyses of specific implementations.
\end{abstract}

Keywords: applied ethics; disclosive computer ethics; information privacy; mobile app; contact tracing; coronavirus; Covid-19; crisis; pandemic; normative theory

\section{Introduction}

The coronavirus pandemic has confronted public health officials throughout the world with the urgent need to contain infections and stop the spread of the highly contagious and harmful Covid-19 disease. As it spread across the globe, borders were closed, social and economic life came to a standstill, and health infrastructures nearly collapsed. Almost a year into the pandemic, neither medication nor vaccinations were available; in February 2021, the World Health Organization had registered more than 105 million cases and more than 2.2 million fatalities due to Covid-19 worldwide (WHO, 2021b).

To counteract further spread of the virus and prevent sustained economic damage and the loss of human life, public health interventions through which people can avoid exposure to the coronavirus-such as cordons sanitaire, traffic restrictions, and social distancing-have gained momentum (e.g., Di Gennaro et al., 2020, Pan et al., 2020). Beyond that, the WHO has established contact tracing as a key strategy for interrupting transmission chains, as people who have been in contact with an infected person can be identified and advised to quarantine to prevent further transmissions (WHO, 2021a).

However, classical procedures for identifying the contacts of an infected person can be ineffective, if, for instance, a person's contacts are unknown or low levels of automation cause delays in the identification and contacting of people at risk (WHO, 2021a). Therefore, governments have considered, and some have implemented, mobile applications-so-called contact tracing apps-to trace infections and provide health advice to citizens. Mobile applications reduce reliance on human recall and hence can be more effective than classical procedures for contact tracing, especially in densely populated areas with high degrees of mobile connectivity (Budd et al., 2020). These digital tools were thus ascribed an important role in limiting the propagation of the pandemic (WHO, 2021a). 
Contact tracing apps are applications that run on a smartphone and allow tracing encounters between users. They are a technical approach to tracking epidemic chains of infection and stopping the spread of Covid-19. Basically, they are used to alert users who have been in contact with another infected user, but may not (yet) show typical symptoms of the Covid-19 disease. Those users can then be advised to self-isolate and get tested. Users receive a warning via the app that they might be at risk of an infection if they have been close (e.g., within a couple of meters) to another user diagnosed with Covid-19 if that proximity was for an epidemiologically relevant time interval (e.g., 15 or more minutes) within a relevant timeframe (e.g., an estimated incubation period of 14 days for the infected person). Users so warned can then seek medical advice and take appropriate action. If they are themselves diagnosed with Covid-19, they can update their status within the app so others who have been close can also receive warnings (Ahmed et al., 2020).

To enable effective tracing, however, apps need to collect sensitive personal data, which includes records of users' health, movements, and social interactions (Morley, Cowls, Taddeo, \& Floridi, 2020). Experts warned early on that personal information collected through contact tracing apps could be exposed to a number of security risks that threaten user information privacy. Privacy could be compromised due to, for instance, technical problems or cyberattacks, potential misuse of personal data due to large-scale social surveillance, and illegitimate repurposing of the information collected (e.g., Klar \& Lanzerath, 2020). Concerns over data protection and information privacy norms could negatively affect people's intention to use these apps (e.g., Chan \& Saqib, 2021, Fischer, Hattori-Putzke, \& Fischbach, 2019; Fodor \& Brem, 2015), which, in turn, could lower the efficacy of app-based contact tracing (Trang, Trenz, Weiger, Tarafdar, \& Cheung, 2020).

Several guidelines have been developed, both by researchers (e.g., Floridi, 2020; Klar \& Lanzerath, 2020) and public health institutions (e.g., European Commission, 2020; WHO, 2020), to promote the design of apps for Covid-19 contact tracing that preserve users' information privacy. Still, analyses suggest that despite government claims to honor citizen information privacy, several apps have failed to meet essential requirements of privacy-sensitive design (e.g., Hatamian, Wairimu, Momen, \& Fritsch, 2021, Woodhams, 2020). Clearly, the risk of information privacy violations cannot be eliminated through technical implementation alone, but relies on a shared understanding of what constitutes information privacy violations through illegitimate access and use of personal information.

Our work bridges the gap between ethical design principles for and technical evaluations of Covid-19 contact tracing apps. Based on the Restricted Access/Limited Control (RALC) framework of information privacy (Moor, 1997; Tavani \& Moor, 2001), we evaluate the normative and technical design principles that have-explicitly or implicitly-guided the development of apps deployed as early as during the second half of 2020 in five liberal democracies. Our analyses are based on two complementary research questions:

RQ1: What normative and technical design principles to protect information privacy are evident from Covid-19 contact tracing apps?

RQ2: What understanding of information privacy is evident from the design of Covid-19 contact tracing apps?

Going beyond purely normative approaches, we establish a frame of reference that explicates standards of privacy-sensitive design from the perspective of real-world mobile applications, 
thus emphasising principles that are both technically applicable and in line with the ethical standards of liberal democracies. In contrast to mere technical analyses, we elaborate how the identified design principles relate to ethical information-privacy requirements, and discuss how they might contribute to the achievement of normative goals.

Our research approach is one of explicit morality (Stahl, 2012), as we explicate the normative understanding of information privacy that is evident from the design of existing Covid-19 contact tracing apps. Thus, we aim to clarify what users can expect with respect to the protection of their personal information when using these apps. While developing full-fledged ethical theory is beyond the scope of this paper, we identify normative and technical design principles that can guide the design of technical artifacts that allow large-scale collection of sensitive personal data. Finally, our work demonstrates how concepts of normative theory can be analysed based on empirical design choices, which can encourage researchers to abstract information privacy conceptualisations and possible breaches within a certain artifact under investigation and evaluate alternative solutions in terms of how they afford information privacy.

We apply disclosive computer ethics to analyse information privacy conceptualisations evident from existing Covid-19 contact tracing apps, as described by Brey (2000a, 2000b). Key to our work is the assumption that while the apps have been designed to preserve information privacy in line with pertinent laws and social norms (e.g., European Parliament, 2020), their design and other features determine the extent of information privacy when using the apps. Based on an exploratory analysis of information-privacy principles evident from the five analysed apps, we evaluate how the measures implemented relate to normative and technical protections of information privacy, as conceptualised by the RALC framework, and discuss how normative theory can hence guide the design of privacy-enhancing artifacts.

Below, we briefly delineate the theoretical notion of information privacy that underlies our work, and how Covid-19 contact tracing apps might violate it. Furthermore, we explain how normative and technical design principles, according to the RALC framework, could help protect information privacy. On that basis, we describe our research methodology and the findings of the exploratory analysis and theoretical evaluation, and discuss the theoretical and practical implications of our work.

\section{Information Privacy in the Context of Covid-19 Contact Tracing Apps}

Information privacy is a subset of general privacy (Bélanger \& Crossler, 2011) that refers specifically to personal information (Smith, Dinev, \& Xu, 2011), which, in turn, implies "facts about a person which most individuals ... do not want widely known about themselves" (Parent, 1983, pp. 269-270). In a normative sense, information privacy is one of liberal societies' key moral values, whereas in a descriptive sense, it refers to a quality of a situation that can be present or absent (Becker, 2019). Thus, information privacy comprises "the claims of individuals that data about themselves should generally not be available to other individuals and organisations, and that, where data is possessed by another party, the individual must be able to exercise a substantial degree of control over that data and its use" (Clarke, 1999, p. 60).

Digitally enhanced means of information sharing and communication are widely believed to threaten people's information privacy, especially because they enable constant and unobtrusive monitoring and profiling (Becker, 2019). They make it easy to record, analyse, and share personal information about users, retain it for an indefinite time, match it with data from sec- 
ondary sources, and thus generate novel and possibly revealing insights about users (Nissenbaum, 1998). In addition, they may incentivise users to contribute additional information about themselves to facilitate interactions (Volokh, 2000)-a condition commonly known as the "commodification of privacy" (Campbell \& Carlson, 2002).

Information privacy is only one among several ethical issues that require consideration with Covid-19 contact tracing apps (Floridi, 2020). In fact, Blasimme and Vayena (2020, p. 761) conclude that most of these apps "are built with a proactive commitment to privacy-preserving technological features (privacy by design) and only use strictly necessary data (privacy by default)." Existing Covid-19 contact tracing apps have typically been developed with an explicit commitment to pertinent privacy laws and regulations; many, if not most, have been subjected to intensive public debate and scrutiny to enhance their compliance with commonly shared social norms (e.g., European Parliament, 2020).

Still, the risk of misuse and vulnerability of personal information collected on a large scale (e.g., due to hacking or cyberattacks) remains (Klar \& Lanzerath, 2020). Furthermore, absent evidence on the efficacy of the apps, users' information privacy may be threatened by a lack of proportionality, as well as the risk of function creep if the data collected through the apps is repurposed, potential ignorance of sunset clauses and continued use of the apps even after the Covid-19 pandemic is declared contained, and the risk of unrevealed non-voluntariness if social or economic conditions render the use of the apps obligatory in some de facto way (Ishmaev, Dennis, \& van den Hoven, 2021). Furthermore, information privacy risks arise in cases where malevolent users can infer from the app who may be infected, state-level agents or service providers can access personal user information illegitimately, or if such information is leaked due to negligence or malicious attacks (Boutet et al., 2020). Rowe (2020) also observes that governments tend to overemphasise the potential short-term benefits of using Covid-19 contact tracing apps, while downplaying long-run threats to information privacy.

Covid-19 contact tracing apps can threaten users' information privacy in two fundamental ways: they can interfere with users' ability to control access to their personal information (privacy as control); and they can facilitate the access by others to personal information about a user in a given situation (information as a state). While the former defines information privacy in terms of the ability of agents to control access to information about themselves, the latter understands it as a condition in which access to personal information is limited to some extent (Smith et al., 2011). Both conceptions of information privacy have their roots in historical privacy theories, and both come with a number of theoretical virtues and drawbacks (Tavani, $2007,2008)$. However, understanding information privacy merely in terms of control is problematic when agents deliberately relinquish control over information about themselves (Tavani \& Moor, 2001).

In the Restricted Access/Limited Control (RALC) framework of information privacy, by contrast, Moor (1997) and Tavani and Moor (2001) define information privacy primarily in terms of limited access to personal information. They recognize that while perfect control over personal information may be impossible when it comes to digital information and communications technologies, people should be able to rule out undesired access to and use of information about themselves. The RALC framework integrates two elements: the condition of privacythe extent to which information privacy is present in a particular situation, and which relies on the absence of access to personal information; and the management of privacy-people's ability to determine who can access information about them for what purpose and in what ways, which requires that information subjects have control over their personal information. 
Through actively managing access to personal information, agents are hence assumed to determine the amount of information privacy in a given situation.

According to the RALC framework, information privacy is a characteristic of situations in which people are normatively protected from intrusion, interference, and information access by others. Situations are the key unit of the RALC framework; they can comprise locations, relationships, and activities. Situations can be naturally private, meaning there are natural or physical circumstances that protect people from intrusion or observation. In naturally private situations, privacy exists as a matter of fact. When others gain access to information about a person in such situations, that person's privacy is lost but not violated, as they do not have a normative claim to it. In contrast, in normatively private situations, personal information is protected through norms that determine who may access it. These norms constitute a person's right to privacy in a particular situation; privacy is violated only when pertinent norms are trespassed (Moor, 1997; Tavani \& Moor, 2001).

RALC introduces three mechanisms of individual control through which actors can achieve an adequate level of information privacy, although they do not constitute a right to privacy beyond what is granted by situational norms: choice over situations that offer the desired level of information privacy; consent to give up the right to information privacy in a particular situation; and correction of personal information collected (Tavani \& Moor, 2001).

Just as in the case of offline social relations, interactions enabled by digital information and communications technologies can constitute situations (Tavani, 2007). Thus, from a RALC perspective, using a contact tracing app can constitute both a naturally and a normatively private situation, depending on the context of app use and the specific design of the app. While pertinent social and legal norms and a shared understanding that users must somehow be able to determine to whom their personal information is made available are the basis for normative protection of their information privacy, it is the app's technical features that determine the extent to which users are actually protected from intrusion, and hence render app usage naturally private. Figure 1 illustrates how the use of Covid-19 contact tracing apps can be interpreted within the RALC framework.

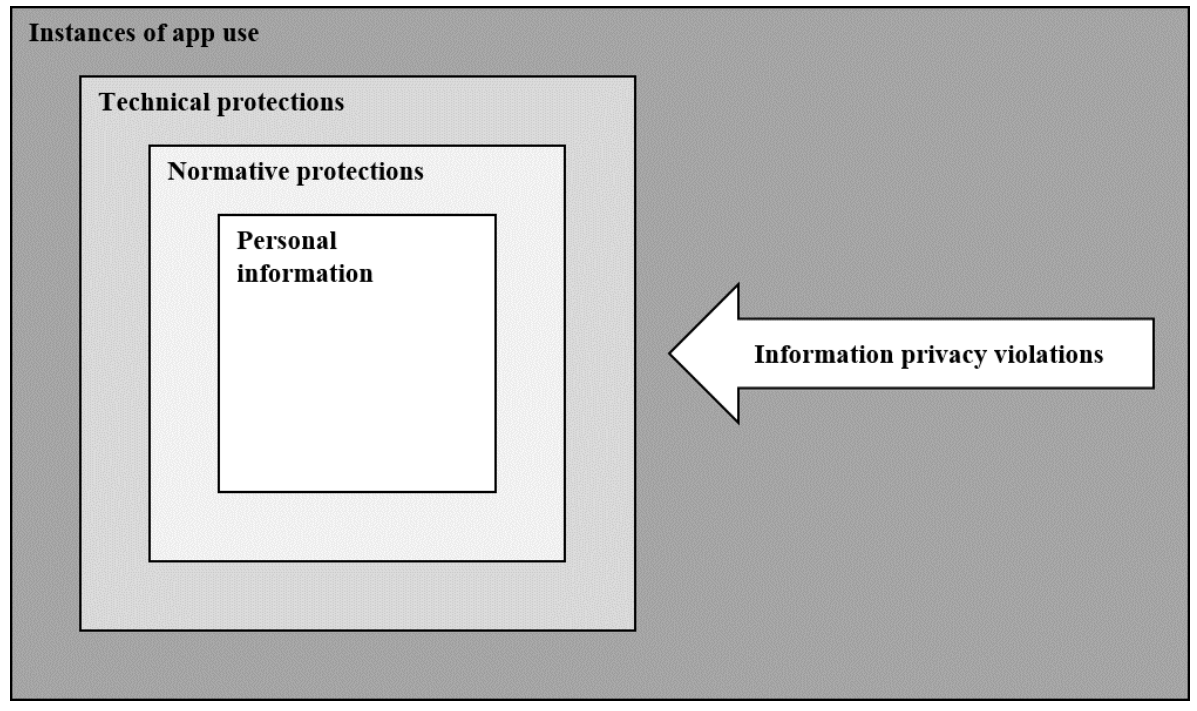

Figure 1 A RALC perspective on information privacy in the context of Covid-19 contact tracing app use. 
In our work, it is instances of app use that constitute the situations to be analysed. Those are characterised by two key attributes: personal information that is exposed to potential information privacy violations, and the information privacy violations that potentially apply. Personal information is embedded within two layers of protection. The first layer is normative protections of information privacy, which consists of norms-broadly defined as principles of action that specify appropriate behaviour in a given society - that determine what information about users may be legitimately accessed through the app, by whom, and under what conditions. Access to personal information contravening these norms is considered to violate users' information privacy. The second layer is technical protections of information privacy, which comprise the particular technical features through which personal information is protected from unwarranted access. These constitute natural barriers in the RALC terminology: they do not grant users a normative right to information privacy, but nevertheless can be effective in preventing access to their personal information.

Below, we explain how we have analysed these key elements of existing Covid-19 contact tracing apps, following a disclosive research approach, and elaborate on what our insights reveal about the understanding of information privacy that is evident from the apps' design.

\section{$3 \quad$ Research Methodology}

\subsection{Disclosive Computer Ethics}

In our research, we have followed the tenets of disclosive computer ethics, assuming that technological artifacts are not morally neutral, but may have hidden moral properties that can be uncovered through disclosive analysis (Brey, 2000a, 2000b). Basically, technological artifacts are assumed to serve as mechanisms that constrain people's individual and social behaviors, and hence can enforce or promote normative action (Brey, 2000b).

Studies in disclosive computer ethics require a two-step approach. Relying on an inductive approach, in the first step, a technological artifact is analysed from the perspective of some moral value to draw preliminary conclusions regarding the relationship of the artifact's features to the moral value of interest. Then, in the second step, moral theory can be applied to evaluate more specifically the artifact's normatively relevant features and properties, which also creates the potential for further developing existing theory (Brey, 2000a, 2000b).

Below, we explain how we have analysed the normative and technical design principles that determine how the technological artifacts in our work-mobile apps for Covid-19 contact tracing-protect information privacy, based on the RALC framework delineated above.

\subsection{Case Selection and Data Acquisition}

Our analyses are based on Covid-19 contact tracing apps from five liberal democracies (according to Freedom House; Repucci \& O'Toole, 2020) that released the apps for their residents to use as early as the second half of 2020: Australia, France, Germany, Japan, and New Zealand. We selected these countries because they provide early examples of privacy-sensitive design for Covid-19 contact tracing apps (as opposed to digital tools applied for other purposes, such as outbreak detection and case identification; Budd et al., 2020) against a somewhat comparable socio-political background.

These countries' governments have all stated that the apps comply with national privacy laws and regulations, and were designed especially to meet pertinent norms of information privacy. In the European Union, for instance, the ROBERT (ROBust and privacy-presERving proximity 
Tracing) protocol was established to facilitate developing privacy-preserving contact tracing apps in line with the pertinent General Data Protection Regulation (GDPR), and governments have established a priori guidelines to guide that work (e.g., European Parliament, 2020). The approaches taken to protect information privacy, however, vary. This purposive sample of Covid-19 contact tracing apps thus allows us to draw conclusions about the implementation of information privacy concerns in liberal democracies based on cases with maximum possible heterogeneity at the time. Table 1 is an overview of the apps analysed.

The five apps we studied are applications for contact tracing that analyse physical contacts between people, using Bluetooth, for instance, to measure the distance between smartphones on the basis of signal strength and thus detect potential encounters between users (i.e., proximity tracing). Unlike other mobile apps that track people's geo-locations (i.e., tracking apps), proximity tracing apps cannot be used to create detailed movement profiles to monitor people's behaviors, for instance, to ensure compliance with quarantine orders. While both involve sensitive data, privacy concerns for the two types of applications differ, and proximity tracing apps are considered, by design, to be more privacy-sensitive (Taddeo, 2020) and also more compatible with privacy expectations in liberal democracies than tracking solutions that have been used in South Korea, Taiwan, and Israel, among other countries (Zastrow, 2021).

We downloaded the official documentation provided by the institutions in each country responsible for the development, infrastructure, and service provision of the apps (date of reference: 2020-06-30). We analysed English versions of the documents, using machine translations (Google Translate) when English texts were not available. 
Table 1 Overview of Covid-19 contact tracing apps

\begin{tabular}{|c|c|c|c|}
\hline $\begin{array}{l}\text { Country } \\
\text { (app name) }\end{array}$ & Description & $\begin{array}{l}\text { Responsible } \\
\text { institutions }\end{array}$ & $\begin{array}{l}\text { Information } \\
\text { sources used } \\
\end{array}$ \\
\hline $\begin{array}{l}\text { Australia } \\
\text { (COVIDSafe) }\end{array}$ & $\begin{array}{l}\text { - To use the app, users must register and provide personally identifying } \\
\text { information that is used to contact them in case they are at risk of infection; the } \\
\text { information is stored on a central server. } \\
\text { - Within the app, each user is represented by an automatically generated ID that } \\
\text { changes at regular intervals to prevent users from inferring their own or others' } \\
\text { IDs. } \\
\text { - The app uses Bluetooth to detect other users nearby. In case of an encounter, it } \\
\text { saves these users' IDs, the date and time of contact, phone model, and Bluetooth } \\
\text { signal strength. } \\
\text { - Infected users are notified by human contact tracers and asked to upload their } \\
\text { encounter information to a central server. If they consent to do so, they receive a } \\
\text { PIN to authorise the transmission. } \\
\text { - Contact tracers then use the encounter information and personal ID information } \\
\text { of other users to identify and prioritise persons who may have been in contact } \\
\text { and advise them of their risk status. }\end{array}$ & $\begin{array}{l}\text { Australian Gov- } \\
\text { ernment De- } \\
\text { partment of } \\
\text { Health }\end{array}$ & $\begin{array}{l}\text { Australian Gov- } \\
\text { ernment, 2020; } \\
\text { Australian Gov- } \\
\text { ernment Depart- } \\
\text { ment of Health, } \\
2020\end{array}$ \\
\hline $\begin{array}{l}\text { France } \\
\text { (StopCovid) }\end{array}$ & $\begin{array}{l}\text { - Once installed, the app creates a unique identifier that represents the user. } \\
\text { - The app uses Bluetooth to detect other users nearby. In case of an encounter, it } \\
\text { saves these users' IDs, the date and time of contact, and the inferred distance } \\
\text { between users based on Bluetooth signal strength. } \\
\text { - Infected users receive a QR code or similar proof from public health services, } \\
\text { which they can use to update their health status within the app. } \\
\text { If they update their status, the infected user's encounter history is uploaded to a } \\
\text { central server and warnings are sent to the devices of other users for whom an } \\
\text { encounter was registered. }\end{array}$ & $\begin{array}{l}\text { Ministry of the } \\
\text { Economy, Fi- } \\
\text { nance and Re- } \\
\text { covery }\end{array}$ & $\begin{array}{l}\text { Inria, 2020a, } \\
\text { 2020b, 2020c; } \\
\text { Ministére De } \\
\text { L'économie des } \\
\text { Finances et de la } \\
\text { Relance, 2020a, } \\
\text { 2020b }\end{array}$ \\
\hline $\begin{array}{l}\text { Germany } \\
\text { (CoronaWarn) }\end{array}$ & $\begin{array}{l}\text { - Each user is represented within the app by an automatically generated ID, which } \\
\text { changes at regular intervals to prevent users from inferring their own or others' } \\
\text { IDs. } \\
\text { - The app uses Bluetooth to detect other users nearby. In case of an encounter, it } \\
\text { saves these users' IDs, the date and time of contact, and the inferred distance }\end{array}$ & $\begin{array}{l}\text { German Fed- } \\
\text { eral Govern- } \\
\text { ment }\end{array}$ & $\begin{array}{l}\text { Corona Warn } \\
\text { App Open } \\
\text { Source Project, } \\
\text { 2020; The Fed- }\end{array}$ \\
\hline
\end{tabular}




\begin{tabular}{|c|c|c|c|}
\hline $\begin{array}{l}\text { Country } \\
\text { (app name) }\end{array}$ & Description & $\begin{array}{l}\text { Responsible } \\
\text { institutions }\end{array}$ & $\begin{array}{l}\text { Information } \\
\text { sources used }\end{array}$ \\
\hline & $\begin{array}{l}\text { between users based on Bluetooth signal strength. } \\
\text { Infected users receive a QR code or similar proof from public health services, } \\
\text { which they can use to update their health status within the app. } \\
\text { - If they update their status, the infected user's ID is uploaded to a central server, } \\
\text { which in turn makes it available to others' devices, which compare it with those } \\
\text { users' own encounter histories and generate warnings if they have registered an } \\
\text { encounter with the infected user. }\end{array}$ & & $\begin{array}{l}\text { eral Govern- } \\
\text { ment, } 2020 \mathrm{~b} \text {, } \\
2020 \mathrm{a}\end{array}$ \\
\hline $\begin{array}{l}\text { Japan } \\
\text { (COCOA - } \\
\text { COVID-19 Con- } \\
\text { tact) }\end{array}$ & $\begin{array}{l}\text { - Each user is represented within the app by an automatically generated ID, which } \\
\text { changes in regular intervals to prevent users from inferring their own or others' } \\
\text { IDs. } \\
\text { - The app uses Bluetooth to detect other users nearby. In case of an encounter, it } \\
\text { saves these users' IDs, the date and time of contact, and the inferred distance } \\
\text { between users based on Bluetooth signal strength. } \\
\text { - Infected users can register with their email address or phone number to receive a } \\
\text { processing number from public health services, which they can use to update } \\
\text { their health status within the app. } \\
\text { - If they update their status, an infected user's ID is uploaded to a central server, } \\
\text { which in turn makes it available to others' devices, which compare it with those } \\
\text { users' own encounter histories and generate warnings if they have registered an } \\
\text { encounter with the infected user. }\end{array}$ & $\begin{array}{l}\text { Ministry of } \\
\text { Health, Labour } \\
\text { and Welfare }\end{array}$ & $\begin{array}{l}\text { Ministry of } \\
\text { Health, Labour } \\
\text { and Welfare, } \\
\text { 2020a, 2020b }\end{array}$ \\
\hline $\begin{array}{l}\text { New Zealand } \\
\text { (NZ COVID } \\
\text { Tracer) }\end{array}$ & $\begin{array}{l}\text { - Users must sign up with their email addresses to use the app. They can add } \\
\text { further personally identifying information to their profiles. } \\
\text { - The app allows users to keep a digital diary of locations visited, which they can } \\
\text { enter by scanning QR codes or manually adding entries of places, activities, dates, } \\
\text { and times visited. } \\
\text { - Users who are confirmed or deemed likely to be infected are notified by contact } \\
\text { tracers to upload their location history to a central server. } \\
\text { - If they update their status, human contact tracers evaluate the location history } \\
\text { and identify locations at which persons in contact with an infected user would } \\
\text { have been at risk of infection. These locations are made available to users' } \\
\text { devices, which in turn generate warnings if they detect a match between their }\end{array}$ & $\begin{array}{l}\text { Ministry of } \\
\text { Health }\end{array}$ & $\begin{array}{l}\text { Ministry of } \\
\text { Health, 2020a, } \\
\text { 2020b }\end{array}$ \\
\hline
\end{tabular}




\begin{tabular}{|l|l|l|l|}
\hline $\begin{array}{l}\text { Country } \\
\text { (app name) }\end{array}$ & Description & $\begin{array}{l}\text { Responsible } \\
\text { institutions }\end{array}$ & $\begin{array}{l}\text { Information } \\
\text { sources used }\end{array}$ \\
\hline & own location entries and a relevant exposure location and timeframe. & \\
& & & \\
\hline
\end{tabular}




\subsection{Exploratory Analysis}

Following from the RALC framework (Moor, 1997; Tavani \& Moor, 2001), we understand information privacy in terms of limited access to information about a person, with the subjects of the information being able to determine by whom, in what ways, and to what end that information is accessed and used. This definition is thus in line with prior research in information systems (Smith et al., 2011), but also broad enough to encompass different understandings of what information is subject to privacy concerns, what constitutes unwarranted access to and use of personal information, and how apps can be designed to protect user information privacy.

We used a multistage qualitative coding procedure to analyse the apps. In the first stage, we identified statements that referred to personal information about users from each app's documentation. In the second stage, we used these statements to develop inductive codes that describe what information about app users was specified as collected or not collected, what kind of access to or use of that information might violate user information privacy, and what normative and technical design principles were applied to afford information privacy protection. In the third stage, we summarised these descriptive codes into coherent categories, which we describe in the following section. Two of the paper's authors undertook qualitative coding, with one in charge of each coding stage and the other reviewing and revising the codes. Disagreements were resolved through consensual discussion.

Below, we summarise our findings on the types of personal information collected by these Covid-19 contact tracing apps, the violations of user information privacy accounted for, and the different approaches to preventing violations spelled out in the documentation.

\section{Results of the Exploratory Analysis of Covid-19 Contact Tracing Apps}

\subsection{Personal Information Collected}

The Covid-19 contact tracing apps we studied collect different types of personal information: person identifying information that allows for identifying a particular person who may be using the app (i.e., users and other persons about whom information is collected through the app); user identifying information that allows for identifying a particular user or device on which the app is installed; encounter information about contacts between users through which Covid-19 might be transmitted; user profile information about user preferences and activities using the app; and health status information about a user's actual or potential Covid-19 infection. Table 2 is an overview of the types of personal information collected by the analysed apps.

Table 2 Personal information collected by Covid-19 contact tracing apps

\begin{tabular}{|c|c|c|c|c|c|}
\hline Countries & AUS & FRA & DEU & JPN & NZL \\
\hline \multicolumn{6}{|c|}{ Person identifying information } \\
\hline Name & $\mathrm{X}$ & & & & \\
\hline Age range & $\mathrm{X}$ & & & & \\
\hline Post code & $\mathrm{X}$ & & & & \\
\hline Phone number & $\mathrm{X}$ & $\mathrm{X}$ & & $\mathrm{X}$ & \\
\hline Email address & & $\mathrm{X}$ & & $\mathrm{X}$ & $\mathrm{X}$ \\
\hline Social contacts & & & & & $\mathrm{X}$ \\
\hline \multicolumn{6}{|c|}{ User identifying information } \\
\hline Device model & $\mathrm{X}$ & & & & \\
\hline Location & & & & & $\mathrm{X}$ \\
\hline Activities & & & & & $\mathrm{X}$ \\
\hline
\end{tabular}




\begin{tabular}{llllll}
\hline Encounter information & & & & & \\
Date and time & $\mathrm{X}$ & $\mathrm{X}$ & $\mathrm{X}$ & $\mathrm{X}$ & $\mathrm{X}$ \\
Spatial proximity & $\mathrm{X}$ & $\mathrm{X}$ & $\mathrm{X}$ & $\mathrm{X}$ & \\
Duration of contact & $\mathrm{X}$ & $\mathrm{X}$ & $\mathrm{X}$ & $\mathrm{X}$ & \\
\hline User profile information & & & & & \\
$\quad$ User identifier & $\mathrm{X}$ & $\mathrm{X}$ & $\mathrm{X}$ & $\mathrm{X}$ & \\
$\begin{array}{l}\text { Encounter history } \\
\text { User interests }\end{array}$ & $\mathrm{X}$ & $\mathrm{X}$ & $\mathrm{X}$ & $\mathrm{X}$ & $\mathrm{X}$ \\
\hline Health status information & $\mathrm{X}$ & & & \\
$\quad \begin{array}{l}\text { Positive test result } \\
\text { Risk status (binary) }\end{array}$ & $\mathrm{X}$ & $\mathrm{X}$ & $\mathrm{X}$ & $\mathrm{X}$ \\
$\begin{array}{l}\text { Risk status (qualita- } \\
\text { tive) }\end{array}$ & $\mathrm{X}$ & $\mathrm{X}$ & $\mathrm{X}$ & $\mathrm{X}$ & $\mathrm{X}$ \\
Health record & & & & \\
\hline
\end{tabular}

Only the Australian app requires users to enter a name, age range, postal code, and contact phone number to facilitate tracing. The New Zealand app allows users to enter personal details and information about their social contacts to identify other people who might be at risk; users must also provide an email address to complete the registration. The French and Japanese apps require an email address or mobile phone number so infected users can receive a verification code to authorise health status updates that indicate they have become infected. The German app does not collect person identifying information.

Both the Australian and the New Zealand apps collect information that can be used to trace individual users. The Australian app registers the model of the smartphone on which the app is installed, and the New Zealand app asks users to enter information about their locations and activities to detect potential encounters. In contrast, the French, German, and Japanese apps stress that no information is collected that would enable identifying the user or the device on which the app is installed. None of the analysed apps collects geolocation information.

In addition to person and user identifying information, all the apps except the New Zealand app create unique identifiers for each user. These are linked to the records of users' previous encounters and are exchanged between nearby devices to constitute encounters; they use Bluetooth to record the dates, times, and estimated duration of encounters and proximity of contact based on Bluetooth signal strength. The New Zealand app does not record encounters directly; rather, it allows users to keep a digital diary of places they have visited and infers from that possible encounters with other users who have checked in at the same location at the same time.

Finally, all the apps allow users to update their health status if they have tested positively for Covid-19. This information is then combined with encounter information to evaluate users' risk status and issue warnings accordingly. Estimated risk status can be binary, as in the French, German, and Japanese apps - that is, the app differentiates only between users who are at risk of infection (because they have been close to an infected user for an epidemiologically relevant period) and those who are not. The Japanese app allows users who have received a warning to enter further information about their health status and possible symptoms so they can be provided with more tailored advice.

The Australian and New Zealand apps allow for more detailed qualitative risk assessments. Risk status with the Australian app is evaluated by human contact tracers, who get in touch 
with users who might be at risk of infection based on their encounter information and other information, such as the number of encounters, duration of contact, and estimated distance between users during an encounter. For the New Zealand app, contact tracers evaluate the locations at which an infection was likely to occur, and issue warnings selectively to persons potentially at risk.

\subsection{Accounting for Potential Information Privacy Violations}

The Covid-19 contact tracing apps we studied account for three broad types of information privacy violations: illegitimate acquisition of personal information without a justified cause or in an unjustified way; misrepresentation of personal information respectively users based on information that is collected by the app but does not accurately describe the user or their condition; and misuse of personal information by processing or utilising it in an unjustified way or for an unjustified purpose. Table 3 is an overview of information privacy breaches for which we found precautions spelled out in the official documentation of the analysed Covid-19 contact tracing apps.

Table 3 Information privacy violations accounted for by existing Covid-19 contact tracing apps

\begin{tabular}{|c|c|c|c|c|c|}
\hline Countries & AUS & FRA & DEU & JPN & NZL \\
\hline \multicolumn{6}{|c|}{ Illegitimate acquisition of personal information } \\
\hline Forced use of the app & $\mathrm{X}$ & $\mathrm{X}$ & $\mathrm{X}$ & $\mathrm{X}$ & $\mathrm{X}$ \\
\hline Forced self-disclosure & $\mathrm{X}$ & $\mathrm{X}$ & $\mathrm{X}$ & $\mathrm{X}$ & $\mathrm{X}$ \\
\hline Uneconomic data collection & & $\mathrm{X}$ & $\mathrm{X}$ & $\mathrm{X}$ & \\
\hline Prolonged data collection & $\mathrm{X}$ & $\mathrm{X}$ & & & \\
\hline \multicolumn{6}{|c|}{ Misrepresentation of personal information } \\
\hline $\begin{array}{l}\text { and } \\
\text { use of the app }\end{array}$ & $\mathrm{X}$ & & & & $\mathrm{X}$ \\
\hline $\begin{array}{l}\text { Misreporting personal } \\
\text { information }\end{array}$ & $\mathrm{X}$ & $\mathrm{X}$ & $\mathrm{X}$ & $\mathrm{X}$ & $\mathrm{X}$ \\
\hline \multicolumn{6}{|c|}{ Misuse of personal information } \\
\hline Illegitimate access & $\mathrm{X}$ & $\mathrm{X}$ & $\mathrm{X}$ & $\mathrm{X}$ & $\mathrm{X}$ \\
\hline Aggregation & & $\mathrm{X}$ & & & \\
\hline Recombination & & $\mathrm{X}$ & $\mathrm{X}$ & $\mathrm{X}$ & \\
\hline Repurposing & $\mathrm{X}$ & & $\mathrm{X}$ & $\mathrm{X}$ & $\mathrm{X}$ \\
\hline
\end{tabular}

The institutions responsible for all five apps agree that installation and use of the app must be voluntary. Furthermore, they state that users must not be forced to provide any personal information. In particular, they must not be obligated to provide information about their health status, disclose test results within the app, or share any personal data with health authorities or other agents.

In the documentation for the French, German, and Japanese apps, collecting data beyond what is absolutely necessary and relevant to enable contract tracing is considered a violation of users' information privacy. For the Australian and French apps, prolonged data collection beyond the duration of the coronavirus pandemic is characterised as a potential breach of information privacy.

The documentation also accounts for the fact that misrepresenting users based on the personal information collected could potentially threaten the integrity of the apps, and so information 
collected must be accurate, complete, and up to date. For the French, German, and Japanese apps, this refers in particular to encounter information and information about a user's health status and test results-users are encouraged to submit timely information about positive test results. False reports regarding positive tests for Covid-19 are prevented by enabling the update of the infection status only through a code provided by the responsible health institution. The documentation for the Australian and New Zealand apps states that misrepresenting person or user identifying information that is used to identify potential contacts is not approved.

The accompanying documentation for all five apps address illegitimate access to personal information as a violation of information privacy: other app users, service providers, health authorities, and third parties are not allowed unauthorised access to personal information, nor may this information be made available or transmitted to them. In addition, the French app's documentation explicitly forbids data aggregation, which means personal information must not be accumulated in a way that allows clustering of users based on that information (e.g., compiling lists of infected users). The French, German, and Japanese apps further prohibit the recombination of personal information-that is, associating or matching personal information to make inferences about other users' personal attributes (e.g., their health status or social contacts). Finally, the documentation for all but the French app discourage the use of personal information provided through the app for purposes other than Covid-19 contact tracing (e.g., preventing access to restaurants and other facilities, or monitoring user compliance with quarantine orders), although data are generally used to provide use statistics and improve app functionality. While we expect that the same holds true for the French app, we were not able to identify corresponding statements in the documentation.

\subsection{Design Principles to Protect Users' Information Privacy}

The analysed apps are based on several design principles aimed at protecting personal information from illegitimate access and use. These include voluntariness, that is, no one is compelled to install or use the app or add personal data, any information entered can be deleted, and the app can be uninstalled at any time. The apps are based on transparency that makes the manner in which the app collects and uses personal information known to users. Data minimisation ensures that only data that are absolutely necessary and relevant for contact tracing are collected. The app design can include pseudonymisation-only user-chosen or automatically generated pseudonyms are used to refer to users. The protection of personal information from unwarranted access by users and others is part of the apps' design and, finally, data quality enhancement can enable users to verify, review, and correct their personal information. Table 4 is an overview of the design principles through which the analysed Covid-19 contact tracing apps seek to prevent violations of information privacy.

Table 4 Principles to protect users' information privacy in Covid-19 contact tracing apps

\begin{tabular}{lccccc}
\hline \multicolumn{1}{c}{ Countries } & AUS & FRA & DEU & JPN & NZL \\
\hline Voluntariness & & & & & \\
$\quad$ Voluntary use of the app & $\mathrm{X}$ & $\mathrm{X}$ & $\mathrm{X}$ & $\mathrm{X}$ & $\mathrm{X}$ \\
Voluntary self-disclosure & $\mathrm{X}$ & $\mathrm{X}$ & $\mathrm{X}$ & $\mathrm{X}$ & $\mathrm{X}$ \\
$\quad$ Discontinuance of use & $\mathrm{X}$ & $\mathrm{X}$ & $\mathrm{X}$ & $\mathrm{X}$ & $\mathrm{X}$ \\
\hline Transparency & & & & & \\
$\quad$ Transparent privacy stand- & $\mathrm{X}$ & $\mathrm{X}$ & $\mathrm{X}$ & $\mathrm{X}$ & $\mathrm{X}$ \\
ards & $\mathrm{X}$ & $\mathrm{X}$ & $\mathrm{X}$ & $\mathrm{X}$ & $\mathrm{X}$ \\
$\quad$ Government approval & & $\mathrm{X}$ & $\mathrm{X}$ & & \\
Agency involvement & & &
\end{tabular}




\begin{tabular}{|c|c|c|c|c|c|}
\hline \multirow{2}{*}{\multicolumn{6}{|c|}{$\begin{array}{l}\text { Open source development } \\
\text { Data minimisation }\end{array}$}} \\
\hline & & & & & \\
\hline \multicolumn{2}{|l|}{$\begin{array}{l}\text { Qualitative data collection } \\
\text { thresholds }\end{array}$} & $\mathrm{X}$ & $\mathrm{X}$ & $\mathrm{X}$ & \\
\hline \multicolumn{2}{|l|}{$\begin{array}{l}\text { Quantitative data collection } \\
\text { thresholds }\end{array}$} & $\mathrm{X}$ & $\mathrm{X}$ & $\mathrm{X}$ & \\
\hline $\begin{array}{l}\text { Temporally restricted stor- } \\
\text { age }\end{array}$ & \multicolumn{2}{|l|}{$\mathrm{X}$} & $\mathrm{X}$ & $\mathrm{X}$ & \\
\hline $\begin{array}{l}\text { Discontinuance of service } \\
\text { provision }\end{array}$ & $\mathrm{X}$ & $\mathrm{X}$ & & & \\
\hline \multicolumn{6}{|l|}{ Data protection } \\
\hline Encrypted storage & $\mathrm{X}$ & $\mathrm{X}$ & $\mathrm{X}$ & $\mathrm{X}$ & $\mathrm{X}$ \\
\hline Decentralised storage & & & $\mathrm{X}$ & $\mathrm{X}$ & $\mathrm{X}$ \\
\hline Centralised storage & $\mathrm{X}$ & $\mathrm{X}$ & & & \\
\hline $\begin{array}{l}\text { Restricted device-to-device } \\
\text { transmission }\end{array}$ & $\mathrm{X}$ & $\mathrm{X}$ & $\mathrm{X}$ & $\mathrm{X}$ & $\mathrm{X}$ \\
\hline Secure transmission & & & $\mathrm{X}$ & $\mathrm{X}$ & \\
\hline \multicolumn{6}{|l|}{ Pseudonymisation } \\
\hline Personal pseudonyms & $\mathrm{X}$ & & & & \\
\hline Random user identifiers & $\mathrm{X}$ & $\mathrm{X}$ & $\mathrm{X}$ & $\mathrm{X}$ & \\
\hline Dynamical user identifiers & $\mathrm{X}$ & & $\mathrm{X}$ & $\mathrm{X}$ & \\
\hline Logical disconnectedness & & $\mathrm{X}$ & $\mathrm{X}$ & $\mathrm{X}$ & \\
\hline \multicolumn{6}{|l|}{ Data quality enhancement } \\
\hline Technical redundancies & & $\mathrm{X}$ & $\mathrm{X}$ & $\mathrm{X}$ & $\mathrm{X}$ \\
\hline Verification & $\mathrm{X}$ & $\mathrm{X}$ & $\mathrm{X}$ & $\mathrm{X}$ & $\mathrm{X}$ \\
\hline Revision & $\mathrm{X}$ & & & & $\mathrm{X}$ \\
\hline
\end{tabular}

To implement the principle of voluntariness, the adoption and use of all analysed apps is left to people's discretion: neither governments nor other agents may force or otherwise exert pressure on people to install the apps. Further, providing personal information within the apps-particularly about a user's health status and a potential Covid-19 infection-is optional. Users may uninstall the app at any time, and doing so will delete all personal information stored on their devices; if information pertaining to them is stored on some central server, they can request its deletion.

All the responsible institutions emphasise transparent design. Privacy information is made available to users both within the app and online. Applicable privacy laws and regulations are explicitly referenced, and contacts for privacy-related inquiries are provided. Furthermore, governments have approved the design of the apps, either implicitly or explicitly; for instance, French and German government and civil agencies responsible for information privacy and data protection were involved in their country's app development to ensure compliance with privacy standards. Furthermore, the French and German apps are open source, meaning the source code and documentation of the apps are publicly available, and community members and external experts are encouraged to review and comment on the code.

The French, German, and Japanese app documentation strongly emphasises minimisation with respect to data collection. These apps do not require user identifying information to be entered to use the app, and only minimal person identifying information is required for the setup. Furthermore, they impose quantitative thresholds on data collection, which implies that encounters are recorded and stored only when some threshold values in proximity and duration are 
exceeded (less than 1 meter for 15 minutes or more for the French and Japanese apps, and more than 10 minutes for the German app). Both the Australian and the New Zealand app documentations, in contrast, emphasise data richness to allow for graded risk assessment. While they do not track user geolocations, both collect data that could be used to identify particular users.

The Australian, German, and Japanese apps store encounter information only for a limited period (14 days for Germany and Japan; 21 days for Australia). While we cannot rule out the possibility that the other apps impose similar restrictions, we were not able to confirm that based on official documentation. Furthermore, the Australian and French apps, according to official announcements, are to be discontinued at the end of the Covid-19 pandemic, including automatic deletion of all personal information stored. We were not able to identify similar statements regarding the other apps.

Pseudonymisation is another measure taken to protect users' information privacy. The Australian app allows users to enter false names or self-chosen pseudonyms upon regstration. Other apps employ user IDs that are generated automatically within the app and are linked to user digital profiles, which allows for retracing a user's encounters. With the exception of the New Zealand app, all apps analysed use these randomly generated identifiers. The accompanying documentation for the Australian, German, and Japanese apps also state that these identifiers change at regular intervals to prevent users from identifying nearby other users or retracing infected users.

Documentation of the apps also stresses that user pseudonyms are logically disconnected from other pieces of personal information, which means they are inherently unrelated. For instance, in the French, German, and Japanese apps, user identifiers are generated randomly and are not based on any person identifying information. Similarly, the codes that users enter to verify test results are independent of these identifiers, so servers or users' devices can only know that some user has tested positively for Covid-19, but cannot infer that user's identity. While the Australian app also uses randomly generated identifiers for exchanges between users, those are connected to person identifying information made available to contact tracers, which means they can infer the identity of infected or potentially infected users. Similarly, for the New Zealand app, contact tracers know the identities of infected users, although they cannot directly identify users at risk. None of the apps provides real-time alerts, which means that the apps cannot be used to detect infected persons in a user's proximity.

For all apps, encrypted storage is key to protecting personal information from unwarranted access. Apps differ, however, in their data storage models: the German and Japanese apps use decentralised storage of personal information, which means that as little information as possible is transmitted from the individual users' devices to central servers. Instead, the identifiers of infected users are uploaded so other devices can compare them with their own encounter histories. Similarly, users of the New Zealand app who have tested positive for Covid-19 can upload their location histories so that warnings can be generated for particular locations and other users' devices can compare their own entries. The French app, in contrast, asks infected users to upload their encounter histories; each device knows only its own encounters, and matching is performed on a central server. The Australian app relies even more on a central server infrastructure: upon registration, users provide person identifying information, which is stored centrally. In case of an infection, users are asked to upload their encounter histories, and both sources of information are matched by human contact tracers to identify and prioritise contacts. 
Secure transmission between devices and servers can be an issue, although only the German and Japanese app documentation refers explicitly to secure device-to-server transmission, and only the latter mentions prospective security measures to obscure transmissions (e.g., sending false notifications that are discarded on the server to create background noise).

Both storage models are generally motivated in terms of information privacy concerns. Decentralised storage, on the one hand, minimises the threat that health agencies or service providers can access personal information stored on a central server, or that sensitive data could be released unintentionally if servers are compromised. Centralised storage, on the other hand, can hinder individual users from accessing user identifying information (e.g., their identifiers), reduces information privacy risks from smartphone security holes and loss or theft of devices, and allows for bundling the responsibility for data protection with one or a few dedicated agents. Decentralised storage does not imply that no personal information is transmitted to a central server; at the very least, all apps that rely on this approach use central servers to verify test results and make the identifiers of users diagnosed with Covid-19 available to others' devices. Similarly, centralised storage does not mean that no information is stored on users' devices, but that information about which users are infected is not made available to others.

Furthermore, all the apps, to a greater or lesser degree, restrict the information that is exchanged between devices. The New Zealand app allows no information to be exchanged between devices, but encounters are inferred ex post based on shared attributes (i.e., locations and activities recorded by each user). Device-to-device transmissions are limited in the other four apps analysed: the only information exchanged are the user identifiers required to represent encounters (possibly contingent on further thresholds of data collection).

Finally, some measures exist within all the apps to ensure the accuracy and completeness of personal information. To enhance data integrity, the Australian, Japanese, and New Zealand apps require some type of initial verification to set up the app. The French, German, and Japanese apps require users to verify their test results when declaring themselves infected with Covid-19. To do so, they receive a one-time code that can be entered in multiple ways to prevent misreporting and ensure that information is entered reliably. Similarly, the New Zealand app provides multiple ways to enter locations and activities and to add supplementary information to encourage completeness. It also lets users review their digital profiles and revise and complement their visits and other information. Similarly, the Australian app allows users to reinstall the app to correct personal information. As a rule, however, all the apps-except for the one deployed in New Zealand-store encounter information in a secure section of the device that cannot be accessed by users; this prevents users from reidentifying other users, particularly infected persons.

\section{Theoretical Evaluation of Information Privacy in the Context of Covid-19 Contact Tracing Apps}

Thus far, we have analysed design principles evident from existing Covid-19 contact tracing apps, based on the broad understanding of information privacy as limited access to information about a person (condition of privacy) who might be able to control, to a certain extent, how that information is accessed and used (management of privacy). Table 5 summarises the normative and technical design principles to protect users' information privacy.

Table 5 Normative and technical design principles to protect users' information privacy 


\begin{tabular}{|l|l|l|}
\hline & $\begin{array}{l}\text { Normative design princi- } \\
\text { ples to protect infor- } \\
\text { mation privacy }\end{array}$ & $\begin{array}{l}\text { Technical design princi- } \\
\text { ples to protect infor- } \\
\text { mation privacy }\end{array}$ \\
\hline $\begin{array}{l}\text { Design principles aimed at } \\
\text { limiting access to personal } \\
\text { information (condition of } \\
\text { privacy) }\end{array}$ & Does not apply. & $\begin{array}{l}\text { - Data minimisation } \\
\text { - Data protection } \\
\text { (centralised vs. } \\
\text { decentralised) } \\
\text { - Pseudonymisation }\end{array}$ \\
\hline $\begin{array}{l}\text { Design principles aimed at } \\
\text { granting users control } \\
\text { over their personal infor- } \\
\text { mation (management of } \\
\text { privacy) }\end{array}$ & $\begin{array}{l}\text { - Voluntariness } \\
\text { - Transparency }\end{array}$ & - Data quality enhancement \\
\hline
\end{tabular}

Based on the findings of the exploratory analysis, we conclude that the understanding of limited access to personal information that is evident from the apps varies along two dimensions. The first is the centralised-decentralised dimension. The Australian and French apps in particular pursue a centralised approach, meaning that they do not transmit information about infected users to others' devices, but perform all matching and processing of personal information on central servers. In contrast, the decentralised approach of the German and Japanese apps, and, somewhat differently, the New Zealand app, entrusts users' devices with these tasks, largely reducing central servers to a transmittal function.

The second dimension, which we refer to as the data minimisation-richness dimension, is based on the data minimisation and pseudonymisation design principles evident from our analyses. Along this dimension, the German, French, and Japanese apps limit access to personal information by minimising the information collected and through effective use of logically disconnected user pseudonyms to eliminate illegitimate access of person or user identifying information. In contrast, the Australian and the New Zealand apps specifically ask users to contribute personal information to be used for enhanced risk assessment and contact tracing.

With respect to the management of information privacy, the voluntariness and transparency principles relate to choice and consent; they enable users to control whether and what information about themselves they make available in the first place. Voluntariness implies that users can choose whether to use the apps and, if they do so, whether to provide the requested information. For instance, users who test positive for Covid-19 can decide whether to make that information available to others or can use the app without doing so and still receive warnings-although the effectiveness of contact tracing would clearly suffer. Transparency implies that users can make informed decisions about using the app based on the information provided.

In contrast, measures that allow for enhancement of data quality relate to the ex post correction of personal information that has been collected. While this does not protect users from illegitimate access and use of their personal information, it does enable them to ensure that such information is accurate, complete, and up to data, and hence that adequate conclusions (in particular about their own and others' risk status) can be drawn. This tradeoff between design principles for limiting and managing access to personal information indicates that the former may come at the expense of generating more precise and targeted warnings. 
The design principles for limiting access to users' personal information we identified are, in principle, technical, as they can-depending on the effectiveness of their implementationreduce exposure to unwarranted access to and prevent accumulation and recombination of personal. Such technical measures can only help constitute naturally private situations, where user personal information is protected from particular violations as a matter of fact, but implemented protections do not grant normative rights to information privacy. Similarly, design principles related to correction through data quality enhancement are inherently technical, as they provide actual opportunities for users to revise and complement personal information. In contrast, design principles for managing information privacy through choice and consent are primarily normative. While the documentation for all the apps state that voluntariness and transparency are desirable, they do not describe measures taken to ensure they are obeyed. For instance, it is beyond the scope of app design to ensure that health agencies and other agents do not take measures to enforce app use.

\section{Discussion}

Our insights into the normative and technical design principles are clearly related to the broader discourse in information systems and other disciplines regarding the adoption and use of mobile applications for contact tracing, and parallel the findings of prior research on information privacy in the context of Covid-19 contact tracing apps.

Our findings confirm that the design of apps deployed early on by five liberal democracies considers key ethical principles identified in the literature. In particular, the documentation we analysed stress the role of voluntariness, which is deemed crucial for privacy-sensitive design. The voluntariness principle goes beyond the mere adoption of an app, but includes people's decisions to carry a smartphone, download and install the app, leave the app operating in the background, react to alerts, share contact logs if they test positive, and uninstall the app together with removing collected data (Klar \& Lanzerath, 2020).

However, voluntariness only protects people's information privacy in a normative sense. As Ishmaev et al. (2021) point out, even if adoption and use of apps for Covid-19 contact tracing is declared non-mandatory, social or economic conditions may still create pressure to do so. Voluntariness is also contingent on user understanding of how and what information is accessed by the apps. In an early analysis, Zhang, Chow, and Smith (2020) conclude that the privacy-related information provided by the Australian and New Zealand app documentation, for instance, may be too complex for users to read and understand. Also, only two of the apps have open source code, meaning that in-depth inspection of the apps' functionalities even by experts is not always possible, leaving the implementation of normative information-privacy protections to the responsible institutions' goodwill and competences.

What is more, proportionality is a key criterion for privacy-sensitive app design (Morley et al., 2020). However, concerns were raised that contact tracing apps may not be effective in containing the spread of Covid-19 because they can make a real difference only if a significant percentage of the population (e.g., $56 \%$ or more) use them (Hinch et al., 2020). If that threshold is not met-as was the case in the five countries at the time of our study-a potential sacrifice of information privacy may be unjustified.

Overall, many privacy-related aspects-in particular, voluntariness, user consent, anonymity (in terms of pseudonymisation), purpose specification, provision of app providers' contact information, and specification of data retention parameters and the decommissioning process 
(Klar \& Lanzerath, 2020; Morley et al., 2020) — have been systematically addressed by the apps analysed. However, not all have adopted corresponding design principles in equal measure, and other potential threats to user information privacy, such as special protection of data collected from children, updates to the apps' privacy policy changes, and privacy breach notices (e.g., Hatamian et al., 2021; Kolasa, Mazzi, Leszczuk-Czubkowska, Zrubka, \& Péntek, 2021), are not explicitly evident from the apps' accompanying documentation. While we expect that such issues have been addressed since our study was completed, it is revealing how even proactive privacy-sensitive app design may deviate at least from some of the previously suggested ethical standards.

In addition, works such as that of Hatamian et al. (2021) suggest that the extent to which the applied design principles are actually suited to limit access to personal information depends considerably on their actual implementation-which, according to them, still leaves room for improvement. In addition, further measures that could be taken, such as data protection through random noise signals (e.g., Sharma \& Bashir, 2020), have not (yet) been explicitly addressed by the majority of apps we have analysed.

Our findings hint at an unsurprising but nevertheless critical tension between normative and technical design principles: if normative principles, such as voluntariness and transparency, are not supported by technical measures, the risk of information privacy violations could be real. If, for instance, information-privacy policy documentation is insufficient, or people are encouraged to use the app to avoid other constraints, these principles could be undermined. However, if technical protections such as secure storage and pseudonymisation lack normative justification, they can only be evaluated against the benchmark of the efficacy of implementation-which is not be feasible for laypersons, and which may undergo unnoticed changes at any time.

Contrasting the design principles identified from the apps analysed, we find striking similarities between the information-privacy standards they set. This is likely due to the homogeneous sample of apps originating from liberal democracies. It is hence not unexpected that these apps afford similar levels of information privacy. Still, from a theoretical point of view, it is interesting to see what the apps' design reveals about the understanding of information privacy. One aspect in this regard is the distinction between centralised and decentralised storage. Both approaches can, in principle, be privacy preserving (WHO, 2020); still, they are based on different assumptions regarding the origins of potential information privacy threats. While centralised design stresses the risk that individual users might recombine distinct pieces of information about others and thus re-identify other users and draw conclusions about their health status, decentralised design emphasises threats due to the existence of central stores of aggregated information that, if compromised, could expose a large number of users.

Another aspect relevant for our theoretical understanding of information privacy is the tension between data minimisation and pseudonymisation, on the one hand, and the data richness demand posed by several apps, on the other. The former stresses the condition of privacy, where access to personal information is largely restricted. It is in line with the postulate to favor privacy by default and design to ensure exposure to potential information-privacy violations is effectively minimised, and it is clearly in line with much prior research that interprets information privacy in terms of autonomy, or the absence of intrusion into users' private sphere (Becker, 2019). 
While all the apps analysed generally agree that certain types of personal information, such as GPS data, is not necessary to enable contact tracing and hence should not be collected (WHO, 2021a), the data richness postulate indicates a more differentiated view regarding what constitutes illegitimate access to and use of user personal information, such that particular types of personal information (e.g., health status information) demand higher levels of protection than others that may be shared more carelessly. It hence shifts the focus of information privacy from autonomy to integrity, ensuring appropriate representation of users through their personal information based on a notion of information privacy as effective control over the flow of such information in a given context (as postulated by, for instance, Floridi, 2006).

\section{Conclusion}

In summary, we have analysed the normative and technical design principles through which Covid-19 contact tracing apps deployed in five liberal democracies aspire to protect information privacy: voluntariness, transparency, data minimisation, pseudonymisation, protection of personal information (through centralised and decentralised designs), and data quality enhancement.

The contributions of disclosive computer ethics studies can be found at three levels: the disclosure level, which explicates the hidden moral properties of the technological artifacts under study; the theoretical level, which refines and further develops existing theory; and the application level, which refers the theoretical insights back to the disclosure level (Brey, 2000a, $2000 \mathrm{~b}$ ). At the disclosure level, in response to RQ1, we have spelled out the normative and technical design principles through which the apps analysed protect information privacy. At the theoretical level, in response to RQ2, we have explained what these principles reveal about the understanding of information privacy that has, explicitly or implicitly, guided the design of these apps, and how this relates to the condition and management of information privacy according to the RALC framework. Furthermore, we have discussed how the principles identified complement or contradict each other, and how these evident tensions can enrich our theoretical understanding of information privacy in the given context. Finally, at the application level, we expect that our insights can inform the design of contact tracing apps and help evaluate the measures taken to protect user information privacy both in newly released apps and in updated versions of the apps analysed.

The contribution of our work lies in the space between normative papers that develop design guidelines from an ethical perspective (e.g., Morley et al., 2020) and technical papers that analyse how those guidelines are implemented (e.g., Hatamian et al., 2021). Our work is intended to inform app design by providing real-world examples of privacy-sensitive design that are motivated by well-grounded ethical theory and inspired by practical examples. Thus, we approach the refinement of ethical theory to develop and evaluate design principles for actually usable technological artifacts, as demanded, amongst others, by Bélanger and Crossler (2011).

Our argument is based on the RALC framework of information privacy (Moor, 1997; Tavani \& Moor, 2001), which conceptualises information privacy in terms similar to much information systems research: as a state in which access to information about a person is limited, or in which people are able to control information about themselves (Popovič, Smith, Thong, \& Wattal, 2017; Smith et al., 2011). It captures the potential of technological artifacts to threaten information privacy while also providing opportunities for users manage it actively, and is said to be sufficiently comprehensive to apply to a wide range of related concerns (Tavani, 2007). 
As Solove (2006) explains, privacy theories will typically have problems to apply to information privacy in digital environments, as the corresponding information and communications technologies have capacities to collect, store, process, and disseminate information about their users that go well beyond those of the means of communication addressed in the original debates. In addition, few existing theories recognise privacy breaches that result from practices such as the constant and unobtrusive surveillance of users, data mining, and user profiling, which are nonetheless key information privacy concerns put forth in the given context (Clarke, 2019; Stahl, 2019; Volokh, 2000). Still, our theoretical perspective implies that the interpretations put forth in this paper are meaningful only in the context of the RALC framework, which, as we have discussed, may have issues accounting for the trade-off between users' autonomy and the integrity of representation.

Another limitation comes from the small sample of apps we analysed. Our results are based on apps deployed as early as June 2020 in liberal democracies, which means that our contribution is restricted to outlining example design principles rather than providing a representative summary. Further, different countries will typically continue to pursue different approaches to the development of apps, owing to social and cultural preferences and path dependencies. To raise awareness of alternative approaches and justifications, we have articulated what we think are the evident design choices. Our results are by no means final, as apps are typically developed further while in use, and new contact tracing apps have become available since we conducted our study. What is more, while official documentation is an informative source of information, complementary analyses would be required to determine, for instance, the effectiveness of how the principles we identified were implemented.

Our work is also relevant for the design of digital information and communications technologies in other social and economic settings with the potential for large-scale data collection and public surveillance, which are on the rise. For instance, fitness apps enable the large-scale collection of fitness and health data: where, when, and for how long users are active and with whom they compare themselves. Widely used dating apps enable matches between users based on their geographical locations and other criteria. Restaurants and hotels use apps and similar tools to manage reservations digitally, saving customer data that is often poorly protected in cloud services with little regard for or even awareness of information privacy issues (Chaos Computer Club, 2020). For those, knowledge of existing conceptualisations of information privacy and corresponding design principles could be particularly useful.

Information privacy is of growing interest in information systems research, as the digitisation of different sorts of information increases, along with the use of technology and methods for capturing information, such as online platforms and big data analysis. We responded to calls for more context-specific research in this area: that digital artifacts and privacy-related practices need to be analysed within the context they are used; and that theories from other fields need to be applied meaningfully given that information security is an interdisciplinary research field (e.g., Bélanger \& Crossler, 2011; Lowry, Dinev, \& Willison, 2017). We focused on disclosing and integrating moral properties evident from existing technological artifacts, and so the outcome of our work cannot be characterised as full-fledged ethical theory. Rather, we have illustrated how ethical theory can inform the design of technological artifacts in general, and how empirical design choices can contribute to advancing such theory vice versa.

In ethical terms, privacy theory must include not only a descriptive account of but also a normative justification of privacy (Parent, 1983). In this paper, we have clearly focused on the former. A normative justification that clarifies not only whether information privacy is present 
in a certain artifact, but also the extent to which there is a justifiable claim to information privacy in a certain use context, would be valuable, especially for Covid-19 tracing apps. With respect to Covid-19, there are alternative approaches (e.g., tracking apps) that are generally regarded as less privacy friendly than the tracing apps we have analysed, and by far not all countries deploy those apps on a voluntary basis for people to use at their own discretion. Our work should hence be seen as an initial step towards challenging and refining existing ethical theory.

\section{References}

Ahmed, N., Michelin, R. A., Xue, W., Ruj, S., Malaney, R., Kanhere, S. S., . . Jha, S. K. (2020). A Survey of COVID-19 Contact Tracing Apps. IEEE Access, 8, 134577-134601. https://doi.org/10.1109/ACCESS.2020.3010226

Australian Government (2020). Privacy Policy. Retrieved from https://covidsafe.gov.au/privacy-policy.html*, accessed on 11th July 2020.

Australian Government Department of Health (2020). COVIDSafe App. Retrieved from https://www.health.gov.au/resources/apps-and-tools/covidsafe-app\#get-th*, accessed on 11th July 2020.

Becker, M. (2019). Privacy in the digital age: comparing and contrasting individual versus social approaches towards privacy. Ethics and Information Technology, 21(4), 307-317. https://doi.org/10.1007/s10676-019-09508-z

Bélanger, F., \& Crossler, R. E. (2011). Privacy in the Digital Age: A Review of Information Privacy Research in Information Systems. MISQuarterly, 35(4), 1017-1041.

Blasimme, A., \& Vayena, E. (2020). What's next for COVID-19 apps? Governance and oversight. Science (New York, N.Y.), 370(6518), 760-762. https://doi.org/10.1126/science.abd9006

Boutet, A., Bielova, N., Castelluccia, C., Cunche, M.: Lauradoux, C., Le Métayer, D., \& Roca, V. (2020). Proximity Tracing Approaches - Comparative Impact Analysis. Retrieved from https://hal.inria.fr/hal-02570676v1*, accessed on 20th August 2020.

Brey, P. (2000a). Disclosive Computer Ethics. ACM SIGCAS Computers and Society, 30(4), 1016. https://doi.org/10.1145/572260.572264

Brey, P. (2000b). Method in Computer Ethics: Towards a Multi-Level Interdisciplinary Ap-

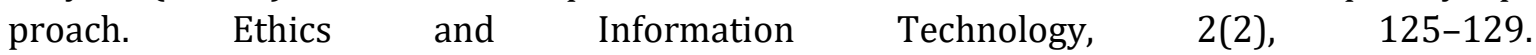
https://doi.org/10.1023/A:1010076000182

Budd, J., Miller, B. S., Manning, E. M., Lampos, V., Zhuang, M., Edelstein, M., ... McKendry, R. A. (2020). Digital technologies in the public-health response to COVID-19. Nature Medicine, 26(8), 1183-1192. https://doi.org/10.1038/s41591-020-1011-4

Campbell, J. E., \& Carlson, M. (2002). Panopticon.com: Online Surveillance and the Commodification of Privacy. Journal of Broadcasting \& Electronic Media, 46(4), 586-606. https://doi.org/10.1207/s15506878jobem4604_6

Chan, E. Y., \& Saqib, N. U. (2021). Privacy concerns can explain unwillingness to download and use contact tracing apps when COVID-19 concerns are high. Computers in Human Behavior, 119, 106718. https://doi.org/10.1016/j.chb.2021.106718 
Chaos Computer Club (2020). CCC hackt digitale "Corona-Listen". Retrieved from https://www.ccc.de/de/updates/2020/digitale-corona-listen/*, accessed on 29th August 2020 .

Clarke, R. (1999). Internet Privacy Concerns Confirm the Case for Intervention. Communications of the ACM, 42(2), 60-67. https://doi.org/10.1145/293411.293475

Clarke, R. (2019). Risks Inherent in the Digital Surveillance Economy: A Research Agenda. Journal of Information Technology, 34(1), 59-80. https://doi.org/10.1177/0268396218815559

Corona Warn App Open Source Project (2020). Frequently Asked Questions about the CoronaWarn-App. Retrieved from https://www.coronawarn.app/en/faq/*, accessed on 29th June 2020.

Di Gennaro, F., Pizzol, D., Marotta, C., Antunes, M., Racalbuto, V., Veronese, N., \& Smith, L. (2020). Coronavirus Diseases (COVID-19) Current Status and Future Perspectives: A Narrative Review. International Journal of Environmental Research and Public Health, 17(8). https://doi.org/10.3390/ijerph17082690

European Commission (2020). COMMUNICATION FROM THE COMMISSION: Guidance on Apps supporting the fight against COVID 19 pandemic in relation to data. Retrieved from https://ec.europa.eu/info/sites/default/files/5_en_act_part1_v3.pdf*, accessed on.

European Parliament (2020). Covid-19 tracing apps: ensuring privacy and use across borders, accessed on November 5, 2020.

The Federal Government (2020a). The Corona-Warn-App: Helps us Fight the Coronavirus. Retrieved from https://www.bundesregierung.de/breg-de/themen/corona-warn-app/coronawarn-app-englisch*, accessed on 29th June 2020.

The Federal Government (2020b). Frequently Asked Questions. Retrieved from https://www.bundesregierung.de/breg-de/themen/corona-warn-app/corona-warn-appenglisch/corona-warn-app-faq-1758636*, accessed on 29th June 2020.

Fischer, D., Hattori-Putzke, J., \& Fischbach, K. (2019). Crisis Warning Apps: Investigating the Factors Influencing Usage and Compliance with Recommendations for Action. In Proceedings of the Hawai'i International Conference on System Science.

Floridi, L. (2006). Four Challenges for a Theory of Informational Privacy. Ethics and Information Technology, 8(3), 109-119. https://doi.org/10.1007/s10676-006-9121-3

Floridi, L. (2020). Mind the App-Considerations on the Ethical Risks of COVID-19 Apps. Philosophy \& Technology, 1-6. https://doi.org/10.1007/s13347-020-00408-5

Fodor, M., \& Brem, A. (2015). Do privacy concerns matter for Millennials? Results from an empirical analysis of Location-Based Services adoption in Germany. Computers in Human Behavior, 53(2), 344-353. https://doi.org/10.1016/j.chb.2015.06.048

Hatamian, M., Wairimu, S., Momen, N., \& Fritsch, L. (2021). A privacy and security analysis of early-deployed COVID-19 contact tracing Android apps. Empirical Software Engineering, 26(3), 36. https://doi.org/10.1007/s10664-020-09934-4 
Inria (2020a). FAQ on the Technical Aspects of the StopCovid Application. Retrieved from https://www.inria.fr/en/faq-technical-aspects-stopcovid-application*, accessed on 3rd July 2020 .

Inria (2020b). StopCovid Inria Press Release. Retrieved from https://www.inria.fr/en/stopcovid*, accessed on 3rd August 2020.

Inria (2020c). The StopCovid Project-Team Starts Publishing the Source Code and Documentation of the StopCovid Application. Retrieved from https://www.inria.fr/en/stopcovid-sourcecode*, accessed on 3rd August 2020.

Ishmaev, G., Dennis, M., \& van den Hoven, M. J. (2021). Ethics in the COVID-19 pandemic: Myths, false dilemmas, and moral overload. Ethics and Information Technology, 1-16. https://doi.org/10.1007/s10676-020-09568-6

Klar, R., \& Lanzerath, D. (2020). The Ethics of COVID-19 Tracking Apps - Challenges and Voluntariness. Research Ethics, 1-9. https://doi.org/10.1177/1747016120943622

Kolasa, K., Mazzi, F., Leszczuk-Czubkowska, E., Zrubka, Z., \& Péntek, M. (2021). State of the Art in Adoption of Contact Tracing Apps and Recommendations Regarding Privacy Protection and Public Health: Systematic Review. JMIR MHealth and UHealth, 9(6), e23250. https://doi.org/10.2196/23250

Lowry, P. B., Dinev, T. [Tamara], \& Willison, R. (2017). Why Security and Privacy Research Lies at the Centre of the Information Systems (IS) Artefact: Proposing a Bold Research agenda. European Journal of Information Systems, 26(6), 546-563. https://doi.org/10.1057/s41303017-0066-x

Ministére De L'économie des Finances et de la Relance (2020a). FAQ StopCovid. Retrieved from https://www.economie.gouv.fr/stopcovid-faq*, accessed on 3rd July 2020.

Ministére De L'économie des Finances et de la Relance (2020b). https://www.economie.gouv.fr/stopcovid. Retrieved from https://www.economie.gouv.fr/stopcovid\#*, accessed on 3rd July 2020.

Ministry of Health (2020a). NZ COVID Tracer App. Retrieved from https://www.health.govt.nz/our-work/diseases-and-conditions/covid-19-novel-coronavirus/covid-19-novel-coronavirus-resources-and-tools/nz-covid-tracer-app*, accessed on 31st July 2020.

Ministry of Health (2020b). Questions and Answers on NZ COVID Tracer. Retrieved from https://www.health.govt.nz/our-work/diseases-and-conditions/covid-19-novel-coronavirus/covid-19-novel-coronavirus-resources-and-tools/nz-covid-tracer-app/questions-andanswers-nz-covid-tracer*, accessed on 31st July 2020.

Ministry of Health, Labour and Welfare (2020a). Contact Confirmation Application Privacy Policy. Retrieved from https://www.mhlw.go.jp/stf/seisakunitsuite/english_pp_00032.html*, accessed on 31st July 2020.

Ministry of Health, Labour and Welfare (2020b). Q \& A for Users of the Contact Tracing App. Retrieved from https://www.mhlw.go.jp/stf/seisakunitsuite/bunya/kenkou_iryou/covid19_qa_kanrenkigyou_00009.html*, accessed on 31st July 2020. 
Moor, J. H. (1997). Towards a Theory of Privacy in the Information Age. ACM SIGCAS Computers and Society, 27(3), 27-32. https://doi.org/10.1145/270858.270866

Morley, J., Cowls, J., Taddeo, M., \& Floridi, L. (2020). Ethical guidelines for COVID-19 tracing apps. Nature, 582(7810), 29-31. https://doi.org/10.1038/d41586-020-01578-0

Nissenbaum, H. (1998). Protecting Privacy in an Information Age: The Problem of Privacy in Public. Law and Philosophy, 17(5/6), 559. https://doi.org/10.2307/3505189

Pan, A., Liu, L., Wang, C., Guo, H., Hao, X., Wang, Q., ...Wu, T. (2020). Association of Public Health Interventions With the Epidemiology of the COVID-19 Outbreak in Wuhan, China. JAMA, 323(19), 1915-1923. https://doi.org/10.1001/jama.2020.6130

Parent, W. A. (1983). Privacy, Morality, and the Law. Philosophy \& Public Affairs, 12(4), 269288. Retrieved from http://www.jstor.org/stable/2265374

Popovič, A., Smith, H. J., Thong, J. Y. L., \& Wattal, S. (2017). MIS Quarterly Research Curation on Information Privacy. MIS Quarterly, Updated: June 2018; August 2019.

Repucci, S., \& O'Toole, S. (2020). Freedom in the World 2020: The Annual Survey of Political Rights \& Civil Liberties. New York, NY, Washington, DC and Lanham, Boulder, New York, London: Freedom House and Rowman \& Littlefield.

Rowe, F. (2020). Contact Tracing Apps and Values Dilemmas: A Privacy Paradox in a Neo-Liberal World. International Journal of Information Management, 102178. https://doi.org/10.1016/j.ijinfomgt.2020.102178

Sharma, T., \& Bashir, M. (2020). Use of apps in the COVID-19 response and the loss of privacy protection. Nature Medicine, 26(8), 1165-1167. https://doi.org/10.1038/s41591-020-0928$\mathrm{y}$

Smith, H. J., Dinev, T. [T.], \& Xu, H. (2011). Information Privacy Research: An Interdisciplinary Review. MIS Quarterly, 35(4), 989. https://doi.org/10.2307/41409970

Solove, D. J. (2006). A Taxonomy of Privacy. University of Pennsylvania Law Review, 154(3), 477. https://doi.org/10.2307/40041279

Stahl, B. C. (2019). Teaching Ethical Reflexivity in Information Systems: How to Equip Students to Deal With Moral and Ethical Issues of Emerging Information and Communication Technologies. Ournal of Information Systems Education, 22(3), 253-260.

Stahl, B. C. (2012). Morality, Ethics, and Reflection: A Categorization of Normative IS Research. Journal of the Association for Information Systems, 13(8), 636-656. https://doi.org/10.17705/1jais.00304

Taddeo, M. (2020). The Ethical Governance of the Digital During and After the COVID-19 Pandemic. Minds and Machines, 1-6. https://doi.org/10.1007/s11023-020-09528-5

Tavani, H. T. (2007). Philosophical Theories of Privacy: Implications for an Adequate Online Privacy Policy. Metaphilosophy, 38(1), 1-22. https://doi.org/10.1111/j.14679973.2006.00474.x 
Tavani, H. T. (2008). Informational Privacy: Concepts, Theories, and Controversies. In K. E. Himma \& H. T. Tavani (Eds.), The Handbook of Information and Computer Ethics (pp. 131164). Hoboken, N.J: Wiley. https://doi.org/10.1002/9780470281819.ch6

Tavani, H. T., \& Moor, J. H. (2001). Privacy Protection, Control of Information, and Privacy-Enhancing Technologies. ACM SIGCAS Computers and Society, 31(1), 6-11. https://doi.org/10.1145/572277.572278

Trang, S., Trenz, M., Weiger, W. H., Tarafdar, M., \& Cheung, C. M.K. (2020). One App to Trace Them All? Examining App Specifications for Mass Acceptance of Contact-Tracing Apps. European Journal of Information Systems, 94(1), 1-14. https://doi.org/10.1080/0960085X.2020.1784046

Volokh, E. (2000). Personalization and Privacy. Communications of the ACM, 43(8), 84-88. https://doi.org/10.1145/345124.345155

WHO (2020). Ethical considerations to guide the use of digital proximity tracking technologies for COVID-19 contact tracing. Retrieved from https://www.who.int/publications/i/item/WHO-2019-nCoV-Ethics_Contact_tracing_apps-2020.1

WHO (2021a). Contact tracing in the context of COVID-19. Retrieved from https://www.who.int/publications/i/item/contact-tracing-in-the-context-of-covid-19*, accessed on.

WHO (2021b). COVID-19 Strategic Preparedness and Response Plan (SPRP 2021). Retrieved from https://www.who.int/publications/i/item/WHO-WHE-2021.02*, accessed on November 27th, 2021.

Woodhams, S. (2020). COVID-19 Digital Rights Tracker. Retrieved from https://www.top10vpn.com/research/covid-19-digital-rights-tracker/*, accessed on November $5,2021$.

Zastrow, M. (2021). Coronavirus contact-tracing apps: can they slow the spread of COVID-19? Retrieved from https://www.nature.com/articles/d41586-020-01514-2*, accessed on October 26, 2021.

Zhang, M., Chow, A., \& Smith, H. [Helen] (2020). Covid-19 Contact-Tracing Apps: Analysis of the Readability of Privacy Policies. Journal of Medical Internet Research, 22(12), e21572. https://doi.org/10.2196/21572 
Appendix A3

Use of Social Media by Response Organizations 


\section{Appendix A3.1: Paper X}

Leveraging Online Social Capital: How the German Red Cross Uses Social Networking Sites

\section{Fact Description}

Bibliographic data $\quad$ Fischer-Preßler, D., Marx, J., Ehnis, C. and Fischbach, K. (2019).

"Leveraging Online Social Capital: How the German Red Cross Uses

Social Networking Sites," in Australasian Conference on Information Systems.

https://aisel.aisnet.org/acis2019/5/ 


\section{Appendix A3.2: Paper XI}

Social Media Governance and Social Capital Raising: Strategies for Humanitarian Non-Government Organizations

\section{Fact Description}

Bibliographic data $\quad$ Fischer-Preßler, D., Marx, J., Bunker, D., Stieglitz, S., and Fischbach, K. „Social Media Governance and Social Capital Raising: Strategies for Humanitarian Non-Government Organizations".

Status of publication Unpublished working paper submitted to Information \& Management

Copyright notice The copyright resides with the authors. 


\title{
Social Media Information Governance and Social Capital Raising: Strategies for Nonprofit Organizations that Operate on Different Organizational Levels
}

\begin{abstract}
Social media information governance has become an increasingly important organizational objective as strategic social media use positively influences organizational goals such as the formation of long-term accrual of social capital. It is particularly important for non-governmental organizations, which rely on accurate and timely information regarding socially altruistic behavior (donations, voluntarism etc.) in order to provide their activities. Despite the potential of information provided via social media to influence social capital raising, effective social media information governance is a necessary condition for this to occur. Humanitarian non-governmental organizations (HNGOs), however, struggle with conflicts and tensions in their social media information governance as their different organizational operation levels (i.e., regional, intermediate and national), require different social media information governance strategies. We offer the notion of transitions through self-organizing systems as a means of conceptualizing social media information governance for social capital raising in multi-level organizations, highlighting the resulting tensions and possible solutions. This study reveals eight (8) key social media information governance focus areas, and it contributes to IS scholarship by developing eight (8) strategies for social media information governance which leverage internal and external organizational relations for social capital raising across different organizational levels.
\end{abstract}

Keywords: Social Media, Online Social Capital, HNGOs, Information Governance

\section{Introduction}

The importance of social capital raising for non-governmental organizations with a humanitarian focus (hereafter referred to as HNGOs) such as the Red Cross can foster access to human, material, informational, and monetary resources (Hillig and Connell, 2018). In an ever-shrinking resource base, HNGOs must draw on their relationships and networks with individuals, communities, organizations and governments to achieve their objectives. As web-based public social media such as Facebook, Twitter, and Instagram have become pervasive, the HNGO sector has increasingly embraced their potential value for managing humanitarian aid activities (Zheng and $\mathrm{Yu}, 2016$ ). Prior to social media, HNGOs were often autarkic, not embedded in broader societal networks and focused on location-specific, short-term issues (Buckland, 1998). With the global diffusion of social media platforms, however, the technological foundation of organizational networking has fundamentally changed.

Social media has opened the potential for organizations to enhance communication and networking and mobilize individuals and groups, thus lowering transaction costs and increasing participation and impact. In particular, social media affordances such as public profiles, search mechanisms, or bi-directional communication enable and shape the establishment of existing and new online relationships and the virtual consolidation of existing offline communities (Smith et al., 2017). Real-time access to social media profiles, for instance, enable ad-hoc relations between different unrelated stakeholders such as the general public and other organizations or governments (Leong et al., 2015). This online bridging of different networks in realtime can support an HNGO-coordinated response to an impacted community by identifying needs and distributing and accessing resources independently from a geographical location and between otherwise disconnected groups (Tim et al., 2017; Tim et al., 2018). In addition, HNGOs that develop networks from frequent interaction with a community accrue high levels of relational trust and positive expectations supporting their activities (Hillig and Connell, 2018). Social media, in this context, can foster the strategic creation of online communities by 
facilitating networking opportunities and by providing a publicly accessible space for information exchange and bi-directional communication with volunteers and organizations. The development of social capital, subsequently, can also be transferred to offline environments.

Despite the potential of social media, optimal support of the overarching organizational goals can only be established by coordinated and joint information governance activities of organizational social media experts. However, even for-profit organizations struggle to employ public social media effectively when they lack appropriate information governance strategies or structures. In addition, strategic social media governance and use requires resources such as modern IT infrastructure, budget for creating digital content, favorable organizational structures, and trained employees (Linke and Zerfass, 2013). For HNGOs there is added complexity, since HNGO organizational units often act at different levels and in different ways, i.e., from regional to national, and thus involving different networks of collaborators with differing aims. While regional HNGO units act at a level within certain geographical boundaries creating regional identities, national organizational units act at a level often aimed at reaching a broader network of civil society. Moreover, access to resources such as knowledge or funding for social media information governance and use may vary a lot between those levels even within the same organization (Liu et al., 2015). While researchers agree that social media offer HNGOs a low-cost way to strengthen their networks and build social capital (Lovejoy et al. 2012, Greenberg and MacAulay 2009), scholarship has yet to provide adequate information governance principles for social media for HNGOs and further little has been done to address governance at multiple organizational levels and how these translate to the creation and maintenance of social capital by each organizational level and the organization as a whole. This is crucial as HNGOs require clear directions with measurable outcomes or indicators to enable them to improve their effective and proper use of social media information (Brass et al., 2018).

In this study, we offer the notion of transitions, i.e., dynamic co-evolutionary processes that evolve from the "interplay of many unlike, particular processes" (Kemp et al., 2005, p.23 through non-physical autopoietic social systems (Mingers, 2002, 2004), as a means to investigate how SM information governance and network activation creates social capital for an HNGO's operations. Hence, we aim to answer the following research questions:

1. How do transitions allow us to conceptualize social media information governance and social capital raising for HNGOs at different organizational levels?

2. What tensions emerge from this transitional approach for social media information governance and what changes to transitions would enhance social capital raising?

To answer these questions, we conducted semi-structured interviews with eighteen social media experts from five HNGOs who work in regional, intermediate, and national offices in Germany. Additionally, we analyzed the social media profiles of the five HNGOs. From our analysis of the interviews, we explain how online social capital is leveraged by HNGOs through transitions, at different organizational levels (regional, intermediate, national) as well as the information governance tensions that emerge. We furthermore highlight information governance implications for SM practitioners in the HNGO sector from this analysis. Finally, we outline how HNGOs can leverage trust, pool scarce resources, foster public awareness of their objective's contributions, and streamline their public relations processes through improvements to these transitions. 


\section{Literature Review and Theoretical Background}

\subsection{Social Capital}

The notion of "social capital" was first introduced by Jakobs (1965) in community studies, then popularized by Bourdieu (1986) in sociology. It describes networks of strong, crosscutting personal relationships developed over time that provide the basis for trust, cooperation, and collective action (Nahapiet and Ghoshal, 1998). Such relations, in theory, yield resources which can enable individuals or organizations to attain desired outcomes (Bizzi, 2015). Although there has been conceptual confusion about how social capital may be defined or whether it refers to actual or potential resources (Smith et al., 2017), it signifies the access to resources for future action and can be derived from the network of an individual, community, or organization.

We draw on this network perspective on social capital because of its compatibility with social media, which shape all kinds of relational activities such as liking, sharing, or connecting (Phua et al., 2017). This relational view comprises both the structure of a community network as well as advantages that can be achieved by this set of relationships (Nahapiet and Ghoshal, 1998). Hence, unlike other forms of capital such as human capital that resides in an individual's knowledge and skills, social capital resides in social relationships (Coleman, 1990). Social capital, thus, implies that properties of social structures that act as resources for individuals enable them to pursue a certain outcome with a minimum of costly negotiation (Goh and Wasko, 2012).

The various types of resources available in networks as well as the dynamic nature of their deployment and use highlights the requirement to differentiate between dimensions of social capital. Nahapiet and Ghoshal (1998) highlight three social capital dimensions: structural, relational, cognitive. Structural social capital constitutes the network ties, configuration, and the organization. It relates to properties and metrics of the entire network, such as the linkages between individuals or units. It comprises the relationships between actors in the network and their positions (Hsu and Hung, 2013). The latter can be an asset in its own right as it determines who is able to reach whom and how. Relational social capital concerns trust, norms, obligations, and identity. This comprises the resources or assets that result from and are harnessed through relationships (Petter et al., 2020). As opposed to the structural dimension, the relational dimension aims at the personalization of linkages, i.e., consolidating a history through repeated interactions. The cognitive dimension deals with shared codes and languages, as well as mutual narratives. In particular, this refers to mutual ways of representing, interpreting and creating meaning between actors in the network. In short, structural social capital features the properties of a network and provides access to resources, whereas relational and cognitive social capital underpin the motivation for exchanging resources. However, all dimensions are highly interrelated and sometimes are difficult to clearly differentiate in practice (Nahapiet and Ghoshal, 1998).

Other theories also explain the dynamics of social relations from a network perspective such as those of bridging and bonding (Burt, 2000, 2005). Bridging social capital occurs by structurally broadening a given network to establish connections with others and describes horizontal connections, that is, links between groups that may have different views or aims, and thus, the ability of a group to engage with external stakeholders. It refers to weak, distant, external relationships between individuals that make available opportunities for information sharing. Bridging social capital, for instance, helps to draw on useful resources. Bonding social capital, in contrast, emerges from repeated interactions with the social contacts within a network. It applies to strong, internal relationships providing emotional kinship, trust, and social support. Consequently, this type of social capital is relational rather than structural. It manifests in links 
between people with similar objectives and can be found in different types of groups and organizations such as HNGOs (Putnam, 2000).

As social capital constitutes resources that individuals can draw from relationships and networks to facilitate collective action and cooperation for mutual and/or organizational benefit, social capital plays a vital role for HNGOs. Therefore, it is also vital to identify what resources are transferred within these networks and what resources HNGOs are dependent on to enable social capital raising activities.

\subsection{Social Media Use and Social Capital Raising for HNGOs}

NGOs comprise a group of organizations referred to as a third sector or civil society (Katz, 1999). They have highly diverse structures and operations and engage in a variety of activities, such as humanitarian, educational, health care, environmental, political, and other activities. HNGOs play a crucial role in societies worldwide by covering human needs, providing public goods and services and social value that are not met by governmental or for-profit organizational activities. In contrast to for-profit organizations, HNGOs aim to maximize utility rather than profit. HNGOs are funded primarily by donations, which entails non-profit distributing, that is, if a financial surplus is generated, it is not distributed to owners. HNGOs remain private and institutionally detached from governments; they are self-governing and thus able to manage their own activities. While they may also employ paid staff, their members are primarily volunteers (Lewis, 2001). Nevertheless, similar to for-profit organizations, individuals working in HNGOs pursue a common goal (Johnson and Prakash, 2007). To implement these shared objectives and goals, HNGOs are in need of resources that depend on voluntarism, both actively and passively, which is in turn impacted by the formation of social capital (Putnam, 2000).

With the popularization of social media, scholars have scrutinized the impact of these platforms for social capital development (for organizations in general). Although social media constitute open and dynamic types of social platforms, services and technologies they do serve quite different purposes (Schlagwein and $\mathrm{Hu}$, 2017). Following Kane et al. (2014), we define social media as web-based platforms that allow users to build a unique user profile, create and access digital content, establish relations to other users of these platforms, and view and traverse these connections. (Smith et al., 2017) argue that the four features of social media, i.e., a digital user profile, network transparency, digital search, and digital relations enable affordances that, when used and maintained meaningfully, can convert to social capital building in the organizational context.

From a structural perspective, social media facilitates networks and their visibility and thus enables access to resources for HNGOs that otherwise is not possible. Social media help to create opportunities for public voluntary activities and are accessible to a broad audience in realtime. Without social media information may only circulate within a small part of a community, limiting HNGO access to resources. During disasters, for instance, social media foster bridging capital by facilitating the connection with ad-hoc digital volunteers or grassroots communities and enabling them to connect, provide potentially useful information and foster easy and realtime information exchange between involved parties (Vaast et al., 2017). Furthermore they enable the connection of otherwise disconnected individuals such as those affected by a disaster who seek help from those who have the resources independently of their geographical location (e.g., Leong et al., 2015; Tim et al., 2017).

From a relational perspective, social media enable two-way communication of relevant stakeholders. A purposeful dialogue with social media users or responding to their comments can foster trust and legitimacy to mobilize resources (Chen et al., 2021). Although HNGOs do not aim for profitability, they do aim for financial stability in the long run to support their service offerings. In doing so they need to attract and sustain a network of donors. Potential supporters 
such as governments, private and public individuals or institutions are typically asked for donations and support from multiple HNGOs, and they of course, want confirmation that these donations are used for legitimate purposes. When users perceive networks as legitimate and trustworthy, they are more likely to commit resources to it, even in the absence of immediate returns (Randolph et al., 2020). HNGOs must have a strategy that is a foundation for communications and relationship building to attract supporters and donors and achieve competitive advantage in their fundraising (Gazzola et al., 2019). The relational structure of social media content enables the discovery of a user profile that owns relevant information and thus access to knowledge. However, the mere existence of these features does not automatically result in social capital raising. Instead, relationships must be carefully developed by platform-specific relationship maintenance behavior (Ellison et al., 2007). Through repeated social interactions with others, HNGOs can develop trust, legitimacy, confidence in their competence and reliability, and thus, positively affect visibility and network growth, legitimacy and sponsorship in a social system (Hillig and Connell, 2018).

In regards to the cognitive dimension of social capital, social media enables HNGOs to maintain, edit, and share information as well as to communicate their identity, values, and goals to the public as well as engage with interested stakeholders. Projects and activities may experience increased visibility and, at the same time, HNGOs can publish relevant content about governance, accomplishments, or use of funding which can lead to improved transparency of the organization. Hence, social media can provide a space to share values and meaning between users by publishing relevant content in the organizational profile and making use of social media affordances and features. Social media also allow HNGOs to take part in societal discussions publicly, and mitigate Buckland's critique (1998) of not being embedded in broader networks so as to gain social capital to tackle long-term societal issues. HNGOs need to attract long-term voluntary and permanent human resources to successfully maintain their services. Thus, they need to meet their staff and volunteers' expectations, increasing their loyalty and decreasing absenteeism by engaging participation and socially responsible practices (Gazzola et al., 2019). We see that common paradigms and goals as well as a collective vision and a unified culture are important for the emergence of social capital in organizations (Nahapiet and Ghoshal, 1998). To summarize the theoretical basis of this study, Table 1 provides an overview of the social capital concepts we intend to build on.

\begin{tabular}{|c|c|c|c|}
\hline Concept & Working Definition & HNGO Focus & Authors \\
\hline $\begin{array}{l}\text { Social cap- } \\
\text { ital raising } \\
\text { pre-social } \\
\text { media }\end{array}$ & $\begin{array}{l}\text { "The sum of the actual and poten- } \\
\text { tial resources embedded within, } \\
\text { available through, and derived } \\
\text { from the network of relationships } \\
\text { possessed by an individual or so- } \\
\text { cial unit. Social capital thus com- } \\
\text { prises both the network and the } \\
\text { assets that may be mobilized } \\
\text { through that network." (p. } 243 \text { ) }\end{array}$ & $\begin{array}{l}\text { The focal point of social } \\
\text { capital raising pre social } \\
\text { media was the establish- } \\
\text { ment of short-term } \\
\text { structural social capital } \\
\text { by connecting with } \\
\text { stakeholders and con- } \\
\text { solidating ties that re- } \\
\text { sult in networks of mu- } \\
\text { tual benefit. }\end{array}$ & $\begin{array}{l}\text { Nahapiet and } \\
\text { Ghoshal } 1998\end{array}$ \\
\hline $\begin{array}{l}\text { Online so- } \\
\text { cial capital } \\
\text { raising en- } \\
\text { abled } \\
\text { through } \\
\text { social me- } \\
\text { dia }\end{array}$ & $\begin{array}{l}\text { Potential resources embedded in } \\
\text { a digital network structure that } \\
\text { are accessed and/or mobilized by } \\
\text { the affordances of social media. }\end{array}$ & $\begin{array}{l}\text { Social Media offer pre- } \\
\text { defined structures ena- } \\
\text { bling the raising of struc- } \\
\text { tural capital and also the } \\
\text { establishment of stake- } \\
\text { holder-relationships } \\
\text { that facilitate relational }\end{array}$ & $\begin{array}{l}\text { Smith et al., } \\
2017 ; \\
\text { Lin } 2011\end{array}$ \\
\hline
\end{tabular}




\begin{tabular}{|l|l|l|}
\hline & & $\begin{array}{l}\text { and cognitive social capi- } \\
\text { tal raising. }\end{array}$ \\
\hline
\end{tabular}

Table 1. HNGO Social Capital Raising - Pre and Post Social Media

\subsection{Social Media Information Governance, Transitions and Social Capital Raising}

Based on others, Mikalef et al. (2020, p. 3) describes information governance as "a collection of competences or practices for the creation, capture, valuation, storage, usage, control, access, archival, and the deletion of information and related resources over its life cycle". Their work highlights and develops many critical aspects of information governance for big data analytics purposes such as its positive moderation on the relationship big data analytics and an organisation's radical innovative capability but this does not directly address the dynamics of information governance between stakeholders on social media platforms.

In their recent research on platform eco systems ${ }^{8}$, however, (Lee et al., 2019, p. 6377) state that "It is essential to understand how data should be managed in platform ecosystems where there is complicated relationships between multiple participating groups. However, this topic has been rarely addressed in industry and academia". These authors then go on to explore "data governance decisions" and "what practices need to be implemented" for these data governance decisions in order to meet some of the shortcomings of information governance approaches to date.

We argue however that, additionally to decisions, when it comes to social media information governance within organizations like HNGOs, it is essential that information governance processes, roles, standards and metrics must reflect and accommodate the overarching organizational and stakeholder goals and objectives since they constitute all communication and information use to, from and by the organization and its relevant stakeholders on these platforms, at different organizational levels. HNGOs primarily operate in regional, intermediate and national organizational units, which all possess their own goals and objectives regarding social media use to connect and engage with their stakeholders and to gather and govern information relating to social capital raising.

For instance, at a regional level, where the HNGO operates within a bounded jurisdiction, social media profiles may be used to support activities, resource needs, and stakeholders within their geographical boundaries. At the national level, in contrast, often supported by a professional social media department, HNGOs may strive to engage with a broader network of supporters using social media for public relations and inform stakeholders on broad set of activities within the HNGO (Greenberg and MacAulay, 2009). In addition, organizational units are deployed differently in terms of goals and objectives regarding resources, plans for sharing content and information and control structures or needs, which can create tensions between units in terms of social media information governance strategies that may lead to an inconsistent organizational public image. Hence, the different organizational units may use and govern social media information when driven by different goals, objectives, needs and resources therefore creating a public image that stands in contrast to each other, i.e., varying organizational "faces". While HNGO, are formally organized they do have semi-autonomous self-organizing properties at each level and they use social media in differing ways for social capital raising purposes. HNGOrelated social media information governance must account for multiple organizational levels but should still focus on the overall organizational goal, which encompasses "fitting and

8 Is defined as a "platform which constitutes two or more sided networks transacting with each other. It allows interactions between multiple groups by providing a meeting place. It is regarded as the building blocks that act as a foundation upon which an array of firms can develop complementary products, technologies or services." Lee et al. (2019), p. 6377-6386 
proper" social media information governance to achieve effective and efficient social capital raising.

In order to conceptualise and understand social media information governance in multi-level organizations, and the processes, roles, standards and metrics that must be managed, we argue that transitions, i.e., dynamic co-evolutionary processes that evolve from the "interplay of many unlike, particular processes" (Kemp et al., 2005, p. 23) can best accommodate governance approaches (Bunker et al., 2013). Transitions present us with a means to manage multi-level organisational structures as they are "aimed and guided in an iterative, forward-looking, adaptive manner, using markets, institutions and hierarchy (the three basic forms of coordination)" (Kemp et al., 2005, p. 23) in order to achieve good information governance. There are four critical rules for managing transitions: "1) be careful not to get locked into sub-optimal solutions: 2) embed transition policy into existing decision-making frameworks and legitimise transition management; 3) take the long view of a dynamic mechanism of change; and 4) engage in multi-level coordination" (Kemp et al., 2005, p. 24).

Organisational transitions directly influence social media information governance for social sustainability purposes such as social capital raising, through the nature and dynamics of $a u-$ topoiesis or self-producing/constructing physical systems (Bunker et al., 2013; Mingers, 2002, 2004). These systems: continually self-produce; require contingent maintenance (to avoid breakdown); are structurally open but organisationally closed; are structurally determined; can be coupled to other systems structurally by mutual specification and/or co-evolution; and can embrace embodied cognition and self-reference/recursion to enable self-construction/production (Mingers, 2002, p. 280).

Mingers develops the idea of conceptual, i.e., non-physical autopoietic social systems that encompass "concepts or descriptions, or rules, or communications which interact or self-produce" (Mingers, 2002, p 283). This type of conceptual self-producing/constructing information system could reflect the use of social media in an "organisationally closed but structurally open" manner through self-reference to its own organising principles. These organising principles might then reflect information governance in a self-sustaining manner.

To highlight how organisational transitions, i.e., non-physical autopoietic social systems, affect social media information governance for social capital raising, we have investigated how HNGOs use social media to grow and maintain online social capital, by conducting interviews with social media experts from various organizational unit levels within the HNGO sector as well as analyzing the social media pages of five HNGOs.

\section{Research Design}

In our study, we attempt to explore the potential of HNGOs' social media information governance and use to grow, develop and maintain social capital. We further aim to detect "patterns of use" that are absent, similar or different to those found in existing literature. Our research approach is supported by the collection of qualitative semi-structured interview data gathered from HNGO social media experts within Germany. These experts had varying levels of expertise and organizational roles within the sector (Flyvbjerg, 2006). It was intended that these interviews would produce rich data, grounded by constructs found in the social media literature and supported by additional expert insights to extend existing, or develop new frameworks or theories on social media information governance for social capital raising and maintenance by HNGOs. Our interview data was also triangulated with data collected from the social media pages of the HNGOs where these social media experts worked (see Appendix 2). 


\subsection{HNGO Organizational Context and Levels of Operations}

Typically, each HNGO located in Germany has a three-level operational structure based on the German federal structure, with a national office, intermediate offices, and regional units (see figure 1). The intermediate offices sit between the regional and national levels and may correspond to a German state or administrative region.

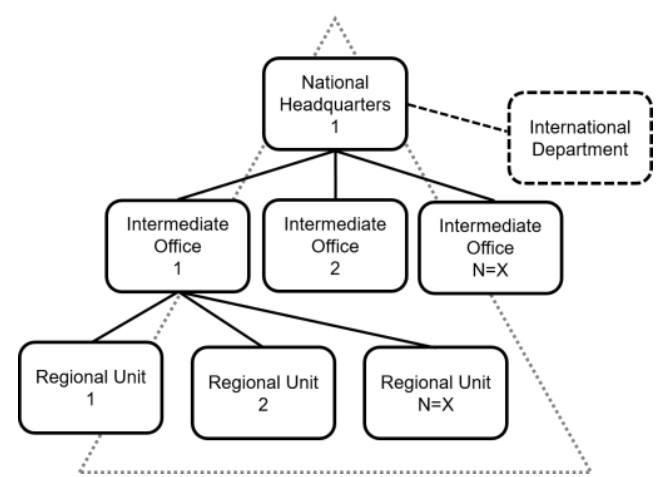

Figure 1. HNGO Organizational Structure

The regional units establish the most direct connections to paid staff, volunteers, and people needing help. These offices do the fieldwork, such as providing medical and rescue services, patient care, and public education (such as first aid training). Most people who work with HNGOs are trained volunteers; only a minority are paid staff. Each regional unit has a high degree of autonomy, maintaining its own website and presence on social media through Facebook, Instagram, or Twitter. In the national and intermediate offices, paid staff handle mostly administrative work, and managing events and training programs for regional units. This may also include disseminating best practices, establishing guidelines, and designing templates for social media governance use within the HNGO as a whole.

\subsection{Participant Sampling Strategy}

To examine how HNGOs foster and establish online social capital using social media, interviewing social media experts who worked within HNGOs was integral to understanding this phenomenon. Given the diversity of HNGOs, their locations and their activities, we decided to undertake interviews with social media experts; working in national and international HNGOs located in Germany; which focused on human wellbeing and delivery of human and health services. We invited social media experts from organizations such as the Red Cross, Malteser, and Johanniter to join our study. Acknowledging that social media experts may have multiple overlapping and sometimes conflicting interpretations and perceptions of social media governance and use for social capital raising, we sampled for a range of experts.

To construct our sample, we searched the Facebook profiles of social media experts working at different organizational levels in German HNGOs and invited these experts to participate in the study via email or social media messenger (convenience sampling). We initially used Facebook to locate social media experts as we already knew it was a widely used channel by HNGOs and so was a good mechanism to identify participants for our study.

Upon acceptance of our invitation, we organized a time to conduct an interview and asked the interviewee for additional contacts that they knew, who had expertise in the use and governance of social media (snowball sampling). In total, we conducted nine semi-structured interviews at the regional level, six at the intermediate level, and three at the national office level. The interviewees came from five different HNGOs and so we feel that we achieved a reasonable 
level of data saturation for this population. The interviews were conducted in German via Skype or by telephone across 2019 and 2020. All interviews were between 30 minutes and 2and-a-half hours, depending on how detailed responses were; but interviews conducted later in the study tended to be longer as we refined our interview guide and protocols. Table 2 is an overview of the interviews. Interviewees were mostly volunteers working at regional unit level as this is where most volunteers are engaged by HNGOs, while paid staff interviewees were mostly located in Intermediate and national units as this is where most permanent operations and headquarters are located, and so our sample reflected these organizational structures.

\begin{tabular}{|c|c|c|c|c|c|c|}
\hline Unit Level & ID & $\begin{array}{l}\text { Years HNGO } \\
\text { social media } \\
\text { management } \\
\text { experience }\end{array}$ & Gender & Age & $\begin{array}{l}\text { Organizational } \\
\text { relationship } \\
\text { with HNGO }\end{array}$ & $\begin{array}{l}\text { Inter- } \\
\text { view } \\
\text { Dura- } \\
\text { tion } \\
\text { (mins) }\end{array}$ \\
\hline \multirow[t]{8}{*}{ Regional } & R1 & 10 & Female & 50 & Volunteer & 104 \\
\hline & R2 & 7 & Female & 37 & Staff & 53 \\
\hline & R3 & 6 & Male & 59 & Volunteer & 33 \\
\hline & $\mathrm{R} 4$ & 3 & Male & 30 & Volunteer & 34 \\
\hline & R5 & 9 & Male & 58 & Volunteer & 30 \\
\hline & R6 & 6 & Male & 55 & Volunteer & 35 \\
\hline & R7 & 3 & Male & 21 & Volunteer & 31 \\
\hline & R8 & 7 & Female & 25 & Volunteer & 67 \\
\hline \multirow[t]{7}{*}{ Intermediate } & I1 & 1,5 & Female & 27 & Staff & 149 \\
\hline & $\mathrm{I} 2$ & 7 & Male & 55 & Staff & 73 \\
\hline & I3 & 1 & Male & 36 & Staff & 94 \\
\hline & $\mathrm{I} 4$ & 1 & Male & 35 & Staff & 65 \\
\hline & I5 & 4 & Male & 34 & Staff & 55 \\
\hline & I6 & 4,5 & Male & 36 & Staff & 50 \\
\hline & I7 & 3 & Female & 32 & Staff & 35 \\
\hline \multirow[t]{3}{*}{ National } & N1 & 2,5 & Male & 35 & Staff & 54 \\
\hline & N2 & 4 & Male & 40 & Staff & 52 \\
\hline & N3 & 3 & Female & 34 & Staff & 41 \\
\hline
\end{tabular}

Table 2. Interviewee profiles

\subsection{Interview Guide and Protocols}

We used a semi-structured interview guide to gain interviewee insights about structural, relational, and cognitive dimensions of social media governance for social capital raising, and resources drawn from networks as well as relationships, trust, cooperation, and collective action.

- Structural dimensions included questions on social media governance focused on: communications channels; stakeholders; functionality of social media use; workflow support; and use in emergencies;

- Relational dimensions included questions on social media governance focused on: frequency of use; information origin; intensity of use; feedback; use for sourcing of resources; and development of trust; and

- Cognitive dimensions included questions on social media governance focused on: references to followers; vernacular; post design; use of coding; and symbology.

This allowed us to direct the interview according to our research focus while offering some flexibility to allow the interviewee to lead us into other areas for exploration. The final interview guide is supplied in Appendix 1. 
We also analyzed the organizational social media pages and posts at each interviewees' unit level i.e., national, intermediate and regional looking at their posts, follower numbers, and likes in order to triangulate the information supplied by the interviewee. Table A1 (Appendix 2) is an overview of the public social media profiles of these HNGOs on the platforms they typically use. We only included platforms that were mentioned as actively used by the experts, that is, Facebook, Instagram, Twitter, and YouTube. From this analysis we see that most of the intermediate units have fewer followers and less social media activity than regional units. This can be attributed to some of the intermediate units corresponding to relatively small geographic areas and some regional units having been successful at engaging stakeholders and/or doing work in a larger city. Oftentimes, regional units are more "hardwired" to their communities through local volunteers which might account for more social media activity than in the more formally staffed intermediate and national units.

\subsection{Data Collection and Analysis}

Through an abductive research approach we applied established qualitative methods of data collection and analysis (Alvesson and Kärreman, 2007; Gioia et al., 2013). All interviews were digitally recorded and transcribed following protocols outlined by Hepburn and Bolden (2017). We then utilized thematic analysis techniques based on theories and constructs from the literature that underlie the definitions of social media governance and online social capital.

We coded our data using these theories and constructs as a basis using MaxQDA 2018 (Alvesson and Kärreman, 2007). For instance, we began by categorizing the interview data into the three main social capital dimensions (structural, relational, and cognitive) with the aim of identifying the social media information governance facets, concepts, and themes underlying this phenomenon (Gioia et al., 2013). We then applied open coding techniques and, thus, used paragraphs or sentences from our transcriptions as coding units. One of the authors coded the interview textual expressions or simple descriptive phrases (themes). These themes (secondorder themes) were then grouped into first-order themes and then classified under the dimensions taken from the social capital literature (Lin, 2011). As we proceeded with our analysis, we also identified narrative examples of national, intermediate, and regional social media information governance activities and coded these under the social capital categories as highlighted within the literature section.

As a consistency check, coding was replicated by a second member of the research team. Where there was a low level of coding agreement between research team members, this was discussed in order to develop a "theme" consensus. The interviews were mainly in German, and the quotes provided in this manuscript were translated by fluent German/English speakers on our research team.

\section{Results}

In order to answer the research questions, we firstly discuss our data analysis as it relates to the social media information governance of each social capital dimension. Table 3, 4 and 5 summarize our findings across these dimensions and focus areas of social capital raising for our five HNGOs. We firstly identify the establishment and impact of social media information governance as transitions, i.e., "dynamic co-evolutionary processes" on HNGO operations at each level (national, intermediate, regional). We then highlight the "emerging tensions" between those levels as they relate to the establishment of social media information governance through these transitions. We have also provided summaries and extracts from our interview data (after each table) to add meaning and context to our findings as well as to highlight valuable and critical insights from our study participants. 


\subsection{Structural Dimension of HNGO's Social Media Governance and Use for Social Capital Raising}

Focus Area: Network Maintenance comprises the maintenance of existing online structures and relationships. HNGOs have begun to use social media in parallel with its popularization. This comprises their national headquarters, intermediate offices, and regional units. National offices use a variety of channels and have dedicated social media experts who work within a larger department for social media information governance regarding communication. Intermediate offices-depending on their area of responsibility-have a larger budget for social media activities than regional units and work within a department for social media communication (one to a few experts). Regional units mostly have one dedicated volunteer social media expert often focusing on a single channel with mature structures and relationships. In this regional channel (often Facebook), followers are part of a committed community and regions claim that they can achieve the widest reach among all platforms.

In addition, many of the trained volunteers who help with social media information governance at this level are familiar with features of Facebook and are confident about using it "I use Facebook because I'm in the target group myself and I know the platform" (R1). The focus by regional HNGO units on one main channel is mostly due to limited resources (time, money) for pursuing social media activity or because those responsible who are mostly volunteers know one channel well, do not commit to educate staff about the features of other social media platforms, and/or reach their community easily through this mature structure.

At the regional level, other channels are sometimes seen as less relevant due to specific platform affordances "I don't want to do Trump-like politics. I actually want to provide information about daily operations. So, I don't see the value of Twitter" (R6). In fact, the overall picture is that most regional units have longstanding audiences on Facebook, which has enabled them to build sound relationships with their closest volunteers. Some of the platform's features such as Facebook groups are particularly useful, for instance, to engage and updating stuff and volunteers by announcing events. On this platform, the activities primarily serve the cultivation of an existing social network: "I always suspected that a large proportion of followers were employees, which is certainly also the case in other units. But then I would really try to address other interested people even more strongly" (N2). While national headquarter criticizes this focus on volunteers and staff and stresses the importance of informing and attracting people outside the HNGO in social media at all levels, they do not overrule the autonomy of lower-level units: "Of course, there are many regional HNGO profiles on different social media platforms. That is something we cannot do from here. They report on what they experience on-site" (N1).

Generally, social media information governance and use in regional units depends on one local expert, who is intrinsically motivated to take responsibility for building and maintaining relationships for that unit. This strongly impedes continuous improvement in social media information governance training and execution. In particular, volunteers deal with the social media information governance in their leisure time and do not always have social media training or background and are often focused on social media network maintenance rather than network growth. 


\begin{tabular}{|c|c|c|c|c|c|}
\hline $\begin{array}{l}\text { Information } \\
\text { Governance } \\
\text { Focus Area }\end{array}$ & Description & $\begin{array}{l}\text { Social Media Transi- } \\
\text { tions at National } \\
\text { Level }\end{array}$ & $\begin{array}{l}\text { Social Media Transitions at } \\
\text { Intermediate Level }\end{array}$ & $\begin{array}{l}\text { Social Media Transitions at } \\
\text { Regional Level }\end{array}$ & $\begin{array}{l}\text { Emerging Tensions in Social } \\
\text { Media Information Govern- } \\
\text { ance }\end{array}$ \\
\hline $\begin{array}{l}\text { (1) Network } \\
\text { Maintenance }\end{array}$ & $\begin{array}{l}\text { Cultivation } \\
\text { of existing } \\
\text { online struc- } \\
\text { tures and } \\
\text { relation- } \\
\text { ships }\end{array}$ & $\begin{array}{l}\text { *Multiple social me- } \\
\text { dia experts (staff) re- } \\
\text { sponsible for public } \\
\text { and social media } \\
\text { communication } \\
\text { *Maintenance of mul- } \\
\text { tiple social media } \\
\text { channels for organi- } \\
\text { zational awareness } \\
\text { raising }\end{array}$ & $\begin{array}{l}\text { *One to multiple social me- } \\
\text { dia experts (staff)-de- } \\
\text { pending on the size of the } \\
\text { intermediate unit-respon- } \\
\text { sible for public and social } \\
\text { media communication } \\
\text { *Maintenance of one to } \\
\text { multiple social media chan- } \\
\text { nels for organizational } \\
\text { awareness raising }\end{array}$ & $\begin{array}{l}\text { *One local social media ex- } \\
\text { pert (volunteer), also re- } \\
\text { sponsible for other tasks } \\
{ }^{*} \text { Often one focus social me- } \\
\text { dia channel that affords for } \\
\text { relationship building with lo- } \\
\text { cal community } \\
\text { *Grown (local) online com- } \\
\text { munity over the years }\end{array}$ & $\begin{array}{l}\text { *Focus on staff and volun- } \\
\text { teers vs. openness to inter- } \\
\text { ested people beyond the or- } \\
\text { ganization } \\
\text { *Coordinated and synchro- } \\
\text { nized social media strategy } \\
\text { across HNGO levels vs. many } \\
\text { profiles on all levels }\end{array}$ \\
\hline $\begin{array}{l}\text { (2) Network } \\
\text { Growth }\end{array}$ & $\begin{array}{l}\text { Establish- } \\
\text { ment of new } \\
\text { online struc- } \\
\text { tures and } \\
\text { relation- } \\
\text { ships by } \\
\text { bridging } \\
\text { networks } \\
\text { and contacts }\end{array}$ & $\begin{array}{l}\text { *Use of multiple } \\
\text { channels to reach di- } \\
\text { verse stakeholders } \\
\text { *Supervise and moni- } \\
\text { tor the use of new } \\
\text { emerging social me- } \\
\text { dia platforms by in- } \\
\text { novative units of the } \\
\text { HNGO } \\
\text { *Do not over-rule } \\
\text { lower-level units in } \\
\text { their social media } \\
\text { channels }\end{array}$ & $\begin{array}{l}\text { *Focus on a few channels } \\
\text { but see potential of differ- } \\
\text { ent platforms for different } \\
\text { demographics } \\
\text { * More resources for chan- } \\
\text { nel experimentation }\end{array}$ & $\begin{array}{l}\text { *Use of established SM chan- } \\
\text { nels-build trust and loyalty } \\
\text { to stakeholders } \\
\text { *Extra channels sometimes } \\
\text { become disused "ghost chan- } \\
\text { nels" } \\
\text { *Testing of newer social me- } \\
\text { dia platforms to attract new } \\
\text { or younger members } \\
\text { *Limited resources for multi- } \\
\text { platform development and } \\
\text { use }\end{array}$ & $\begin{array}{l}\text { *Network retention vs. net- } \\
\text { work growth } \\
\text { *Limited resources may al- } \\
\text { low only one focus social me- } \\
\text { dia channel } \\
\text { *Experimenting with new } \\
\text { platforms vs. risk of ghost } \\
\text { profiles } \\
\text { *Strategic awareness vs. lo- } \\
\text { cal needs/daily operations }\end{array}$ \\
\hline $\begin{array}{l}\text { (3) Resource } \\
\text { Pooling }\end{array}$ & $\begin{array}{l}\text { Transfer of } \\
\text { resources } \\
\text { up and } \\
\text { down in the }\end{array}$ & $\begin{array}{l}\text { *Provide guidelines } \\
\text { and rules for social }\end{array}$ & $\begin{array}{l}* \text { Design templates for so- } \\
\text { cial media content creation } \\
\text { for regional units }\end{array}$ & $\begin{array}{l}\text { *Use templates and follow } \\
\text { guidelines *Locally gener- } \\
\text { ated content often not } \\
\text { shared with upper levels }\end{array}$ & $\begin{array}{l}\text { *Broad representation of op- } \\
\text { erations at national level vs. }\end{array}$ \\
\hline
\end{tabular}




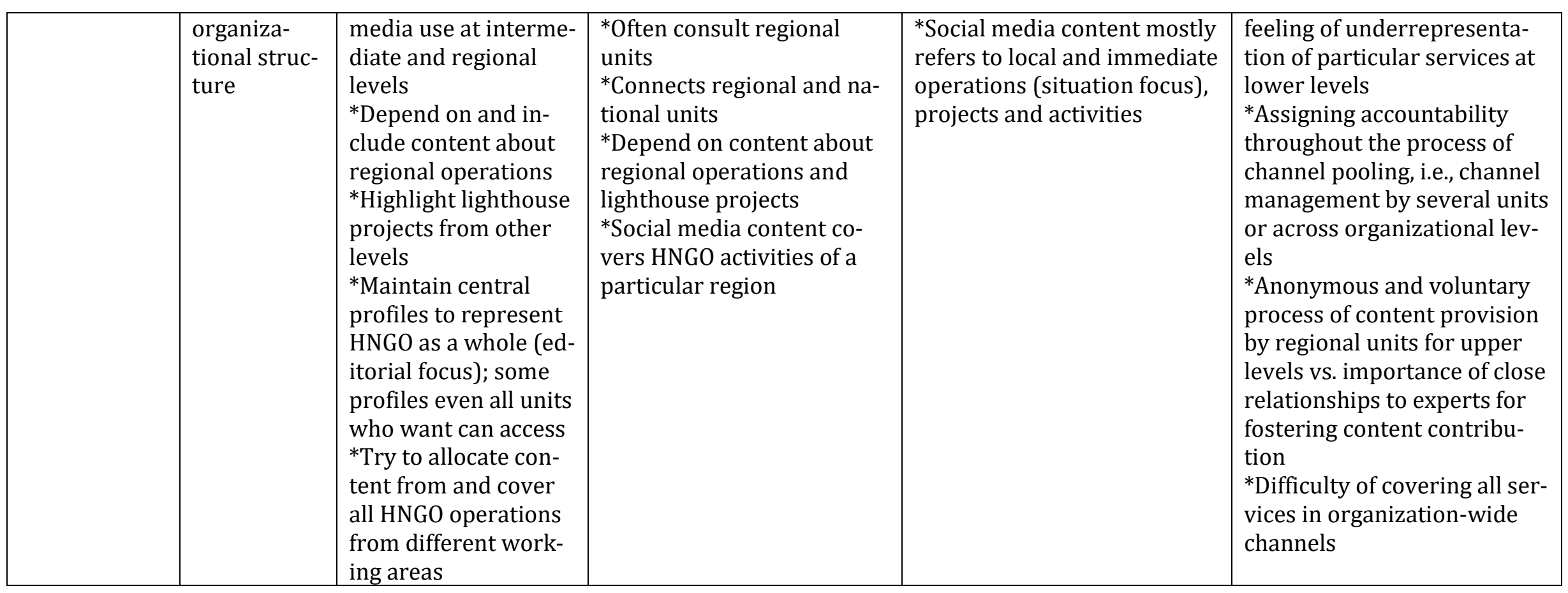

Table 3. Information Governance and Transitions for Structural Social Capital Raising—Emerging Tensions 
Focus Area: Network Growth comprises the extension of network ties by establishing new relationships, which will consequently lead to increased online social capital. Our interviewees were generally aware that each platform has different characteristics to address different stakeholder groups. "In terms of demographics, some platforms reach older users more effectively whereas other services captivate users younger than 30 years" (I6). In this respect, experts with limited resources need to weigh maintaining and growing an existing network against cultivating an additional network that promises more structural social capital. Whereas the experts generally agree that being present in newly emerging social media platforms is necessary for structural growth, they do not necessarily pursue these opportunities. Implementing new information governance structures requires time, personal interest, training, and resources. While network growth is important for establishing new social capital by diversifying stakeholder groups, it is important to respond to the governance needs of the existing groups, especially in regional units. N2 identified a gap between this aspiration and the actual strategy: "We have to try to explain ourselves more. Of course, this is always in contrast to those who already know us and would like to have an insider story. But our focus is that everyone understands what we do and that we can reach different target groups" (N2). Hence, the two objectives of information governance for network maintenance and network growth can sometimes conflict.

In regional units in particular, social media enthusiasts sometimes open a new channel for the HNGO but then lack the resources to use it effectively, thus compromising governance: "We're careful with new channels because our maxim is to first implement the channels you have in a good way before open a new channel, and in doing so, have your capacities and resources in mind. We have a tendency in the HNGO that certain people open 10 channels but don't use them in a targeted and a meaningful way and that is strategically wrong" (N2). Those channels may also become a ghost profile for the HNGO-with no content contribution and activity. Although such channels were launched with good intent, they are not well managed and governed and do not contribute to aggregate social capital of local units and the entire HNGO may sustain reputational damage as a result. However, a few regional social media experts have successfully pursued a multi-channel strategy. They see the rewards of reaching different target groups-e.g., younger users through Instagram-as outweighing possible deficiencies in network maintenance efforts. For instance, one regional expert focuses on reporting about the regional unit's operations and activities and reflects upon what other units are doing to increase their follower numbers: "We have 4,200 Instagram followers. That is pretty good. I'm afraid I can't say we're the best with the most followers, because there's a regional unit with more than 12,000 followers. But I don't know what their goal is, because they also report about the HNGO all over Germany and about the fire brigade and rescue service. We only report about our regional unit, and with 4,200 followers we are actually at the top here" (R8).

National headquarters also show openness to innovative governance and use of social media channels. For instance, as N2 explains, its younger staff are increasingly motivated to use and test new channels such as TikTok. Together with upper-level experts and under close supervision, they are free to use the channel in the HNGO's name: "They are allowed to test it. I think that is important, and we look at it with great interest. If we introduced it at the federal office, that would be easier, but then we automatically would have to think about what the rest of the HNGO does" (N2). Sub-units such as the youth association or innovative regional units are places to "test the waters" on the governance and use of new digital platforms and technology.

Focus Area: Resource Pooling refers to the upward and downward allocation of resources within the organization. Resource pooling may operate in both directions: regional units contribute using templates, guidelines, and ideas from central offices; the latter may learn from exceptional campaigns implemented by the regions. While larger intermediate offices focus on a consulting role for regional units, national headquarters provide social media information 
governance guidelines and rules for the intermediate and regional offices within the HNGO to some extent. For instance, in one HNGO social media experts are required to post on Facebook at least twice a week to ensure the channel is not neglected (N2).

National headquarters are typically in charge of the overall social media information governance for the HNGO as a whole. They maintain central profiles, which have a wider reach than regional and intermediate profiles and aim at addressing a nationwide interest group reaching from the general interested public, donors, politicians, or public media. When it comes to managing these central HNGO profiles, some national headquarters build on the operations of subordinate units: "We are sitting here in the head office in [city], but the real HNGO world and what people experience with us is happening out there somewhere. We depend on it, and half our content is about what good deeds our members do in our name and under our banner" (N1). Another HNGO, in contrast, uses its national profile to showcase only one lighthouse project of regional units a week: "We share content from these units once a week. We have to decide on what I call a 'lighthouse project,' ... something so exciting that it is interesting nationally and not only for this particular region" (N2).

While close relations between the different levels and departments are crucial for receiving up-do-date information on local operations and events, interviewees note that national level cannot maintain contact with every single regional unit. There are just too many and thus, often intermediate units bundle contacts. While national offices also directly enable the submission of content, not all units, though, are content with the process of submitting their social media contributions. One regional social media manager criticizes this procedure: "They always do something on their own. They don't share the content of the regional units. That's too bad. But you can send something. Then it goes to the editors. It's pretty anonymous" (R8).

The diversity of service areas for which HNGOs are responsible-day-care centers, worldwide disaster relief, civil protection, first aid courses, schools, blue light emergencies, medical service, hospices, grief work, psychological care, and delivery of hot meals, among others-actually can also hinder efforts to balance the content published on a national level, where the social media experts may find it difficult to decide what content to share. This makes it impossible to reach all stakeholders. Regional-level content creation depends on daily operations, whereas there is often an editorial plan at the intermediate and national levels to inform the general public about the HNGO's activities in a broader sense: "If we publish ad hoc content, which is from a regional unit, or we get up-to-date information about a crisis and report on it, then it comes rather spontaneous. Or we have planned content, in which we, for example, introduce employees in social media. That's content one can easily plan long term" (I5).

One HNGO decided to create two organization-wide channels on YouTube and Twitter to centralize communication and capture synergies from different units (CS3). They give regional and intermediate units access to these channels to upload content. This avoids having multiple channels within the organization that are seldom updated, enables regional units a reach of their content beyond their region, and ensures a common social media presence: "It is utopian to think that [regional units] can actually produce a lot of video content. That's why the idea was that the stronger ones deliver for the weaker ones and the weaker ones profit from the stronger ones, and we all profit from there always being something happening on this channel-and we don't have $x$ number of YouTube channels where something happens only once a year or three times a year" (N2). This pooling of resources at a national level also frees lower-level units from work and concentrates efforts toward a unified strategy.

At all levels, relationships to specialists are highly relevant as social media experts are not familiar with all subject matters in the diverse HNGO segments. "When covering topics and content where we are not experts, whether it be civil protection or daycare centers, we have to work closely with colleagues from the specialist departments every now and then" (I6). 


\subsection{Relational Dimension of HNGO's Social Media Governance and Use for Social Capital Raising}

Focus Area: Trust Building. The development of trust and goodwill within social media relationships is the first focus area of the relational dimension of online social capital. For an HNGO, being active on social media is an indispensable step in building trust between the organization and people outside the organization and positively influence accountability and reputation. Interviewees believe that a communications department that doesn't use social media misses the point. Social media experts at intermediate and national level agree that social media communication is superior to traditional channels-say, a press release-when it comes to building trust: "The most direct way between the people outside and us is social media. We show we are active, what we do, and that we do it all in the interest of humanity, in line with our goals. And thus, we also directly build up trust between us and the people" (I4).

Our interviewees at intermediate and national level deem it important in building trust to react to issues raised by users within and outside the organization or take seriously suggestions for improvement. Transparency and a sympathetic presentation of the social media content are also important. Being transparent applies not only to highlighting an HNGO's day-to-day activities, but also to address negative publicity and wrongdoing. For instance, there have been incidents in the press going back to the 1990s about financial and sexual misdeeds at NGOs that have negatively affected reputations and raised public indignation (Gibelman and Gelman, 2001) - especially problematic for a sector based on high ethical and moral standards and that relies on public resources and donations. Some HNGOs are affiliated with religious institutions and receive negative comments resulting from those connections: "We also get attacked for our church affiliation ... 'Fu $\mathrm{u}^{* * * * *}$ [religious group], they are all child molesters', or something. It's rare, but it happens" (I2). Transparency in social media information governance is established as a guiding principle when the HNGO faces a precarious situation, even if it is self-inflicted: "We are not sugarcoating anything. No misrepresenting of things. If there was a mistake made by the $H N G O$, we don't try to cover it up, but deal with it very openly and take a very clear position. And we admit we made the mistake, that we have a solution, and that we are really honest with our followers" (I1).

Most of the interviewees at intermediate and national level have opinions about how to build trust, e.g., "by providing good, reliable, comprehensive, and honest information as quickly as possible. So, ultimately, by working competently" (I2) or by integrating "sensefluencers," (N2) who are popular and try to use their online influence for social issues. At a regional level the communication is more ad-hoc and less focused on specific trust-building content, but also at this level social media experts experience what one interviewee from the regional level (R1) calls "candystorms" - many positive online reactions of approval for a certain topic-that help build trust, but which happens only rarely.

Focus Area: Community Management. Managing the online community based on stakeholders' needs is another focus area. HNGOs are relationship-driven organizations based on loyalty to the organization and passion for the common good. Regional social media activities are largely focused on community management, which confirms the community-based nature of this work. We found that regional units draw on a strong participative culture among their staff and active members and try to bring together people with common interests. These relationships are crucial to building and maintaining an active network both online and offline. 


\begin{tabular}{|c|c|c|c|c|c|}
\hline $\begin{array}{l}\text { Information } \\
\text { Governance } \\
\text { Focus Areas }\end{array}$ & Description & $\begin{array}{l}\text { Social Media Transi- } \\
\text { tions at National Level }\end{array}$ & $\begin{array}{l}\text { Social Media Transi- } \\
\text { tions at Intermediate } \\
\text { Level }\end{array}$ & $\begin{array}{l}\text { Social Media Transitions at Re- } \\
\text { gional Level }\end{array}$ & $\begin{array}{l}\text { Emerging Tensions in So- } \\
\text { cial Media Information Gov- } \\
\text { ernance }\end{array}$ \\
\hline $\begin{array}{l}\text { (4) Trust } \\
\text { Building }\end{array}$ & $\begin{array}{l}\text { Development } \\
\text { of trust and } \\
\text { goodwill within } \\
\text { the online com- } \\
\text { munity }\end{array}$ & $\begin{array}{l}\text { *Sensitive to communi- } \\
\text { cating the "right infor- } \\
\text { mation" } \\
\text { *Transparency } \\
\text { *Publicity focused } \\
\text { *Foster organizational } \\
\text { reputation and legiti- } \\
\text { macy }\end{array}$ & $\begin{array}{l}\text { *Sensitive to communi- } \\
\text { cating the "right infor- } \\
\text { mation" } \\
\text { *Transparency } \\
\text { *Organizational repu- } \\
\text { tation } \\
\text { *Focus on activities } \\
\text { and projects in a par- } \\
\text { ticular region }\end{array}$ & $\begin{array}{l}\text { *Ad-hoc communication along } \\
\text { the unit's field activities } \\
\text { *Local community events, pro- } \\
\text { motional activities, social ser- } \\
\text { vices and contributions show- } \\
\text { cased in social media }\end{array}$ & $\begin{array}{l}\text { *Strategic trust vs. opera- } \\
\text { tional trust } \\
\text { *Professionally counter } \\
\text { criticism and negativity } \\
\text { (sensitivity) vs. ad hoc } \\
\text { communication }\end{array}$ \\
\hline $\begin{array}{l}\text { (5) Commu- } \\
\text { nity Manage- } \\
\text { ment }\end{array}$ & $\begin{array}{l}\text { Cultivation of } \\
\text { an online com- } \\
\text { munity based } \\
\text { on stakeholder } \\
\text { needs to bond } \\
\text { with existing } \\
\text { community }\end{array}$ & $\begin{array}{l}\text { *Legitimacy from } \\
\text { stakeholders-often } \\
\text { external to the organi- } \\
\text { zation-in social me- } \\
\text { dia } \\
\text { *Focus on external } \\
\text { communication } \\
\text { *Improvement of in- } \\
\text { ternal communication } \\
\text { within and between } \\
\text { levels }\end{array}$ & $\begin{array}{l}\text { *Manage interests of } \\
\text { diverse stakeholders } \\
\text { reaching from mem- } \\
\text { bers in this region to } \\
\text { other organizations by } \\
\text { showcasing projects } \\
\text { and activities from re- } \\
\text { gional area and mate- } \\
\text { rial from national unit }\end{array}$ & $\begin{array}{l}\text { *Focus on local community } \\
\text { management } \\
\text { *Relationships based on loy- } \\
\text { alty, common deeds, participa- } \\
\text { tion, social interests } \\
\text { *Closed groups } \\
{ }^{*} \text { Operational external commu- } \\
\text { nications } \\
\text { *Company newsletter commu- } \\
\text { nications }\end{array}$ & $\begin{array}{l}\text { *External communications } \\
\text { vs. internal communica- } \\
\text { tions } \\
{ }^{*} \text { Blurred lines between } \\
\text { public and private commu- } \\
\text { nications } \\
{ }^{*} \text { Competence conflict be- } \\
\text { tween internal (e.g., social } \\
\text { intranet) and public social } \\
\text { media (e.g., Facebook) }\end{array}$ \\
\hline (6) Brokerage & $\begin{array}{l}\text { Efforts and } \\
\text { openness to in- } \\
\text { corporate ex- } \\
\text { ternal re- } \\
\text { sources and en- } \\
\text { gage different }\end{array}$ & $\begin{array}{l}\text { *Participation in cross- } \\
\text { organizational initia- } \\
\text { tives and networks } \\
{ }^{*} \text { Care with sharing in- } \\
\text { formation from other } \\
\text { HNGOs }\end{array}$ & $\begin{array}{l}\text { *Participation in cross- } \\
\text { organizational online } \\
\text { initiatives and net- } \\
\text { works }\end{array}$ & $\begin{array}{l}\text { *Try to publish consistent in- } \\
\text { formation via social media be- } \\
\text { tween HNGOs, e.g., during lo- } \\
\text { cal emergencies or common is- } \\
\text { sues }\end{array}$ & $\begin{array}{l}\text { *Well-planned day-to-day } \\
\text { operations within HNGOs } \\
\text { escalating to (partially) so- } \\
\text { cial media coordinated cri- } \\
\text { sis communication }\end{array}$ \\
\hline
\end{tabular}




\begin{tabular}{|l|l|l|l|l|l|}
\hline $\begin{array}{l}\text { relevant stake- } \\
\text { holders by } \\
\text { bridging net- } \\
\text { works and } \\
\text { online contacts }\end{array}$ & *HNGO connectedness & $\begin{array}{l}\text { *Care with sharing in- } \\
\text { formation from other } \\
\text { HNGOs }\end{array}$ & $\begin{array}{l}\text { *Incorporation of spontaneous } \\
\text { *Leverage relation- } \\
\text { shigital to other organi- } \\
\text { about who turns up, skill sets, } \\
\text { management etc. }\end{array}$ & $\begin{array}{l}\text { *HNGO competition vs. col- } \\
\text { laboration and co-opera- } \\
\text { tion within and between } \\
\text { HNGOs } \\
\text { zations and the public } \\
\text { unteers during emergen- } \\
\text { cies vs. missing strategies } \\
\text { of incorporating them } \\
\text { meaningfully }\end{array}$ \\
& & & & \\
\hline
\end{tabular}

Table 4. Information Governance and Transitions for Relational Social Capital Raising—Emerging Tensions 
Content serves to foster a community feeling, which is often amplified after field operations that involve a large number of volunteers: "Especially after a field operation, we receive 'thanks.' It happens quite often that online content about the operation is shared. Our volunteers then post on their private profiles and express gratitude, I'd say that's appreciation, too" (R8). Social media managers emphasize online appreciation by sharing stories about the work. Thus, at the regional level, social media relationships foster participation, the organization of events, socializing, and sharing information. The focus is on bringing together the community through social media information governance.

In some cases, HNGO communities also communicate in closed, self-governed groups that were created by motivated affiliated volunteers to foster online relations and that have grown organically over the years. Upper levels of the HNGO do not see managing these groups as necessary: "Yes, there are Facebook groups created by members. That we could not and did not want to close" (N2). These groups are mostly about sharing knowledge among volunteers and staff of a specific HNGO from different regions, but are closed to others. They have group names related to their topics, such as "[HNGOs name] peddlers market," "[HNGOs name] youth night," "You are a [HNGOs name] member, if you...," "[HNGOs name professional group on press and communication]", and "former [HNGOs name] member" (N2). The number of members of these groups ranges from three to more than 10,000.

Social media information governance and use by HNGOs has shifted its purpose over the years. At first, regional units in particular focused on building relationships by reaching out to their own staff and volunteers. But as time has passed, social media information governance use has become professionalized from the top level of the HNGO using social media to primarily inform external stakeholders such as politicians, donors, or other organizations as potential partners, and the lines between internal and external communication channels has become blurred, with implications for the adoption of new internal systems such as a social intranet: "When we train our members, we always point out that Facebook is a channel for external communication and should be used as such. I think this is somewhat historically justified, in our organization, because this social intranet did not exist until last year. And you could reach a lot of colleagues quite well via Facebook" (N2). The same expert said that HNGOs in general struggle with the divide-internal vs. external communication-using and governing social media only as internal platforms, as staff and volunteers often do. This blurring often becomes generalized, because volunteers do not receive updates as easily as paid staff in regional units. Some regional interviewees refer to social media as a "company newsletter" and refer to a constant balancing act between internal and external communication. Too much focus on internal communication risks excluding people outside the group and limits their integration into the HNGO's work.

Focus Area: Brokerage. The third focus area within the relational dimension mirrors the organization's openness and efforts to engage with relevant stakeholders that may be from the same organization, other organizations, or the general public. We found that social media experts, seeking several types of benefits, incorporate outside information, resources, and contacts into an HNGO's social media information governance approach. Social media are seen as useful tools to establish relations between different units of the same HNGO or between HNGOs. This becomes especially important during and after major operations in which HNGOs often work together: "We link to each other or coordinate posts when we do joint field operations during major emergencies, when we operate with other relief organizations ... so that we all publish similar information online" (I2). In major emergencies, this communication typically happens within a common incident structure that is established among all responsible stakeholders. In dynamic times of high uncertainty, false information can spread easily via social media, consequently social media experts stress the importance of a common communications strategy and information governance apporach - which can be challenging if contact points are unclear. 
The rivalry among HNGOs can sometimes limit openness to the activities of other organizations, and is reliant on individuals and their attitudes. Despite having shared goals and visions, some interviewees at the intermediate level emphasized organizational competitiveness: "We link and comment on the content of other HNGOs, but within reason. Of course, I wouldn't share content about their rescue dog team if we have our own. We check: Is the content a direct competition or not?" (I1). But another noted: "When I started, the department would have considered it a terrible thing-posting something from another HNGO. I don't share that opinion at all... In my experience, if I repost something, I receive positive feedback. Honestly, we all do the same work. And in many emergency situations, it's not just our HNGO, but also the Red Cross, maybe the Malteser, and so on. It's always a cooperative effort" (N2). All HNGOs in our case study carefully select what to share from other HNGOs.

Openness toward content from other HNGOs is especially apparent when it comes to topics that affect the entire humanitarian aid sector. For instance, during the COVID-19 crisis, many people were calling the emergency hotline for information and updates. The hotline, though, is for acute emergency situations. So HNGOs banded together to inform their members about which hotline to call for coronavirus updates, linked to reliable information, and explained the importance of keeping the emergency hotline available for emergencies.

We observed a positive effect from bridging and bonding beyond the relationship between organizations. The relationship with the public, too, becomes a valuable resource in times of high uncertainty and when there is a need for spontaneous volunteers to support the HNGO. "We reported in social media that we're on site helping refugees, and a lot of volunteers showed up. Some have stayed connected to us. So, depending on the situation, we benefit from this quick and direct communication with people" (I1).

Social media challenges existing hierarchies as the situation with dealing with spontaneous volunteers' shows. Integrating them into a response depends significantly on the particular emergency and can be a difficult task, as they must be integrated into fixed hierarchical organizational structures. HNGOs give careful consideration to posting calls for volunteers in such situations because management processes can easily be overwhelmed-no one can be sure how many volunteers might show up. The fact that HNGOs follow a clear commandand-control structure similar to the military in these situations adds to the challenges of managing volunteers. Often, they are hesitant to use social media to reach out to potential volunteers as an interviewee at regional level states: "I would only make calls for help very carefully via social media, because something like this can get out of hand very quickly. You have to know exactly what kind of help you need, where people should report, who takes care of them, who allocates them, and so on" (R1).

\subsection{Cognitive Dimension of HNGO's Social Media Information Governance and Use for Social Capital Raising}

Focus Area: Emotional Empathy. This key driver refers to mutual meanings, symbols, and language that define the cognitive dimension of online social capital- or, more precisely, the organization's ability to address pressing social topics, provide relief information, and reduce uncertainty in ambiguous situations. Our interviews shed light on the prevalence and manifestation of these elements of communication in the cultivation of social capital within the HNGO. Interviewees mentioned that HNGOs deal with emotional topics that often lead to emotional reactions: "Especially in our projects or when we report on crises, it is always emotional, and you notice that the reactions are the same-both positive and negative. But that's definitely something where people take an interest" (N3). However, the experts stress that they need to be careful about what they post regarding sensitive material and wouldn't show inappropriate content of victims, blood etc.-most importantly they emphasize "political neutrality". Furthermore, reporting on emotional topics such as calls for stem cell donations for a specific patient or assistance of victims of emergency events encourages emotional responses, as one interviewee noted. 


\begin{tabular}{|c|c|c|c|c|c|}
\hline $\begin{array}{l}\text { Information } \\
\text { Governance } \\
\text { Focus Areas }\end{array}$ & Description & $\begin{array}{l}\text { Social Media Transi- } \\
\text { tions at National Level }\end{array}$ & $\begin{array}{l}\text { Social Media Transi- } \\
\text { tions at Intermediate } \\
\text { Level }\end{array}$ & $\begin{array}{l}\text { Social Media Transitions } \\
\text { at Regional Level }\end{array}$ & $\begin{array}{l}\text { Emerging Tensions in Social } \\
\text { Media Information Governance }\end{array}$ \\
\hline $\begin{array}{l}\text { (7) Emotional } \\
\text { Empathy }\end{array}$ & $\begin{array}{l}\text { Sensitivity to- } \\
\text { wards societal } \\
\text { challenges and } \\
\text { individual needs } \\
\text { within social me- } \\
\text { dia }\end{array}$ & $\begin{array}{l}{ }^{*} \text { Communications } \\
\text { more anonymous and } \\
\text { rather informative- } \\
\text { social control weaker }\end{array}$ & $\begin{array}{l}{ }^{*} \text { Communications less } \\
\text { anonymous as on the } \\
\text { national level but still } \\
\text { diverse range of stake- } \\
\text { holders-focus on } \\
\text { both, emotions and } \\
\text { empathy }\end{array}$ & $\begin{array}{l}{ }^{*} \text { Communications less } \\
\text { anonymous-social con- } \\
\text { trol stronger, less nega- } \\
\text { tive emotion and more } \\
\text { empathy }\end{array}$ & $\begin{array}{l}\text { *Maintaining political neutrality } \\
\text { (e.g., during conflicts) while at- } \\
\text { tracting attention for abuses of } \\
\text { power in social media } \\
\text { *Showing sensitive material vs. } \\
\text { whitewashing humanitarian } \\
\text { grievances } \\
\text { *Conflicts between HNGO } \\
\text { agenda (e.g., raise donations) } \\
\text { and community preferences/ex- } \\
\text { pectations (e.g., information on } \\
\text { new equipment or upcoming ac- } \\
\text { tivities) }\end{array}$ \\
\hline $\begin{array}{l}\text { (8) Common } \\
\text { Identity }\end{array}$ & $\begin{array}{l}\text { Feeling of cama- } \\
\text { raderie and } \\
\text { shared values } \\
\text { within social me- } \\
\text { dia }\end{array}$ & $\begin{array}{l}\text { *Symbology and slo- } \\
\text { gans important } \\
\text { *Establishment of an } \\
\text { organization-wide } \\
\text { HNGO identity } \\
\text { *Countering anony- } \\
\text { mous negative com- } \\
\text { ments } \\
\text { *Promoting positive } \\
\text { HNGO roles }\end{array}$ & $\begin{array}{l}\text { *Symbology and slo- } \\
\text { gans are important } \\
\text { *Appreciation of vol- } \\
\text { untary work } \\
\text { *Strategic positioning } \\
\text { of the HNGO in social } \\
\text { media as provider of } \\
\text { dedicated services exe- } \\
\text { cuted by regional units }\end{array}$ & $\begin{array}{l}\text { *Symbology and slogans } \\
\text { are important } \\
\text { *Appreciation of volun- } \\
\text { tary work } \\
\text { *Creation of regional } \\
\text { identity } \\
\text { *Developing volunteer } \\
\text { identity, camaraderie, } \\
\text { community, ethical } \\
\text { standards, community } \\
\text { name, e.g., social media } \\
\text { group name }\end{array}$ & $\begin{array}{l}\text { *Alignment of central identity } \\
\text { vs. local identity }\end{array}$ \\
\hline
\end{tabular}

Table 5. Information Governance and Transitions for Cognitive Social Capital Raising-Emerging Tensions 
He also mentioned some techniques he uses with his content to arouse emotions: "As a rule, you don't put the picture of the emergency backpack on Facebook, but you put the picture of the person who carries it. Or any picture, because you are publicizing a volunteer service. Even showing a helper kneeling down to help someone, has an effect. ... It's important that you bring the connection to the people, the emotional side" (R6). At a regional level, interviewees stated that fans and followers are mostly staff and volunteers and thus they are more interested in updates about the unit's activities such as arrival of new equipment, upcoming regional events, showing empathy for staff who have been impacted by a crisis, and so forth. At intermediate and national level, in contrast, the stakeholders are more anonymous and emotional topics reach a more diverse group of stakeholders.

Focus Area: Common Identity. This key driver encompasses feelings of camaraderie and the extent to which members of an HNGO share the same values when engaging in social media. It comprises the cognitive perception and interpretation of an HNGO's social media information governance and activity. The community is built by establishing the required online structures and then maintaining them operationally through careful community management. Common identity within social media also requires commitment to ethical standards and communication, which allows HNGOs to be more resilient. On social media information governance-especially at the intermediate or national level-communication is often more anonymous and mechanisms of social control are weaker than in offline communities. In this respect, HNGOs are also subjected to negative comments about their work but explain that the shared values of their own communities are very strong and members do not tolerate racism and other slurs. For instance, during the time when many refugees came to Germany and refugee shelters were built, "We actually experienced a lot of online racism and hate. But we have great followers, Facebook fans who intervene and say: 'No, this is not right. We are members of [HNGO], we are people who stand up for this, and we do not tolerate that here'” (N2). In regional units, social media experts try to create a local and volunteer identity: "The appreciation, the camaraderie. It's like being in a community. It's like a soccer club. Only we cannot lose. We have the camaraderie, we're friends. With 125 people, not everyone is friends with everyone, that is obvious. But you also push each other, because you pull each other" (R8).

In addition, by showcasing that everyone is part of the same HNGO regardless of role or task fosters both the feeling of community but also a common identity conveyed in the organizational name or slogan: "It is our task to represent the entire community. I don't think it was ever a slogan, but it comes to me quite often: 'As a [HNGO member], you are never alone.' And that's what the social media channels are supposed to suggest. Although we are active in so many different areas, we are all part of a community, all [HNGO name] and all connected to each other and all doing good works" (I1). The emphasizing appreciation of the voluntary aspect of the work is common: "Especially since people don't get paid for their work, they are certainly happy when they see themselves in a Facebook photo captioned with 'look at the great work of our volunteers' or 'what a great job they are doing.' I think this appreciation is something very, very important. That their work gets noticed is meaningful, although they don't get paid for it" (I1).

The interviews further revealed that giving a name to the social media-based groups-as in the name a Facebook group might be given - helps foster the common understanding and identity building. This community label is represented in a symbolic way which can also play an important role for communicating the common identity. "I think you can show the community spirit quite well with emojis or visual language or text. By talking about 'we' and 'us.' So, it's not me the intermediate office but we the [HNGO]" (I4).

\section{Discussion}

In asking how do transitions allow us to conceptualize social media information governance and social capital raising for HNGOs at different organizational levels our study has 
found that with the advent and maturation of social media platforms that HNGOs have been able to govern and use social media characteristics and functionality, to raise social capital through organizational transitions. This has been achieved by: 1) extending social capital raising structurally, relationally and cognitively through the development, maintenance and growth of member groups, resource pooling, trust and stakeholder engagement, relationship broking, identity building and emotional empathy; and 2) governing social media information along organizational levels for the establishment of social capital as part of the organization's IT strategy.

Our study highlights that social media platforms can be governed and used for social capital raising purposes through multi-level organisational transitions via non-physical autopoietic social systems. This study highlights that HNGO social media information governance systems:

- Continually self produce-this is illustrated through the dynamic nature of the governance approaches used by HNGO such as testing and experimenting with newer platforms to attract younger stakeholders, use of localised content templates, sensitivity to information communicated etc. for social capital purposes;

- Require contingent maintenance (to avoid breakdown)-for instance, managers in these organisations highlighted the need for central supervision and monitoring of newer platform use whilst not stifling innovation at intermediate and regional level;

- Are structurally open but organisationally closed - this is reflected in the governance tension between external and internal communications, operational and crisis communications. There is a need to distinguish between and effectively govern social media for social capital raising versus organisational operations;

- Are structurally determined-we see a number of tensions that emerge from these interviews that highlight the difficulties in navigating multi-level organisational structures for social media information governance purposes. How the organisation is represented, who communicates what, how sensitive and potentially damaging information is handled, all rely on constant review and communication of organisational structures, roles, responsibilities;

- Can be coupled to other systems structurally by mutual specification and/or co-evolutionthis was highlighted in the interest shown by these managers in using social media governance to focus on, connect to and co-ordinate with other HNGOs for social capital raising collaboration and effective distribution of resources; and

- Can embrace embodied cognition and self-reference/recursion to enable self construction/production-respondents all had varying levels of social media management experience but through the richness of their responses we saw a pattern of learning and experimentation to improve social media information governance while retaining flexibility and innovation of social media use for social capital raising (Mingers, 2002, p. 280).

Three of Kemp's four critical rules for managing transitions also seem to have been intuitively observed by these HNGO social media managers.

1. Not getting locked into sub-optimal solutions - by allowing each organisational level to develop information governance approaches suitable to their local conditions;

2. Embedding of transition policy into existing decision-making frameworks-by integrating their organisational social capital raising objectives with their social media governance approaches-although it would appear that there is no recognition or legitimisation of transition management as an official position per se;

3. Taking the long view of a dynamic mechanism of change-long-term objectives where not the focus of this study but the general feeling of respondents was that social media information governance and use for social capital raising is an evolving issue; and 


\begin{tabular}{|c|c|c|c|c|}
\hline Focus area & $\begin{array}{l}\text { Information Governance Ten- } \\
\text { sions }\end{array}$ & Level & $\begin{array}{l}\text { Social media information governance recom- } \\
\text { mendations }\end{array}$ & $\begin{array}{l}\text { Potential social capital out- } \\
\text { comes }\end{array}$ \\
\hline \multirow[t]{2}{*}{$\begin{array}{l}\text { (1) Network } \\
\text { Mainte- } \\
\text { nance }\end{array}$} & \multirow{2}{*}{$\begin{array}{l}\text { *Focus on staff and volunteers } \\
\text { vs. openness to interested peo- } \\
\text { ple beyond the organization } \\
\text { *Coordinated and synchronized } \\
\text { social media strategy across } \\
\text { HNGO levels vs. many profiles } \\
\text { on all levels }\end{array}$} & Regional & $\begin{array}{l}\text { Using channels that respond to the needs of a } \\
\text { local community by engaging and updating the } \\
\text { community along the unit's operations and ac- } \\
\text { tivities; Depending on available resources a } \\
\text { single-channel consistency to maintain net- } \\
\text { work is recommended }\end{array}$ & $\begin{array}{l}\text { Volunteer work resulting from } \\
\text { long-term relationships with } \\
\text { local volunteers, staff and } \\
\text { other regional stakeholders }\end{array}$ \\
\hline & & $\begin{array}{l}\text { Intermediate } \\
\text { and national }\end{array}$ & $\begin{array}{l}\text { Maintenance of different social media channels } \\
\text { to reach a supra-regional and diverse network } \\
\text { of stakeholders (e.g., journalists via Twitter, } \\
\text { donators via Instagram) }\end{array}$ & $\begin{array}{l}\text { Long-term financial stability } \\
\text { from a network of donors; } \\
\text { Reputation among stakehold- } \\
\text { ers }\end{array}$ \\
\hline \multirow[t]{2}{*}{$\begin{array}{l}\text { (2) Network } \\
\text { Growth }\end{array}$} & \multirow{2}{*}{$\begin{array}{l}\text { *Network retention vs. network } \\
\text { growth } \\
\text { *Limited resources may allow } \\
\text { only one focus social media } \\
\text { channel } \\
\text { *Experimenting with new plat- } \\
\text { forms vs. risk of ghost profiles } \\
\text { *Strategic awareness vs. local } \\
\text { needs/daily operations }\end{array}$} & Regional & $\begin{array}{l}\text { Focusing on platforms that enable rich stories } \\
\text { of regional activities and are used by regional } \\
\text { stakeholders }\end{array}$ & $\begin{array}{l}\text { Engaging new local contacts } \\
\text { and attracting them to be vol- } \\
\text { unteers, supporters, or con- } \\
\text { tractors for new service offer- } \\
\text { ings }\end{array}$ \\
\hline & & $\begin{array}{l}\text { Intermediate } \\
\text { and national }\end{array}$ & $\begin{array}{l}\text { Focusing on multi-channel diversity and agile } \\
\text { use of emerging platforms to broaden network }\end{array}$ & $\begin{array}{l}\text { Organizational growth and } \\
\text { continuity by establishing a } \\
\text { pool of new donors and alli- } \\
\text { ances with partner organiza- } \\
\text { tions which tie them to the or- } \\
\text { ganization long-term }\end{array}$ \\
\hline $\begin{array}{l}\text { (3) Re- } \\
\text { source Pool- } \\
\text { ing }\end{array}$ & $\begin{array}{l}\text { *Broad representation of opera- } \\
\text { tions at national level vs. feeling } \\
\text { of underrepresentation of par- } \\
\text { ticular services at lower levels }\end{array}$ & All & $\begin{array}{l}\text { Content co-creation and reuse across organiza- } \\
\text { tional levels; Use of an organization-wide pro- } \\
\text { file (e.g., YouTube) to which units of all levels } \\
\text { have access; Provision of clear contact points } \\
\text { for content exchange between units }\end{array}$ & $\begin{array}{l}\text { Sharing organizational } \\
\text { knowledge across levels; Sav- } \\
\text { ing resources by shared con- } \\
\text { tent creation; Enabling re- } \\
\text { gional units to present local } \\
\text { activities to a larger network }\end{array}$ \\
\hline
\end{tabular}




\begin{tabular}{|c|c|c|c|c|}
\hline & $\begin{array}{l}\text { *Assigning accountability } \\
\text { throughout the process of chan- } \\
\text { nel pooling, i.e., channel man- } \\
\text { agement by several units or } \\
\text { across organizational levels } \\
\text { *Anonymous and voluntary pro- } \\
\text { cess of content provision by re- } \\
\text { gional units for upper levels vs. } \\
\text { importance of close relation- } \\
\text { ships to experts for fostering } \\
\text { content contribution } \\
\text { *Difficulty of covering all ser- } \\
\text { vices in organization-wide } \\
\text { channels }\end{array}$ & & & $\begin{array}{l}\text { of stakeholders and profit } \\
\text { from the structural capital of } \\
\text { other levels }\end{array}$ \\
\hline \multirow[t]{3}{*}{$\begin{array}{l}\text { (4) Trust } \\
\text { Building }\end{array}$} & \multirow[t]{3}{*}{$\begin{array}{l}\text { *Strategic trust vs. operational } \\
\text { trust } \\
\text { *Professionally counter criti- } \\
\text { cism and negativity (sensitivity) } \\
\text { vs. ad hoc communication }\end{array}$} & Regional & $\begin{array}{l}\text { Immediate and ad-hoc showcasing of regional } \\
\text { activities and projects, explaining values of the } \\
\text { organization; Highlighting regional impact of } \\
\text { their activities }\end{array}$ & $\begin{array}{l}\text { Creating multiple contact } \\
\text { points for new relations; Es- } \\
\text { tablishment of trust from local } \\
\text { community; Receiving funding } \\
\text { for regional services and pro- } \\
\text { jects; Establishment of reputa- } \\
\text { tion as regional service pro- } \\
\text { vider }\end{array}$ \\
\hline & & Intermediate & $\begin{array}{l}\text { Retrospective compilation of cross-regional ac- } \\
\text { tivities; } \\
\text { Collaboration with other intermediate levels of } \\
\text { HNGOs, ministries, or companies }\end{array}$ & $\begin{array}{l}\text { Cross-regional legitimacy } \\
\text { through reliability as a service } \\
\text { provider and independent pil- } \\
\text { lar of public life; Trusted coop- } \\
\text { eration partner for projects }\end{array}$ \\
\hline & & National & $\begin{array}{l}\text { Expression of values and visibility of social ser- } \\
\text { vice projects worldwide; Highlighting societal } \\
\text { impact; Responding to criticism via (internal) } \\
\text { crisis PR; Collaborating with sensefluencers }\end{array}$ & $\begin{array}{l}\text { Nationwide legitimacy, involv- } \\
\text { ing an image that stands for }\end{array}$ \\
\hline
\end{tabular}




\begin{tabular}{|c|c|c|c|c|}
\hline & & & & $\begin{array}{l}\text { and reinforces the social func- } \\
\text { tion of the HNGO and commits } \\
\text { to sustainability disclosure }\end{array}$ \\
\hline \multirow[t]{3}{*}{$\begin{array}{l}\text { (5) Commu- } \\
\text { nity Man- } \\
\text { agement }\end{array}$} & \multirow{3}{*}{$\begin{array}{l}\text { *External communications vs. } \\
\text { internal communications } \\
\text { *Blurred lines between public } \\
\text { and private communications } \\
\text { *Competence conflict between } \\
\text { internal (e.g., social intranet) } \\
\text { and public social media (e.g., Fa- } \\
\text { cebook) }\end{array}$} & Regional & $\begin{array}{l}\text { Purposeful moderation; Content along the } \\
\text { unit's activities; Bi-directional communication; } \\
\text { Appreciation for voluntary work }\end{array}$ & $\begin{array}{l}\text { Improvement of services, staff } \\
\text { and volunteer management } \\
\text { through social media based in- } \\
\text { ternal communication }\end{array}$ \\
\hline & & Intermediate & $\begin{array}{l}\text { Coalescing best practices from regional unit } \\
\text { paragons; Provision of social media tutorials } \\
\text { for regional units }\end{array}$ & $\begin{array}{l}\text { Aligned demeanor across re- } \\
\text { gional units; Internal } \\
\text { knowledge transfer }\end{array}$ \\
\hline & & National & $\begin{array}{l}\text { Internal: Adoption of an HNGO enterprise so- } \\
\text { cial network to enable connections within the } \\
\text { HNGO nationwide; Providing affiliation-based } \\
\text { communities a virtual space to connect } \\
\text { External: Responding to interests of a broad } \\
\text { range of stakeholders }\end{array}$ & $\begin{array}{l}\text { Internal: Streamlining of inter- } \\
\text { nal communication pathways } \\
\text { and capturing organizational } \\
\text { knowledge } \\
\text { External: Reputation estab- } \\
\text { lishment, synergy effects from } \\
\text { involvement in projects and } \\
\text { collaborations }\end{array}$ \\
\hline \multirow[t]{3}{*}{$\begin{array}{l}\text { (6) Broker- } \\
\text { age }\end{array}$} & \multirow{3}{*}{$\begin{array}{l}\text { *Well-planned day-to-day oper- } \\
\text { ations within HNGOs escalating } \\
\text { to (partially) social media coor- } \\
\text { dinated crisis communication } \\
{ }^{*} \text { HNGO competition vs. collabo- } \\
\text { ration and co-operation within } \\
\text { and between HNGOs } \\
{ }^{*} \text { Help through digital volunteers } \\
\text { during emergencies vs. missing } \\
\text { strategies of incorporating them } \\
\text { meaningfully }\end{array}$} & Regional & $\begin{array}{l}\text { Building strategic alliances by providing con- } \\
\text { tact points in the context of different organiza- } \\
\text { tional services }\end{array}$ & $\begin{array}{l}\text { Strategic alliances with other } \\
\text { organizations or the local pub- } \\
\text { lic at regional level to receive } \\
\text { relevant information, resource } \\
\text { allocation etc. }\end{array}$ \\
\hline & & Intermediate & $\begin{array}{l}\text { Connecting regional, national, and other inter- } \\
\text { mediate units by interlinking pillar content and } \\
\text { profiles }\end{array}$ & $\begin{array}{l}\text { Strengthened relations be- } \\
\text { tween units and across levels } \\
\text { of the HNGO; Consistent social } \\
\text { media engagement within the } \\
\text { HNGO }\end{array}$ \\
\hline & & National & $\begin{array}{l}\text { Defining roles of brokers who actively connect } \\
\text { and identify relevant stakeholders; Providing } \\
\text { strategies for lower-level units for incorporat- } \\
\text { ing digital ad hoc volunteers }\end{array}$ & $\begin{array}{l}\text { Strategic alliances with other } \\
\text { organizations, politicians, or } \\
\text { journalists at national level to }\end{array}$ \\
\hline
\end{tabular}




\begin{tabular}{|c|c|c|c|c|}
\hline & & & & $\begin{array}{l}\text { receive relevant information, } \\
\text { resource allocation etc. }\end{array}$ \\
\hline \multirow[t]{2}{*}{$\begin{array}{l}\text { (7) Emo- } \\
\text { tional Em- } \\
\text { pathy }\end{array}$} & \multirow{2}{*}{$\begin{array}{l}\text { *Maintaining political neutrality } \\
\text { (e.g., during conflicts) while at- } \\
\text { tracting attention for abuses of } \\
\text { power in social media } \\
\text { *Showing sensitive material vs. } \\
\text { whitewashing humanitarian } \\
\text { grievances } \\
\text { *Conflicts between HNGO } \\
\text { agenda (e.g., raise donations) } \\
\text { and community preferences/ex- } \\
\text { pectations (e.g., information on } \\
\text { new equipment or upcoming ac- } \\
\text { tivities) }\end{array}$} & Regional & $\begin{array}{l}\text { Highlighting achievements and commitments; } \\
\text { Express gratitude and appreciation; Provide } \\
\text { public acknowledgment for organisational } \\
\text { members }\end{array}$ & $\begin{array}{l}\text { High staff and volunteer reten- } \\
\text { tion; Word-of-mouth recom- } \\
\text { mendation; Positive impres- } \\
\text { sion management }\end{array}$ \\
\hline & & $\begin{array}{l}\text { Intermediate } \\
\text { and National }\end{array}$ & $\begin{array}{l}\text { Increasing (online) presence around pressing } \\
\text { social issues; Show respect to societal issues; } \\
\text { Provide emotional support in crisis situations, } \\
\text { e.g. pandemics }\end{array}$ & $\begin{array}{l}\text { Claiming high authority within } \\
\text { the HNGO sector; Ability to in- } \\
\text { fluence public debate }\end{array}$ \\
\hline $\begin{array}{l}\text { (8) Common } \\
\text { Identity }\end{array}$ & $\begin{array}{l}\text { *Alignment of central identity } \\
\text { vs. local identity }\end{array}$ & All & $\begin{array}{l}\text { Using consistent symbols and messaging } \\
\text { throughout regional, intermediate and national } \\
\text { communications (both up and down the chain) }\end{array}$ & $\begin{array}{l}\text { Staff and volunteer retention } \\
\text { and loyalty; Public recognition } \\
\text { value }\end{array}$ \\
\hline
\end{tabular}

Table 7. Recommended Social Media Information Governance Approaches for Organizational Levels and Social Capital Potential. 
4. Engaging in multi-level coordination-these respondents were all cognizant of, sensitive and receptive to multi-level social media information governance approaches to meet overall social capital raising objectives. In fact, many expressed the view that this was the strength of social media platforms in this instance.

The results of this study have highlighted the emergence of a self producing/constructing information governance system reflected in an "organisationally closed but structurally open" manner through self-reference to its own organising principles. We see that social media information governance for social capital raising, has been managed in a self-sustaining-manner in our study, but there are a number of findings, that provide a focus for further research and information governance improvement.

In answer to what tensions emerge from this transitional approach for social media information governance and what changes to transitions would enhance social capital raising we have recommended changes to existing information governance approaches, in order to reconcile these tensions through more effective stakeholder alignment thus providing better social capital outcomes (see table 7).

Findings from our data support a number of assertions which underpin social media information governance for HNGO stakeholder alignment and are the basis of the recommended changes as outlined in table 7 . These are explained in detail in the section that followsWhile we found that social media affordances ${ }^{9}$ give HNGOs the opportunity to raise online social capital structurally, relationally and cognitively-these forms of social capital vary widely between the regional, intermediate and national levels of an HNGO, as social media experts have to take into account the different stakeholder groups they can reach and the resources they need at each level. Certain social media affordances (Kane et al., 2014; Smith et al., 2017), adopted at each organizational level determines how social media information should be governed and used from a strategic perspective.

Within the structural dimension of organizational online social capital raising (network maintenance, growth, and resource pooling), regional units benefit from maintaining and governing platforms that allow the showcasing of rich stories and enables them to engage their offline community in the online sphere. They aim to engage people from their regional communities to volunteer for the HNGO-limiting the number of potential followers mainly to this region and thus are comprised of people who also meet face-to-face. A well-maintained profile showcasing rich stories of local operations and events enables the HNGO to provide a high level of transparency, update its staff and volunteers and offers visibility. This is in contrast to national levels who have a nation-wide reach and aim for acquiring long-term financial stability and a nation-wide reputation comprising geographically dispersed stakeholders who may never meet.

Assertion: To advance social capital raising theories through social media governance, it is necessary to acknowledge different social media affordances are relevant at each organizational level.

Social media generally provides HNGOs with the opportunity to embed their presence in broader networks, where this was not possible pre-social media (Buckland, 1998). Our results indicate that most regional units, due to limited resources, are better off pursuing a singlechannel information governance and communications strategy focusing on social media platforms that allow updating of local staff and volunteers to maintain reliable volunteers and service contractors based on long-term local relationships. This strategy can avoid the creation of

9 ".... the concept of affordance is generally used to describe what material artifacts such as media technologies allow people to do" Bucher and Helmond (2018) p. 236 
ghost or neglected channels that can negatively affect social capital raising by losing interested followers.

To advance network growth of social capital raising, there are significant social media information governance prerequisites for HNGO units: advances in key network maintenance and additional capabilities. As for the latter, intermediate and national offices may use their workforces to acquire and distribute knowledge about secondary channels and their features and how they may contribute in the long term to multi-channel diversity within the organization.

Assertion: In terms of information governance, establishing relationships on social media requires the consideration of the costs and benefits of cultivating a new and physically unconnected network by using additional technological platforms and resources at all organizational levels.

Due to the diversity of topics within an HNGO, a single point of social media information governance may not be appropriate to respond to diverse stakeholder-expectations (Linke and Zerfass, 2013). Rather, an HNGO should distribute information governance activities among several experts and centralize management of channels that aim to publish a broad range of content on HNGO activities. Regional units especially profit from centralized channels as they can contribute content but don't have to if they don't want to (or can't). In addition, they profit from these channels' online structural capital in that they enable showcasing of their regional activities to a broader network that is maintained and governed by upper-level units. Hence, to achieve a stronger overall network, the establishment of a joint profile representing all levels, and to which units can add content and take responsibility for some portion of the work, is recommended. Of course, to make the joint profile valuable for all levels of an HNGO, consideration must be given to the platform affordances and the expectations of the respective stakeholders.

In addition, versions of similar content provided by upper level units' saves resources and streamlines decision-making processes, as editorial content can be aligned across levels. For instance, recurring events such as flu season can be approached with a consistent strategy across regions and levels.

Assertion: To develop effective social media information governance approaches, intermediate and national units, in particular, need to coordinate content development. In this regard, centrally managed social media channels to which all units can contribute content enables lower-level units to conserve resources and to profit from upper level structural online social capital, by receiving attention for their content development beyond their region.

The absence of clear social media information governance contact points and responsibilities within an HNGO, can hamper effective content and knowledge exchange among the different levels and types of organisational units. Upper levels should provide clear (digital) contact points to which regional units can submit their content and clarify how and what regional content should be published on profiles maintained by national units.

While the community factor is important to maintaining a successful network with its own members, some units interpret the use of social media as a technology that merely extends formal structures to the online space. However, member engagement within successfully utilized social media platforms may also perceive value simply from being part of the community. Hence, it is important to understand the role of social media information governance for each stakeholder group at each level and match content to their needs. At the regional level, that includes daily updates of regional activities, appreciation of volunteer work, and recruiting volunteers in their area of responsibility; at the national level, the focus is on showcasing a broad range of topics the HNGO is responsible for such as national and international projects and on how the HNGO's activities serve society-building trust in the organization's purpose and connecting to diverse set of stakeholders. Generally, at all levels, bi-directional communication- 
meaning the interactivity of social media users-has proven to be crucial to long-term stakeholder engagement (Greenberg and MacAulay, 2009). This can be facilitated with polls, stories, quizzes, and other interactive elements that go beyond one-directional reporting.

Assertion: When focusing on the relational dimension of social media information governance for online social capital raising, establishing a community feeling, especially in regional units is crucial; whereas at national level focus it is on the nationwide legitimacy and trust building in organization-wide HNGOs activities.

While a negative reputation arising from wrongdoing may persist over a long period, inclusiveness and transparency of social media information governance facilitates the development of trust by social media users of the HNGO. Being open to criticism and responding to it competently shows that an organization takes social media governance concerns seriously. Showcasing services and activities and leveraging their impact through meaningful multimedia representations (images, videos, live streams) can help establish trust as it shows what HNGOs do for the common good. Open communication and visibility of their activities, mission and objectives also legitimates their initiatives publicly. Thus, for HNGOs it is critical to engage their external stakeholders with their social media information governance approaches to how the HNGOs meet social objectives. The more an HNGO ensures the transparency of their practices and goals, the more trustworthy and reliant the relationships to public, donors, and other relevant stakeholder will develop (Gazzola et al., 2019).

Assertion: Trust building is a main long-term facilitator of successful HNGO social media information governance on all levels.

Social media enables the development of communities on topics of interest that are created by and restricted to permanent and volunteer HNGO staff and that do not follow formal social media information governance guidelines. While some of the national and intermediate experts look at social media-only groups with skepticism, as they are not professionally managed, the establishment of these topic-based, self-governed, and unofficial groups show that members have a need for information exchange within the HNGO community only on certain topics across organizational levels and units. Such groups, started by interested trained volunteers that identify a specific need for a topic-based approach to social media, are not officially governed by a dedicated social media expert. Evidence of large follower numbers illustrate that for some topics many people find value in these self-governed groups.

Assertion: Self-governed topic-based social media groups that are created by non-social media experts to connect with staff and volunteers across units and levels, are also important for social capital raising.

While these self-governed groups contribute to knowledge sharing, common identity, loyalty, and other things, they show that there is a need in HNGO for nationwide, internal social media information governance and sharing. However, they also highlight that there are challenges or gaps in using internal information governance tools. Self-governed groups create a risk that important organizational knowledge might get "lost" in public social media information streams, without managers ever knowing of its existence. In addition, regional HNGO units often use public social media mainly to update their local staff, creating blurred lines between internal and external public social media use. Hence, we suggest that HNGOs should introduce and govern organizational internal social networks that enable internal and nationwide information exchange. 
Assertion: The adoption and information governance of organizational internal social media to which volunteers and staff have access and that enable social capital building is crucial to maintain knowledge long-term in the HNGO and can reduce the focus on HNGO internal communication in public social media channels.

While prior research found that social media can help integrate external resources, for instance, during emergencies (Leong et al., 2015), we identified that reservations persist regarding relationships and information governance activities being conducted in conjunction with other HNGOs who are seen as competitors, or with volunteers during emergency events-especially at the regional level. Also, the nature of formal structures within HNGOs - derived from the military-can hinder the including of spontaneous volunteers in information governance approaches. However, in emergency situations HNGOs must cooperate, coordinate and compromise with others to effectively run operations, and the use of social media. Reluctance to establish information governance approaches with other HNGOs could, during emergencies, lead to uncoordinated publishing of information regarding operations. As for spontaneous volunteers, HNGOs should develop strategies to reach out and integrate these helpers in social media information governance in times of need. If done well, this may provide an opportunity to retain these volunteers over the long term. This is crucial in a sector built on altruistic behavior but that in some regions struggles to find new members.

Assertion: Social media platforms can act as brokers between and within HNGOs and the public and foster short-term real-time exchange of information but also long-term relations between these stakeholders. However, social media information governance approaches that include ad hoc volunteers are often missing and competition between HNGOs can hinder effective social media governance and use between HNGOs.

Upper level organisational should also provide training for lower-level units to develop competence in connecting different relevant stakeholders, as well as pay attention to activities in units that exclude external relationships. In addition, clear and regular communication of social media governance approaches with internal units, external organizations, and the public helps strengthen ties and processes, building greater understanding of the needs of relevant stakeholders, and establishing new relationships that foster online social capital.

Social media governance practices that showcase an HNGO in positive emotional ways build emotional empathy. Establishing emotional connections, for instance during emergencies, can leverage organizational online social capital and focus attention on HNGO requirements, such as donations, by reinforcing trust in HNGOs activities, retaining volunteers, or attracting new members.

Assertion: Sensitivity towards the information governance and use of social media channels to raise awareness of societal and individual challenges and needs in times of crisis, supports the cognitive dimension of organizational social capital raising.

\section{Limitations and Further Research}

We acknowledge that our sample may underrepresent experts at a national level and overrepresented regional levels of HNGO social media knowledge. We were able to conduct only three interviews at the national level: because of the dearth of available social media experts, they were difficult for us to recruit as interviewees. Moreover, we had to rely on the assessments of individuals who may have some reluctance about questioning the social media practices of their organization.

Furthermore, given that our study involves only five German HNGOs, there are limits to its generalizability. Future research should examine whether other organizations with the same three-level structure (national, intermediate, and regional) use social media in similar ways 
and what types of information governance practices might better suit their organizational and cultural contexts. Future research could also capture the opinion of HNGO staff and volunteers at different levels who "tap into" social media to understand their views about successfully managing and governing social media.

In addition, future research could investigate and develop measures of social media information governance for social capital raising, identified using social media analytics, adjusted monitoring, and listening features. This could be achieved through the development of a dashboard that incorporates information governance and social capital indices specified by an individual organization and that provide benchmarks against monitored social media data. A related open question is how the focus areas of information governance for social capital raising, analyzed in our study can be leveraged in times of uncertainty and contribute to the ability of HNGOs to convert their online social capital into actual social action when most needed.

\section{Conclusions}

This study investigates HNGO social media information governance approaches to foster organizational online social capital development. By conducting interviews with experts at the regional, intermediate, and national levels of five HNGOs, we have provided insights into how social media are governed and used at the different organizational levels to build and maintain a network of collaborators, and thus, foster relationships with volunteers, cooperation within and among organizations, and collective action. As a result, we identified eight focus areas of social media information governance for organizational online social capital raising. In the structural dimension, network retention, network expansion, and resource pooling facilitate organizational online social capital. In the relational dimension, we identified the establishment of trust, community management, and brokerage. The cognitive dimension of online social capital can be addressed by emotional empathy and building a common identity. For each focus area, we identified emerging tensions between in social media information governance in each organizational level, and we derived social media information governance approaches that experts and organizations can implement to leverage these key drivers for cultivating online social capital. We found that while regional units focus on regional community management by maintaining smaller communities and more homogenous networks, the focus shifts to maintaining larger and/or more heterogeneous communities at the intermediate and national levels. Beyond officially managed and governed social media groups, the study identifies unofficial, topic-related, and self-governed groups created by interested members. We derived implications for managing social media within HNGOs based on this shift of focus.

\section{References}

Alvesson, M. and Kärreman, D. (2007) 'Constructing mystery: Empirical matters in theory development', Academy of Management Review, vol. 32, no. 4, pp. 1265-1281.

Bizzi, L. (2015) 'Social Capital in Organizations', in International Encyclopedia of the Social \& Behavioral Sciences, Elsevier, pp. 181-185.

Brass, J. N., Longhofer, W., Robinson, R. S. and Schnable, A. (2018) 'NGOs and international development: A review of thirty-five years of scholarship', World Development, vol. 112, pp. 136-149.

Bucher, T. and Helmond, A. (2018) 'The Affordances of Social Media Platforms', in Burgess, A., Marwick, A. and Poell, T. (eds) The SAGE Handbook of Social Media, Sage Publications, pp. 233-253.

Buckland, J. (1998) 'Social capital and sustainability of NGO intermediated development projects in Bangladesh', Community Development Journal, vol. 33, no. 3, pp. 236-248.

Bunker, D., Ehnis, C., Seltsikas, P. and Levine, L. (2013) 'Crisis Management and Social Media: Assuring Effective Information Governance for Long Term Social Sustainability', in IEEE International Conference on Technologies for Homeland Security. 
Burt, R. S. (2000) 'The network structure of social capital', Research in Organizational Behaviour, vol. 22, pp. 345-423.

Burt, R. S. (2005) Brokerage and Closure: An Introduction to Social Capital, Oxford, Oxford University Press.

Chen, X., Ma, J., Wei, J. and Yang, S. (2021) 'The role of perceived integration in WeChat usages for seeking information and sharing comments: A social capital perspective', Information \& Management, vol. 58, no. 1, p. 103280.

Coleman, J. S. (1990) Foundations of Social Theory, Cambridge, MA, Belknap Press.

Ellison, N. B., Steinfield, C. and Lampe, C. (2007) "The benefits of Facebook "friends:" Social capital and college students' use of online social network sites', Journal of Computer-Mediated Communication, vol. 12, no. 4, pp. 1143-1168.

Flyvbjerg, B. (2006) 'Five Misunderstandings About Case-Study Research', Qualitative Inquiry, vol. 12, no. 2, pp. 219-245.

Gazzola, P., Amelio, S., Papagiannis, F. and Michaelides, Z. (2019) 'Sustainability reporting practices and their social impact to NGO funding in Italy', Critical Perspectives on Accounting, p. 102085.

Gibelman, M. and Gelman, S. R. (2001) 'Very public scandals: Nongovernmental organizations in trouble', Voluntas: International Journal of Voluntary and Nonprofit Organizations, vol. 12, no. 1, pp. 49-66.

Gioia, D. A., Corley, K. G. and Hamilton, A. L. (2013) 'Seeking qualitative rigor in inductive research', Organizational Research Methods, vol. 16, no. 1, pp. 15-31.

Goh, S. and Wasko, M. (2012) 'The Effects of Leader-Member Exchange on Member Performance in Virtual World Teams', Journal of the Association for Information Systems, vol. 13, no. 10, pp. 861-885.

Greenberg, J. and MacAulay, M. (2009) 'NPO 2.0? Exploring the web presence of environmental nonprofit organizations in Canada', Global Media Journal, vol. 2, no. 1, pp. 63-88.

Hepburn, A. and Bolden, G. B. (2017) Transcribing for social research, Los Angeles, London, New Delhi, Singapore, Washington DC, Melbourne, SAGE.

Hillig, Z. and Connell, J. (2018) 'Social capital in a crisis: NGO responses to the 2015 Nepalese earthquakes', Asia Pacific Viewpoint, vol. 59, no. 3, pp. 309-322.

Hsu, J. S.-C. and Hung, Y. W. (2013) 'Exploring the interaction effects of social capital', Information \& Management, vol. 50, no. 7, pp. 415-430.

Jakobs, J. (1965) The death and life of great American cities, London, Penguin Books.

Johnson, E. and Prakash, A. (2007) 'NGO research program: a collective action perspective', Policy Sciences, vol. 40, no. 3, pp. 221-240.

Kane, G. C., Alavi, M., Labianca, G. and Borgatti, S. P. (2014) 'What's different about social media networks? A framework and research agenda', MIS Quarterly, vol. 38, no. 1, pp. 274-304.

Katz, S. N. (1999) 'Where did the serious study of philanthropy come from?', Nonprofit and Voluntary, vol. 28, no. 1, pp. 74-82.

Kemp, R., Parto, S. and Gibson, R. B. (2005) 'Governance for sustainable development: moving from theory to practice', International Journal of Sustainable Development, vol. 8, 1/2, p. 12.

Lee, S. U., Zhu, L. and Jeffery, R. (2019) 'Data Governance Decisions for Platform Ecosystems', in Hawaii International Conference on System Sciences, pp. 6377-6386.

Leong, C. M. L., Pan, S. L., Ractham, P. and Kaewkitipong, L. (2015) 'ICT-Enabled Community Empowerment in Crisis Response: Social Media in Thailand Flooding 2011', Journal of the Association for Information Systems, vol. 16, no. 3, pp. 174-212.

Lewis, D. (2001) The Management of Non-Governmental Development Organizations: An Introduction, London and New York, Routledge.

Lin, C.-P. (2011) 'Assessing the mediating role of online social capital between social support and instant messaging usage', Electronic Commerce Research and Applications, vol. 10, no. 1, pp. 105-114. 
Linke, A. and Zerfass, A. (2013) 'Social media governance: regulatory frameworks for successful online communications', Journal of Communication Management, vol. 17, no. 3, pp. 270-286.

Liu, G., Wang, E. and Chua, C. (2015) 'Leveraging Social Capital to Obtain Top Management Support in Complex, Cross-Functional IT Projects', Journal of the Association for Information Systems, vol. 16, no. 8, pp. 707-737.

Lovejoy, K., Waters, R. D. and Saxton, G. D. (2012) 'Engaging stakeholders through Twitter: How nonprofit organizations are getting more out of 140 characters or less', Public Relations Review, vol. 38, no. 2, pp. 313-318.

Mikalef, P., Boura, M., Lekakos, G. and Krogstie, J. (2020) 'The role of information governance in big data analytics driven innovation', Information \& Management, vol. 57, no. 7, p. 103361.

Mingers, J. (2002) 'Can Social Systems Be Autopoietic? Assessing Luhmann's Social Theory', The Sociological Review, vol. 50, no. 2, pp. 278-299.

Mingers, J. (2004) 'Can Social Systems be Autopoietic? Bhaskar's and Giddens' Social Theories', Journal for the Theory of Social Behaviour, vol. 34, no. 4, pp. 403-427.

Nahapiet, J. and Ghoshal, S. (1998) 'Social capital, intellectual capital, and the organizational advantage', Academy of Management Review, vol. 23, no. 2, pp. 242-266.

Petter, S., Barber, C. S. and Barber, D. (2020) 'Gaming the system: The effects of social capital as a resource for virtual team members', Information \& Management, vol. 57, no. 6, p. 103239.

Phua, J., Jin, S. V. and Kim, J. (2017) 'Uses and gratifications of social networking sites for bridging and bonding social capital: A comparison of Facebook, Twitter, Instagram, and Snapchat', Computers in Human Behavior, vol. 72, pp. 115-122.

Putnam, R. D. (2000) Bowling Alone: The Collapse and Revival of American community, New York, Simon \& Schuster.

Randolph, R. V., Hu, H.-f. and Silvernail, K. D. (2020) 'Better the devil you know: Inter-organizational information technology and network social capital in coopetition networks', Information \& Management, vol. 57, no. 6, p. 103344.

Schlagwein, D. and Hu, M. (2017) 'How and why Organisations Use Social Media: Five Use Types and their Relation to Absorptive Capacity', Journal of Information Technology, vol. 32, no. 2, pp. 194-209.

Smith, C., Smith, J. B. and Shaw, E. (2017) 'Embracing digital networks: Entrepreneurs' social capital online', Journal of Business Venturing, vol. 32, no. 1, pp. 18-34.

Tim, Y., Pan, S. L., Bahri, S. and Fauzi, A. (2018) 'Digitally enabled affordances for communitydriven environmental movement in rural Malaysia', Information Systems Journal, vol. 28, no. 1, pp. 48-75.

Tim, Y., Pan, S. L., Ractham, P. and Kaewkitipong, L. (2017) ‘Digitally enabled disaster response: the emergence of social media as boundary objects in a flooding disaster', Information Systems Journal, vol. 27, no. 2, pp. 197-232.

Vaast, E., Safadi, H., Lapointe, L. and Negoita, B. (2017) 'Social Media Affordances for Connective Action: An Examination of Microblogging Use During the Gulf of Mexico Oil Spill', MIS Quarterly, vol. 41, no. 4, pp. 1179-1205.

Zheng, Y. and Yu, A. (2016) 'Affordances of social media in collective action: the case of Free Lunch for Children in China', Information Systems Journal, vol. 26, no. 3, pp. 289-313. 


\section{Appendix 2}

\begin{tabular}{|c|c|c|c|c|c|c|}
\hline & $\begin{array}{l}\text { Instagram } \\
\text { Subscriber: } \\
30.03 .2020\end{array}$ & $\begin{array}{l}\varnothing \text { Insta- } \\
\text { gram- } \\
\text { Posts } \\
\text { within last } \\
\text { three } \\
\text { months }\end{array}$ & $\begin{array}{l}\text { Facebook Likes/ } \\
\text { Subscriber: } \\
30.03 .2020\end{array}$ & $\begin{array}{l}\varnothing \text { Face- } \\
\text { book- } \\
\text { Posts } \\
\text { within } \\
\text { last three } \\
\text { months }\end{array}$ & $\begin{array}{l}\text { Twitter } \\
\text { Subscriber: } \\
30.03 .2020\end{array}$ & $\begin{array}{l}\varnothing \text { Twitter- } \\
\text { Posts } \\
\text { within } \\
\text { last three } \\
\text { months }\end{array}$ \\
\hline R3 & 669 & 5 & $2,401 / 2,546$ & 105 & 541 & 32 \\
\hline $\mathrm{R} 4$ & No profile & No profile & $1,330 / 1,415$ & 7 & 25 & 0 \\
\hline R5 & No profile & No profile & $2,157 / 2,255$ & 25 & 240 & 19 \\
\hline R6 & No profile & No profile & $1,902 / 1,970$ & 74 & 92 & 1 \\
\hline R7 & No profile & No profile & $486 / 513$ & 18 & 69 & 10 \\
\hline I4 & $1,2 \mathrm{k}$ & 5 & $4.190 / 4.515$ & 10 & No profile & No profile \\
\hline I5 & No profile & No profile & $2.623 / 2.874$ & 22 & 520 & 37 \\
\hline I1 & 862 & 8 & $2.732 / 2.843$ & 39 & 417 & 16 \\
\hline R1 & 806 & 2 & $2.987 / 3.098$ & 21 & No profile & No profile \\
\hline $\mathrm{R} 2$ & 807 & 0,33 & $3.273 / 3.366$ & 22 & No profile & No profile \\
\hline $\mathrm{I} 2$ & 912 & 3 & $1.016 / 1.110$ & 3 & 67 & 0 \\
\hline I3 & 949 & 7 & $1.654 / 1.721$ & 13 & No profile & No profile \\
\hline N1 & $10,9 \mathrm{k}$ & 18 & $64.507 / 64.844$ & 37 & $2,8 \mathrm{k}$ & 39 \\
\hline R8 & $4,2 \mathrm{k}$ & 14 & $2.615 / 2.783$ & 7 & No profile & No profile \\
\hline I6 & $4,4 \mathrm{k}$ & 22 & $12.771 / 12.932$ & 23 & No profile & No profile \\
\hline N2 & $11,3 \mathrm{k}$ & 14 & $58.801 / 58.424$ & 30 & $11,2 \mathrm{k}$ & 17 \\
\hline N3 & $10,2 \mathrm{k}$ & 109 & $36,199 / 37,014$ & 116 & $150,7 \mathrm{k}$ & 211 \\
\hline I7 & No profile & No profile & $721 / 743$ & 19 & No profile & No profile \\
\hline
\end{tabular}

Table A1. Social Media Profiles of HNGOs Interviewees - Extracted Data 
Appendix A4

Use of Social Media by the Public in Emergency Situations 


\section{Appendix A4.1: Paper XII}

Usage Behavior of Social Network Sites in the Aftermath of Terrorist Attacks

\section{Fact Description}

Bibliographic data $\quad$ Fischer, D., Eismann, K., and Fischbach, K. (2016). "Usage Behavior of Social Network Sites in the Aftermath of Terrorist Attacks," short paper, in Proceedings of the International Conference on Information Systems, Dublin, Ireland.

https://aisel.aisnet.org/icis2016/HumanBehavior/Presentations/7/ 


\section{Appendix A4.2: Paper XIII}

Collective sense-making in times of crisis: Connecting terror management theory with Twitter user reactions to the Berlin terrorist attack

\section{Fact Description}

Bibliographic data $\quad$ Fischer-Preßler, D., Schwemmer, C., and Fischbach, K. (2019). "Collective sense-making in times of crisis: Connecting terror management theory with Twitter user reactions to the Berlin terrorist attack," in Computers in Human Behavior, 100, 138-151.

DOI: $10.1016 / j . c h b .2019 .05 .012$

https://www.sciencedirect.com/science/article/abs/pii/S0747563219301876 


\section{Appendix A4.3: Paper XIV}

Social Networking Sites in the Aftermath of Crisis Events - The Enabling Role for Self-Organization

\section{Fact Description}

Bibliographic data

Fischer, D. (2018). "Social Networking Sites in the Aftermath of Crisis Events - The Enabling Role for Self-Organization," in Proceedings of the Hawaiian Conference on Information Systems, Big Island, Hawaii. (Best Paper Nomination).

https://aisel.aisnet.org/hicss-51/cl/crisis_and_disaster_management/7/ 


\section{Publications}

Fischer-Preßler, D., Bonaretti, D., and Fischbach, K., (2021). "A Protection-Motivation Perspective to Explain Intention to Use and Continue to Use Mobile Warning Systems," Business \& Information Systems Engineering (BISE), 59(2).

Bonaretti, D. and Fischer-Preßler, D. (2021). "The Problem with Campus Warning: An Evaluation Based on Recipients Spatial Awareness," in International Journal of Disaster Risk Reduction.

Fischer-Preßler, D., Bonaretti, D., and Fischbach, K. (2021). "Understanding Failures of Emergency Warning Systems from a Representation Perspective: A Case Study from Germany" in Proceedings of the International Conference on Information Systems, Austin. (Best Paper Nomination)

Bonaretti, D., and Fischer-Preßler, D. (2021). "Design guidelines for emergency warning apps" in Proceedings of the International Conference on Information Systems, Austin, Texas.

Fischer-Preßler, D., Eismann, K., Pietrowski, R., Fischbach, K., and Schoder, D. (2020). "Information Technology and Risk Management in Supply Chains," in International Journal of Physical Distribution \& Logistics Management, 50(2), pp. 233-254.

Fischer-Preßler, D., Bonaretti, D., and Fischbach, K. (2020). "Effective Use of Mobile-Enabled Emergency Warning Systems," in 28th European Conference on Information Systems, Marrakesh, Marocco.

Heymann, S. D., Fischer-Preßler, D., and Fischbach, K. (2020). "Negative Effects of Enterprise Social Networks on Employees - A Case Study," in 28th European Conference on Information Systems, Marrakesh, Marocco.

Fischer-Preßler, D., Schwemmer, C., and Fischbach, K. (2019). "Collective sense-making in times of crisis: Connecting terror management theory with Twitter user reactions to the Berlin terrorist attack," in Computers in Human Behavior, 100, 138-151.

Fischer-Preßler, D., Marx, J., Ehnis, C. and Fischbach, K. (2019). "Leveraging Online Social Capital: How the German Red Cross Uses Social Networking Sites," in Australasian Conference on Information Systems.

Fischer, D., Hattori-Putzke, J., and Fischbach, K. (2019). "Crisis Warning Apps: Investigating the Factors Influencing Usage and Compliance with Recommendations for Act", in Proceedings of the Hawaiian Conference on Information Systems, Maui, Hawaii.

Fischer, D., Schwemmer, C., and Fischbach, K. (2018). "Terror Management and Twitter: The Case of the 2016 Berlin Terrorist Attack", in Proceedings of the 15th ISCRAM Conference, Rochester, New York.

Eismann, K., Fischer, D., Posegga, O., and Fischbach, K. (2018). “Using Social Network Analysis to Make Sense of Radio Communication in Emergency Response", in Proceedings of the International Workshop on Modeling, Analysis, and Management of Social Networks and their Applications.

Fischer, D. (2018). "Social Networking Sites in the Aftermath of Crisis Events - The Enabling Role for Self-Organization", in Proceedings of the Hawaiian Conference on Information Systems, Big Island, Hawaii. (Best Paper Nomination)

Fischer, D., Eismann, K., and Fischbach, K. (2016). “Usage Behavior of Social Network Sites in the Aftermath of Terrorist Attacks," short paper, in Proceedings of the International Conference on Information Systems, Dublin, Ireland.

Fischer, D., Posegga, O., and Fischbach, K. (2016). "Communication Barriers in Crisis Management: A Literature Review," in Proceedings of the European Conference on Information Systems, Istanbul, Turkey. 
Kiesling, S., Klünder, J., Fischer, D., Schneider, K., and Fischbach, K. (2016). “Applying Social Network Analysis and Centrality Measures to Improve Information Flow Analysis", in Product-Focused Software Process Improvement, Springer International Publishing. 


\section{Zusammenfassung (German Summary)}

Natürliche und von Menschen verursachte Katastrophen wie Überschwemmungen, Epidemien oder Terroranschläge stellen weltweit eine große Bedrohung dar. In Katastrophensituationen sind Informationen entscheidend und können lebensrettend sein. Per Definition sind Katastrophen verheerende, unsichere, hoch komplexe und unvorhersehbare Ereignisse, bei denen eine große Anzahl von Organisationen, wie z.B. Behörden und Organisationen mit Sicherheitsaufgaben, Regierungsbehörden und Unternehmen, aber auch betroffene Gemeinden zusammenarbeiten, um die Situation zu bewältigen (Kreps 1985). Der Weltkatastrophenbericht von 2013 betont, dass im Katastrophenfall der Zugang zu Informationen genauso wichtig ist wie der Zugang zu Wasser und Lebensmitteln (IFRC, 2013, S. 73).

In der Forschung ist anerkannt, dass Hindernisse beim Zugang zu und der Verbreitung von Informationen zu einer Reihe von Fehlern führen können, wie z.B. unangemessene Ressourcenzuteilungen, verzögerte Evakuierungen oder falsche Priorisierung von Hilfsmaßnahmen (z.B. Day et al. 2009; Junglas and Ives 2007; Pan et al. 2012). Dieses Versagen kann wiederum zu einer Eskalation der Katastrophe und einer höheren Anzahl von Opfern führen, wie eine Reihe von Studien belegt (Bharosa et al. 2010; Day et al. 2009). Um dies zu verhindern werden Notfallmanagement-Informationssysteme (EMIS) im Krisenmanagement genutzt (Turoff et al. 2004).

EMIS sind Informationssystemen, die Aktivitäten bei der Katastrophenvorbereitung, -bewältigung und -wiederherstellung unterstützen (Turoff et al. 2004). Sie sind Grundlage für die Speicherung, Visualisierung, Verteilung und den Zugriff auf katastrophenbezogene Daten. Darüber hinaus ermöglichen sie eine digitale Darstellung ereignisspezifischer Daten und unterstützen den Informationsaustausch zwischen Personen, die am Katastrophenmanagement beteiligt sind. EMIS umfassen Technologien wie proprietäre Einsatzmanagementsoftware, Datenbanken oder Funkgeräte (z.B. Allen et al. 2014; Chen et al. 2008a; Chen et al. 2008b), Warnsysteme wie Sirenen, Funk- oder Warn-Apps (z.B. Fischer-Preßler et al. 2020; Kaufhold et al. 2018; Tan et al. 2017) oder Open-Source-Software (z.B. Alexander 2014; Currion et al. 2007). Darüber hinaus werden zunehmend öffentliche digitale Plattformen wie Social Media zur Unterstützung der Kommunikation im Katastrophenmanagement eingesetzt (z.B. Ling et al. 2015; Reuter et al. 2018; Tim et al. 2017).

Viele der Aufgaben, die von EMIS unterstützt werden, wie zum Beispiel die Ressourcenzuteilung, Warnung der Öffentlichkeit oder Zusammenarbeit zwischen Organisationen, sind abhängig vom spezifischen Informationsbedarf der verschiedenen Beteiligten (Fischer et al. 2016). Darüber hinaus sind einige der EMIS nur für eine eingeschränkte Benutzergruppe zugänglich, wie z.B. Einsatzsoftware, die von Behörden und Organisationen mit Sicherheitsaufgaben (BOS) verwendet werden, während andere Systeme öffentlich zugänglich sind, wie beispielsweise Social Media. Dementsprechend können EMIS in Bezug auf die verschiedenen Nutzergruppen sowie in Bezug auf deren Informationsbedarf kategorisiert werden: Informationsbedarf innerhalb und zwischen Organisationen, Informationsbedarf zwischen Organisationen und der Öffentlichkeit sowie der Informationsbedarf innerhalb der Öffentlichkeit (Fischer et al. 2016).

Die EMIS-Nutzung ist von entscheidender Bedeutung, da sie das Katastrophenmanagement bei der Bereitstellung relevanter Informationen unterstützen und die Zusammenarbeit innerhalb der beteiligten Gruppen fördern. Allerdings machen EMIS nicht per se einen Unterschied, sondern nur dann, wenn sie effektiv genutzt und in die Aktivitäten des Katastrophenmanagements integriert werden (IFRC 2013). Eine effektive Nutzung von EMIS bedeutet, dass die Nutzer, wie 
BOS, aber auch betroffene Gemeinden und Unternehmen, fundierte und sachkundige Hilfsmaßnahmen ergreifen können, um auf ein Katastrophenereignis zu reagieren (Burton-Jones and Grange 2013). Vor diesem Hintergrund ist das übergeordnete Ziel dieser kumulativen Dissertation, Forscher und Praktiker dabei zu unterstützen, ein tiefes Verständnis über das Potenzial von EMIS für das Notfallmanagement zu erlangen. Die in dieser Dissertation enthaltenen Studien zielen darauf $a b$, theoretisch fundierte und empirisch verifizierte Erkenntnisse sowie praktische Empfehlungen über den Einsatz von EMIS im Katastrophenmanagement durch Organisationen und die Öffentlichkeit zu liefern. Insbesondere stellt diese Dissertation die folgende übergreifende Forschungsfrage:

Welches Potenzial haben EMIS für die Notfallkommunikation und wie kann dieses Potenzial genutzt werden?

Zur Beantwortung der Forschungsfrage ist die Dissertation in vier Teile gegliedert:

Der erste Teil der Arbeit gibt einen Überblick zu EMIS, deren Potentiale sowie zu möglichen Hindernissen im Krisenmanagement. Dieser Teil umfasst mehrere Literaturreviews und einen Artikel, der eine Methode zur Analyse von digitalen Spurendaten im Krisenmanagement vorstellt. Die Literaturreviews umfassen das Framework-Paper sowie zwei weitere systematische Literaturreviews. Das Framework-Paper gibt einen umfassenden Überblick zu bestehenden Technologien im Notfallmanagement sowie zur theoretischen Vorgehensweisen, die zur Analyse dieser Technologien in den Studien angewandt wurden. Ein zweiter systematischer Literaturreview bietet umfassende Einblicke in bestehende technische, soziale und organisationale Hindernisse, die eine effektive Zusammenarbeit und Kommunikation im Katastrophenmanagement behindern. Darüber hinaus enthält die Dissertation eine systematische Literaturrecherche zum Einsatz von IT im Risikomanagement entlang von Versorgungsketten. Die Literatur ist in die Dimensionen des Risikomanagements zusammengefasst, stellt den aktuellen Forschungsstand dar und deckt Lücken für zukünftige Forschung auf. Die Ergebnisse der Literaturrecherchen bieten für die weitere Forschung eine umfassende Übersicht zur bestehenden Literatur über die Nutzung von EMIS im Krisenmanagement, zu EMIS für das Risikomanagement entlang von Versorgungsketten sowie zu verschiedenen Barrieren im Krisenmanagement. Schließlich gibt eine methodische Studie Einblicke dazu, wie Methoden der Netzwerkanalyse genutzt werden können, um digitale intra-organisationale Krisenkommunikation zu analysieren. Die Methode verhilft der Forschung und Praxis zu einer zielgerichteten Analyse von digitalen Kommunikationsdaten im Krisenmanagement.

Der zweite Teil der Arbeit fokussiert sich auf die effektive Nutzung von Warnsystemen. Mithilfe mehrerer empirischer Studien wird der effektive Einsatz von mobilen Warnsystemen untersucht. Diese Kanäle können Warnungen zeitnah an mobile Endgeräte von Betroffenen senden, sodass diese Betroffenen Schutzmaßnahmen ergreifen können. Damit solche Kanäle auch von der Bevölkerung genutzt werden, müssen sie den Erwartungen der Nutzer entsprechen. Empirische Studien dieser Arbeit untersuchen, welche Erwartungen die Öffentlichkeit an mobilfunkgestützte Warnsysteme hat und wie BOS diesen gerecht werden können. Für letzteres müssen unter anderem Defizite in der Notfallkommunikation und der effektiven Nutzung von Plattformen für die Versendung von Warnungen überwunden werden. Darüber hinaus untersucht die Arbeit mithilfe empirischer Studien in denen psychometrische Modelle getestet werden, verschiedene Faktoren, die dazu führen oder verhindern, dass Menschen solche Systeme nutzen. Für Forschung und Praxis decken diese Studien Motivationen und Faktoren auf, die helfen zu verstehen, wie mobile Warnsysteme beworben werden können und wie sie effektiver gestaltet werden können. 
Der dritte Teil befasst sich mit der Nutzung öffentlicher Social Media durch Behörden und Organisationen mit Sicherheitsaufgaben. Social Media, wie Facebook, Instagram oder Twitter, bieten einen modernen, digitalen Informationskanal für BOS, um mit der Öffentlichkeit zu interagieren und zu kommunizieren, sowie Informationen vor, während und nach einem Notfall zu verbreiten. Die Vorteile dieser Plattformen sind vielfältig. Zum Beispiel können BOS während und nach einem Notfall direkt Informationen veröffentlichen, sie können auf Ressourcen zugreifen und neue Freiwillige gewinnen, Spendenaufrufe verbreiten oder auf Augenzeugenberichte zugreifen. Empirische Studien dieser Arbeit liefern Erkenntnisse zum Einsatz von digitalen Plattformen in BOS. Die Arbeiten basieren auf qualitativen Daten und untersuchen, wie Social Media innerhalb von BOS auf verschiedenen Ebenen genutzt werden kann, damit das Potential der Social-Media-Nutzung ausgeschöpft werden können. Die daraus abgeleiteten Strategien dienen Social Media effektiv zu managen.

Der vierte Teil der Arbeit bietet Einblicke in die Nutzung von Social Media durch die Öffentlichkeit während Krisenereignissen. Die weitverbreitete Nutzung von Social Media hat Einfluss auf das Katastrophenmanagement, denn die Plattformen ermöglichen den Austausch von Informationen über Katastrophenereignisse zwischen räumlich verteilten Nutzern in Echtzeit. Die Zusammenarbeit der Öffentlichkeit ist eine fundamentale Voraussetzung für ein effektives Katastrophenmanagement. Eine Studie dieser Arbeit konzentriert sich darauf, wie und warum Menschen Social Media nutzen, um auf eine Katastrophe zu reagieren. Auf Basis eines Literaturüberblicks beleuchtet die Arbeit Faktoren, die die Nutzung sozialer Medien durch die Öffentlichkeit zur Sinnfindung und Selbstorganisation beeinflussen. Zwei weitere Studien befassen sich mit der Nutzung von Social Media nach Terroranschlägen. Dabei behandelt eine Studie ein theoretisches Modell, welches Faktoren erklärt, die zur Nutzung von Social Media nach Terroranschlägen führt. Eine weitere Studie zu diesem Thema, deckt Themen auf Twitter auf, die Nutzer nach solchen Krisenereignissen posten und teilen, um solche Anschläge zu bewältigen. Erkenntnisse in diesem Bereich helfen zu verstehen, wie Menschen bei zukünftigen Ereignissen auf digitalen Plattformen reagieren werden und warum sie dies tun. 